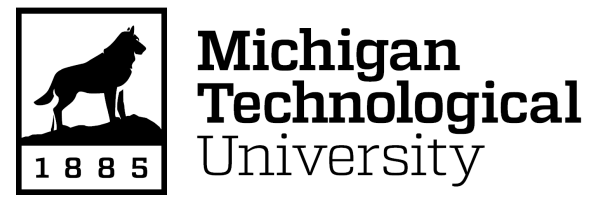

Michigan Technological University Digital Commons @ Michigan Tech

Dissertations, Master's Theses and Master's Reports

2016

\title{
Archaeological Investigations And Historical Survey, Fort Wllkins Historic State Park: Keweenaw County, Michigan
}

Eric T. Pomber

Michigan Technological University, etpomber@mtu.edu

Copyright 2016 Eric T. Pomber

\section{Recommended Citation}

Pomber, Eric T., "Archaeological Investigations And Historical Survey, Fort WIlkins Historic State Park: Keweenaw County, Michigan", Open Access Master's Report, Michigan Technological University, 2016. https://doi.org/10.37099/mtu.dc.etdr/137

Follow this and additional works at: https://digitalcommons.mtu.edu/etdr

Part of the Archaeological Anthropology Commons 


\title{
ARCHAEOLOGICAL INVESTIGATIONS AND HISTORICAL SURVEY, FORT WILKINS HISTORIC STATE PARK: \\ KEWEENAW COUNTY, MICHIGAN
}

\section{By}

Eric T. Pomber

\author{
A REPORT \\ Submitted in partial fulfillment of the requirements for the degree of \\ MASTER OF SCIENCE \\ In Industrial Archaeology \\ MICHIGAN TECHNOLOGICAL UNIVERSITY \\ 2016 \\ (c)2016 Eric T. Pomber
}


This report has been approved in partial fulfillment of the requirements for the Degree of MASTER OF SCIENCE in Industrial Archaeology.

Department of Social Sciences

Report Advisor: Dr. Timothy J. Scarlett

Committee Member: Dr. Patrick E. Martin

Committee Member: Barry James

Department Chair: Dr. Hugh S. Gorman 


\section{Contents}

\begin{tabular}{ll} 
Introduction & 1 \\
\hline
\end{tabular}

Physical Description of Project Area 3

$\begin{array}{lr}\text { Historical Summary } & 4\end{array}$

The Geology of the Keweenaw Peninsula $\quad 4$

$\begin{array}{ll}\text { Prehistoric Context } & 4\end{array}$

Early Reports of the Keweenaw Peninsula and Copper Harbor 6

History of Fort Wilkins $r$

$\begin{array}{lr}\text { The Astor House Hotel } & 14\end{array}$

$\begin{array}{lr}\text { Copper Harbor Range Lighthouse } & 18\end{array}$

Works Progress Administration and Fort Wilkins Historic State Park 32

$\begin{array}{ll}\text { Methods } & 32\end{array}$

Survey of Historic and Archival Records $\quad 32$

Michigan State Archaeological Site Files $\quad 32$

Maps $\quad 35$

$\begin{array}{lr}\text { Fieldwork } & 45\end{array}$

$\begin{array}{lr}\text { Artifact Collection and Analysis } & 46\end{array}$

Discussion of Archaeological Sensitivity of the Project Area 47

$\begin{array}{ll}\text { Previous Archaeological Investigations } & 47\end{array}$

Regarding the Prehistoric Sensitivity of the Project Area 48

\begin{tabular}{l} 
Results \\
\hline 55
\end{tabular}

$\begin{array}{lr}\text { Lack of Prehistoric Evidence } & 55\end{array}$

$\begin{array}{lr}\text { Feature 1 } & 55\end{array}$

$\begin{array}{lr}\text { Feature } 2 & 55\end{array}$

$\begin{array}{lr}\text { Feature } 3 & 56\end{array}$

$\begin{array}{lr}\text { Feature } 4 & 64\end{array}$

$\begin{array}{lr}\text { Feature } 5 & 72\end{array}$

$\begin{array}{lr}\text { Feature } 6 & 73\end{array}$

$\begin{array}{lr}\text { Feature } 7 & 75\end{array}$

$\begin{array}{lr}\text { Feature } 8 & 76\end{array}$

$\begin{array}{ll}\text { Recommendations } & 77\end{array}$

$\begin{array}{lr}\text { Feature 1 } & 77\end{array}$

$\begin{array}{ll}\text { Feature } 2 & 76\end{array}$

$\begin{array}{lr}\text { Feature } 3 & 77\end{array}$

\begin{tabular}{lr} 
Feature 4 & $\mathbf{8 0}$ \\
\hline
\end{tabular}

$\begin{array}{lr}\text { Feature } 5 & \mathbf{8 0}\end{array}$

$\begin{array}{lr}\text { Feature } 6 & \mathbf{8 1}\end{array}$

\begin{tabular}{lr} 
Feature 7 & 81 \\
\hline
\end{tabular}

\begin{tabular}{lr} 
Feature 8 & 81 \\
\hline
\end{tabular}

$\begin{array}{lr}\text { Historic Barn } & 81\end{array}$

$\begin{array}{ll}\text { Bibliography } & 83\end{array}$

$\begin{array}{ll}\text { Photograph Catalog } & \mathbf{8 7}\end{array}$ 
List of Figures

Figure Description

Figure 1 Map of Copper Harbor, Fort Wilkins, and survey area

Figure 2 USGS Geologic Map of Copper Harbor, Fort Wilkins, and survey area

Figure 3 Survey of Location No. 4 for the Pittsburgh \& Boston Copper Harbor Mining Co.

Figure 4 Military Reservation: Fort Wilkins Michigan

Figure $5 \quad$ Birds Eye View of Copper Harbor from Charles T. Jackson's Report of 1849

Figure 6 Original Plans for the Copper Harbor Range Lights 20

Figure 7 The front range light as built 20

Figure $8 \quad$ Range lighthouse 21

Figure 9 Photograph showing dormers added and redesigned fencing 21

Figure 101945 Photograph showing electric lamp mounted outside of original light bay 22

Figure $11 \quad 1924$ Photograph showing the new front range 22

Figure 12 Earliest photograph showing the barn 24

Figure 13 Ramp leading to large west facing door visible at right 24

Figure 14 Current location of bachelor's quarters 25

Figure 151940 's adjustment to 1910 Brown map 26

Figure 16 View showing privy with dark siding and washhouse 28

Figure 17 South view of washhouse showing deck constructed in rear and items in front 28

Figure 18 Charles Davis and wife in back of washhouse, log footbridge evident to right 29

Figure 19 Photograph showing washhouse with privy just in frame to left 29

Figure $20 \quad$ Bridge towards end of period of use 30

Figure 21 Charles Haven and wife. 30

Figure 22 Department of Conservation map of the historic fort property, 1924

Figure 23 Historic Preservation Office 33

Figure 24 Chart of Copper Harbour, Keweena Point, Lake Superior, circa 1843

Figure 251845 William Ives Survey Map 37

Figure 26 General Land Office plat map of Township 59N Range 28W, May 8, $1846 \quad 38$

Figure 27 Survey of the N. and N.W. Lakes 39

Figure 28 Map accompanying a letter from Col. W.R. Reynolds to L.H. Board dated Feb. 28,1865

Figure 29 From the records of the Lake Survey 41

Figure 30 Copper Harbor, Michigan, Light House Reservation, 1877

Plan of Enclosures of Garrison Grounds and Elevation of Buildings, Fort Wilkins,

Figure 31 Copper Harbor, Lake Superior, year unknown.

Figure 32 Map of Fort Wilkins State Park Property, 1957

Figure $33 \quad$ STP testing strategy 50

Figure 34 Range Lighthouse Excavation Map 51

Figure 35 Detail, Range Lighthouse Excavations 52

Figure 36 North Section of Property Site Map 53 
Figure 37 Astor House Excavation Detail 54

Figure $38 \quad$ Feature 2 showing bolt mounting pattern 56

Figure 39 Detail Trench 2, Level 2 showing subtlety of stain 20 minutes after excavation 59

Figure 40 Trench 4, Level 3 showing stain approximately 10 minutes after excavation 60

Figure 41 Trench 6, Level 2 showing stain immediately after excavation 61

Figure 42 Sample of pipe fragments from Feature 3

Figure 43 Sample of ceramics from Feature 3

Figure 44 Sample of metal artifacts recovered from Feature $3 \quad 63$

Figure 451941 photograph showing sidewalk leading to privy and water tower 66

Figure 46 Sidewalk slabs uncovered during test pitting 66

Figure 47 Trench 1, Level $2 \quad 67$

Figure 48 Trench 3, Level 4 showing sandy soil in west side of unit 68

Figure 49 Trench 9, Level $4 \quad 69$

Figure 50 Detail of stone alignment in Trench 9

Figure 51 Sample of ceramics recovered from Feature 4

Figure 52 Sample of metal artifacts recovered from Feature 4

Figure 53 Sample of non-window glass recovered from Feature 4

Figure 54 Sample of bone fragments recovered from Feature 4

Figure 55 Detail, Feature $5 \quad 72$

Figure 56 Fanny Hooe Creek 1889

$\begin{array}{lll}\text { Figure } 57 & \text { Feature } 6 & 74\end{array}$

Figure $58 \quad$ Feature $7 \quad 75$

Figure 59 Feature 8 from east bank of Fanny Hooe Creek 76

Figure 60 Hypothetical floor plan of Astor House 79 


\begin{abstract}
Michigan Technological University has been performing archaeological and historical surveys at Fort Wilkins Historic State Park as part of a multi-year contract since 2013 with each year's work focused on different properties held by the Park. The 2015 field season focused on the 6 acre Copper Harbor Range Lighthouse (20KE33) property immediately west of Fanny Hooe Creek resulting in the identification of eight archaeological features through a combination of pedestrian survey, shovel pit testing, and excavation. Among the features identified are the Astor House (20KE83), an early hotel in the region which was noted in the writings of travelers visiting the region, and outbuildings associated with the Copper Harbor Range Lighthouse. Included within this report is an historical overview of the property, the results of field work, recommendations for further work, and interpretation options for the features located.
\end{abstract}




\section{Introduction}

In the summer of 2014 the Michigan Department of Natural Resources, representing the State of Michigan, awarded a contract to Michigan Technological University to perform Phase I-II surveys at Fort Wilkins State Park. This was a multi-year contract in which the summer of 2014 resulted in a Phase I-II survey and completed report of said surveys. The survey area for the 2014 field season was the Pittsburgh and Boston Copper Harbor Mining Company site, approximately 14.5 acres on the south shore of Copper Harbor, bounded between Fanny Hooe Creek (Garden Brook) on the west, the eastern limit of the Fort property and to the south by US 41 . The survey resulted in the identification of archaeological sites within the survey area.

The survey area for the 2015 season focused on the Copper Harbor Range Lighthouse property of approximately 6 acres bounded by Fanny Hooe Creek (Garden Brook) to the east, US 41 to the south, the property line to the west, and Lake Superior to the north. The survey team identified several archaeological features and excavated on two of these features.

Beginning on May 3, 2015 the survey team performed a two-week archaeological survey in the Range Lighthouse property. Dr. Patrick Martin directed work; MTU graduate student Eric T. Pomber supervised fieldwork and MTU graduate students Dan Trepal, Adrian Blake, and Marley Chynoweth comprised the rest of the survey crew with help from MTU undergraduate students James Wezensky and Patrick Gillman. The main focus of this survey was the identification all archaeological sites on the property, particularly those associated with the Astor House Hotel and the Range Lighthouse.

This report is the summary of that field work and contains brief background information on the history and geology of this region of the Keweenaw, Fort Wilkins, the Astor House, and the Range Lighthouse. Also included within this report is the archaeological methodology employed by the survey team and the subsequent results of that methodology. This report includes a summary of the archaeological data discovered and recommendations for the park regarding future interpretation of these newly discovered archaeological sites. 


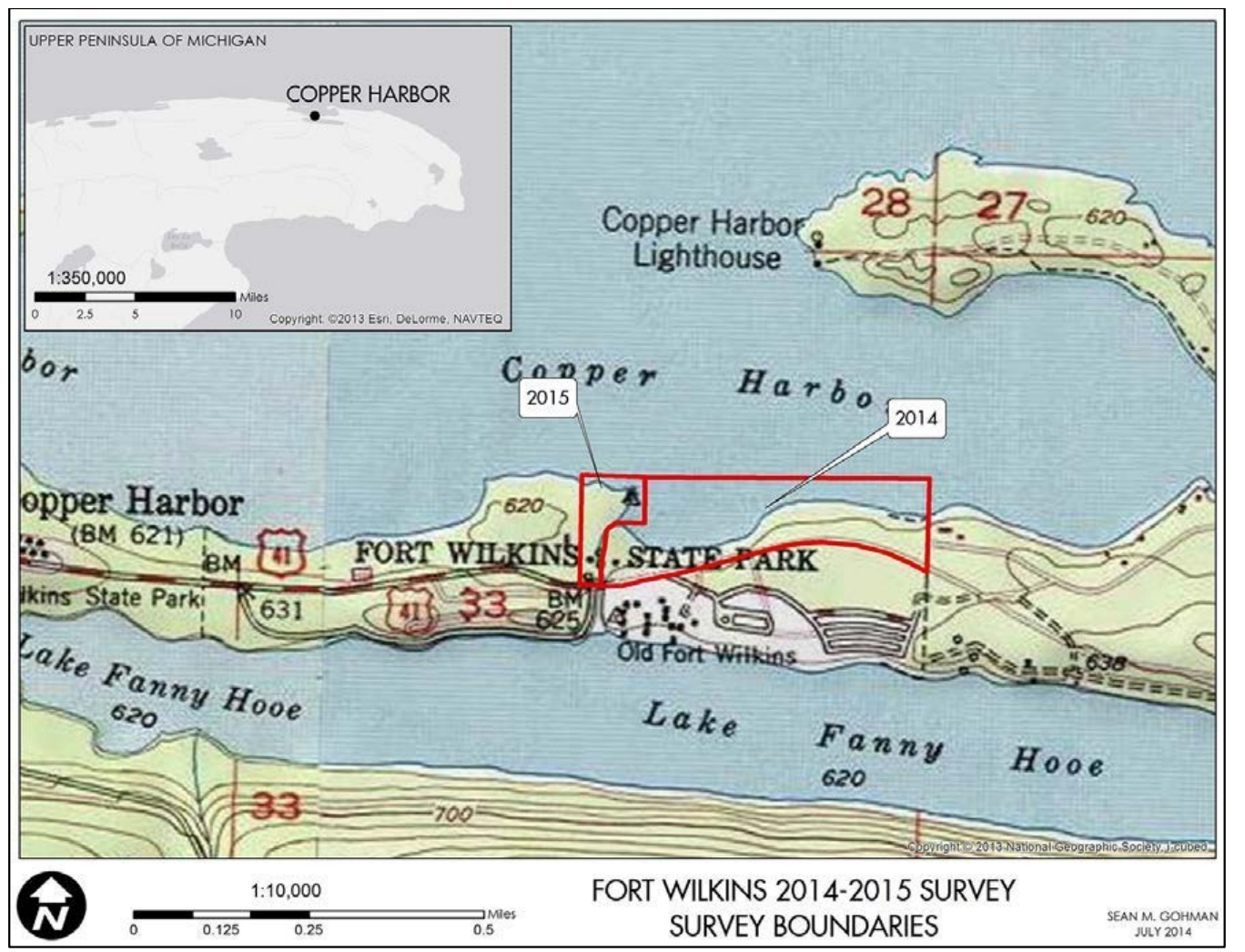

Fig. 1. Map of Copper Harbor, Fort Wilkins, and survey area (outlined in red). Image courtesy of Sean M. Gohman.

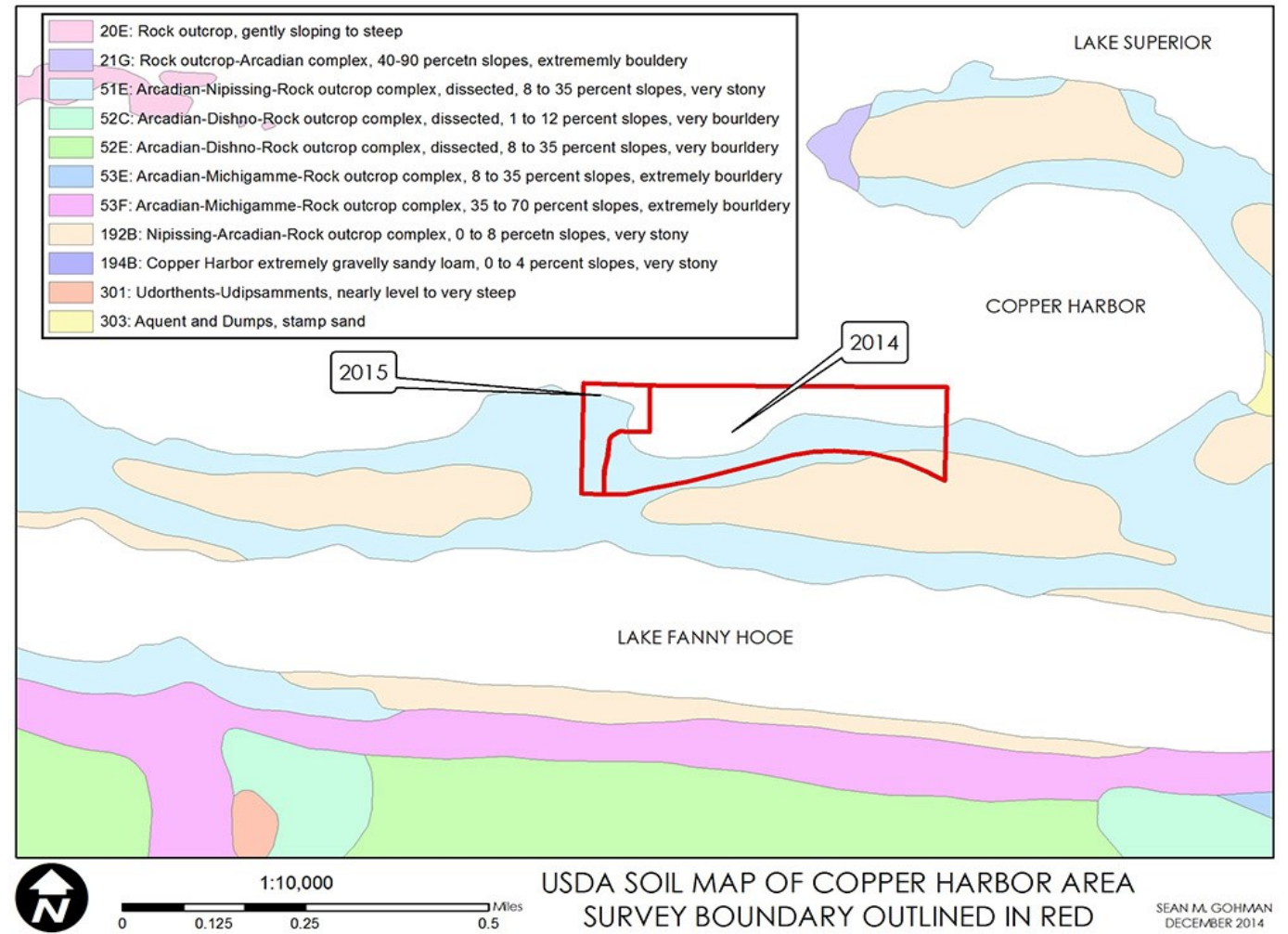

Figure 2. USGS Geologic map of Copper Harbor, Fort Wilkins, and survey area (outlined in red). Image courtesy of Sean M. Gohman. 


\section{Physical Description of Project Area}

The survey area is approximately 6 acres located in Town 59N, Range 28W, Section 33, Lot 2. The borders of the survey area are Fanny Hooe Creek to the east, US-41 to the south, the property line of the lighthouse reservation to the west, and the Lake Superior shoreline to the north (Fig. 1).

The shoreline consists of a conglomerate bedrock outcrop extending between $2 \mathrm{~m}-10 \mathrm{~m}$ inland. The lands immediately south of the shoreline quickly rise several meters then fall approximately $2 \mathrm{~m}$ without major elevation change south to US 41 . The entirety of the soil is "very stony" in the USDA soil survey of Keweenaw County and the grade ranges from $8-35 \%$ along the shoreline to $0-8 \%$ inland nearer to US-41 (Fig. 2). ${ }^{1}$ There is little sediment within the survey boundaries, with bedrock exposed in some locations throughout the survey area. Aside from those defining its borders, there are no bodies of water within the survey area.

Three historic structures stand on the site as well as the modern rear range light and the Fort Wilkins State Park manager's home. The area north of the modern rear range light was clear cut at one time, but much is now overgrown with thick new growth woods and dense shrubbery. The area around the historic Range Lighthouse is lawn space with thick new growth along the bank of Fanny Hooe Creek.

\footnotetext{
${ }^{1}$ Stephen Tardy, "Soil Survey of Keweenaw County Area, Michigan.” (Washington, D.C.: Natural Resources Conservation Service, 2006), 48-52.
} 


\section{Historical Summary}

\section{The Geology of the Keweenaw Peninsula}

The near surface geology of the Keweenaw Peninsula is more than one billion years old. At that time great upheavals in the earth's crust forced a series of lava eruptions over what became the Lake Superior's western basin. Between periods of eruption, the lava flows cooled into bands of basalt, rivers and streams deposited boulders and gravels atop them. Another series of lava flows covered these sedimentary rocks, and solidified under pressure to form conglomerate. Tectonic forces upturned these alternating layers of basalt and conglomerate creating the east and west edges of Lake Superior's western basin. Further fracturing, perpendicular to the flows, allowed for the upward migration of minerals (copper, for example) from deep below the crust on up to the earth's surface.

Within these fissures, the metallic (native) copper filled cavities with solid masses weighing anywhere from several ounces to several hundred tons. ${ }^{2}$ Metallic copper also spread throughout air pockets in the conglomerate bands, leaving behind particles often no larger than grains of sand. These processes also deposited non-metallic copper, in the form of sulfide and oxide ores, and other minerals such as manganese. In the case of Copper Harbor's immediate area, native copper, copper ore, and manganese are all present. $^{3}$

\section{Prehistoric Context}

Prehistoric people occupied the northern Great Lakes for roughly 10,000 years and there is evidence of human activity on the Keweenaw Peninsula dating to the Middle and possibly Early Archaic Periods. As the glaciers covering the region receded Paleoindians advanced in their wake. These people lived in small, highly mobile groups making them well suited to life in the region. These groups' subsistence patterns showed a reliance on hunting, gathering, and fishing to varying degrees depending on the specific group. The small groups likely followed a seasonal pattern of migration into the area during the summer months and out during the harsh winter months. ${ }^{4}$ The Paleo-Indian groups that

\footnotetext{
2 David J Krause, The Making of a Mining District: Keweenaw Native Copper 1500-1870, Great Lakes Books; Variation: Great Lakes Books. (Detroit: Wayne State University Press, 1992). 222.

${ }^{3}$ Gohman, Phase One Archaeological and Historical Survey.

4 Susan R. Martin, Wonderful Power : the Story of Ancient Copper Working in the Lake Superior Basin. (Detroit: Wayne State University Press, 1999), 140-145.
} 
moved into this region found certain areas to be rich with copper, which they soon learned to work.

The groups of prehistoric people that utilized the copper of the northern Great Lakes region are classified into complexes according to the manner in which they made and shaped their goods. As knowledge of these peoples comes only from fragmentary archaeological evidence the names these cultures used are unknown as are many of the finer points of their cultures. What remains of these people is their material culture items, which survive archaeologically and serve as the basis for classification. ${ }^{5}$ The archaeological sites left by these groups are mostly funerary or related to copper extraction. Relatively little work has been done in this area of archaeology and our overall knowledge of this time and these groups of people is extremely limited as a result.

The Old Copper Complex (OCC) is the broadest of these groups which covers a wide variety of cultures over a broad expanse of time with the main commonality between the cultures, aside from their material culture, being their mortuary customs. Sites associated with the OCC cover a range of several thousand years from the Archaic to Early Woodland period, the introduction of ceramics roughly in the middle of the 3rd millennium BCE is the point of distinction. ${ }^{6}$ The Red Ochre Complex (ROC) ranged from roughly $1200 \mathrm{BCE}$ through $400 \mathrm{BCE}$. This grouping of cultures had many shared traits with cultures from the area north of Lake Superior and was chiefly distributed across the Great Lakes region as far east as the Ohio River Valley. Again, the peoples of this group shared common burial characteristics and material culture. The people of Glacial Kame Culture (GKC) produced similar material culture items to the ROC but are more associated with southern Michigan and Ontario. ${ }^{7}$

The people living on the southern shore of Lake Superior were adept at exploiting and working copper by 3000-5000 years ago. Float copper, that which was been torn free from rock by glacial movement and deposited on the ground, was the focus of the earliest efforts but by this period people were actively mining native copper from the bedrock. This mining required the shaping of stone tools which are found at the mining pits or quarries. The main technique used by these early miners for extracting copper was to hammer a piece which was exposed from a vein back and forth until it work hardened and broke free. Aside from hammer stones they also used tools made from copper and wood as scrapers and levers which aided in removing loose rock and prying the copper free. To aid in the removal of the rock which the copper was embedded in, these early miners would build fires to heat the rock which they then doused with water creating

\footnotetext{
${ }^{5}$ Ibid, 149-151.

${ }^{6}$ Ibid., 122-123.

${ }^{7}$ Ibid., 152-254.
} 
thermal shock which rendered the rock more brittle. ${ }^{8}$ This made the process of extraction easier and it appears that this technique saw widespread use.

Once freed, these people used copper in the construction of a wide variety of tools and ornamental goods. Their knowledge of the characteristic of work hardening was key in the creation of projectile points, knives, scrapers, awls, fish hooks, chisels, and choppers as once shaped they would be hard enough to retain a sharp edge. ${ }^{9}$ They would heat copper and allow it to cool slowly so it would become soft, a process called annealing. This property of copper was useful in the creation of goods such as spiral beads which were made by pounding out a strip of copper, annealing it back to a soft state, and wrapping the strip around a mandrel. While multiple groups used copper in similar ways over vast areas and through time, there are variations in cultural behavior and styles among the groups noted above.

Throughout the Middle and Late Archaic trade of copper was confined to a relatively small geographic area, roughly 300km from the source of the metal. During the latter part of the Woodland period trade began to extend beyond this. By 1300 BCE the population of the area grew with the addition of agricultural plants to people's subsistence strategies. Concurrent with this change was an increase in competition between groups. The changing demographics of the area are reflected in an increase in the variety and variations of items, particularly pottery styles. The trade of copper increased with Lake Superior copper being traded amongst groups throughout the eastern half of North America. Artifacts from this period of trade include both tools and ornaments.

The trading of copper continued throughout the Terminal Woodland period until Iroquoian encroachment into the western Great Lakes just prior to the historic period led to the cessation of this trade. ${ }^{10}$ In the early historic period it is clear that the Europeans knew about copper sources to their west as they worked their way up the St. Lawrence drainage. While trade in copper goods continued through the 17th century, reports from French traders and missionaries suggested that natives had ceased active mining. The cessation of copper exploitation by native peoples is likely due to the availability of metals procured from European sources in trade. ${ }^{11}$

\section{Early Reports of the Keweenaw Peninsula and Copper Harbor}

Fur trading spurred initial interest in the Lake Superior region; though the area's potential mineral wealth was acknowledged by the mid-seventeenth century, it was poorly understood. French efforts to mine copper first took place in the early eighteenth century

\footnotetext{
${ }^{8}$ Ibid., 108-112.

${ }^{9}$ Ibid., 230-239.

${ }^{10}$ Ibid., 175-177, 198-199.

${ }^{11}$ Krause, Making of a Mining District, 28-34.
} 
near the Michigan-Wisconsin border, an area later known for its iron deposits. After the Seven Year's War, France ceded the Lake Superior region to the British, and they made another effort to explore and extract the district's copper. Focusing on a great copper boulder found on the Ontonagon River, British miners worked during the years 1771-72 under the guidance of Alexander Henry digging to no avail within the river's upper banks. ${ }^{12}$ Their failure, along with the American War of Independence and the War of 1812, put an end to active interest in its mineral potential for some years.

1820 saw renewed attention in the form of an exploring party led by Territorial Governor Lewis Cass and accompanied by mineralogist, Henry Rowe Schoolcraft. Although copper prospecting was not the primary goal of the expedition (the headwaters of the Mississippi held that honor), Schoolcraft managed a visit to the copper boulder on the Ontonagon River. Schoolcraft's subsequent reports on the boulder and the region's copper prospects though mostly postulating, and sometimes even contradictory, renewed American interest in Lake Superior's south shore. ${ }^{13}$

Schoolcraft returned to Lake Superior in 1831, and brought along with him the physician and naturalist, Douglass Houghton. Houghton accurately publicized the mineral potential of the region, and it was on this trip that he and other scientific minds first encountered the mineral bearing veins in and around Copper Harbor. The expedition spent only a handful of days at Copper Harbor (camping where the harbor's lighthouse currently sits), but noted the presence of native copper and a black oxide of copper, as well as other copper compounds. ${ }^{14}$ Appointed the State Geologist for Michigan in 1837 by the new state government, Houghton was tasked with surveying the State. In 1840 he returned to Copper Harbor, collected mineral samples, gained confidence in the area's mineral potential, and within a year published his annual report. This report came to be known as The Copper Report, and roused a frenzy of interest in the Lake District. ${ }^{15}$

Following the 1842 signing of the Treaty of LaPointe, the Ojibwe people ceded the lands comprising Michigan's Lake Superior District and the Keweenaw Peninsula to the Federal Government. With this treaty in place, the native peoples of Lake Superior's south shore permitted the removal of mineral wealth (above or below ground) anywhere from the Chocolay River near present day Marquette, Michigan, westward to present day Duluth, Minnesota. As a result, American and European adventurers, prospectors, speculators, and investors swarmed the two places copper was confirmed to exist; the Ontonagon River and Copper Harbor.

\footnotetext{
12 Ibid., 34-40.

13 Ibid., 71-90.

${ }^{14}$ Ibid., 104.

15 Ibid., 125, 132.
} 
The Federal Government set up a leasing system to handle the allotment of mineral lands, and installed Mineral Land Agency offices at both locations. ${ }^{16}$ At Copper Harbor, the government established an office on Porter's Island. These early years were filled with excitement, but for the most part that excitement focused on surveying and describing the mineral lands, not on practical mining. The public land survey of the mid-1840s provided a few early descriptions of the lands surrounding Copper Harbor.

In the late summer of 1845, William Austin Burt first staked section corners in Township 59 North of Range 28 West. The following summer William Ives, working for the State Geologist and General Land Office, walked the section lines and meandered the shoreline that bounded Section 33 of T59N-R28W. The 2014 project area of Section 33 is situated between Lake Fanny Hooe (on the south) and Copper Harbor (on the north). Ives noted that, "Between Lake Fanny Hooe \& Copper Harbor it is slightly rolling... [with] soil $3^{\text {rd }}$ rate all stony \& gravelly \& some rock. Aspen, W[hite] Birch, W[hite] \& Y[ellow] Pine, Cedar, Fir, Spruce, \&c” [were all present]. ${ }^{17}$

While conducting the east-west meander along the Lake Superior shore starting where the east side Section 34 and the shoreline intersect, Ives noted several trap rock outcrops and, of great interest to the 2014 project survey, two structures (see Table 1 on the following page). According to Ives' notes, the first store house was located just inland from the stony beach, while the second store house was west of Fanny Hooe Creek, near the base of Astor Point and the current front range light, and within the 2015 project survey boundary.

Table 1. William Ives' Survey Notes and Interpretation

\begin{tabular}{|l|l|l|}
\hline $\begin{array}{l}\text { Bearing } \\
\text { (Degrees) }\end{array}$ & $\begin{array}{l}\text { Distance in } \\
\text { Chains (ft.) }\end{array}$ & Description \\
\hline N82W (277) & $15(990 \mathrm{ft})$. & Over trap rocks 6, 8 \& $10 \mathrm{ft}$. \\
\hline S65W (245) & $4.7(310 \mathrm{ft})$. & 4 chs to conglomerate rock Dip N45 \\
\hline S30W (210) & $3(198 \mathrm{ft})$. & \\
\hline S70W (250) & $6.5(429 \mathrm{ft})$. & 2 chs small store house 1 ch opposite \\
\hline N80W (275) & $7(462 \mathrm{ft})$. & \\
\hline N30W (225) & $3.7(244 \mathrm{ft})$. & 2 chs to stream outlet of Fanny Hooe lake \\
\hline- & - & $\begin{array}{l}\text { The mouth of this stream makes a harbor for } \\
\text { small boats }\end{array}$ \\
\hline N34 ${ }^{1 / 2} \mathrm{E} \mathrm{(34)}$ & $3(198 \mathrm{ft})$. & $\begin{array}{l}1.5 \text { S store house opposite } \\
2.5 \text { S To trap rocks } 5 \mathrm{ft}^{18}\end{array}$ \\
\hline
\end{tabular}

\footnotetext{
${ }^{16}$ Lawrence Fadner, Fort Wilkins, 1844, and the U.S. Mineral Land Agency, 1843 Copper Harbor, Michigan, Lake Superior. (New York: Vantage Press, 1966), 156-59.

${ }^{17}$ William Ives, "General Land Office Survey Notes for Townships 58 and 59 North, Range 28 West, 1846.” (Washington D.C., 1846), 536.

${ }^{18}$ Ibid., 547.
} 


\section{The Pittsburgh and Boston Copper Harbor Mining Company}

The Pittsburgh and Boston Copper Harbor Mining Company acquired a three square mile parcel of land in the Spring of 1843 from the Isle Royale Copper Company which had taken up several leases throughout the region. The company designated this piece of property Lease \#4 and it was situated immediately adjacent to Lake Fanny Hooe. ${ }^{19}$

Initial work at the site began in the spring of 1844 on Lighthouse Point under the direction of John Hayes. Douglass Houghton had previously commented upon this area during his trip to the area in 1830s. Miners sunk three shafts on the point situated on different veins exposing black oxide of copper. They built two structures on the point during this work as well. After tracing the veins across the harbor to just east of Fort Wilkins more black oxide and some native copper were encountered. Several buildings were built on the site including 2 ware/storehouses, six log houses, a mining captain's office, and a blacksmith shop. Captain Jennings began sinking shafts on what was known as the "Wallace Vein". ${ }^{20}$

The precise location of these buildings is difficult to discern as their apparent locations shift slightly from map to map. None of the structures from this early mining effort remain standing making maps and contemporary accounts the best lines of evidence. ${ }^{21}$ A report by on Company holdings by Forrest Shepherd makes it clear that all of these structures were in place by $1846 .{ }^{22}$

The two storage buildings are at times both referred to as being warehouses but the more westerly of the two (which was excavated in 2014) is sometimes referred to as a storehouse. It is not clear if these terms were interchangeable or if they defined different purposes. As with most of the structures built by the company these structures would most likely have been of squared log construction. The blacksmith shop and cooperage were located just north of Fort Wilkins. ${ }^{23}$ Both of these jobs were important to a mining company as a blacksmith would act as farrier to animals, fix broken tools, sharpen drill

\footnotetext{
${ }^{19}$ Ralph Williams, The Honorable Peter White, a Biographical Sketch of the Lake Superior Iron Country (Cleveland: Penton Pub. Co., 1907), 10.

${ }^{20}$ Forrest Shepherd, Geological Survey of the Mineral Lands on the Southern Shore of Lake Superior : Belonging to the Pittsburgh and Boston Copper Harbor Mining Company (Pittsburgh: George Parkin \& Co., 1846), 14-15.

${ }^{21}$ Gary Van Lingen, "The Interpretation of Archaeological Remains at the Pittsburgh and Boston Copper Harbor Copper Mining Company's Second Campsite: Evaluating a Structural Component and its Potential Uses and Contexts.” (Master's thesis, Michigan Technological University, 2003), 16.

${ }^{22}$ Shepherd, Geological Survey, 14-15.

${ }^{23}$ Gary Van Lingen, “The Interpretation of Archaeological Remains at the Pittsburgh and Boston Copper Harbor Copper Mining Company's Second Campsite: Evaluating a Structural Component and its Potential Uses and Contexts." (master's thesis, Michigan Technological University, 2003), 22
} 
steels, and provide necessary hardware for company buildings. A cooper would be needed for making barrels in which to ship copper as well as other carpentry tasks.

In 1845 the company acquired Lease \#5 roughly 30 miles the south. This would eventually be christened the Cliff Mine and most work at Copper Harbor appears to have ceased by 1847. ${ }^{24}$ By 1848 Lease \#4 was abandoned and "Copper Harbor" was removed from the company's name with all attention focused at the Cliff Mine. ${ }^{25}$

While mining at the site was relatively brief and no structures remain, the Pittsburgh and Boston Copper Harbor Mining Company left clear signs of their work in the area which are visible today including trenching features (excavated in 2014), shafts (part of Park interpretation), and archaeological remains.

24 “Lake Superior News and Miners’ Journal." July 24, 1847.

${ }^{25}$ The company dropped "Copper Harbor" from its name by March of 1848, from Charter and By Laws of the Pittsburgh and Boston Mining Company of Pittsburgh, (Pittsburgh: George Parkin \& Co., 1848). ${ }^{31}$ Clarke, Pittsburgh and Boston, 15. 


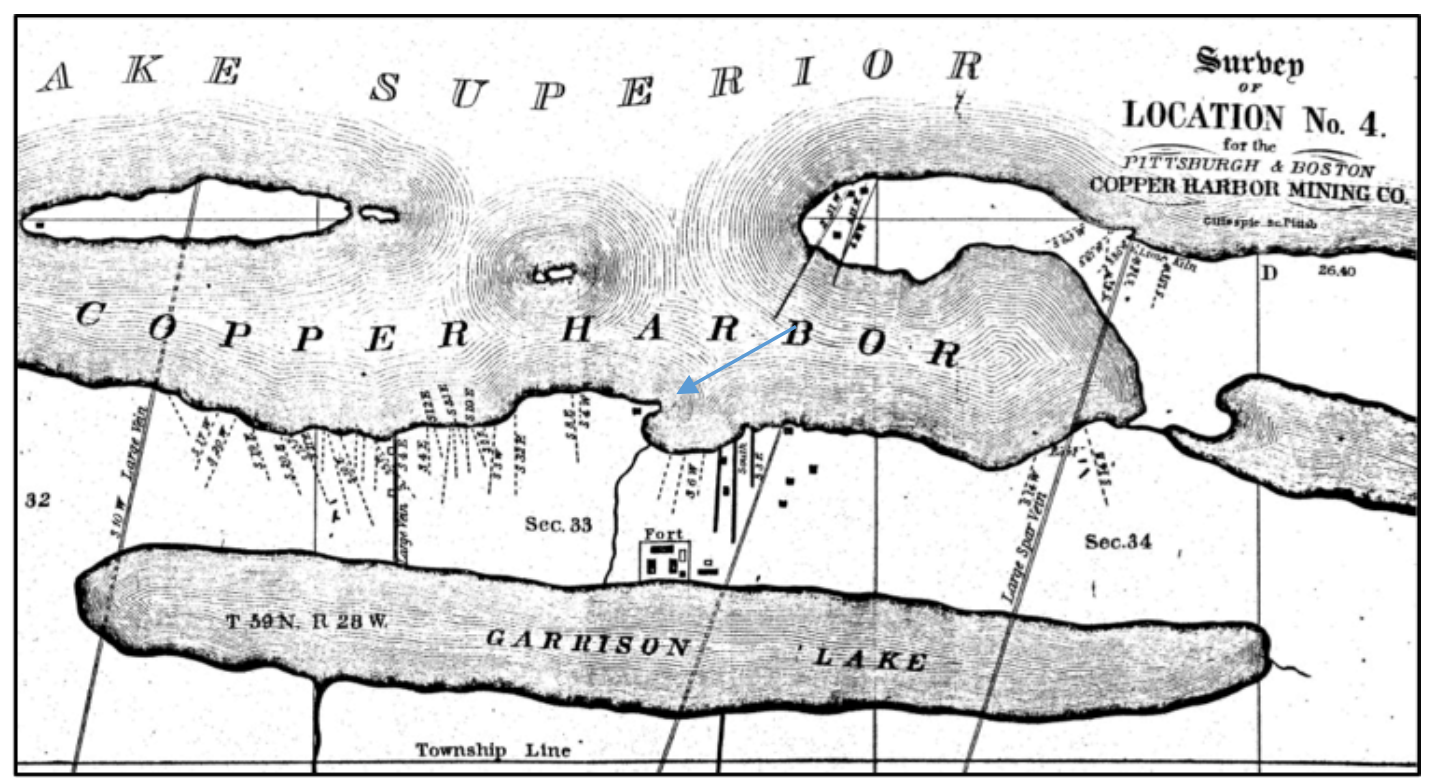

Figure 3. Survey of Location No. 4 for the Pittsburgh \& Boston Copper Harbor Mining Co. From, Geological Survey of the Mineral Lands on the Southern Shore of Lake Superior Belonging to the Pittsburgh \& Boston Copper Harbor Mining Company, 1846. Note structure near Astor Point. Map courtesy of the Michigan Historical Center, Michigan Iron Industry Museum.

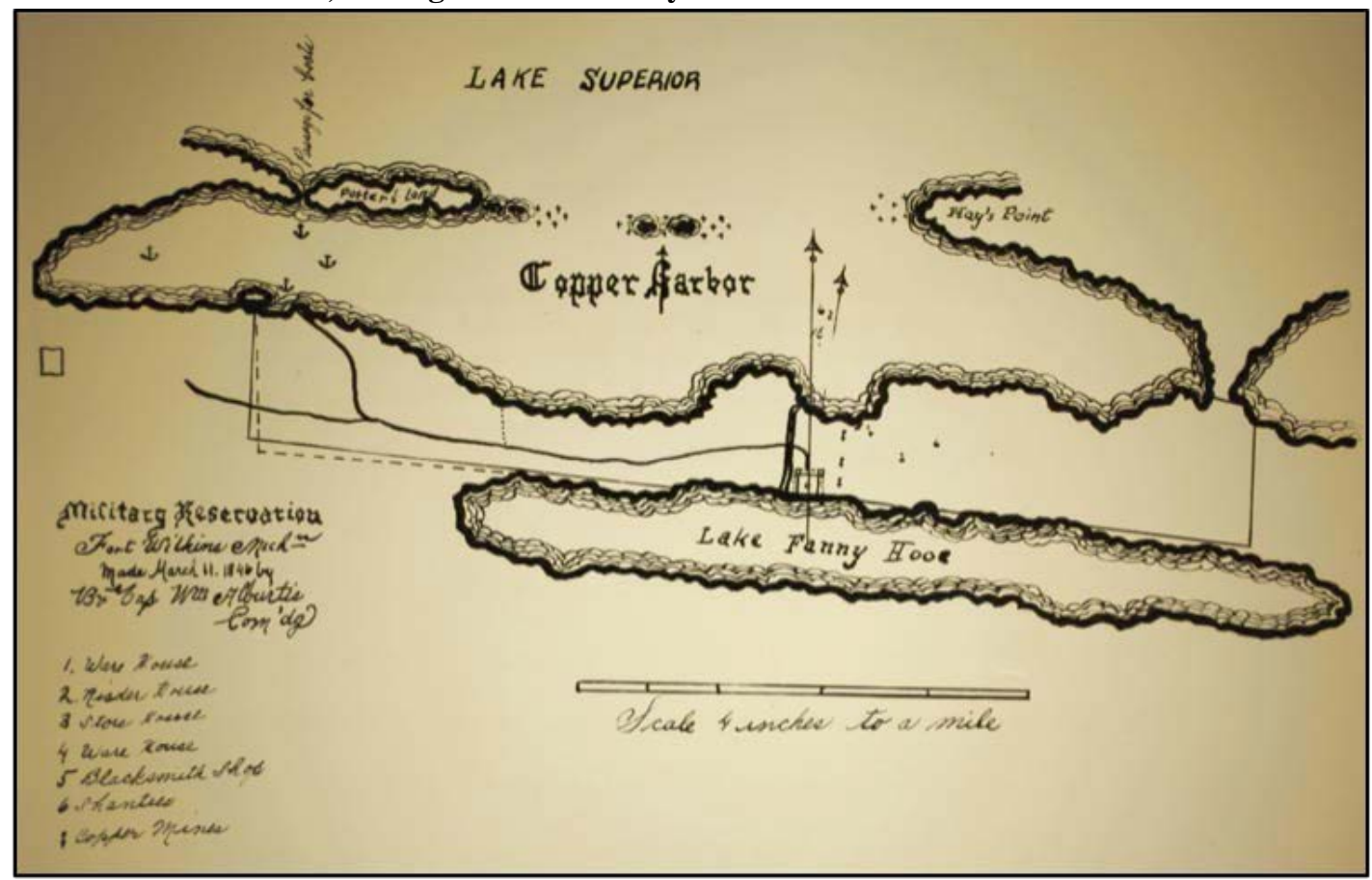

Figure. 4. Military Reservation: Fort Wilkins Michigan Made March 11, 1846 by Captain William Alburtis from the General Photograph Collection, State Archives of Michigan, Lansing, MI. 


\section{History of Fort Wilkins}

The Federal Government established Fort Wilkins to serve as a post that would reinforce the government's authority in the copper mining country of Lake Superior. According to a letter sent to Lt. Woodbridge in Detroit by Captain Robert E. Clary, the officer in charge of the fort, Fort Wilkins had been completed in late October of $1844 .{ }^{26}$ Fort Wilkins, named after the then current Secretary of War William Wilkins, was established to ensure peaceful interactions between white settlers and Native Americans while also enforcing the Treaty of La Pointe. Fort Wilkins also served as means to assert federal authority in the newly opened mineral region. ${ }^{27}$ When first completed Fort Wilkins consisted of sixteen structures and a stockade. The only buildings which still needed construction work in November of 1844 were the powder magazine and married enlisted men's housing.

The United States Army occupied Fort Wilkins in two distinct phases; pre-MexicanAmerican war and post-American Civil War era occupations. The pre-Mexican-American occupation began in 1844, as it was the soldiers who built Fort Wilkins. The first period of occupation by American forces was very short lived. The initial garrison, consisting of Companies A and B under Captain Clary, were dispatched to fight in the MexicanAmerican war in August 1845. Clary and his men were replaced by Captain William Alburtis and the $\mathrm{K}$ and I second infantry companies. Captain Alburtis and his men's tenure at Fort Wilkins lasted just over a year and they set off for Mexican front on July $25^{\text {th }}, 1846$. Captain Alburtis' career and life were abruptly ended when he was beheaded during the Siege of Veracruz on March $11^{\text {th, }} 1847 .^{34}$

The Federal government leased the unoccupied fort to Dr. John S. Livermore from 1855 to 1861. Dr. Livermore maintained the fort and made several improvements while operating it as a health resort. This business failed with his death in 1861 . The primary figure in maintaining Fort Wilkins in the absence of soldiers was William. B. Wright, a career soldier who enlisted at the age of eighteen. Wright was in charge of preserving Fort Wilkins in his capacity as Ordinance Sargent for nine years, when he mustered out of the army in order to remain in the Keweenaw. Wright re-enlisted in the Union Army as a Lieutenant once the American Civil War broke out. He served until he was wounded and discharged at the rank of Colonel in 1864 . He promptly returned to the Keweenaw. ${ }^{28}$

The second major phase of occupation at Fort Wilkins by American forces was just after the conclusion of the Civil War. The perceived need to re-garrison Fort Wilkins was manifest during the late 1860s. The major reasons were to assist in the de-marshaling of

\footnotetext{
${ }^{26}$ Fadner, Fort Wilkins, 48.

${ }^{27}$ Archibald, Robert, Northern Border: History and Lore of Michigan's Upper Peninsula and Beyond (Northern Michigan University Press), 90.

${ }^{28}$ Frimodig, The Fort Wilkins Story, 19.
} 
the large number of officers and soldiers left over from the Civil War who were serving out the end of their enlistments. ${ }^{29}$ Much like the previous military occupations of the fort, the perceived dangers never materialized and the post-Civil War occupation was short lived. This phase of the occupation lasted from September 26, 1867 to August 30, 1870. The Military Road, which was to connect the disparate communities of Keweenaw and open up a reliable overland route was not completed until 1873, a few years after the fort was abandoned by the military due it's remoteness and operating expense. ${ }^{30}$

Life at Fort Wilkins for the roughly 103 officers and enlisted men was quite mundane and tedious. The supposed threat from the natives never materialized and the soldiers' lives consisted of routine tasks such as guard duty and conducting military drills. ${ }^{31}$ The primary concern of the soldier was keeping warm and fed. He passed the doldrums of the day with games of cards, checkers and trading stories. ${ }^{32}$ The soldiers also engaged in some forbidden activities including illicit mining and the consumption of whiskey, when it was available. ${ }^{33}$

Fort Wilkins was used for a number of civilian purposes and occupied by a number of tenants following the final military occupation, including Judson North, who was eventually evicted. The Fort's abandoned powder house was used as a storage area for explosives by John Senter. Houghton County was also granted permission to use the holding cell at the fort as a county jail. Fort Wilkins remained a popular destination for tourists and sportsmen throughout the first half of the $20^{\text {th }}$ century. ${ }^{34}$

Today, nineteen structures stand at Fort Wilkins, twelve of them original dating to 1844 . The other buildings have been reconstructed based on archival and archaeological research. In 1974, historical activities at the park fell under the jurisdiction of the Michigan Historical Museum (Michigan History Division). The historic complex currently interprets three primary themes: early Keweenaw copper mining, Lake Superior maritime history, and nineteenth century military history. Museum exhibits, audio-visual programs, and living history interpretation also take place at the park's properties.

\footnotetext{
${ }^{29}$ Ibid., 14.

${ }^{30}$ La Vanway, Paul, “A History of Keweenaw County’s Road and Highways,” Superior Signal, $2007,5$.

${ }^{31}$ Frimodig, Fort Wilkins, 15.

32 Ibid., 15.

33 Ibid., 13.

${ }^{34}$ Ibid., 26.
} 


\section{The Astor House Hotel}

Early Copper Harbor was a boom town cut from the wilderness with few permanent buildings aside from Fort Wilkins and the Government Land Office located on Porter's Island. As late as 1846 it was described as “...A lively town of white tents”. ${ }^{35}$ Among the permanent buildings outside of government control were two storehouses which were noted by William Ives during his 1846 survey of the area and included in the sketch map he made to accompany his journal. The Pittsburgh and Boston Copper Harbor Mining Company storehouse was located east of Fanny Hooe Creek. MTU archaeologists excavated it in 2014. The other was constructed on the point immediately West of Fanny Hooe Creek adjacent to the Fort Wilkins landing. This storehouse became known as the Astor House providing food and lodging for early visitors to Copper Harbor.

The Astor House was not the only place of lodging in Copper Harbor. Daniel and Lucena Brockway operated a hotel in Copper Harbor from 1846 until they moved to Eagle Harbor. ${ }^{36}$ Brockway was involved in the storage and forwarding of goods as well. There was also the Porter Island House located on Porter's Island adjacent to a bakery and store out in the Harbor. These businesses were operated by Jim Raymond and H. Hamel. ${ }^{37}$

The Astor House was named after the John Jacob Astor (itself named for the founder of the American Fur Company), a 112 ton, 78 foot schooner which would bring supplies to Fort Wilkins and miners. A gale on September 21, 1844 led to the John Jacob Astor dragging her anchor and blowing onto the rocky point at the mouth of Fanny Hooe Creek. Traveler John St. John stayed at the Astor House noting:

"Its name is not a burlesque; it stands upon a point of rock not fifty feet from the wreck of the John Jacob Astor, and by way of designation was first called the 'House by the Astor, or by Astor Point;' and that name, which was there fixed by misfortune, will remain while that landmark for entering the harbor endures...”38

The Astor house was owned by a Mr. Joshua Childs and managed by a "half-breed" gentleman named Francois who also served as the cook, waiter, chambermaid, and clerk of the establishment. Childs was the Agent for the Copper Falls Company and later Copper Falls Mining Company from 1845 until he was replaced in 1851 by Samuel W. Hill. ${ }^{39}$ Being primarily a storehouse, the Astor House was a simple structure made of

\footnotetext{
${ }^{35}$ John Harris Forster, "Early Settlement of the Copper Regions of Lake Superior," Michigan Pioneer and Historical Society Collections 7 (1886), 186-87.

${ }^{36}$ Larry Lankton, Beyond the Boundaries: Life and Landscape at the Lake Superior Copper Mines, 18401875. (New York: Oxford University Press, 1997), 50.

${ }^{37}$ Lake Superior News and Miners Journal, Saturday, July $11^{\text {th }} 1846$.

${ }^{38}$ John St. John, A True Description of the Lake Superior Country. (New York : W.H. Graham, 1846), 30.

${ }^{39}$ Michigan Technological University and Copper Country Archives. MS-048 Calumet and Hecla Mining Abstracts, Box 3, Folder 43.
} 
pine logs measuring 24x16 feet consisting of one and a half stories with a small lean-to serving as a kitchen and dining area. Guests would stay upstairs where they were given space to spread out a mat and a buffalo robe. ${ }^{40}$

Another account of staying at the Astor House tells of sleeping on bags of oats "Up under the roof." In spite of the simple accommodations guests ate well with a dinner consisting of baked trout, pork and beans, bread and butter, dried apple sauce, coffee, tea and sugar all for 25 cents a night. George Thayer recalled "I became a patron of the Astor House and enjoyed its hospitality with great zest." ${ }^{41}$ St. John's and Thayer's accounts of their stays at the Astor House are remarkably similar to one another and are from only one year apart.

The Astor House also served to house the Lake Superior News and Miners Journal in 1846 which coat $\$ 3.00$ for a year's subscription to the four page weekly. In the August $22^{\text {nd }}$ edition of that year the paper noted that the Astor House would be "Destined to be known henceforth as containing the first printing press that ever found its way to Copperdom, and thus adding another item to the interesting reminiscences that already cluster around its bleached and weather-beaten logs." 42 This is presumably the first edition of the paper to be published. Edited by John N. Ingersoll and published by Ezra D. Burr the Lake Superior News and Miners Journal continued to be published in Copper Harbor until 1848. The paper chronicled the mining activities taking place in the new mineral region and featured advertisements for a wide range of services transportation, storage, merchants, and hotels. The Detroit Democratic Free Press stated that "The News is neatly filled with well written editorials and gives quite a glowing account of the copper region." ${ }^{43}$ The successor paper named the Lake Superior Journal was moved to Sault Ste. Marie from 1850 to 1855 before moving to Marquette where it was published until 1867 with the modern successor paper being named the Miners Journal which is still based in Marquette. ${ }^{44}$

It is unclear if the building still served as a lodge or storage space at this time, although it is possible that it could have served these functions simultaneously. Although never mentioned, the most likely type of printing press to see use in a remote area like the Keweenaw in the 1840s is the Washington-style hand press or one of its many copies which proliferated during the period. Designed by Samuel Rust in 1821, the Washington press became very popular. This type of press is similar in action to a Gutenberg press with an arm which swings across lowering the platen onto the paper laid over type forcing the paper into the type. These hand presses would have been relatively

\footnotetext{
${ }^{40}$ Ibid., 29-30.

${ }^{41}$ George W. Thayer, "From Vermont to Lake Superior in 1845," Michigan Pioneer and Historical Society Collections 30 (1905), 549-566.

${ }^{42}$ Lake Superior News and Miners Journal, Saturday, August $22^{\text {nd }} 1846$.

${ }^{43}$ Detroit Democratic Free Press, July 28. 1846.

${ }^{44}$ American Antiquarian Society Newspaper Project. Worchester, Massachusetts.
} 
economical compared to roll-style presses as well as easier to transport. ${ }^{45}$ A press of this type has a footprint of roughly $4 \times 8$ feet with the arm swinging across the long dimension. In addition to the press itself the other equipment which was needed to print included a type case (2x3 foot footprint), a composing stone for setting the type (2x3 foot footprint), and a small table for mixing inks and other assorted tasks. The above dimensions are based on measurements taken from artifacts at The Museum of Printing in Haverhill, Massachusetts.

Given the fact that the Astor House was known to be $16 x 24$ feet it is reasonable to say that even with a generous workspace around each piece of equipment printing would have taken up a most half of the lower level of the structure. In addition, an unknown amount of space would be required for hanging the freshly printed sheets to dry. However, the hanging sheets would not encroach on floor space while perhaps limiting the height things could be stacked or directing how people could move in the structure. The upper half story would be unaffected. The work of printing would require good light for the process of typesetting and examining printed pages suggesting that the Astor House would have had windows which was born out in the archaeology. A hypothetical floorplan can be found in the Recommendations section of this report.

After its mention in the Lake Superior News and Miners Journal the Astor House fades from historical record. As Copper Harbor developed and then diminished in importance, people forgot the small log building that was once the subject of many noted travelers. Even in the Lake Superior News and Miners Journal account, the Astor House appeared to be beginning to fall into disrepair. The Astor House may appear in an 1849 birds eye view of Copper Harbor which depicts a story and a half building immediately to the right of Fort Wilkins which can be identified by the flagpole. History did not record what ultimately became of the Astor House.

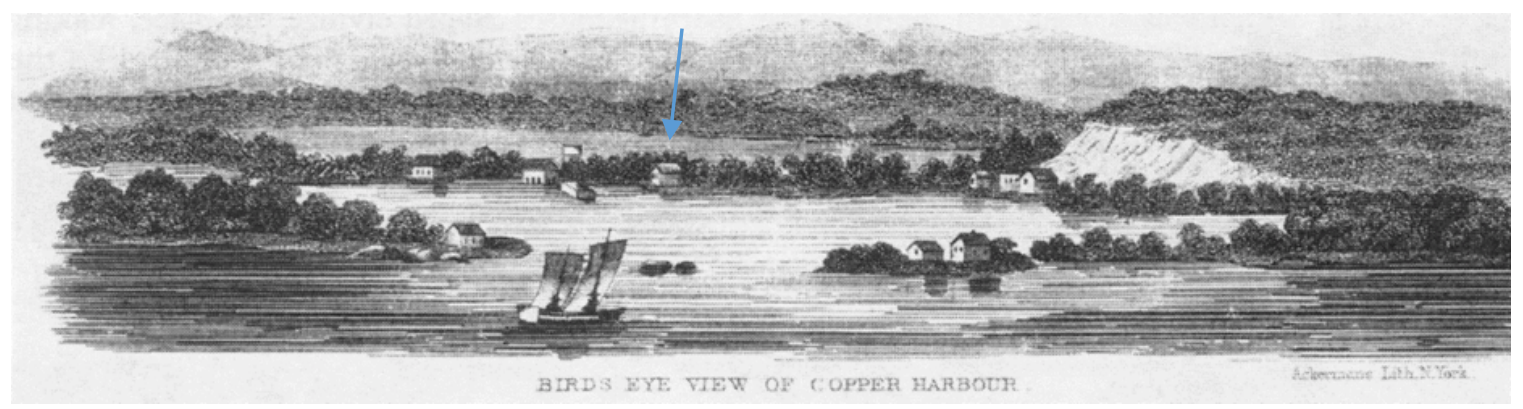

Figure. 5. Birds Eye View of Copper Harbor from Charles T. Jackson's Report of 1849. Potential depiction of the Astor House near the center of the drawing, to the right of Fort Wilkins. Image courtesy of the Michigan Technological University and Copper Country Archives.

\footnotetext{
45 James Moran, "Printing Presses: History and Development from the $15^{\text {th }}$ Century to Modern Times," (Berkley: University of California Press, 1973), 79-81.
} 


\section{Copper Harbor Range Lighthouse}

While Copper Harbor is one of the best harbors on the Keweenaw Peninsula it is not without its hazards. With the importance of Copper Harbor as a port for supplying mining operations it became clear that a lighthouse was necessary to help guide incoming ships. Congress approved the funds to construct a lighthouse in Copper Harbor in 1847, an amount totaling $\$ 5000 .^{46}$ The eastern point of Copper Harbor was chosen as the most suitable location. The resulting light house, while approved in 1847, was not erected until 1848. Due to the rough terrain at this location the keeper's house was built separate from the light tower. ${ }^{47}$ A later iteration of the lighthouse, built in 1866 at a site adjacent to the original, combined the keeper's quarters with the tower. ${ }^{48}$ This is the lighthouse that still stands today.

The Copper Harbor Lighthouse served to warn sailors off the point and guide them to the entrance of the harbor. However, it did not aid them once inside the harbor where shoals provide a challenge to making safe landfall. It became clear that another navigational aid was needed to guide vessels to safe landing. By 1860 Congress authorized the construction of range lights (albeit privately maintained lights) to guide vessels through the safest channel into the harbor. Prior to this authorization sailors utilized Astor Point as a reference for safe passage into the Harbor. ${ }^{49}$ The obvious drawbacks to this arrangement is that Astor Point is not visible in the dark or in poor weather and that sailors had to have prior knowledge of this landmark in order to safely make it into the harbor. Range lights, also known as leading lights, are two separate lights arranged on shore. The rear range is situated higher and further inshore than the front range. When entering the harbor these lights are aligned with the two lights and the vessel forming three points of a line. This line is then followed through the deepest and safest part of the channel entrance.

In 1865 the Government built a set of range lights on the west side of Fanny Hooe Creek that were little more than wooden towers with lights at their peaks. These lights were tended by a keeper who lived in one of the buildings at Fort Wilkins which had been transferred to the Lighthouse Board in 1865 for this express purpose. ${ }^{50}$ Following the regarrisoning of Fort Wilkins in 1867 the keeper moved to the town of Copper Harbor necessitating a commute of over a mile to tend the lights. Colonel William F. Raynolds, Engineer of Lighthouses for the Northern Lakes, saw this arrangement as impractical and proposed the construction of a combined rear range and dwelling in place of the existing wooden tower with an estimated cost of \$3951.55. He further proposed using the men

\footnotetext{
$4630^{\text {th }}$ Congress of the United States, $2^{\text {nd }}$ Session, Senate Document 27:15

47 James, Barry. Lighting the Way: A History of the Copper Harbor Lighthouse. Copper Harbor: Fort Wilkins Natural History Association, 1999. pp. 20.

48 Ibid., pp. 46.

49 John St. John, A True Description of the Lake Superior Country. (New York : W.H. Graham, 1846), 30.

${ }^{50}$ Index of Correspondence, Letter Book 165:208; and AR LHB 1860.
} 
working on the Portage Lake Range Lights to do the construction in an effort to speed up the work and reduce the cost. Congress approved $\$ 5000$ for the project on July 28, 1868. Workers completed the new range lighthouse by the close of the shipping season. ${ }^{51}$ During the early years of the range lights prior to the completion of the Range Lighthouse there was a high turnover rate for light keepers with George W. Perry serving from October 1,1865 to April 2,1866, Henry Meyer serving from April 2, 1966 to July 9, 1866, and William C. Turrell serving from July 9,1866 to June 4, $1867 .{ }^{52}$

The 1868 lighthouse is a one and a half story wood framed structure with the rear range light incorporated into the north end of the second story. Originally constructed without dormers, two were added to the structure by 1910 increasing light on the second story. The front range light was a 22 foot semi-octagonal structure built of wood. In this configuration the Copper Harbor Range Lighthouse was ranked as Class 2 Station meaning that it contained a Fourth Order light, a foghorn, and was continually manned. ${ }^{53}$ The first light keeper to live in the new range lighthouse was Edwin Bennet who served in this station from June 4, 1867 to October 24, 1870. ${ }^{54}$

The next light keeper broke the cycle of short terms of service at the Copper Harbor Range Lighthouse with William Tresise serving from October 24, 1870 to June 11, 1885 along with his family. ${ }^{55}$ There is little known about these early light keepers aside from their time in the Lighthouse Service. This is not the case with Tresise's replacement, Charles T. Davis who would serve at the Copper Harbor Range Lighthouse from June 11, 1885 to August 31, 1930. Davis was fastidious in his note taking and included aspects of his daily life in his log books which now reside in the Michigan Historical Center. His journal entries include standard information about the weather conditions and ships sighted during the course of any given day but also include many other details. Davis noted general maintenance, repairs, new construction, his hunting/farming activities, and personal notes. In 1908 the walkway between the lights was paved with the date marked in each slab. Davis repeatedly earned top marks in his annual efficiency inspections and this fastidiousness is also found in his journal entries. ${ }^{56}$

Following the automation of the Copper Harbor Lighthouse in 1919, keeper Henry Corgan transferred to Detroit. Charles Davis now was responsible for maintaining both

\footnotetext{
${ }^{51}$ Letters Rec'd Inspectors, Letter Book 234:51; Index of Correspondence 17 Sept. 1868; and AR LHB, 1868.

52 Annual Report to the Lighthouse Board, 1865-67.

53 Annual Report to the Lighthouse Board, 1851.

54 Annual Report to the Lighthouse Board, 1870.

${ }^{55}$ Annual Report to the Lighthouse Board, 1880.

${ }^{56}$ Copper Harbor Range Light Station: Selected documents from the National Archives including Inspections in the $11^{\text {th }}$ District. c. 1851-1900. Michigan Technological University and Copper Country Archives Collections, Microfilm: Accession 313.
} 
lighthouses at Copper Harbor. ${ }^{57}$ In 1924, the original wooden front range was replaced by an iron box-like structure which remains in place today. Following Davis' retirement Charles Haven served as keeper from September 1, 1930 to June 30, 1937. By the time Haven retired from his position the Copper Range Lighthouse was no longer of much importance as noted by the District 11 Superintendent who said that it was only being operated for "aged and deserving keepers" who were unable to work at more difficult stations.

Following Haven's retirement the lights were converted to electricity at a cost of $\$ 1060$. The electric lamp for the rear light was mounted outside of the old light bay on a small platform. The acetylene lighting equipment was left in place as a backup to Edison zinc copper oxide batteries. The estimated expected annual savings from electrification of the light was $\$ 1300 .{ }^{58}$ In 1964 a steel tower was built just north of the Range Lighthouse to house the rear light. This structure remains in use today. For a period the Assistant Manager of Fort Wilkins State Park used the Range Lighthouse as a residence although that is no longer the case.

${ }^{57}$ James, Barry. Lighting the Way: A History of the Copper Harbor Lighthouse. Copper Harbor: Fort Wilkins Natural History Association, 1999. pp. 83.

${ }^{58}$ LH Site Files 1454 E, Letter from F.P. Dillon, $11^{\text {th }}$ District Superintendent of Lighthouses, to H.D. King, Deputy Commissioner, Department of Commerce, Bureau of Lighthouses, 30 March 1937. 


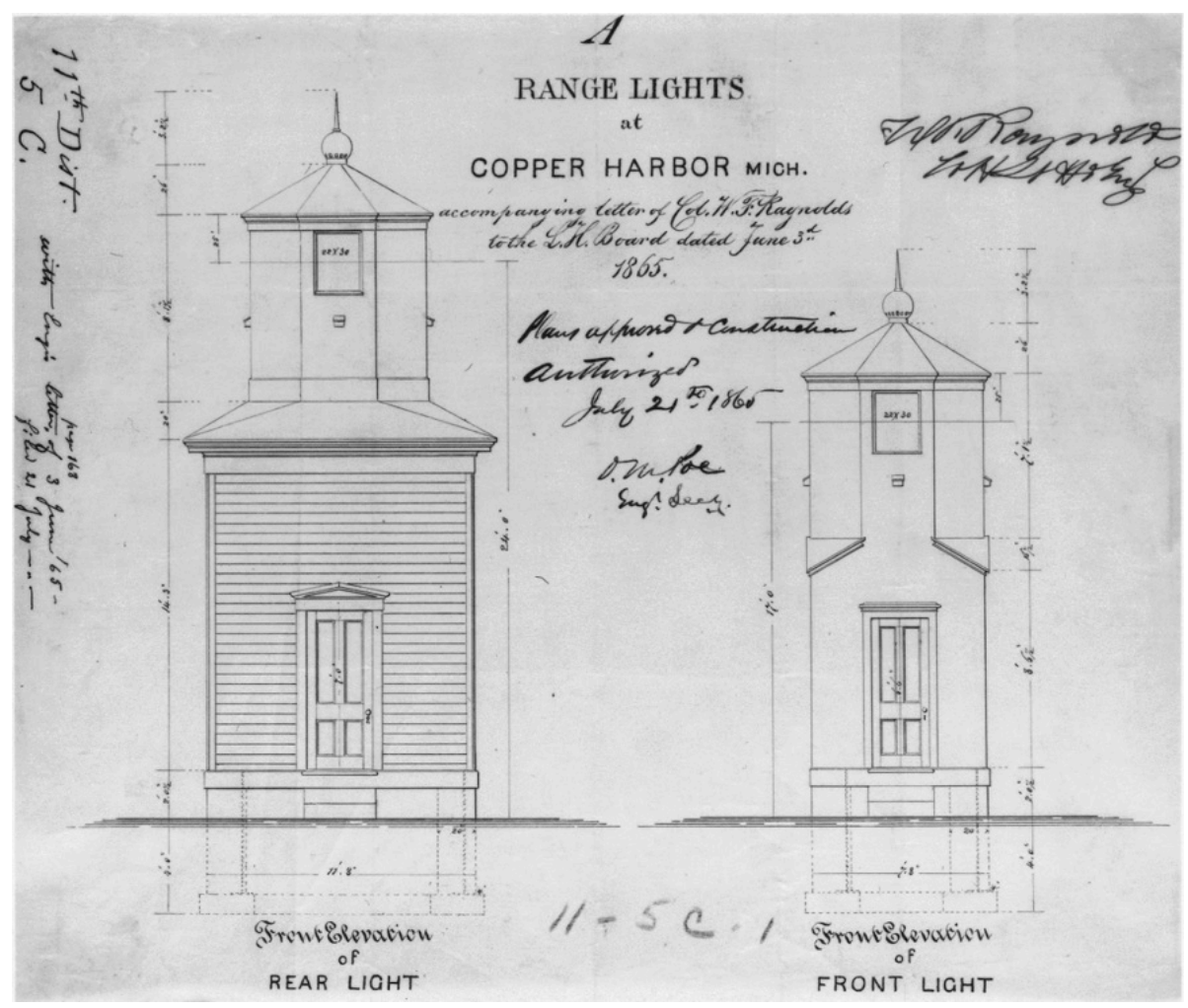

Figure 6. Original Plans for the Copper Harbor Range Lights. 1865. Image courtesy of the Michigan Historical Center, Michigan Iron Industry Museum.

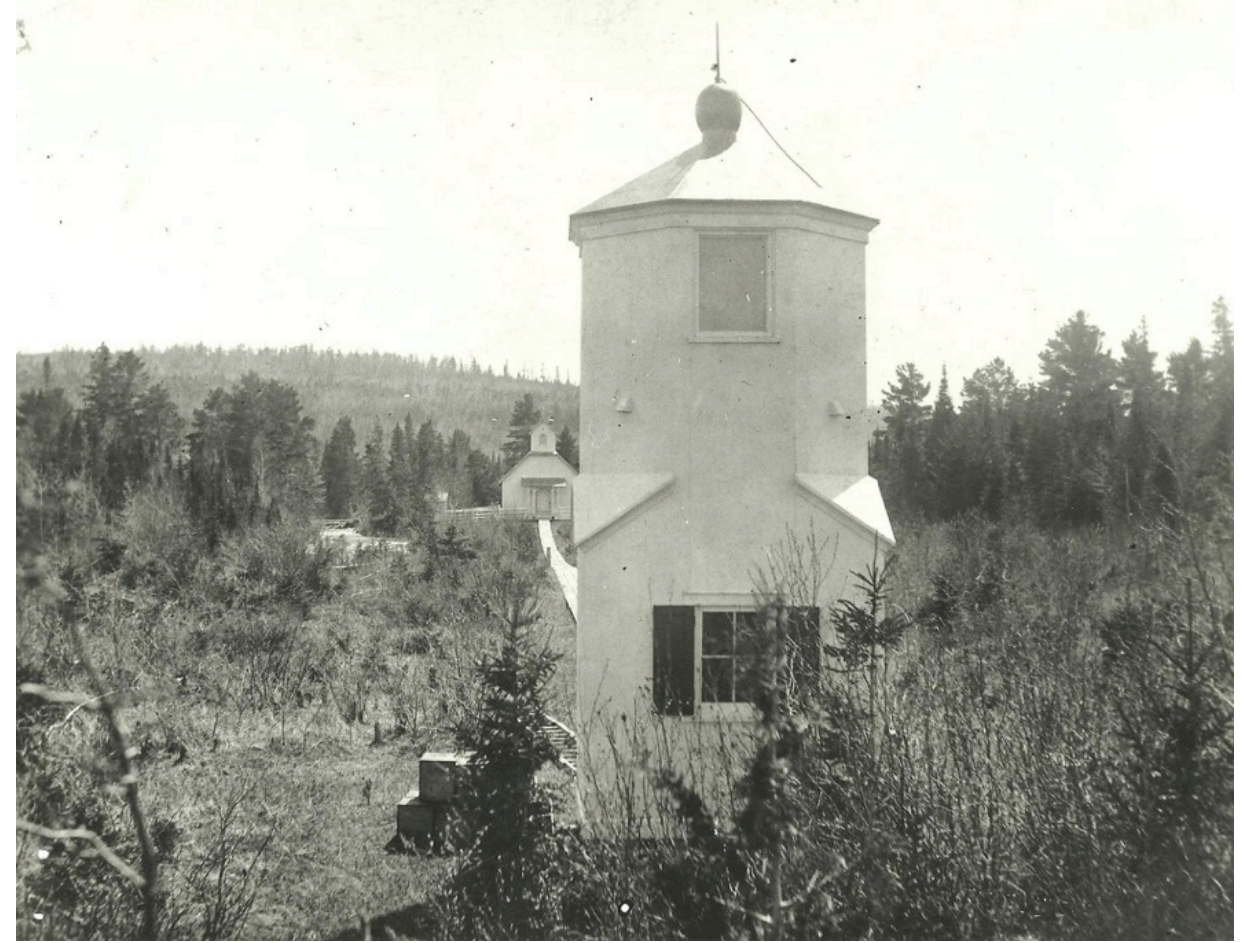

Figure 7. The front range light as built. Photograph from 1912. Image courtesy of the Michigan Historical Center, Michigan Iron Industry Museum. 


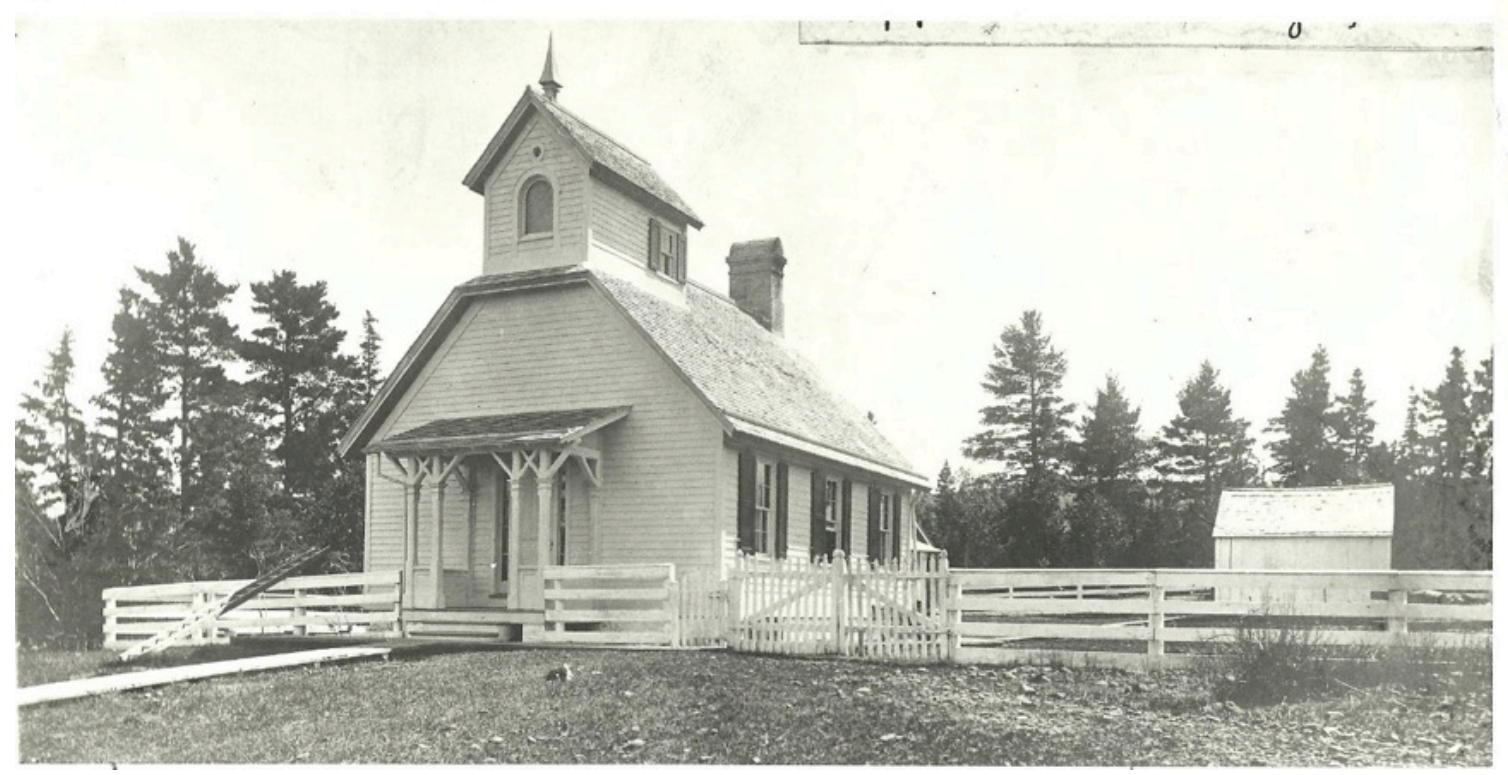

Figure 8. Range lighthouse. Photograph showing the lack of a dormers. Also note shed in background and extensive fencing. 1880. Image courtesy of the Michigan Historical Center, Michigan Iron Industry Museum.

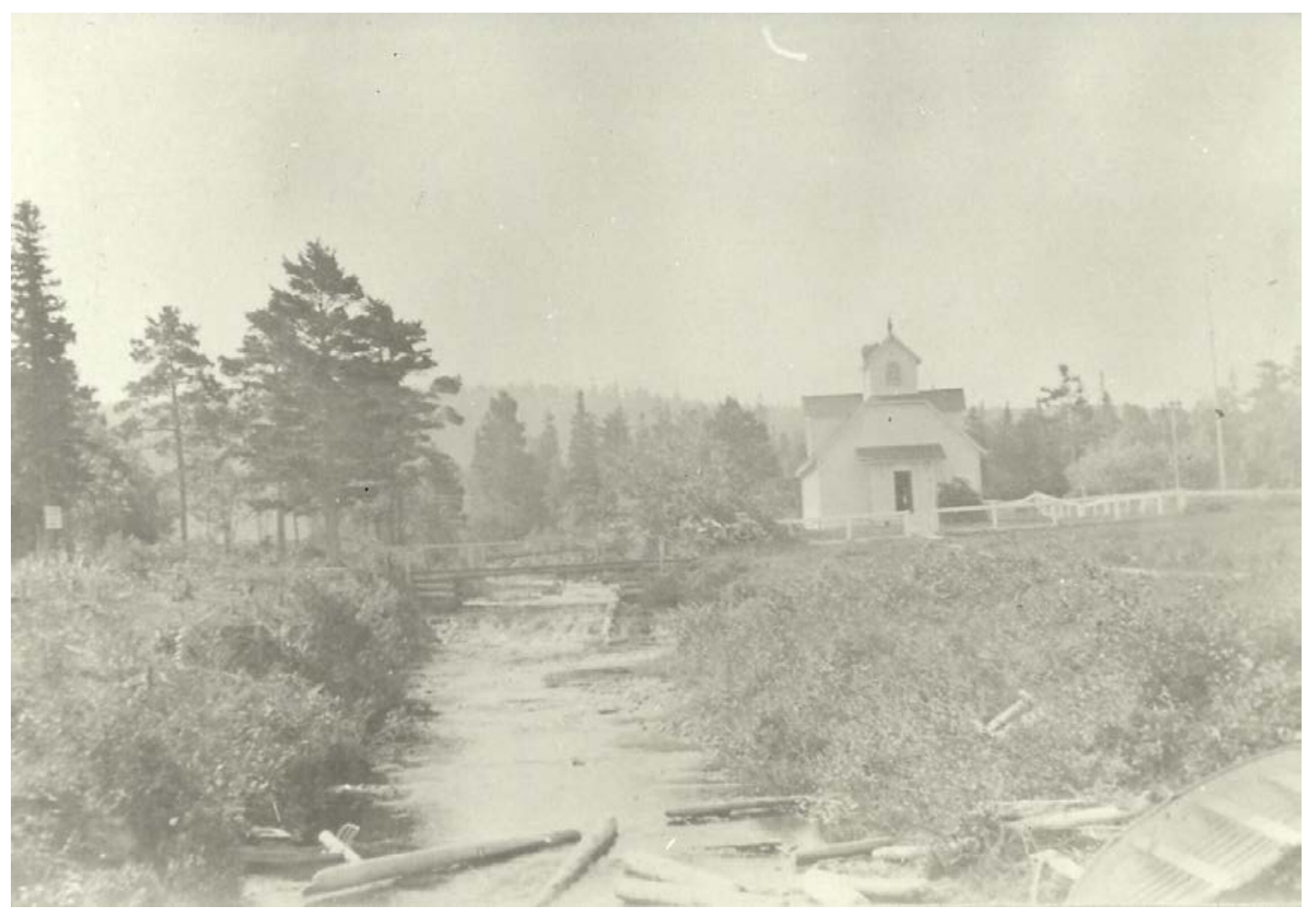

Figure 9. Photograph showing dormers added and redesigned fencing. Note log crib bridge abutments. 1910. Image courtesy of the Michigan Historical Center, Michigan Iron Industry Museum. 


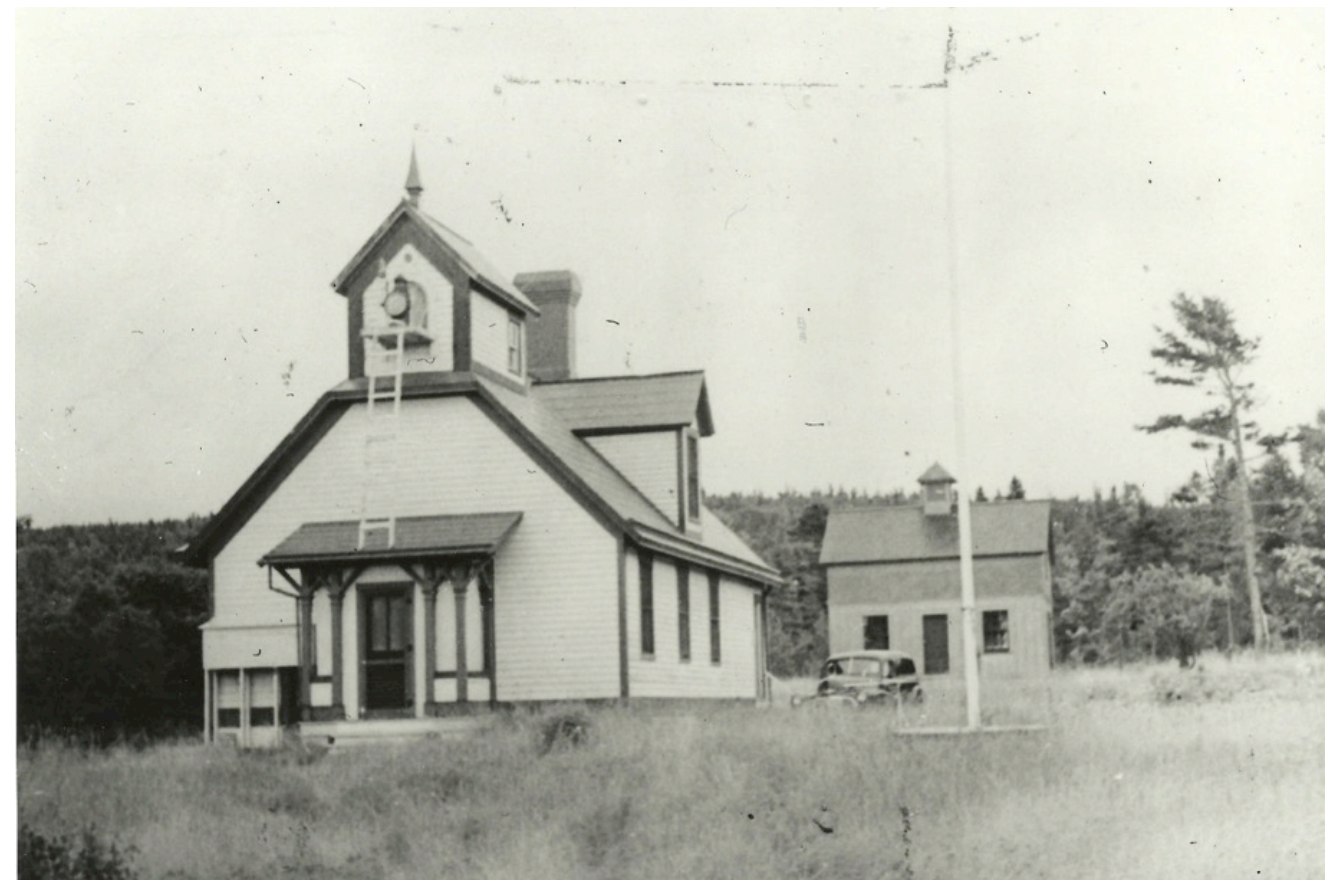

Figure 10. 1945 Photograph showing electric lamp mounted outside of original light bay. Also note lack of fencing. Image courtesy of the Michigan Historical Center, Michigan Iron Industry Museum.

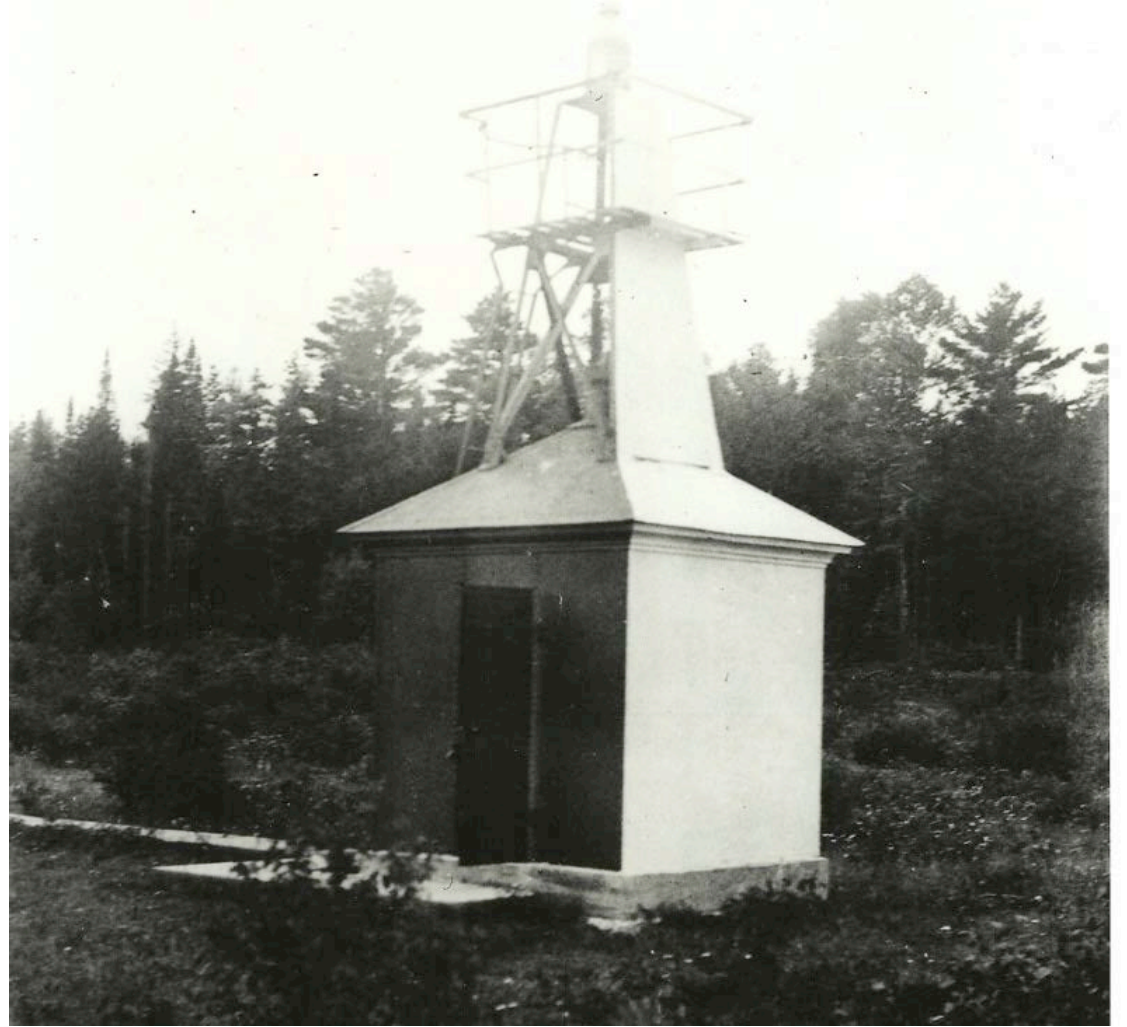

Figure 11. 1924 Photograph showing the new front range. Image courtesy of the Michigan Historical Center, Michigan Iron Industry Museum. 
In addition to the Range Lighthouse, there were outbuildings to the south which served the light keepers and their families. Most of what is known about these structures is derived from historic photographs and passing mentions by Davis. To the west of the lighthouse was a garden plot and through the years there were various iterations of fencing around the property.

The most notable structure is the barn which also served as a garage and later as housing for seasonal employees of Fort Wilkins State Park. Davis reports that construction of the barn began on August $27^{\text {th }} 1902$ with clearing taking place as well as the setting of sill posts. ${ }^{59}$ Work on the $16 \times 24$ foot structure was completed on September $2^{\text {nd }}$ and the old shed that the barn was replacing, which Davis deemed an "eyesore”, was torn down on the $24^{\text {th }}$ of the same month. ${ }^{60}$ The structure is one and a half stories tall and originally had two windows on the North side with a door centered between them. The gable ran east-west with a window at each end for the second story. A large door on the west wall served to allow animals into the barn. By 1931 the barn had been converted to a garage by the addition of ramp leading to the large door as evidenced by a photograph from that year.

Following World War II it was decided to convert the barn, now a garage, into bachelor's quarters for seasonal workers of Fort Wilkins State Park. Along with this conversion the structure was moved to the northwest as documented on the 1940's adjustment to a 1910 map by O.G. Brown. This conversion entailed a substantial redesign of the structure with door being moved to the Southwest corner of the building and the addition of a fireplace/chimney on the east wall. It was also placed on a foundation instead of sill posts. Today, this structure remains in use for the housing of seasonal park employees.

The privy receives little mention, as expected, so what is known about it comes almost entirely from historic photos. It is likely that the privy hole was blasted into the rock given Davis' descriptions of fence construction. The privy was located off of the southeast corner of the Range Lighthouse near the river bank with its gable running eastwest and the door being on the west side of the structure. In older photographs the walls appear to be covered with white clapboard siding. By 1931 it had been sheathed with a dark colored clapboard siding. The privy was removed at some point in the late 1940s.

${ }^{59}$ Journal of the Copper Harbor Range Light Station, 27 August 1902.

${ }^{60}$ Journal of the Copper Harbor Range Light Station, 24 September 1902. 


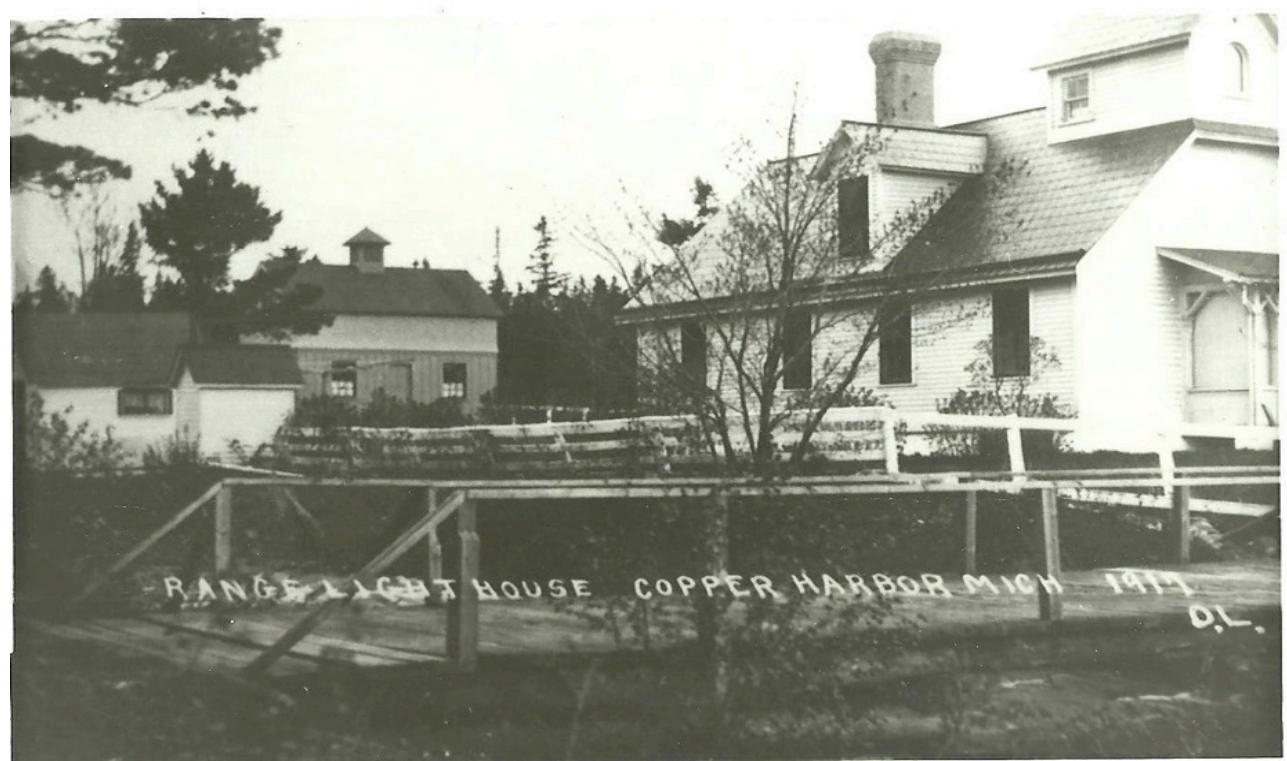

Figure 12. Earliest photograph showing the barn. Also note privy and washhouse to left with white siding. Bridge still in use, appears to have split log decking. 1917. Image courtesy of the Michigan Historical Center, Michigan Iron Industry Museum.

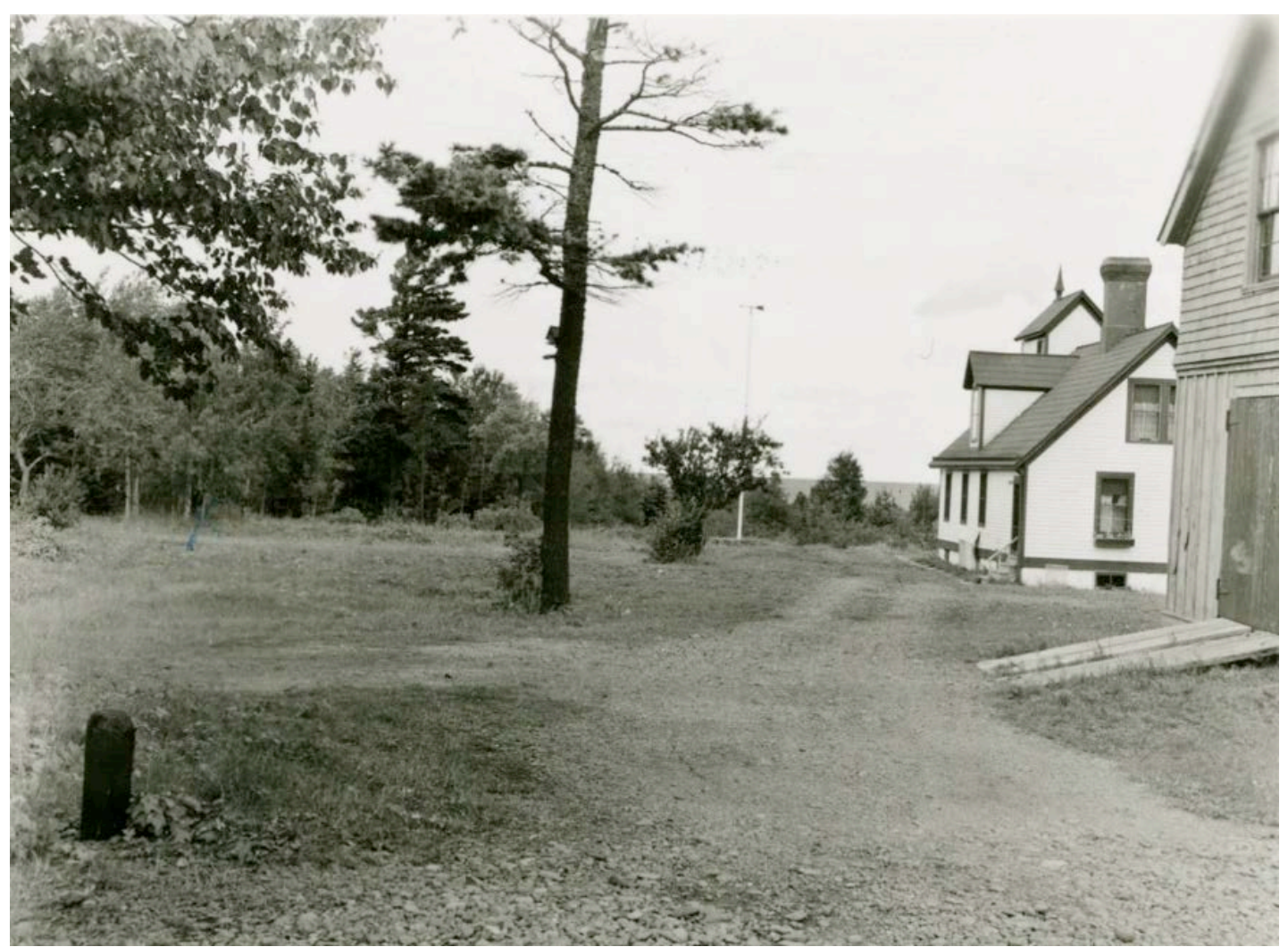

Figure 13. Ramp leading to large west facing door visible at right. Blue marking to left in yard shows future location of the structure. Image courtesy of the Michigan Historical Center, Michigan Iron Industry Museum. 


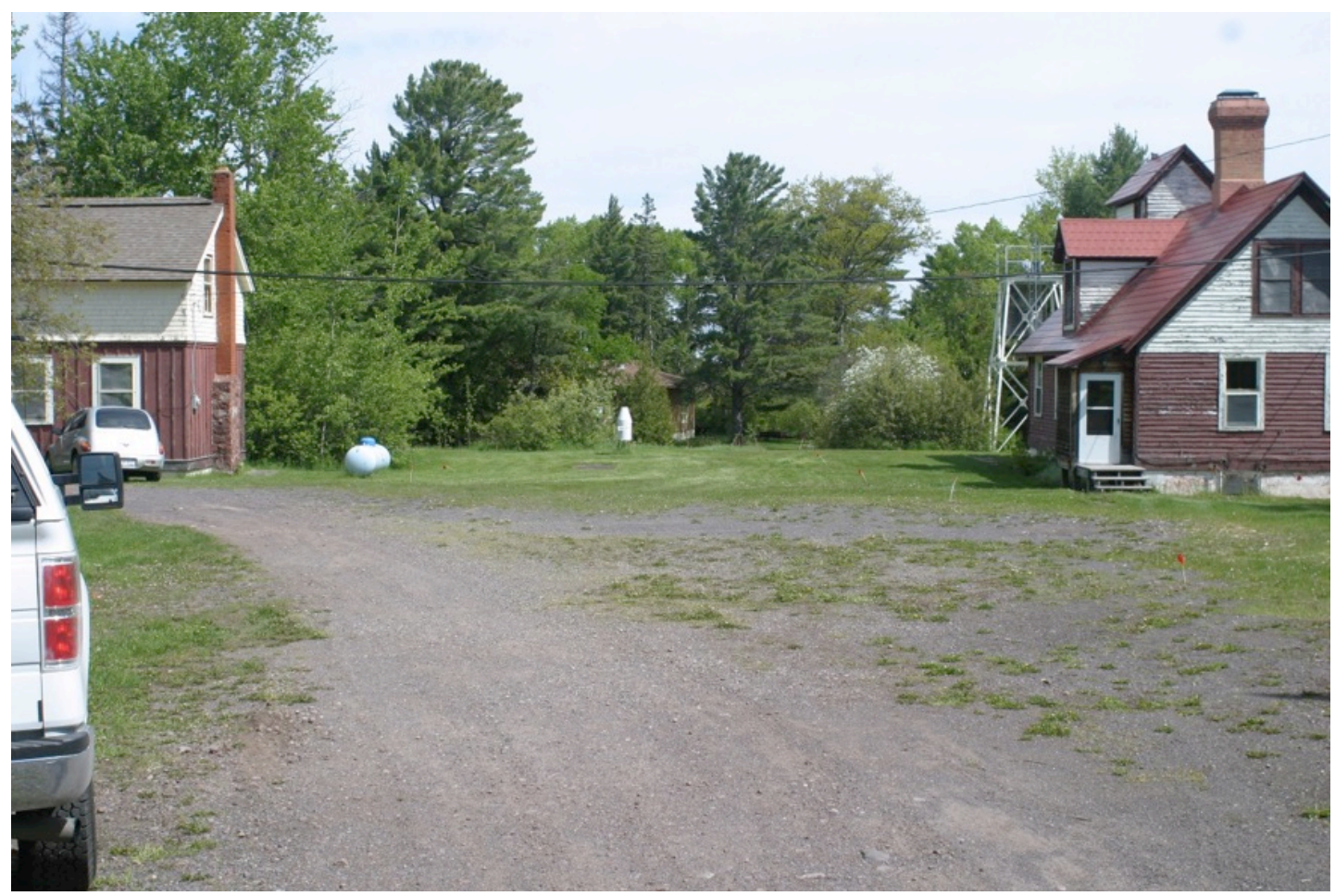

Figure 14. Current location of bachelor's quarters relative to the Range Lighthouse showing that the Conservation Department moved the structure as indicated in Figure 13. Note chimney. Photo by author, 2015. 


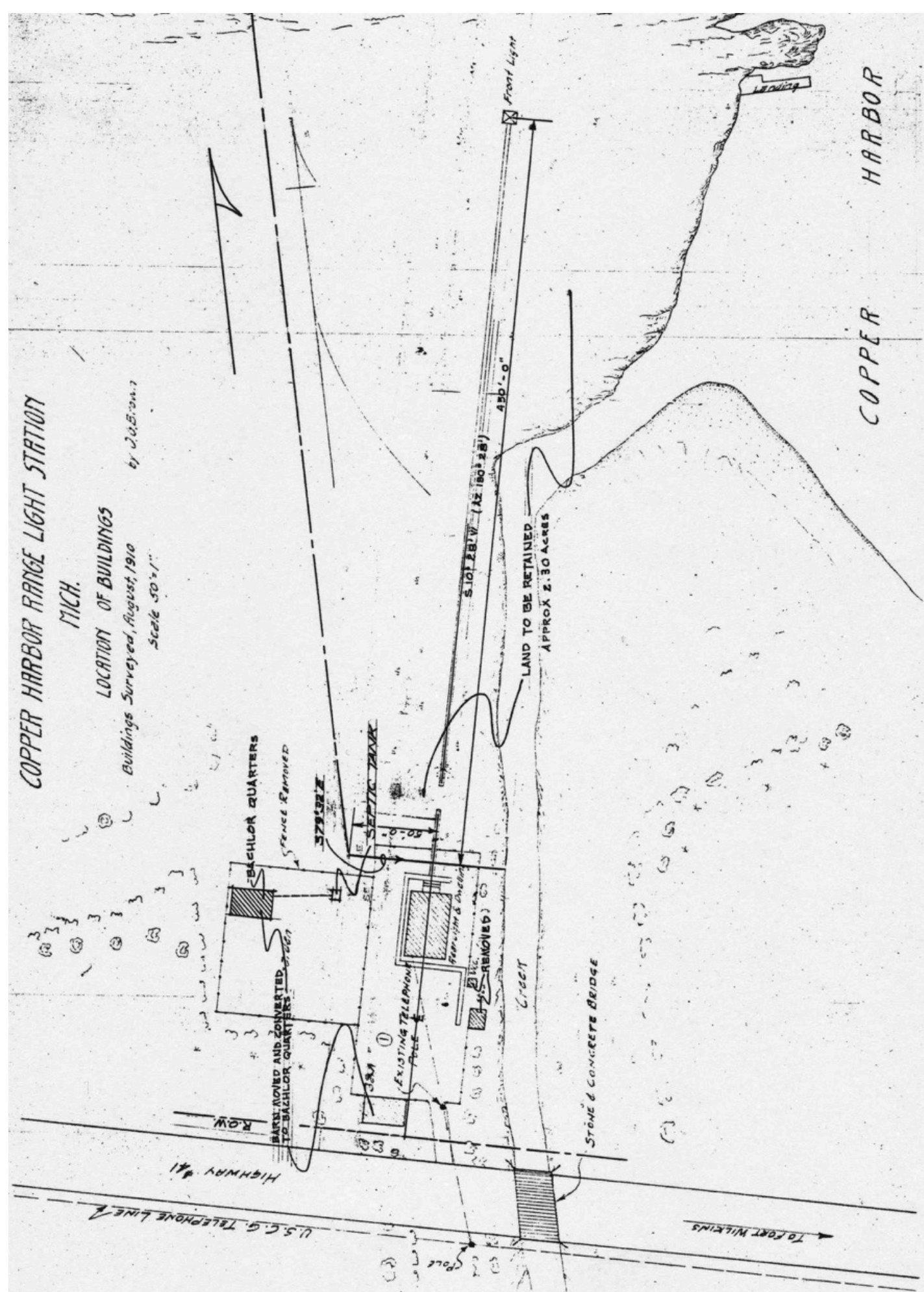

Figure 15. 1940's adjustment to 1910 Brown map showing movement of the barn/garage/bachelors quarters. Also shows removal of privy and washhouse. These structures are shown as being farther apart from one another than photographs suggest. Note that barn placement is incorrect as is washhouse shape with long wall running North-South, not East-West as seen in photographs. Bridge not shown. Image courtesy of the Michigan Historical Center, Michigan Iron Industry Museum. 
Construction on the washhouse began in late May of 1904 by Davis and a helper named George McIver. ${ }^{61}$ Davis finished construction on June 14 noting that "This saves all steam and mess around the house besides making the laundry work much lighter." ${ }^{2}$ Two years later Davis mentioned installing a stove although how they were producing steam in the laundry prior to this is not clear. ${ }^{63}$ The structure that Davis built was located just south of the privy with the rear wall only a few feet from the river bank and was roughly 10x12 feet. Like the privy, the walls were covered with white clapboard siding and the gable ran east-west. There were doors on both the east and west sides in addition to a couple of small windows. On the east side of the building there was a small deck constructed which abuts the edge of the river bank as seen in Fig. 17. At least occasionally logs were laid across the river to this platform making a foot bridge. The area around the washhouse appears to have been a center for much activity as there are tables, benches, ladders, and a clothes drying rack evident in photographs. This structure was also used to some extent as a summer kitchen which would keep the house cooler during the warmer months of the year. In 1910 a paved walkway was laid leading to both the privy and washhouse. ${ }^{64}$ As with the privy it was removed some time during the late 1940s.

The Range Lighthouse was in operation for almost 70 years and during that time it went through many iterations of fencing. What makes this interesting is the extreme lengths taken to build fences. Davis repeatedly mentions drilling and blasting in order to put in fence posts. In spite of what must have been tremendously difficult work, the fencing was constantly being revised until it was all removed by 1945.

A wooden bridge crossing Fanny Hooe Creek just north of the Range Lighthouse was in place by 1865. This bridge facilitated movement between Fort Wilkins and the landing at Astor Point. Other than Davis' mentions of performing repair work on it, most of what is known comes from historic photographs. It was a single span bridge with a deck which appears to split logs with a wooden guardrail. The abutments were originally log and stone cribs. Later, a new concrete abutment was made on the West bank of Fanny Hooe Creek, most likely as an attempt at limiting erosion. Despite appearing rather lightly built, it was capable of supporting the weight of an automobile. (See Fig. 20) While still in place during the late 1910s historic photographs show it was removed prior to the automation of the Range Lighthouse.

${ }^{61}$ Journal of the Copper Harbor Range Light Station, 27 May 1904.

${ }^{62}$ Journal of the Copper Harbor Range Light Station, 14 June 1904.

${ }^{63}$ Journal of the Copper Harbor Range Light Station, 18 April 1906.

${ }^{64}$ Journal of the Copper Harbor Range Light Station, 19 May 1910. 


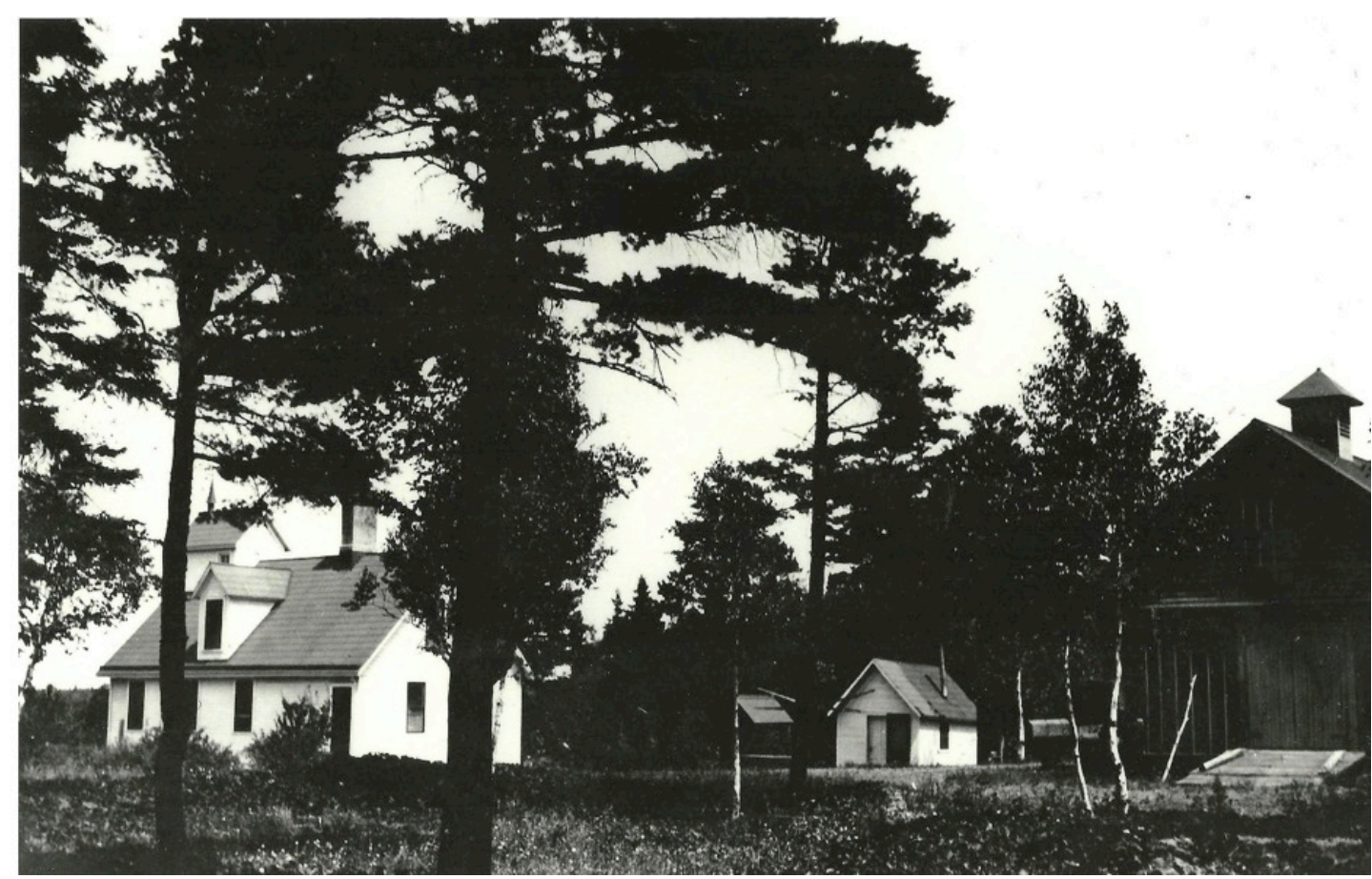

Figure 16. View showing privy with dark siding and washhouse. Also note ramp in place on West end of garage. Image courtesy of the Michigan Historical Center, Michigan Iron Industry Museum.1931.

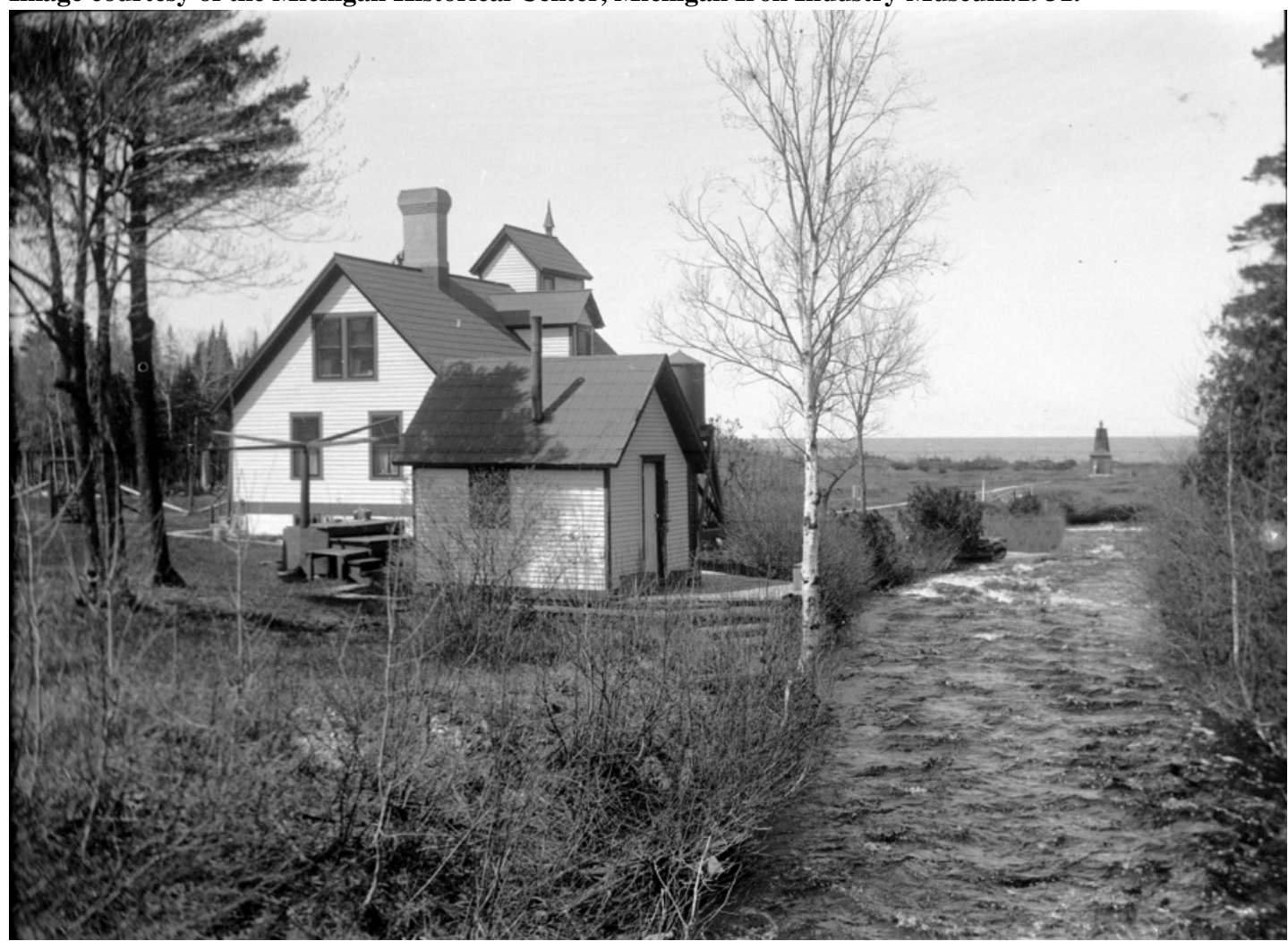

Figure 17. South view of washhouse showing deck constructed in rear and items in front. Some fencing evident at left in background. In background to right bridge abutment is visible. Image courtesy of the Michigan Historical Center, Michigan Iron Industry Museum. 


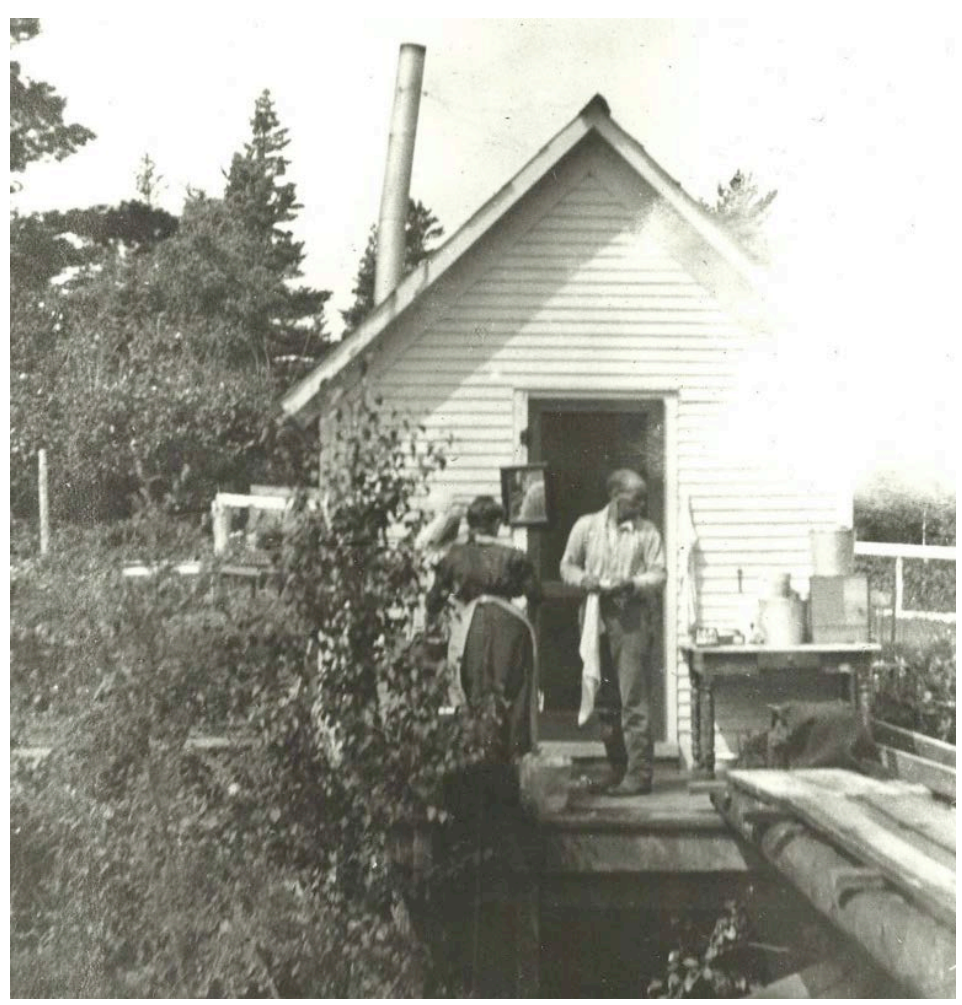

Figure 18. Charles Davis and wife in back of washhouse, log foot bridge evident to right. Note rear deck is less substantial than in Figure 17. Image courtesy of the Michigan Historical Center, Michigan Iron Industry

Museum.

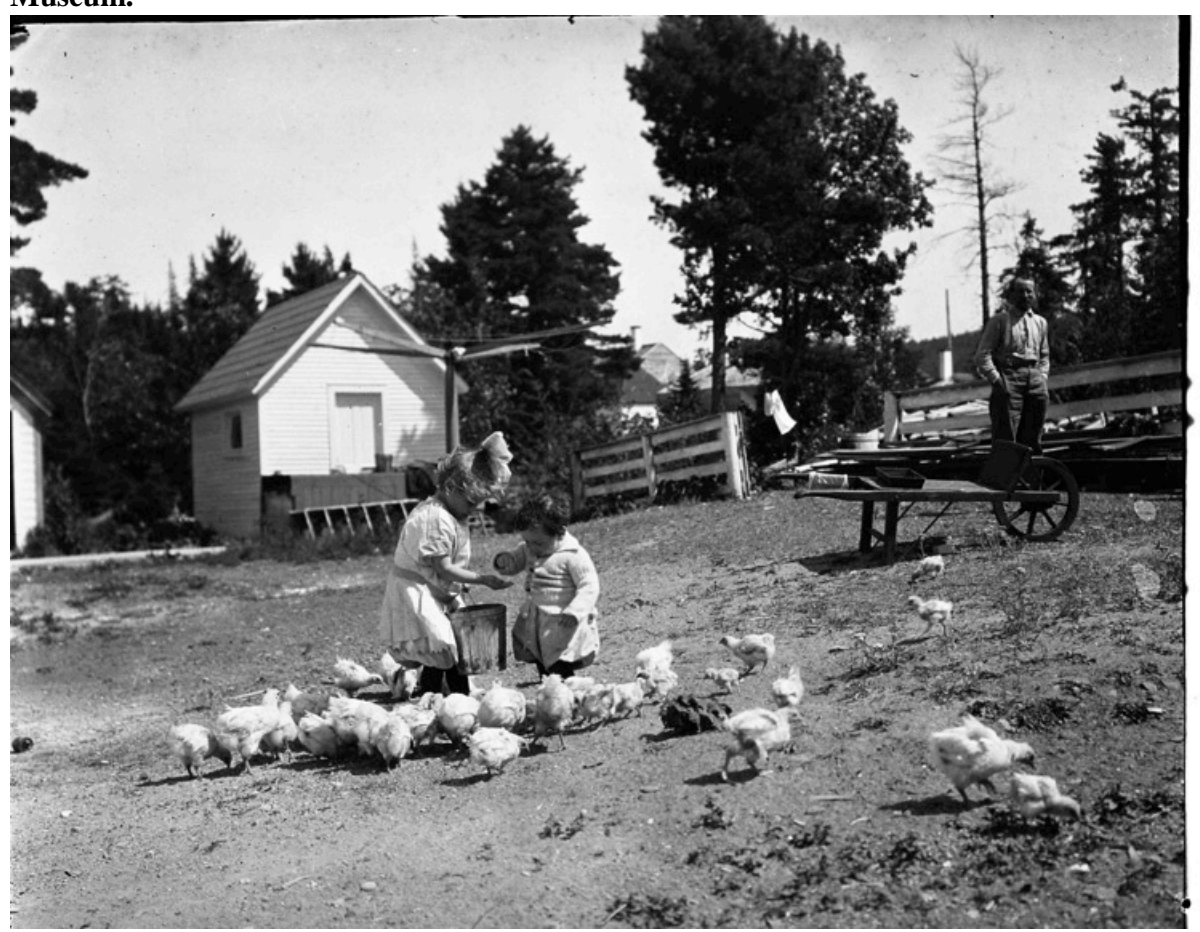

Figure 19. Photograph showing washhouse with privy just in frame to left. Note fencing and paved walkway. Unknown date. Image courtesy of the Michigan Historical Center, Michigan Iron Industry Museum. 


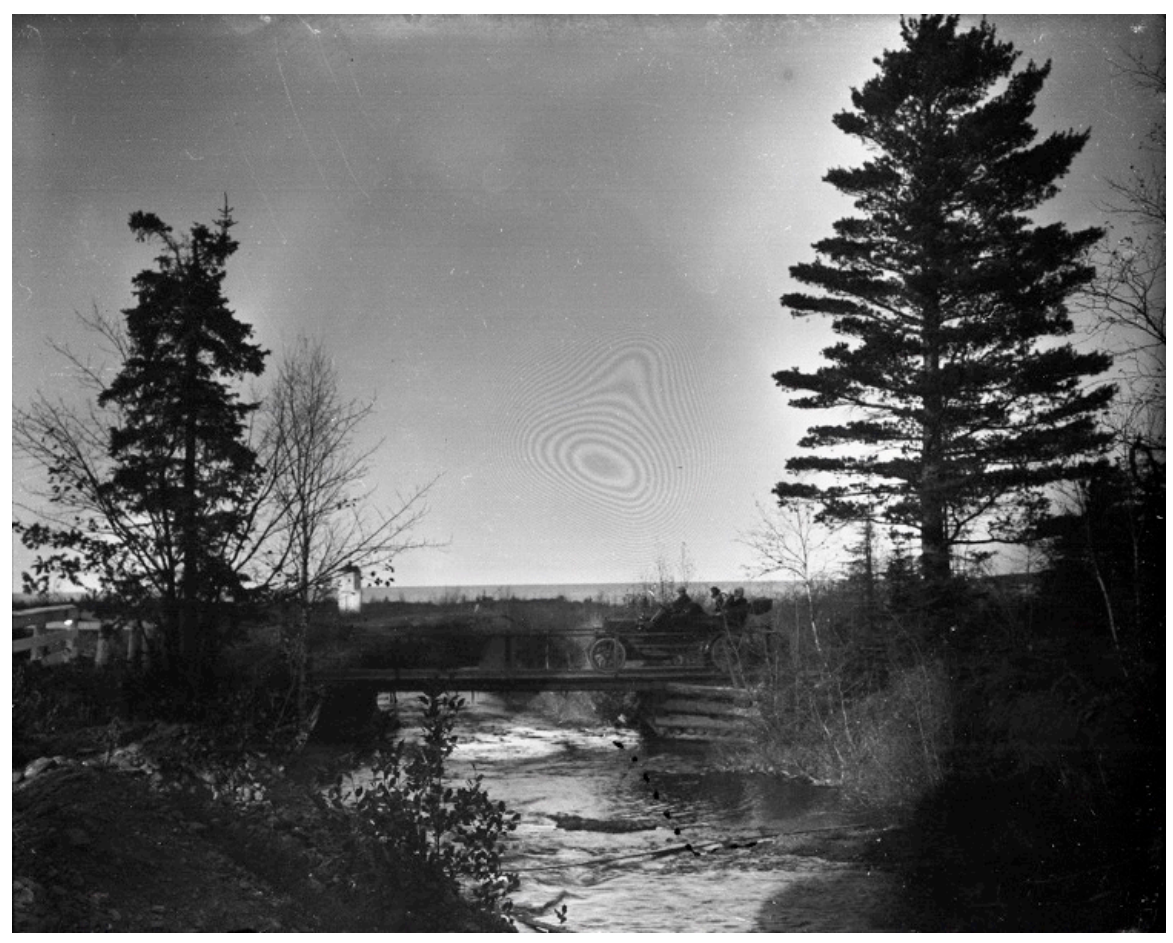

Figure 20. Bridge towards the end of period of use. Note log crib abutment and Model T driving across. Unknown date. Image courtesy of the Michigan Historical Center, Michigan Iron Industry Museum.

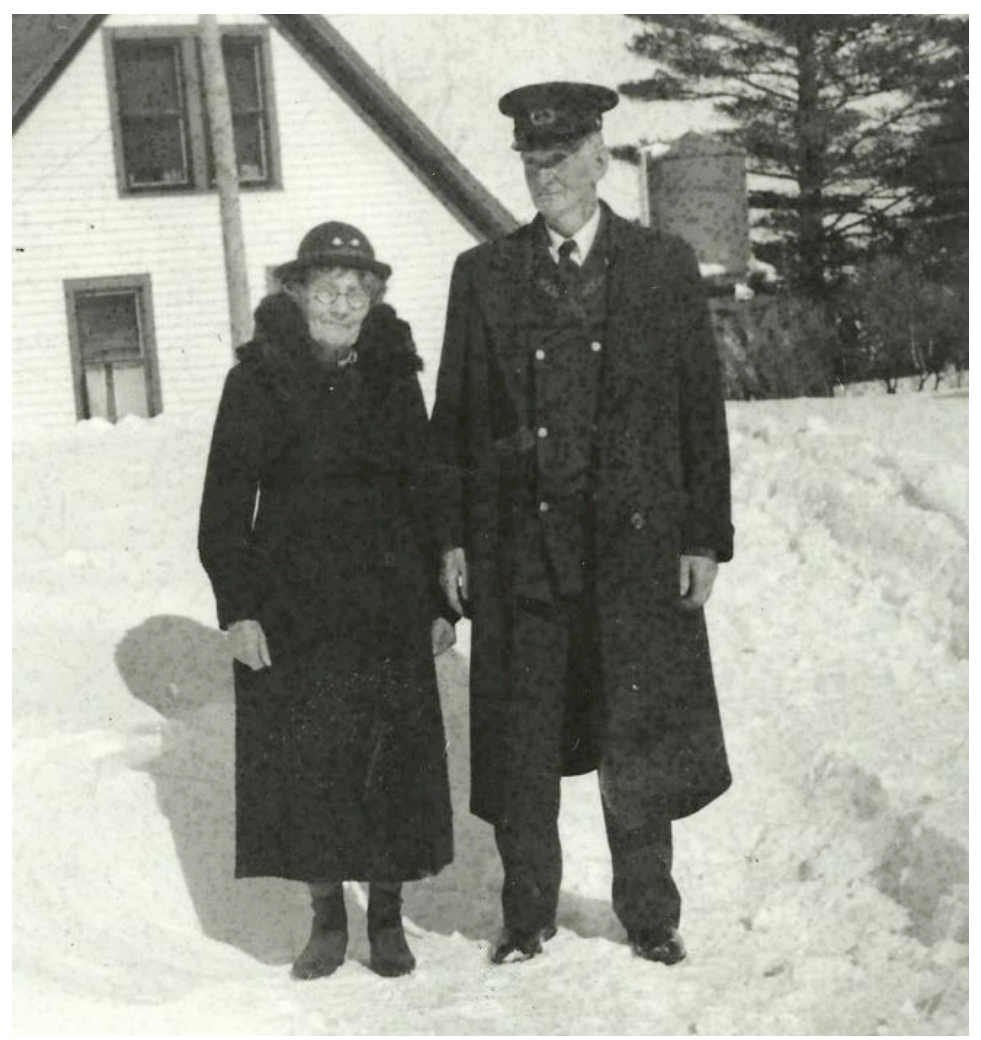

Figure 21. Charles Haven and wife. Last keeper of Copper Harbor Range Lighthouse, “Aged and deserving”. 1930s. Image courtesy of the Michigan Historical Center, Michigan Iron Industry Museum. 


\section{Works Progress Administration and Fort Wilkins Historic State Park:}

Fort Wilkins became a state park in 1923 and soon after work began to restore the fortifications. Major restoration work at Fort Wilkins did not begin until the WPA era, due in part to a lack of funds from the Michigan State government. ${ }^{65}$ This work continued during the 1920s and 1930s, mostly under the direction of the Civilian Conservation Corps, the Civil Works Administration, and later the Works Progress Administration (WPA). Building restorations were guided by Victor Oja, a Finnish immigrant from Mohawk. ${ }^{66}$ The WPA work undertaken at and near Fort Wilkins can be broken down into two major categories: the building of roads and the restoration of the Fort's historic structures.

Starting in the spring of 1933 a new 11.1 mile state highway was constructed connecting Copper Harbor to Eagle Harbor. Originally designated M-129, it was renamed M-26 in 1935. ${ }^{67}$ The other significant piece of roadwork completed at this time was the extension of US-41 from Fanny Hooe Creek Bridge to the eastern camp ground at Fort Wilkins, completed in 1942.

The other major type of work done in the Copper Harbor area was the restoration of Fort Wilkins. This involved repairing and reconstructing the buildings with WPA manpower. In order to achieve a greater accuracy of restorative detail, the WPA workmen built and used a blacksmithing forge to recreate metal parts used in restoration. Other additions to Fort Wilkins State Park included the park concession stand, shower facilities and a new entrance road. ${ }^{68}$ The WPA work in this area lasted nine years in all, from 1933 until the program was shut down in 1942.

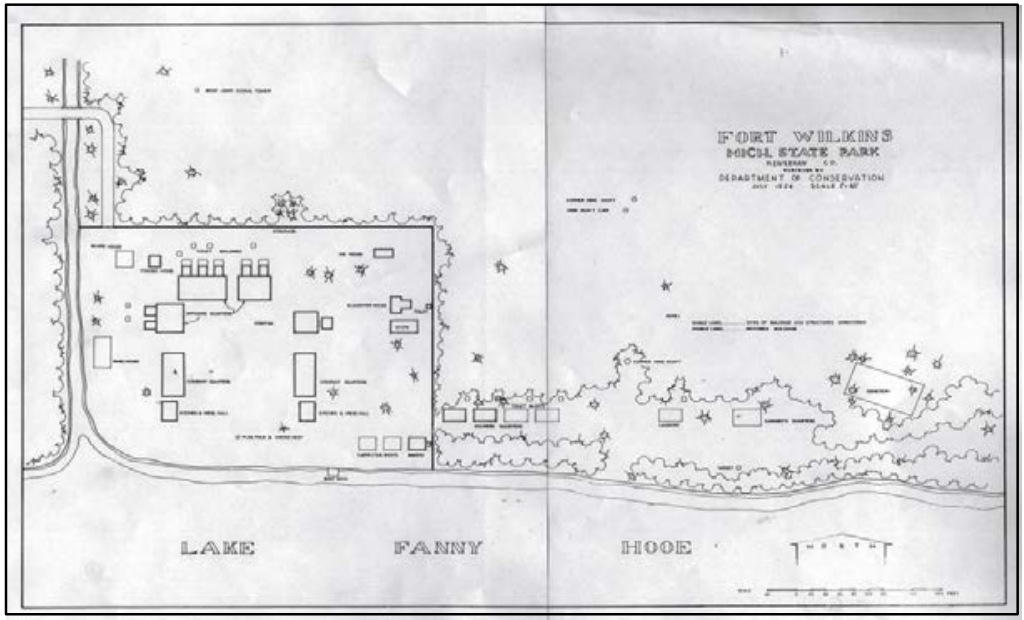

Fig. 22. Department of Conservation map of the historic fort property, 1924. Image courtesy of the Michigan Historical Center, Michigan Iron Industry

${ }^{65}$ Frimodig, Fort Wilkins, 30.

661940 United States Federal Census, Keweenaw County.

${ }^{67}$ La Vanway, History of Keweenaw County's Road, 13.

68 Ibid., 14. 


\section{Methods}

\section{Survey of Historic and Archival Records}

Historical documents and maps from primary and secondary sources were utilized by the staff of the Michigan Technological University research team in preparing and executing the field and laboratory aspects of this project. Archival research focused mostly on the history of the Pittsburgh and Boston Copper Harbor Mining Company at Copper Harbor and the history of Fort Wilkins both during and after military occupation. Unlike some other previous archaeological projects carried out at this area, this survey also focused on work done during the Works Progress/Projects Administration era. This was not initially the intent of the research team, but upon discovering materials and features left behind by WPA employees the scope of historical and archival research was broadened to incorporate this period of American history.

The resources utilized are found at Michigan Technological University Archives and Copper Country Historical Collections (MTU Archives), and the State Archives of Michigan housed in the Michigan Historical Museum in Lansing. The MTU Archives provided a number of maps, photos and drawings of the research area from the historic mining era as well as providing good first-hand accounts from people who lived in Copper Harbor or served in Fort Wilkins itself. The State Archives at Lansing provided a great number of maps depicting various types of surveys done in the research area over the past 170 years. The State Archives also contain the surveyor's notes from the original General Land Office survey.

\section{Michigan State Archaeological Site Files}

There are roughly 300 catalogued archaeological sites in Keweenaw County, though the lion's share, 230-plus, are located within the boundaries of Isle Royale National Park. Grant Township, where Copper Harbor and Fort Wilkins Historic State Park are located, contains 21 sites, many of which are found within a few miles of Park property (Table 2). Sites in Grant Township range from the Prehistoric period to the early twentieth century. Lithic scatters, ceramic assemblages, and evidence of copper processing can be found at sites KE11, KE15, KE20, and KE 32 along the southern shore of Keweenaw Peninsula. Fourteen sites from the historic period are located on the northern shore, including: the Fort complex itself (KE13), the Copper Harbor Lighthouse and range light (KE14 and KE33), features associated with the Pittsburgh \& Boston Copper Harbor Mining Co. (KE52), and three historic mining-related sites identified in 2013. 


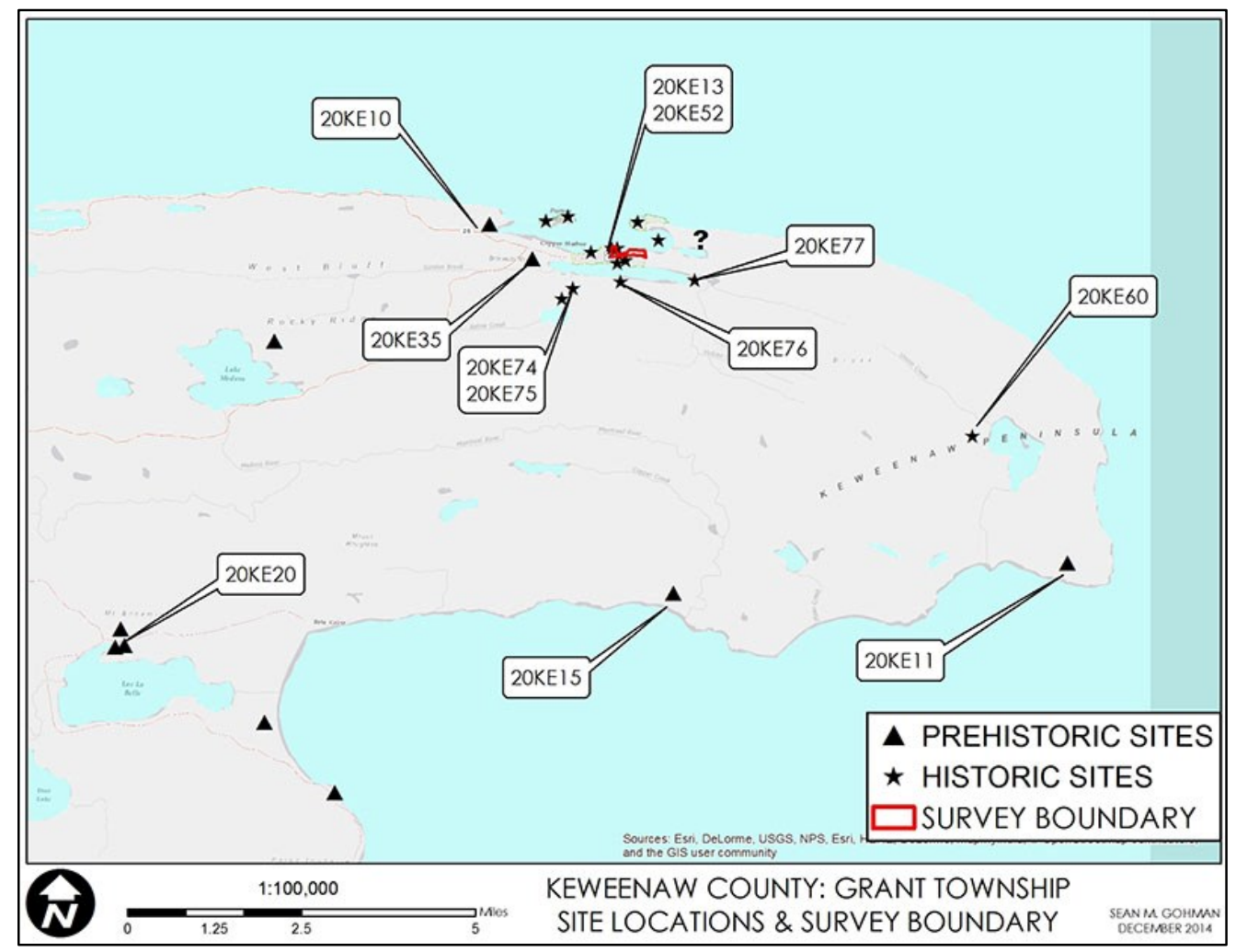

Fig. 23. Archaeological sites in the Copper Harbor area catalogued with the Michigan State Historic Preservation Office. Image courtesy of Sean

M. Gohman. 
Table 2. Archaeological Sites in the vicinity of Copper Harbor, MI

\begin{tabular}{|c|c|c|c|}
\hline $\begin{array}{l}\text { Site } \\
\text { Number }\end{array}$ & Legal Description & Period & Description \\
\hline 20KE9 & T58N, R29W, S03 & Prehistoric & $12-15$ copper pits \\
\hline 20KE10 & T59N, R28W, S31 & Prehistoric & Unverified village site \\
\hline 20KE11 & T58N, R27W, S22, SW QTR & Prehistoric & Unverified village site \\
\hline 20KE13 & T59N, R28W, S33, NE-SW QTR & $19^{\text {th }}-20^{\text {th }}$ century & Historic fort complex \\
\hline 20KE14 & T59N, R28W, S28, SE-SE QTR & $19^{\text {th }}-20^{\text {th }}$ century & Copper Harbor Lighthouse \\
\hline 20KE15 & T58N, R28W, S27, SE-NW-SE QTR & $\begin{array}{l}\text { Late Woodland- } \\
\text { Historic }\end{array}$ & Assemblage of ceramics \\
\hline 20KE20 & $\begin{array}{l}\text { T58N, R29W, S32, S1/2-NE QTR \& } \\
\text { T58N, R29W, S33, SW-NW QTR }\end{array}$ & $\begin{array}{l}\text { Middle } \\
\text { Woodland, Late } \\
\text { Archaic, Middle } \\
\text { Archaic }\end{array}$ & $\begin{array}{l}\text { Copper processing, some } \\
\text { organic preservation }\end{array}$ \\
\hline 20KE21 & T58N, R30W, S15, SW-NE QTR & Prehistoric & Copper mine \\
\hline 20KE23 & T59N, R28W, S34, NE-NW-NW QTR & $19^{\text {th }}$ century & Shipwreck-Astor? \\
\hline 20KE25 & T59N, R28W, S33, NE-NW-SE-NE QTR & $19^{\text {th }}$ century & Survey marker \\
\hline 20KE26 & $\begin{array}{l}\text { T59N, R28W, S33, NE-SW-SW-NE } \\
\text { QTR }\end{array}$ & $19^{\text {th }}-20^{\text {th }}$ century & Dock \\
\hline 20KE27 & $\begin{array}{l}\text { T59N, R28W, S32, NE-NW-NW-NE } \\
\text { QTR }\end{array}$ & $19^{\text {th }}$ century & $\begin{array}{l}\text { Mining settlement- Mineral } \\
\text { Land Agency }\end{array}$ \\
\hline 20KE28 & T59N, R28W, S29, SE-SE-SW-SE QTR & $19^{\text {th }}$ century & $\begin{array}{l}\text { Mining settlement-Locke’s } \\
\text { Encampment }\end{array}$ \\
\hline 20KE31 & T57N, R29W, S11, NE QTR & Prehistoric & Lithic and point assemblage \\
\hline 20KE32 & $\begin{array}{l}\text { T57N, R29W, S03, N1/2-NE-NW-NE } \\
\text { QTR }\end{array}$ & Prehistoric & Unverified assemblage \\
\hline 20KE33 & $\begin{array}{l}\text { T59N, R28W, S33, SW-SW-SW-NE } \\
\text { QTR }\end{array}$ & $19^{\text {th }}-20^{\text {th }}$ century & Copper Harbor Light Station \\
\hline 20KE34 & $\begin{array}{l}\text { T58N, R30W, S15, Center QTR \& } \\
\text { T58N, R30W, S14, Center W1/2 QTR }\end{array}$ & $19^{\text {th }}$ century & Copper mine-Delaware Mine \\
\hline 20KE35 & T58N, R29W, S32, SW-E-NW QTR & Prehistoric & Lithic scatter \\
\hline 20KE36 & $\begin{array}{l}\text { T58N, R29W, S29, SE QTR \& } \\
\text { T58N, R30W, S32, NW-NE-NE QTR }\end{array}$ & $\begin{array}{l}\text { Prehistoric \& } 19^{\text {th }} \\
\text { century }\end{array}$ & $\begin{array}{l}\text { Lithic scatter \& Copper mine } \\
\text { Lac La Belle Mine }\end{array}$ \\
\hline 20KE52 & $\begin{array}{l}\text { T59N, R28W, S33, NE-NE-NW-SW } \\
\text { QTR }\end{array}$ & $19^{\text {th }}$ century & $\begin{array}{l}\text { Mine-Pittsburgh \& Boston } \\
\text { Copper Harbor Mining Co. }\end{array}$ \\
\hline 20KE60 & $\begin{array}{l}\text { T58N, R27W, S08, SE-SE-SE-SW QTR } \\
\text { \& } \\
\text { T58N, R27W, S17, NE-NW-NW-NE } \\
\text { QTR }\end{array}$ & $19^{\text {th }}-20^{\text {th }}$ century & Logging camp \\
\hline 20KE71 & $\begin{array}{l}\text { T59N, R28W, S34, NE QTR \& T59N, } \\
\text { R28W, S35, NW QTR }\end{array}$ & ??? & ??? \\
\hline 20KE74 & T59N, R28W, S32, SE-SE & $19^{\text {th }}$ century & Clark Mine Stamp Mill \\
\hline 20KE75 & T58N, R28W, S5, NE-NE & $19^{\text {th }}$ century & Manganese Location \\
\hline 20KE76 & T59N, R28W, S33, SW-SE & $19^{\text {th }}$ century & Mining-P\&BCHMCo. \\
\hline 20KE77 & T59N, R28W, S34, SW-SE & $19^{\text {th }}-20^{\text {th }}$ century & Historic camp sites \\
\hline
\end{tabular}




\section{Maps}

The earliest map images of Copper Harbor and its environs are from the surveys conducted by the General Land Office and the Pittsburgh \& Boston Copper Harbor Mining Company. The US Army created additional maps, noting the locations of structures and showing change over time. The US Corps of Engineers survey of the Great Lakes in 1864 also provides details about Copper Harbor and the Fort complex. Maps have also been produced the Department of Conservation/Department of Natural Resources and old ones have been modified for Fort Wilkins State Park. 


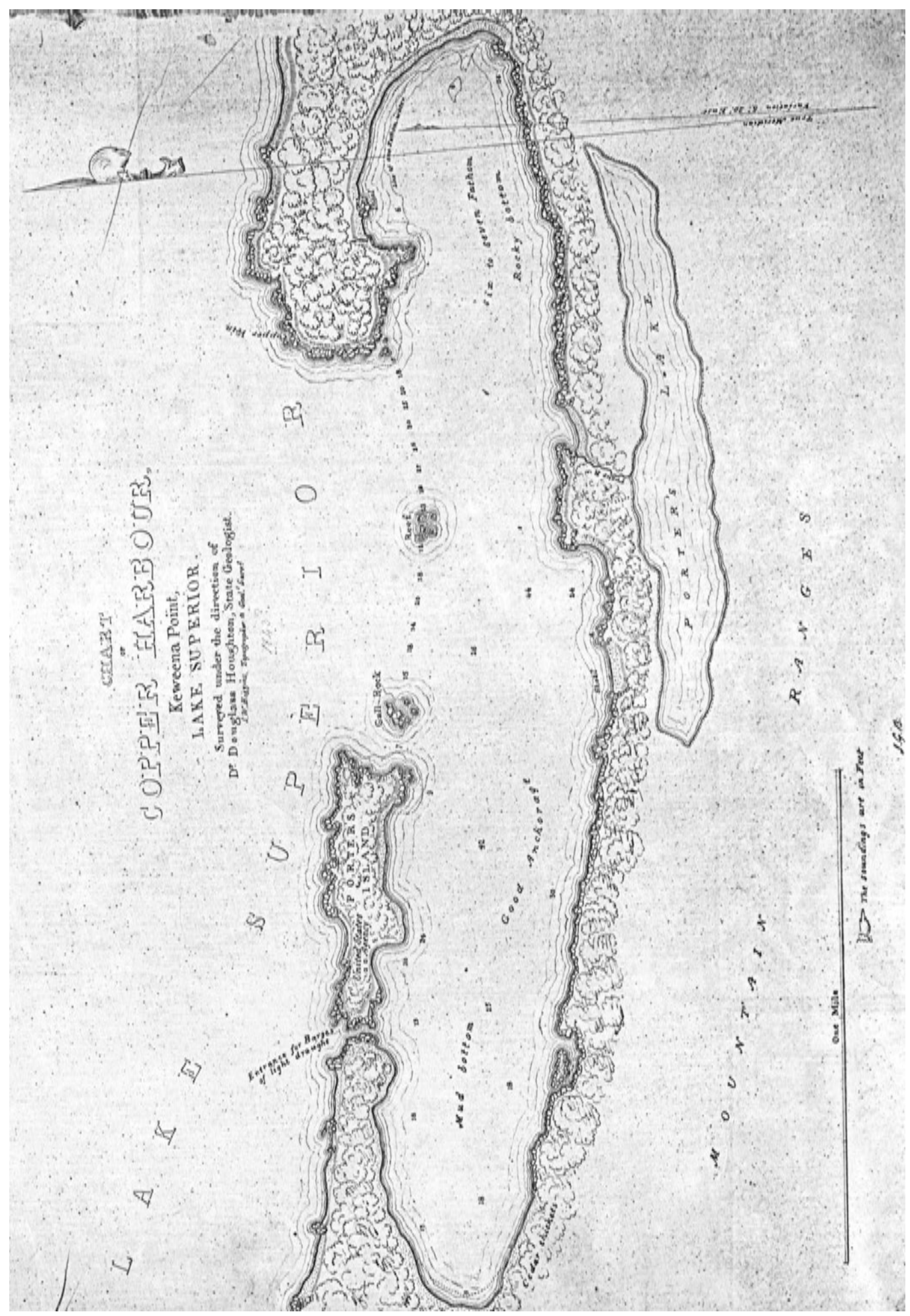

Fig. 24. Chart of Copper Harbour, Keweena Point, Lake Superior, circa 1843. Image courtesy of the Michigan Technological University and Copper Country Archives. 


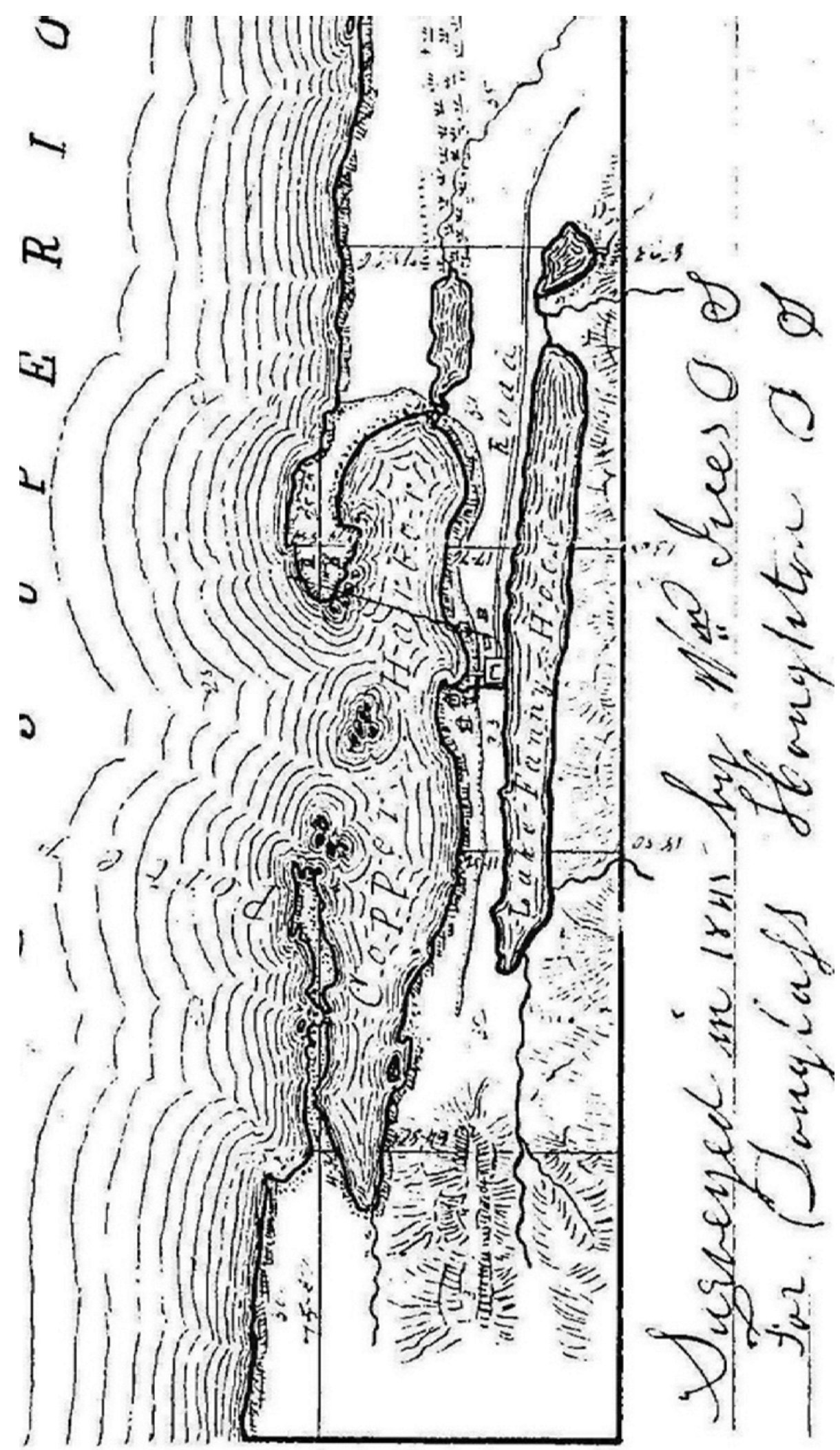

Figure 25. 1845 William Ives Survey Map. Note building on North of Fort Wilkins on the West Side of Fanny Hooe Creek. Probable depiction of the Astor House. Image courtesy of the Michigan Technological University and Copper Country Archives. 


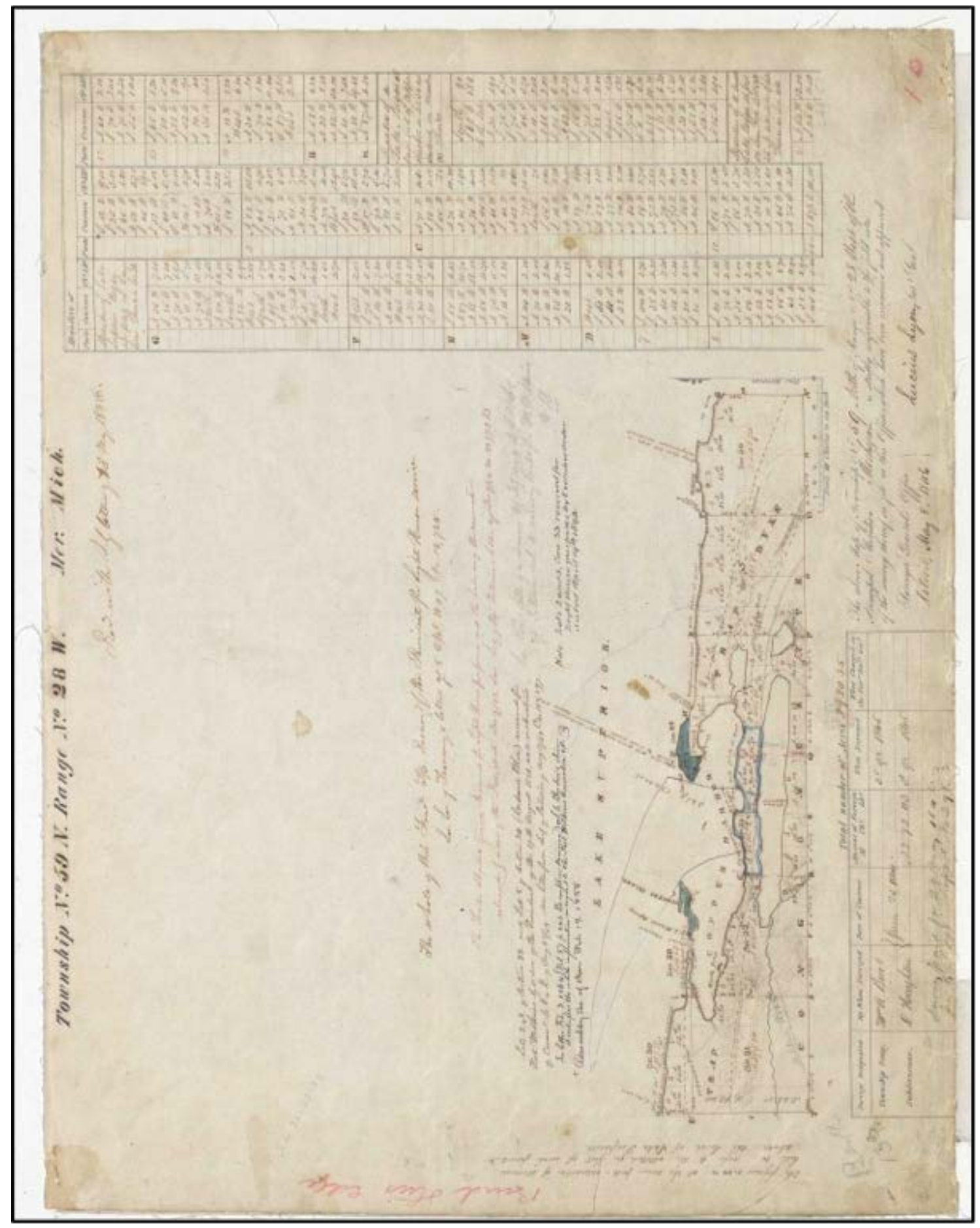

Fig. 26. General Land Office plat map of Township 59N Range 28W, May 8, 1846. From USGS's earthexplorer.usgs.gov. 


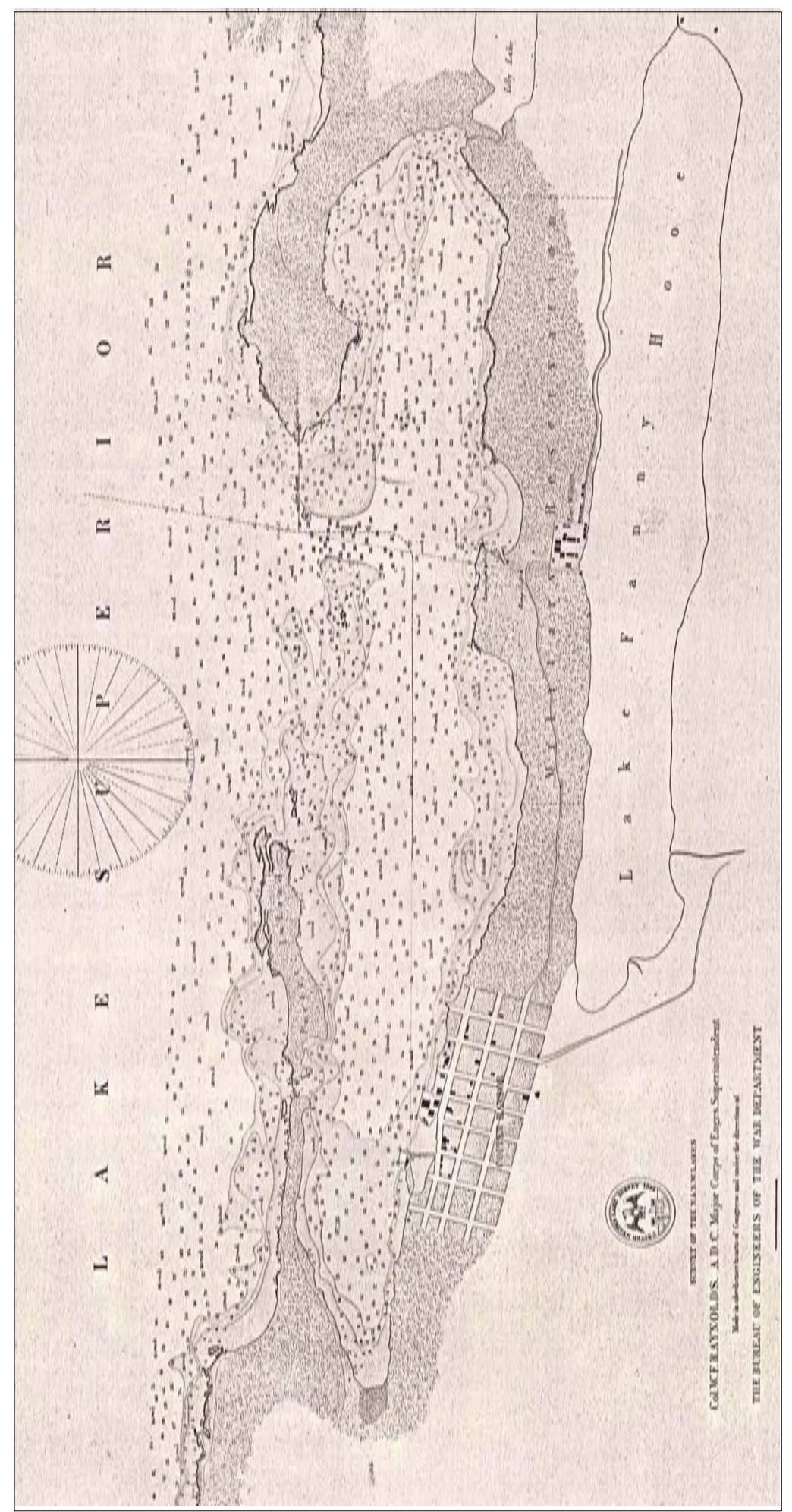

Figure 27. Survey of the N. \& N.W. Lakes. Part of the US Lakes Survey of 1865.

From archival collections of the Iron Industry Museum, Negaunee, MI. Just north of the Fort complex can be seen four structures east of Fanny Hooe Creek. One looks to be a dock on the creek, and the next two moving south are labeled as range lights in the next image.

That leaves the southernmost structure unnamed. Image Courtesy of the Michigan Technological University and Copper Country Archives. 


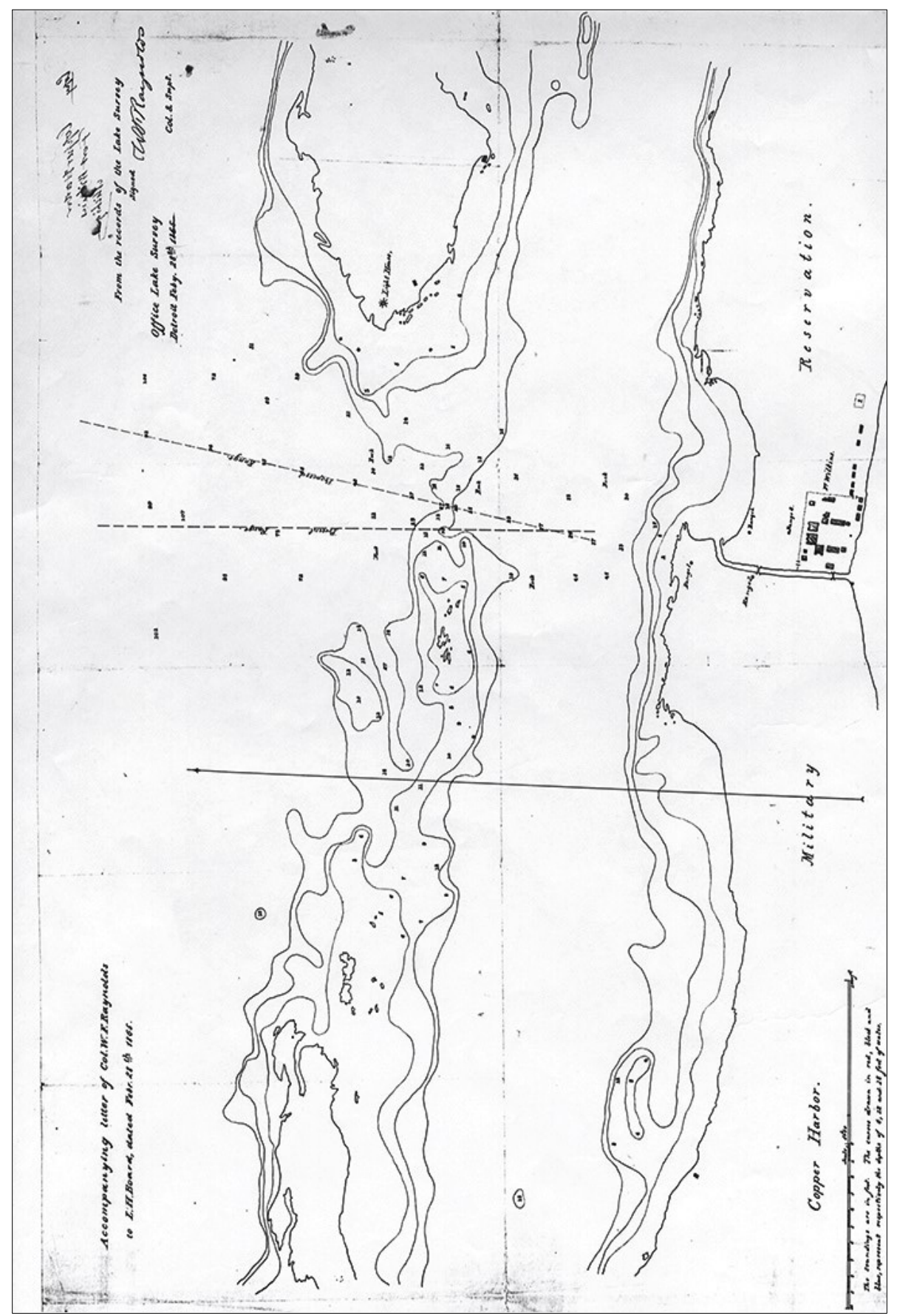

Figure 28. Map accompanying a letter from Col. W.R. Reynolds to L.H. Board, dated Feb. 28 1865. Part of the US Lakes Survey of 1865 . Note the location of two range lights east of Fanny Hooe Creek. Bridge shown in place. Image Courtesy of the Michigan Technological University and Copper Country Archives. 


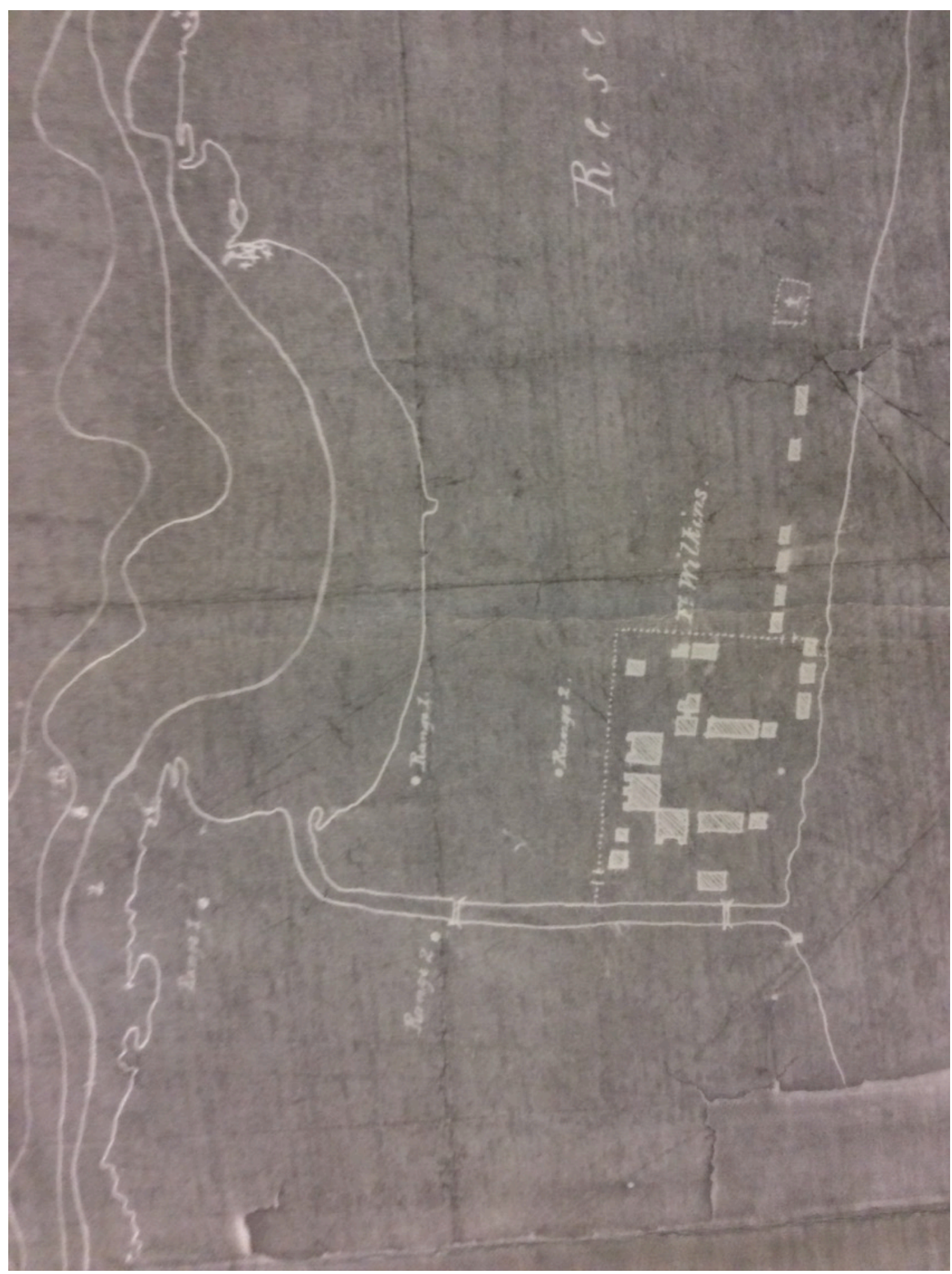

Figure 29. From the records of the Lake Survey. Wm. F. Raynolds, Fort Brady, Office Lake Survey, Detroit, February 28, 1865. Bridge visible near "Range 2". Image courtesy of the Michigan Historical Center, Michigan Iron Industry Museum. 


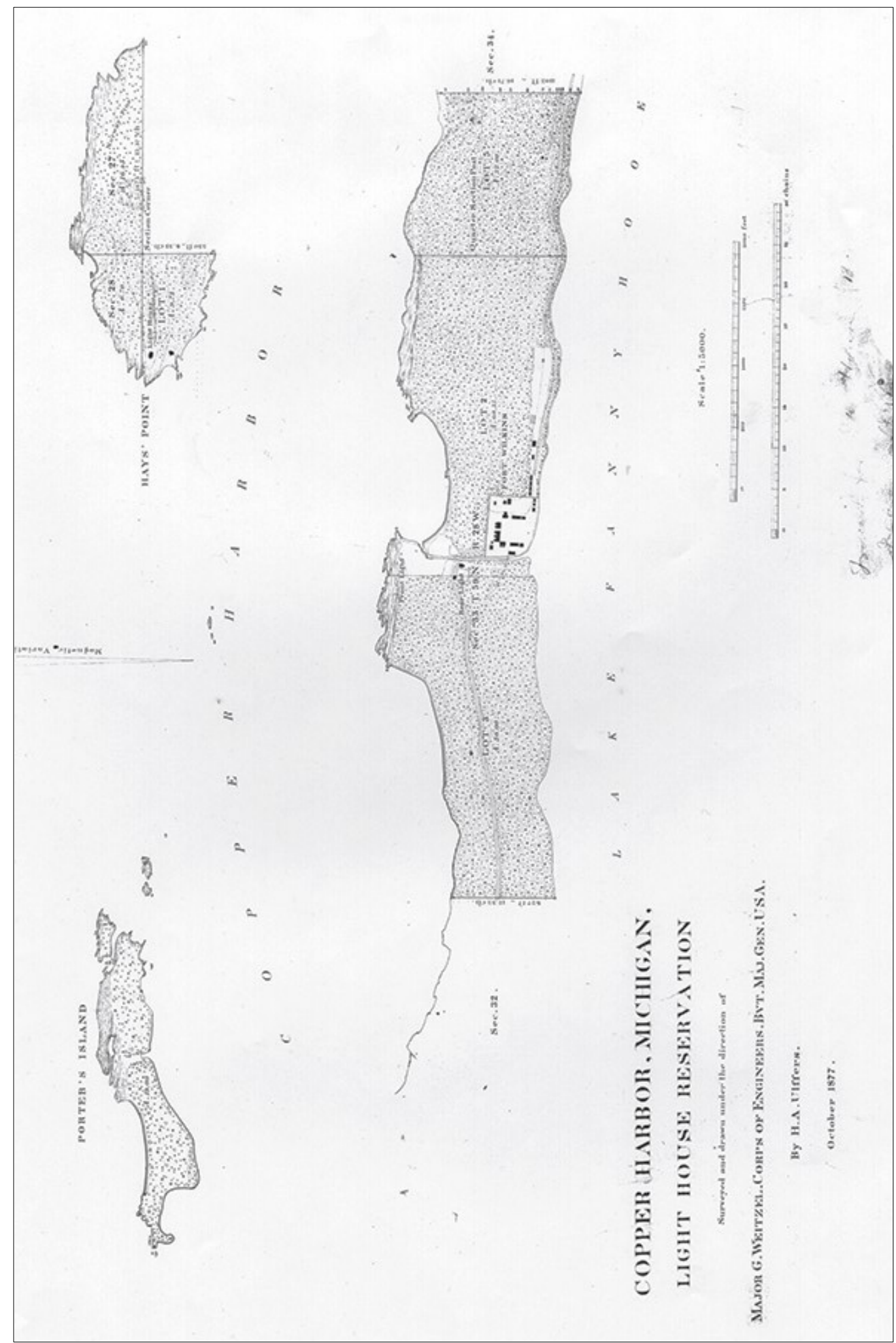

Figure 30. Copper Harbor, Michigan, Light House Reservation, 1877. Note there are no traces of historic mining evident in this map. Image Courtesy of the Michigan Technological University and Copper Country Archives. 


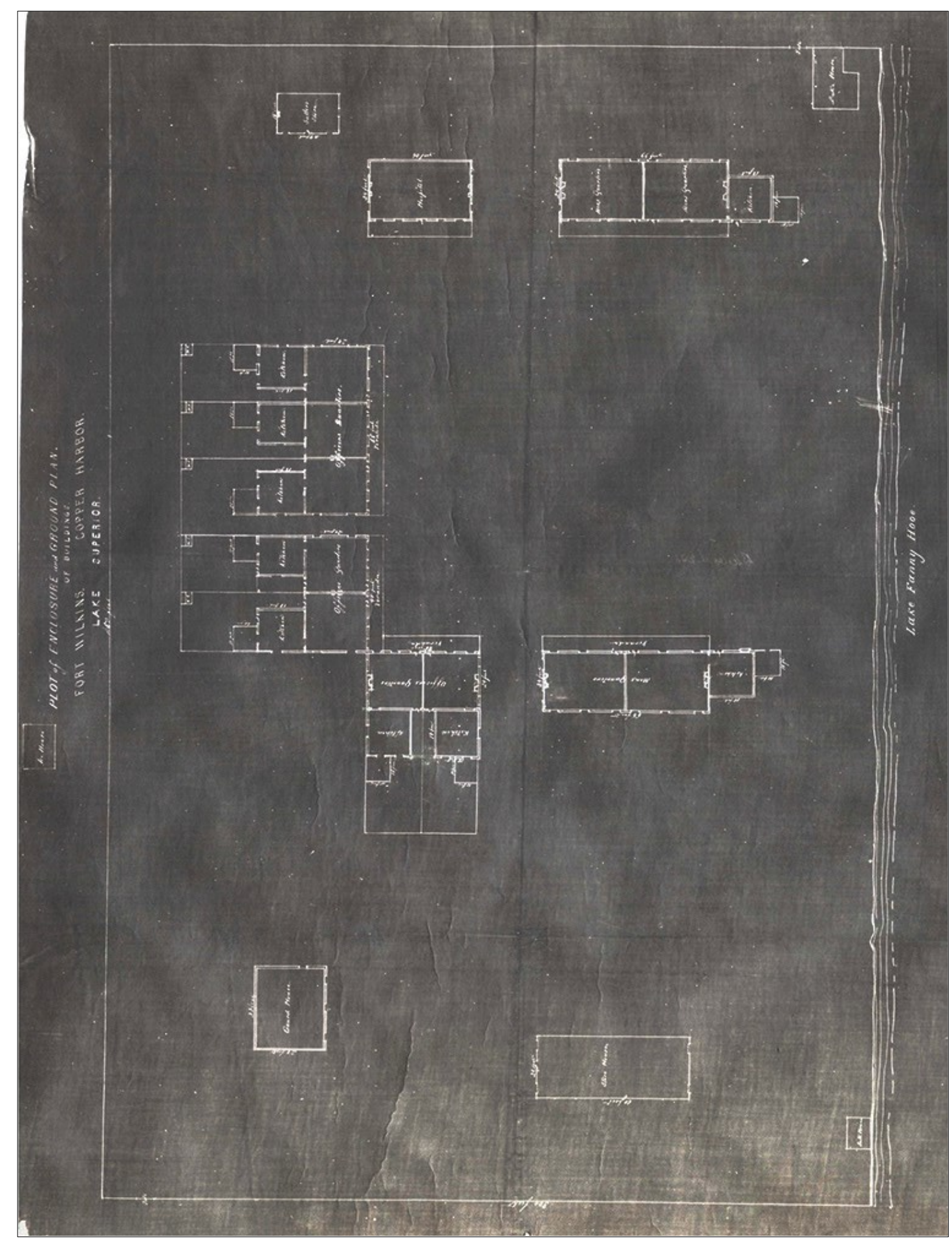

Figure 31. Plan of Enclosures of Garrison Grounds and Elevation of Buildings, Fort Wilkins, Copper Harbor, Lake Superior, year unknown. From the National Archives Record Group 92, Office of Quartermaster General, Consolidated Correspondence File, “Fort Wilkins, Mich.”

Structures on this map are internally precise in their measurements and scale, but not necessarily accurate in their relationship to each other. Note the structure located north of and outside the Fort's fence line (indicated by white rectangle around the edges of the document). 


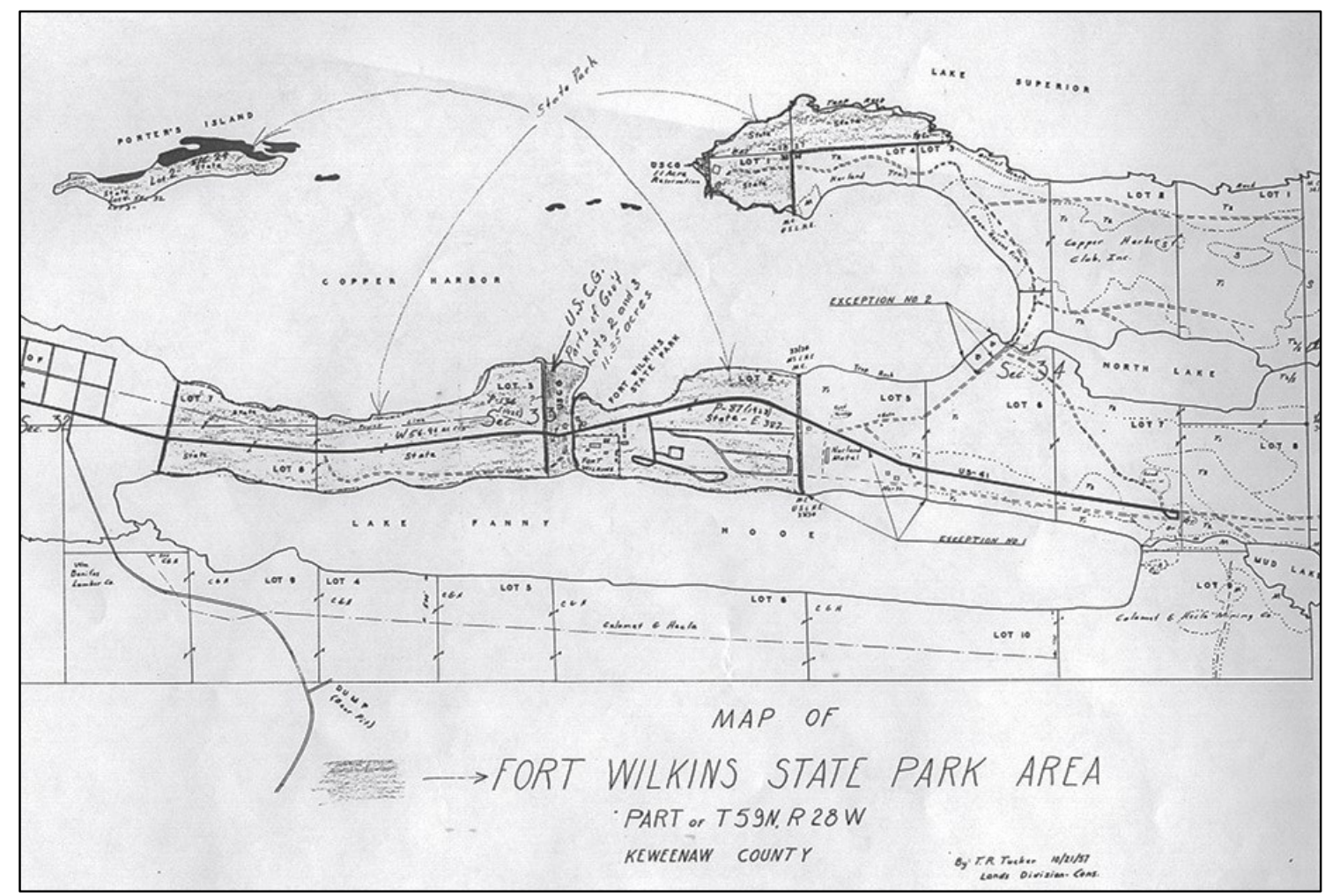

Figure 32. Map of Fort Wilkins State Park property, 1957. Image courtesy of the Michigan Historical Center, Michigan Iron Industry Museum. 


\section{Fieldwork}

Fieldwork began the 11th of May with an initial pedestrian walkover survey of the 6 acre site. The survey team walked transects with members at 5-meter intervals working from East to West. During this initial pedestrian survey any features located were GPSmapped, recorded, and photographed.

Features were recorded with handheld Archer GPS units. Each feature was given an identifying name based on the day's date followed by a sequential number, re-starting with '01' each day. Data recorded in the GPS and pertaining to each feature included feature type (transportation, artifact collection, environmental, isolate, structure), a description of the feature, its dimensions (if applicable), and associated field photograph numbers.

After all locational data were collected it was entered into a GIS database, and analyzed for the identification of collective sites. Once sites were determined, each feature was given a site-specific feature number, made up of the site name followed by a sequential two-digit number. This information was all noted in a water-resistant notebook as well to insure against any loss of data.

Once the initial walking survey was completed a 10m grid was laid out on the whole of the property, utilizing the walking path between the range lights as both the baseline and archaeological North $\left(25^{\circ} \mathrm{E}\right.$ of magnetic North). Each point on the grid was shovel pit tested. Each test pit was numbered with those on the baseline being given single whole numbers with 1 at the northernmost point on the site and 20 being the southernmost point adjacent to US 41. Points to the East or West on the $10 \mathrm{~m}$ grid were given trailing whole numbers. For example, point $2-3 \mathrm{E}$ is $20 \mathrm{~m}$ south of the northernmost point and $30 \mathrm{~m}$ east of the baseline.

Positive test pits tended to be highly concentrated. In these areas a tighter $2 \mathrm{~m}$ grid of test pits was laid over the $10 \mathrm{~m}$ grid in lieu of digging radials. These pits were numbered by adding a single decimal place to the numbering system. For example, point 2.4-3.2E is $24 \mathrm{~m}$ south of the northernmost point and $32 \mathrm{~m}$ east of the baseline. In short, whole numbers represent $10 \mathrm{~m}$ intervals while decimal tenths represent $1 \mathrm{~m}$ intervals.

Shovel testing the entire property at $10 \mathrm{~m}$ intervals was done as the property is known to contain archaeological features but only in relatively isolated areas. This spacing allowed for areas to be located for further testing while still allowing for full coverage of the property. Testing positive areas with a grid of $2 \mathrm{~m}$ was done to aid in defining the boundaries of the potential feature and guide future decisions regarding excavation unit placement. These intervals were considered sufficient given the known history of the property and the number of historic maps/photographs available. 
Field photographs were primarily taken with Olympus Stylus Tough-6020, 14 megapixel digital cameras. A Canon G-11 15 megapixel digital camera was also used for site overview photos, taken after the close of the field season. All images were downloaded and stored on Michigan Technological University servers, and a complete listing of images and their descriptions is included in Appendix A.

Excavations were carried out at two features: Feature 3 and Feature 4, both areas having been identified through a combination of shovel test pitting and historic resources. Trenching was decided upon as it provided the best chance for locating structures. Feature 3 was excavated with $2.5 \times 2 \mathrm{~m}$ trenches and a single .5x1m trench. Feature 4 was excavated with a series of 5 trenches all of which were $.5 \mathrm{~m}$ and varied between $1-2 \mathrm{~m}$ long.

Excavators called level changes with changes in stratigraphy but broke deep stratigraphy into arbitrary levels at $5 \mathrm{~cm}$ intervals. Each level was drawn in plan and photographed. All shovel test pits and excavations were filled in upon completion. The northeast corner pin (a 14" nail) of each excavation unit was left in place, all others were pulled upon the completion of fieldwork.

A variety of mapping and layout techniques were employed throughout fieldwork as this project was done in conjunction with an archaeological field school. The shovel test pit grid was laid out by tape and compass. While it normally would not be necessary to have an actual grid on the landscape for STPs, in this case it was deemed useful both as an exercise and as an insurance that STPs would be evenly spaced given the lack of experience among some of the crew. The area around the Range Lighthouse was initially mapped by tape and compass, this map being used throughout fieldwork for planning excavation units and the $2 \mathrm{~m}$ shovel test pit grids.

The shoreline and excavation units were mapped using a Topcon Total Station. This tool was chosen as it was the fastest way to map the extensive shoreline of the project area and due its excellent accuracy. The Total Station was also used to check earlier work, specifically the tape and compass shovel test pit grid. The baseline of the grid extended 200 meters and went through 3 structures. When the northernmost and southernmost points were measured with the Total Station they were found to within $6 \mathrm{~cm}(+/-1 \mathrm{~cm})$ of 200m. Results were plotted in ArcMap 10.3 and served as the basis for the maps which accompany this report.

\section{Artifact Collection and Analysis}

The survey team previously determined to collect diagnostic artifacts and those with interpretive value to Fort Wilkins Historic State Park. Upon performing fieldwork it became clear that all artifacts should be collected due to the manageable nature of what 
was recovered. All excavated soil was screened through 1/4" wire mesh. Artifacts collected were cleaned, analyzed, and stored within the Department of Social Sciences Archaeological Laboratory and curation facility on the campus of Michigan Technological University. Artifacts were catalogued with a focus on general detail, including their dimensions, diagnostic information, and provenience. A complete listing of artifacts is included in Appendix B.

\section{Discussion of Archaeological Sensitivity of the Project Area}

There is a long and well known history of both private and government use of the property. The government use of the property is well documented with both maps and official records. Private use is far less so, limited to vague images on maps and accounts by travelers. Since becoming a State Park numerous building projects have been undertaken throughout the property and it is reasonable to assume that there have been landscape changes associated with these projects.

While there are numerous maps of the property the locations of features shown on them are rather uncertain due to variations in scale and a relative lack of consistency between maps.

\section{Previous Archaeological Investigations}

Previous archaeological investigations in and around the project area have mostly targeted Fort Wilkins Historic State Park’s historic structures. In 1975, the History Division of the Michigan Department of State contracted with Archaeological Research Services to conduct preliminary archaeological test excavations at the Fort complex. The purpose of that study was to "develop a plan for a long-range archaeological program" at the State Park. Two years later, in 1977, the History Division again contracted with Archaeological Research Services to excavate two married enlisted men's quarters, an icehouse, and three officer's privies. ${ }^{69,70} 1984$ saw the excavation of three extant army officer's quarters cellars, while a guardhouse and possible dumpsite were excavated and tested, respectively, in 1986. The dumpsite was more formally excavated in 1993.

In 1994, MTU archaeologists excavated the site of the 1848 lighthouse on Hays' Point. The years 1999-2001 saw further work by MTU focused both on the Fort's quartermaster warehouse site (1999) and two sites associated with the activities of the Pittsburgh and

\footnotetext{
${ }^{69}$ Field Report, Tempe, AZ, (1978), 1-3.
}

${ }^{70}$ Lyle M. Stone, "Archaeological Investigations at Fort Wilkins State Park, Keweenaw County, Michigan: 
Boston Copper Harbor Mining Company during the mid-1840s (2000 and 2001). ${ }^{71}$ Many of these projects resulted in valuable interpretive materials for the fort as well as information useful for reconstruction and rehabilitation of the Fort's built environment.

In 2013 Michigan Technological University conducted a Phase I archaeological and historical survey of newly acquired lands (557 acres) south of the Fort complex. The survey focused on resources related to historic mining and milling operations on the south shore of Lake Fanny Hooe, as well as an historic town site and saw mill north of Lake Manganese. Four sites were identified and documented: 20KE74, 20KE75, 20KE76, and 20KE77. ${ }^{72}$

In 2014 Michigan Technological University once again conducted a Phase I and II archaeological and historical survey. This survey focused on mining related features found in the 14.5 acre property North of US-41 and between Fanny Hooe Creek and the Eastern boundary of the Park. Several features were identified and a storehouse was partially excavated. No new sites were identified.

\section{Regarding the Prehistoric Sensitivity of the Project Area}

The earliest dated archaeological site in the Keweenaw Peninsula is 20KE20, along the shore of Lac La Belle. Radiocarbon and geomorphological dating place this site at roughly 7,500 BP, making 20KE20 the earliest dated evidence of copper working in the region thus far. This site lacked evidence of sustained habitation, and was rather used for the specific purpose of acquiring and manipulating native copper. ${ }^{73}$

Beyond 20KE20, there is little evidence available to illuminate the activities of aboriginal peoples in the Lake Superior Basin during the Archaic period. This may be due to a drop in population or a lack of identified sites attributable to this period. It is also possible that changes in the level of Lake Superior have simply inundated many of these sites.

20KE20 also showed evidence of Middle Woodland period use ( $1600 \mathrm{BP})$. A cache of copper artifacts was discovered along with fragments of a textile bag. The combination of artifacts suggests both a sedentary as well as an active life. It is still not certain if 20KE20 transitioned from a place of work to a place of settlement from the Archaic to Woodland periods, though this discovery points to a highly technological and adaptive culture. ${ }^{74}$

\footnotetext{
${ }^{71}$ Michael J. Madson, "History and Archaeology of the Pittsburgh and Boston Copper Harbor Mining Company and Blacksmith Shop” (master's thesis, Michigan Technological University, 2002). And, Van Lingen, The Interpretation of Archaeological Remains.

${ }^{72}$ Gohman, Phase One Archaeological and Historical Survey.

${ }^{73}$ Martin, Wonderful Power, 147.

${ }^{74}$ Patrick E. and Susan R. Martin, "Final Report: The 1988 Lac La Belle Archaeological Project” (Field Report, Houghton, MI, 1988) 62.
} 
On Isle Royale there are many archaeological sites attributed to the Terminal Woodland period ( $\sim 00 \mathrm{BP}$ ). Isle Royale was visited by several differing groups of people, returning to the island in the spring and summer months to acquire copper and gather food. As the northern Keweenaw Peninsula is a physical mirror to Isle Royale, it is safe to assume that similar seasonal patterns of visitation and exploitation during this period should be evident. ${ }^{75}$

Evidence for a "rich and diverse" culture was found at 20BG14, Sand Point, on Lake Superior's Keweenaw Bay. This Baraga County site showed evidence of fishing and the hunting and gathering of a wide variety of mammals and plants. Unlike 20KE20, the copper artifacts found at Sand Point are evidence of more a permanent mound-building settlement, not one focused on the acquisition and working of copper. ${ }^{76}$

During the early historic mining period of the mid-nineteenth century, Euro-American miners commonly encountered aboriginal copper mining artifacts during the earliest stages of mine development. The Minesota mine, one of the earliest profitable mines in the region, was first begun at the site of a large, extensively worked native copper deposit, while at the Waterbury, Phoenix, and Forest mines artifacts including stone hammers, wooden scrapers, and copper chisels were all noted. ${ }^{77}$

\footnotetext{
${ }^{75}$ Martin, Wonderful Power, 178.

${ }^{76}$ Ibid., 179.

${ }^{77}$ Krause, The Making of a Mining District, 108.
} 


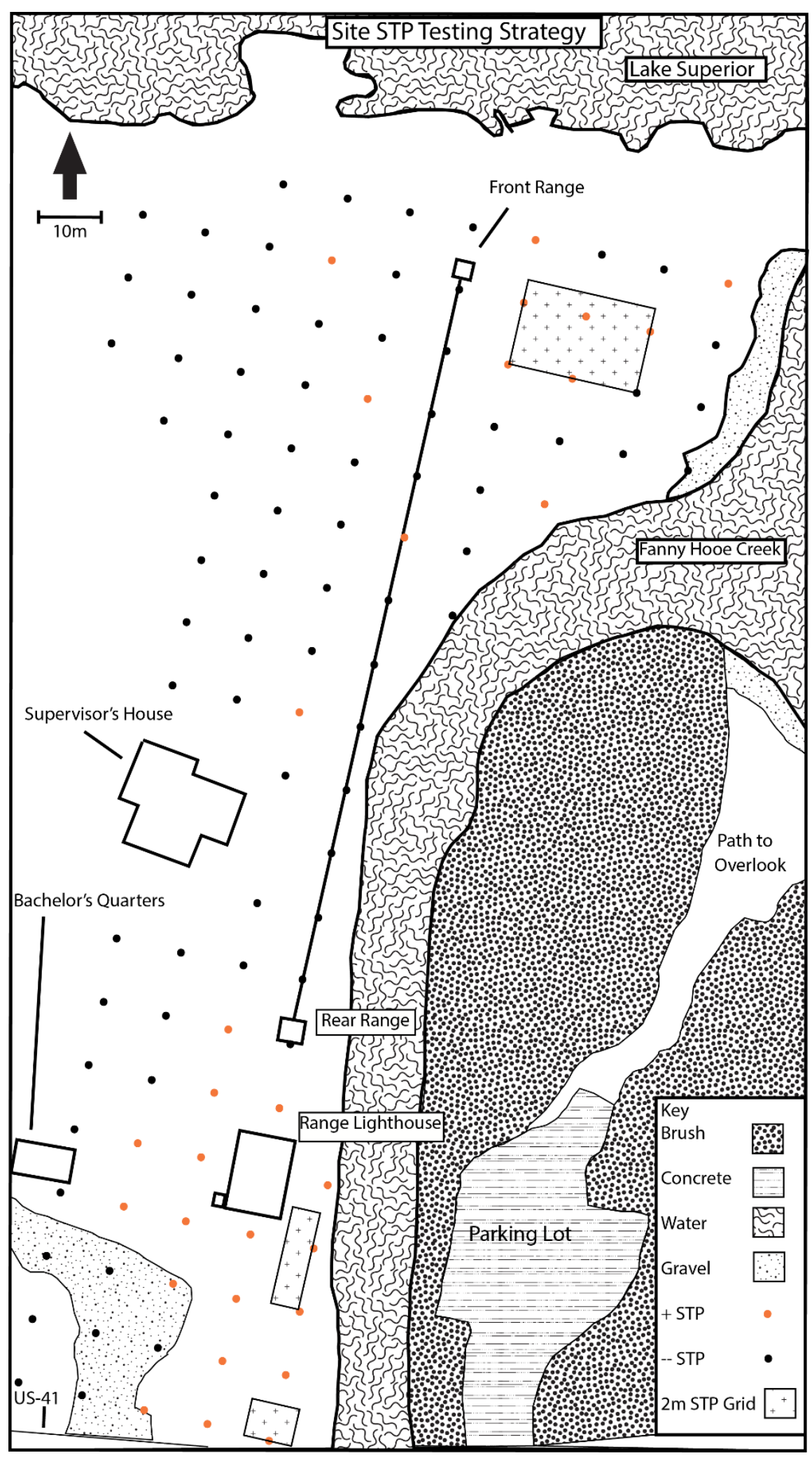

Figure 33. STP testing strategy. Ground cover in testing area omitted for clarity. Map by author, 2015. 


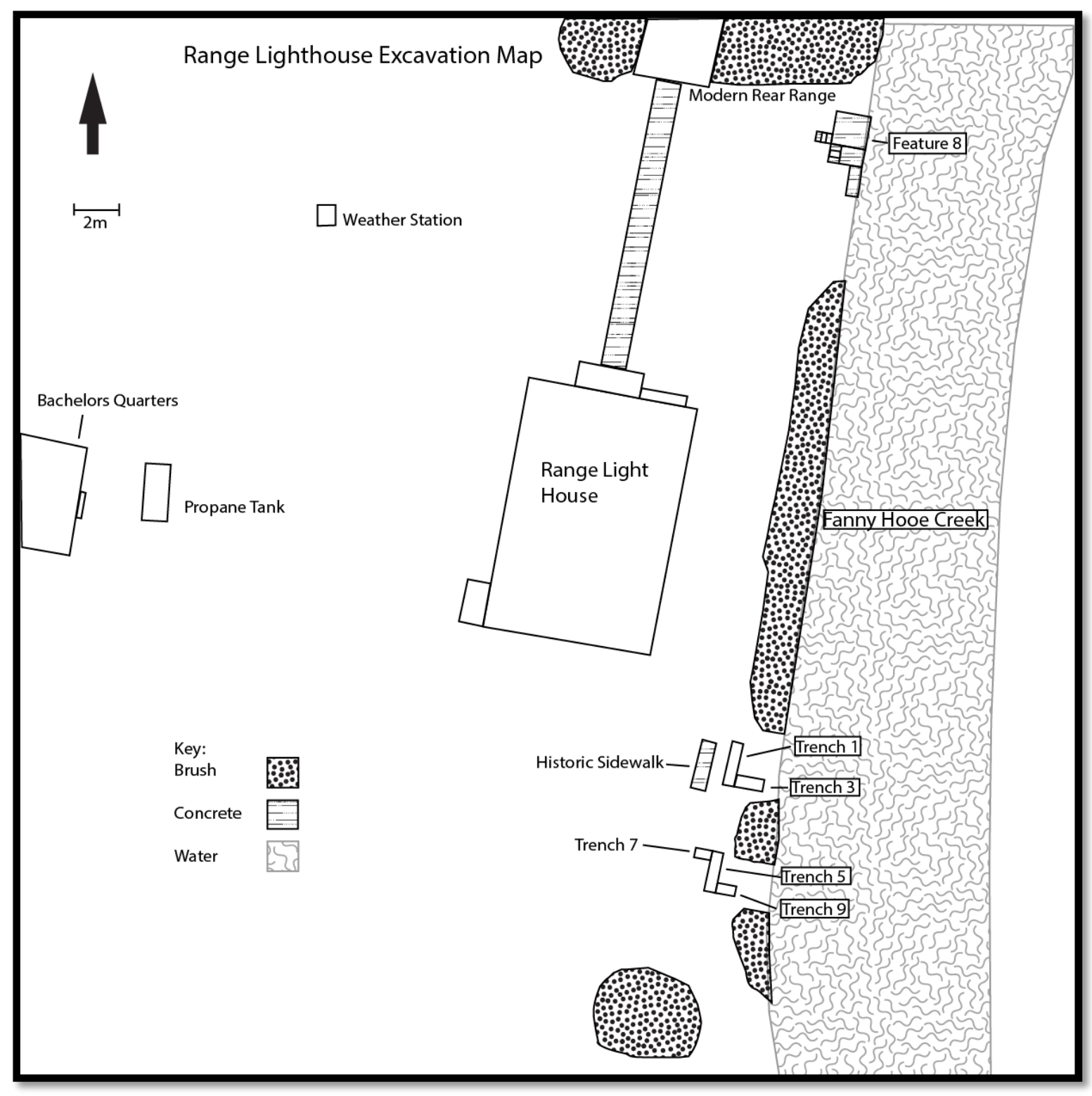

Figure 34. Range Lighthouse Excavation Map. Map by author, 2015. 


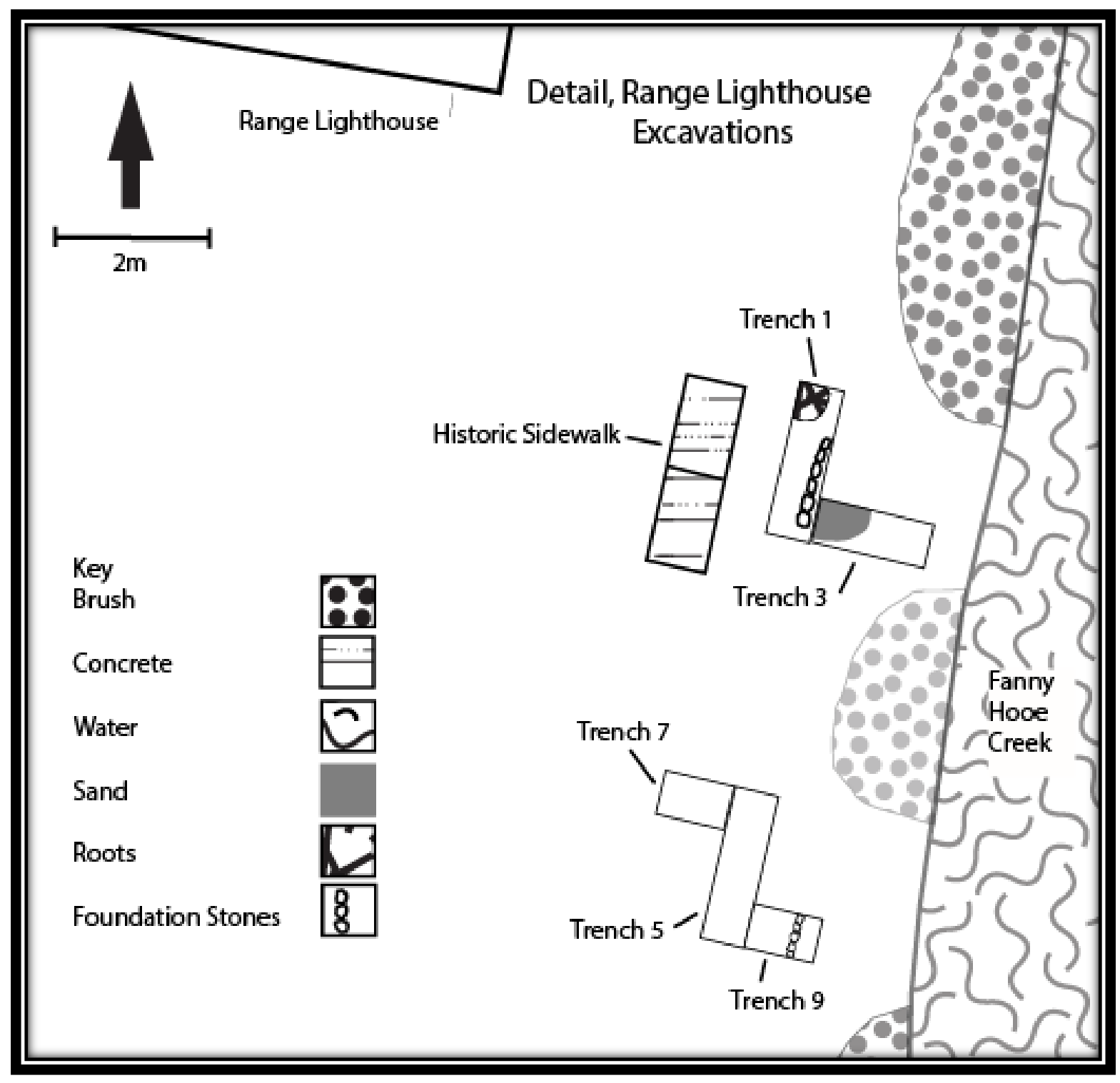

Figure 35. Detail, Range Lighthouse Excavations. Map by author, 2015. 


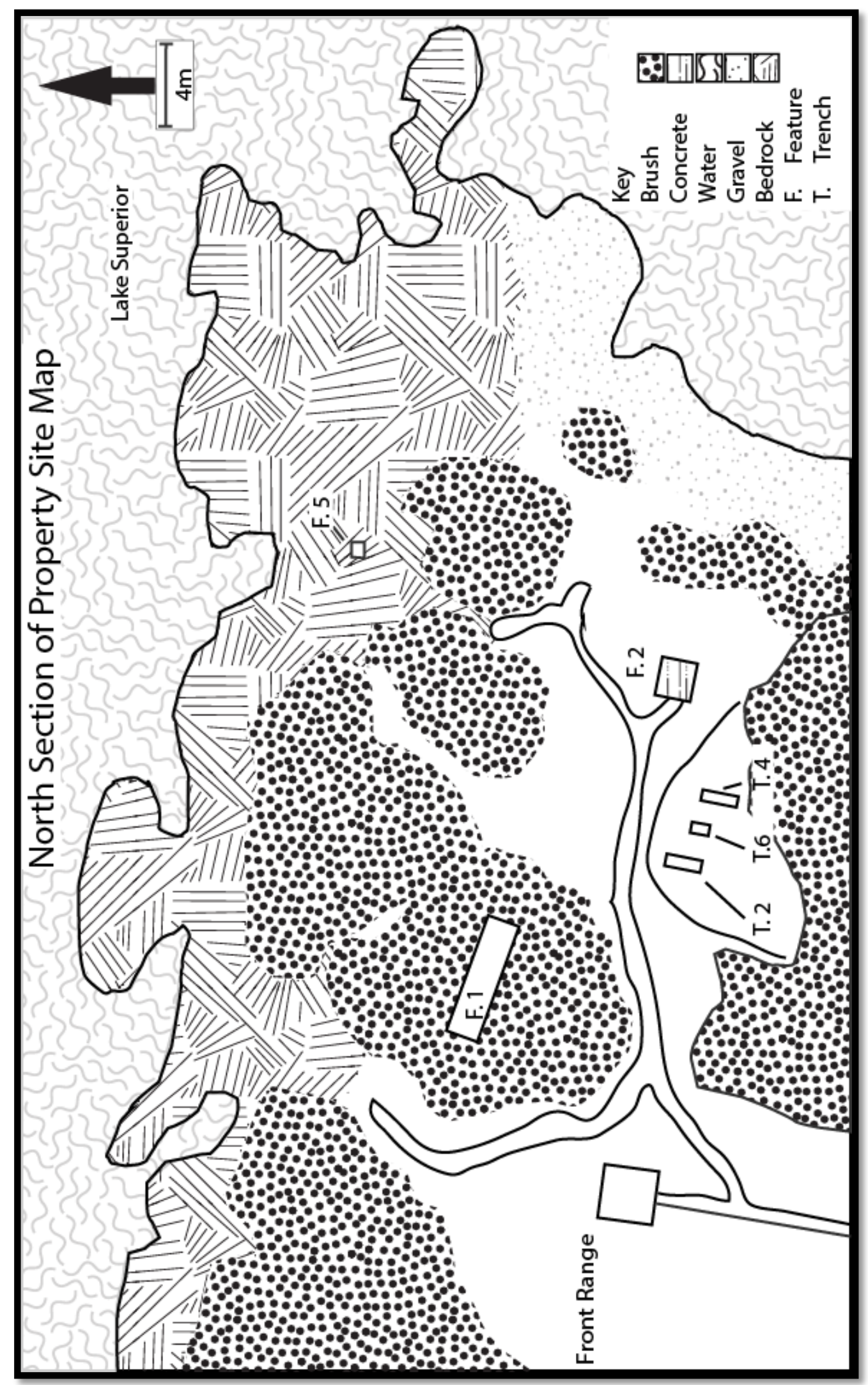

Figure 36. North Section of Property Site Map. Map by author, 2015. 


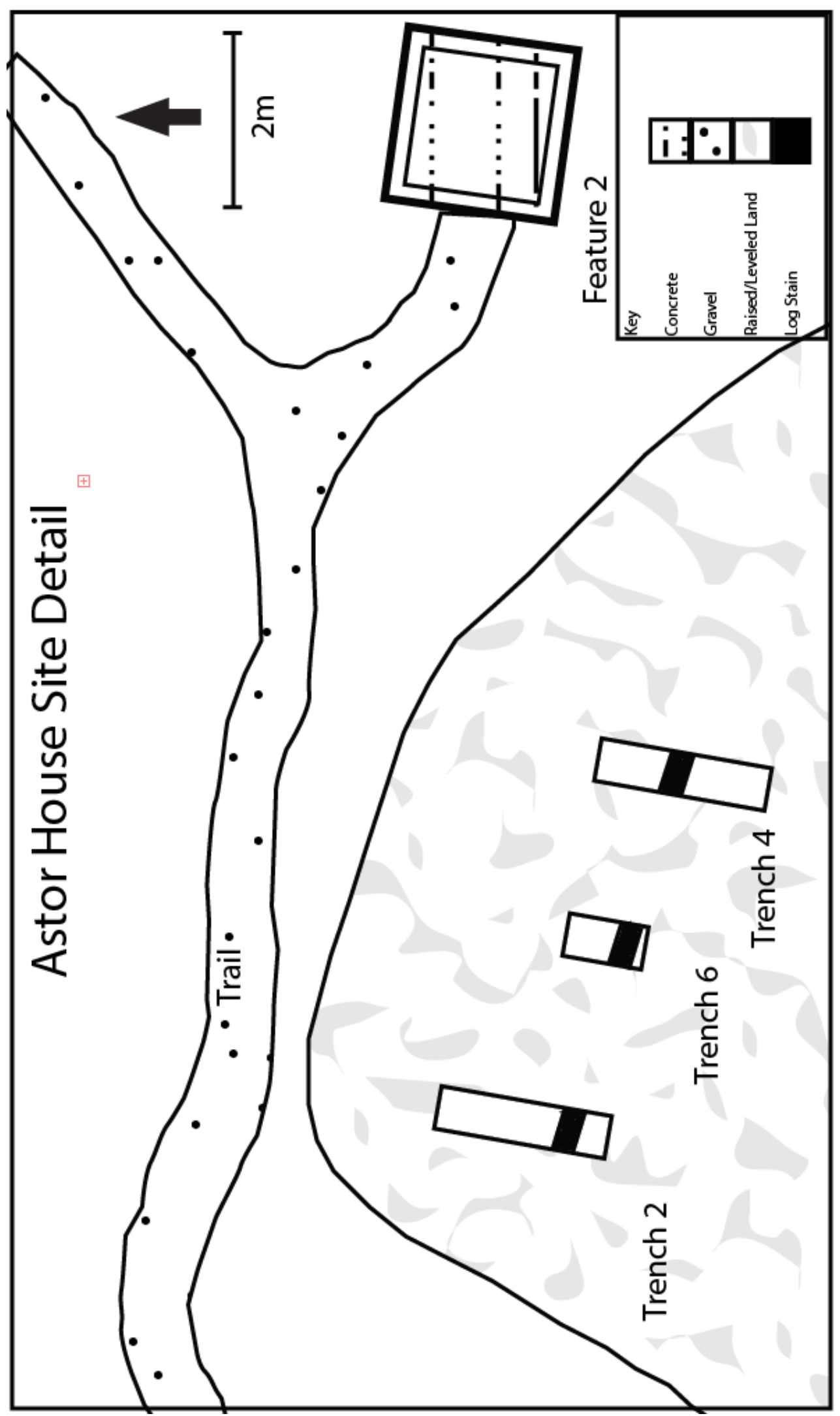

Figure 37. Astor House Excavation Detail. Map by author, 2015. 


\section{$\underline{\text { Results }}$}

\section{Lack of Prehistoric Evidence}

Throughout fieldwork there was a complete lack of evidence of prehistoric activity. The survey team dug shovel test pits around fissures and trenches that appeared to have been excavated; no indications were found suggesting that these features were previously exploited by prehistoric peoples.

It is uncommon to find prehistoric sites not related to the mining or processing of copper on the northern shore of the peninsula. Such sites would likely be very ephemeral due to the biological nature of the artifacts which would have been left. 20KE10, a possible village site located east of Hunter's Point, and 20KE35, a possible lithic scatter south of the Village of Copper Harbor, are the only cataloged prehistoric sites in the vicinity.

As stated in the Methods section, the survey team walked transects over the site with members at 5 meter intervals. The team worked along east-west axes between the property line and Fanny Hooe Creek and started at the shore of Lake Superior working south towards US 41.

\section{Feature 1}

Feature 1 is a trash dump site approximately $15 \mathrm{~m}$ northeast of the front Range Light. It appears to be a natural depression between the bedrock outcrop that forms the shoreline and the relatively flat ground to the South which was utilized for trash disposal. Artifacts recovered relate to maintenance or construction work including paint cans, a fragment of a paint brush, wire scraps, broken pieces of concrete, and various scraps of sheet metal. These artifacts are consistent with WPA era artifacts found in similar trash dumps around the Fort Wilkins property. It is likely that this feature was formed by Lighthouse Service workers performing maintenance on the front Range Light. The area is heavily overgrown at this time.

\section{Feature 2}

Feature 2 is a concrete pad located $10 \mathrm{~m}$ to the Southeast of the base of Astor Point. It is $1.8 \times 1.8 \mathrm{~m}$ square and has twelve mounting bolts cast into it which have been cut off. Park maintenance maps from 1964 show that this was once the base for a light although the type of light or its purpose is not clear. Given the location slightly inland of the 
point it would not serve as a particularly useful navigation aid. This feature is in relatively good condition.

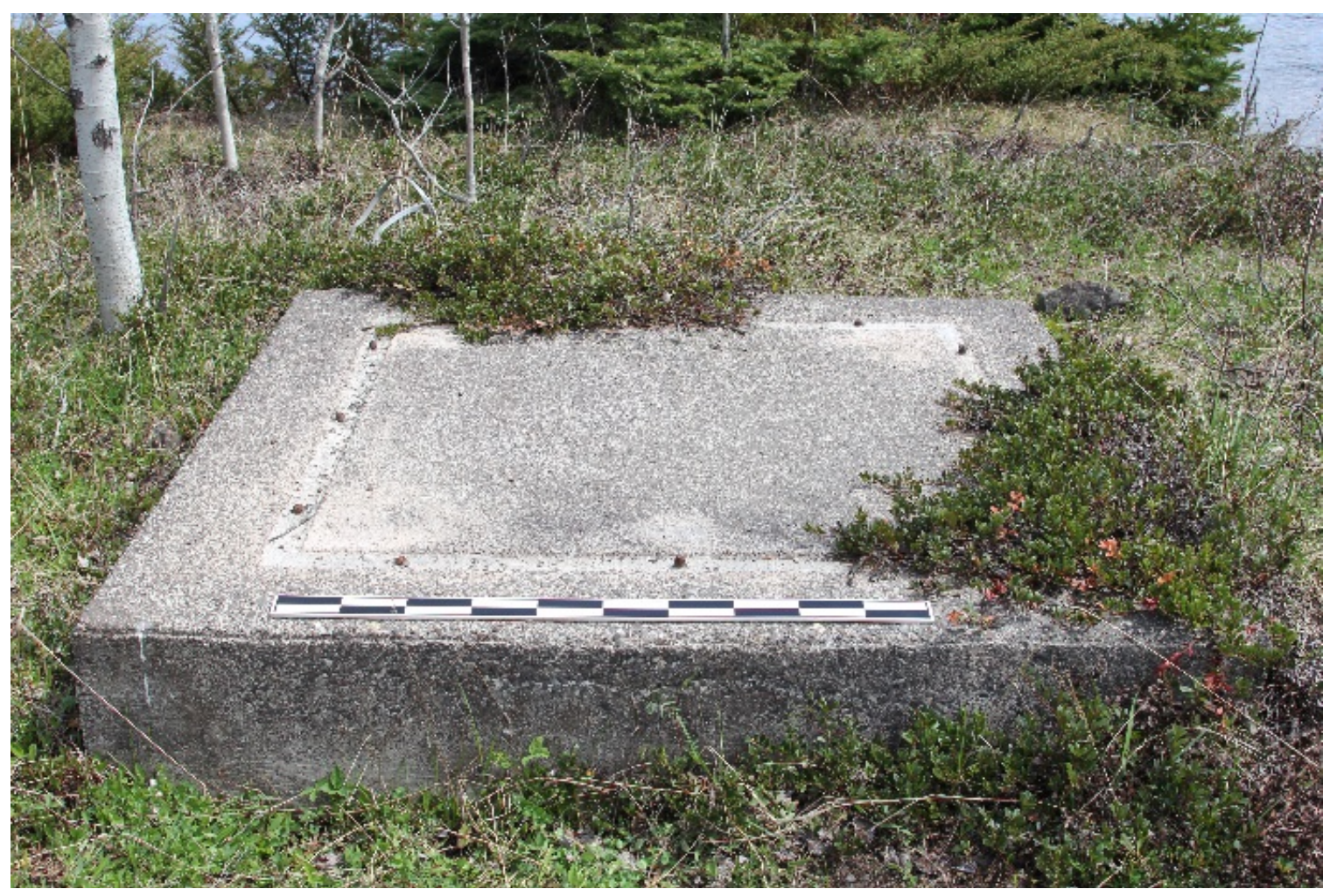

Figure 38. Feature 2 showing bolt mounting pattern. Photo by author, 2015. 


\section{Feature 3}

Feature 3 is located approximately 25 meters east of the Front Range Light. While most of the surrounding area has uneven ground this feature stood out as being very flat and nearly rectilinear extending over a roughly $8 x 6 \mathrm{~m}$ area. This feature was initially noted during a visit to the site prior to fieldwork and once again during the pedestrian survey.

During the initial shovel pit testing of the $10 \mathrm{~m}$ grid there were numerous positive test pits in the area around this flat feature leading to it being examined with a $2 \mathrm{~m}$ grid of test pits arranged within the $10 \mathrm{~m}$ grid. The survey team recovered artifacts including cut nails, window glass fragments, clay pipe fragments, coarse ceramics, and a two tine fork, all items consistent with other mid to late 1840's sites around not only Fort Wilkins, but the whole of the Keweenaw. The trend continued with numerous positive test pits around the feature with only two positives on the flat area proper. Given the historical descriptions of John St. John, George Thayer, and William Ives, this feature was considered a likely candidate for the location of the Astor House.

The St. John account gives the dimensions of the Astor House as 24x16'. Given this information the field crew used two tape measures and pulled them across the feature to gain a sense of how a structure could have been oriented on the site. The only way that a structure of the dimensions given by St. John could have sat on the site would be if the long dimension ran at approximately 110 degrees east southeast.

The goal of excavation was to locate the structure. With this in mind a .5x2m long trench (Trench 2) was laid out to cross over where it was believed the wall of the building would have been in hopes of locating a foundation. $7 \mathrm{~cm}$ below the surface a dark soil stain approximately $30 \mathrm{~cm}$ wide was encountered. A level was called and initially this was believed to be a charcoal deposit but within 5 minutes of being exposed to the bright sun the stain largely disappeared. Further excavation revealed that this stain extended roughly $5 \mathrm{~cm}$ deep and that its edges were well defined and consistent throughout although it continued to quickly disappear when exposed to sun thus drying out the soil. Sterile soil was encountered beneath this depth.

The stain was not square to the unit and in fact roughly matched the angle that was derived through fitting the measuring tapes to the site. This angle was projected 4 meters to the east and the survey team placed another .5x2m trench (Trench 4 ) to cross cut where it was believed the stain would be. $8 \mathrm{~cm}$ below the surface excavators encountered a white stain approximately $30 \mathrm{~cm}$ wide and in line with the dark stain found in Trench 2 . This stain was less than $.5 \mathrm{~cm}$ in depth. Immediately under this stain (which was less than 
$.5 \mathrm{~cm}$ thick) a dark stain was again encountered. This stain also extended roughly $5 \mathrm{~cm}$ deep.

Excavators placed a third trench measuring .5x $1 \mathrm{~m}$ (Trench 6) midway between Trenches 2 and 4 . If the stain could be found where predicted it would make a three point line reaffirming suspicions that the dark stain was in fact a log stain. Excavators quickly dug this unit to $5 \mathrm{~cm}$ below the surface with the photography equipment in place in order to get a clear photograph of the stain immediately when it was exposed. At $8 \mathrm{~cm}$ the stain was once again located passing through the unit on an angle consistent with that found in Trenches 2 and 4.

Excavators found few artifacts throughout the excavation of these three trenches; wrought nails, cut square nails, and window glass fragments being most prevalent. The artifact count is relatively high due to most recovered artifacts being crushed into several pieces. The window glass fragments were analyzed using Randall Moir's dating technique. ${ }^{78}$ The glass fragments had an average thickness of $1.491 \mathrm{~mm}$ which yields a date of $1838+/-7$ years. This is consistent with the known date of the structure as well as other glass samples from around the Fort Wilkins property. The quantity and variation of window glass found in these excavations and the surrounding shovel test pits suggests that the Astor House had multiple windows, a feature which would have been valuable to those using the structure for printing.

Despite having historical accounts of eating at the site, only 2 bone fragments were found. This can be partially attributed to the collection strategy used, simple screening through $1 / 4$ " mesh. Flotation testing of soil samples would likely yield more evidence of dietary items (like fish bones). It also important to note that the privy was not located and given the site's proximity to the lake it is possible that waste (food and other) was simply tossed in the water.

The dark stain is likely a log stain which suggests that the Astor House was built with log sills directly on the ground. This is consistent with a rather coarse structure for which the primary purpose was a storehouse. The location is consistent with both St. John's and Ives' descriptions of the storehouse/Astor House as well as Ives' depiction on the 1845 map. The relative lack of artifacts within the structure is attributed to the fact that the first floor was storage space for goods while people stayed on the second half story. Presumably the goods would have been packaged in a manner that it would have unlikely for things to be deposited below the floor.

\footnotetext{
${ }^{78}$ Moir, Randall W. "Socioeconomic and Chronometric Patterning of Window Glass in Historic Buildings, Material Culture, and People of the Prairie Margin.” Richland Creek Technical Series, vol. V (1987): 7381.
} 
The large number of positive test pits around the structure is a testament to the fact that this would have been an area of heavy activity by people staying at the Astor House, workers unloading goods from boats at the adjacent landing, people lodging at the Astor House, or those who simply hiked out to point for a view. It should be noted that in spite of the large number of positive test pits and relatively large artifact count, there were relatively few complete items recovered. Most of the recovered items were broken into several pieces and were sometimes spread over a wide area.

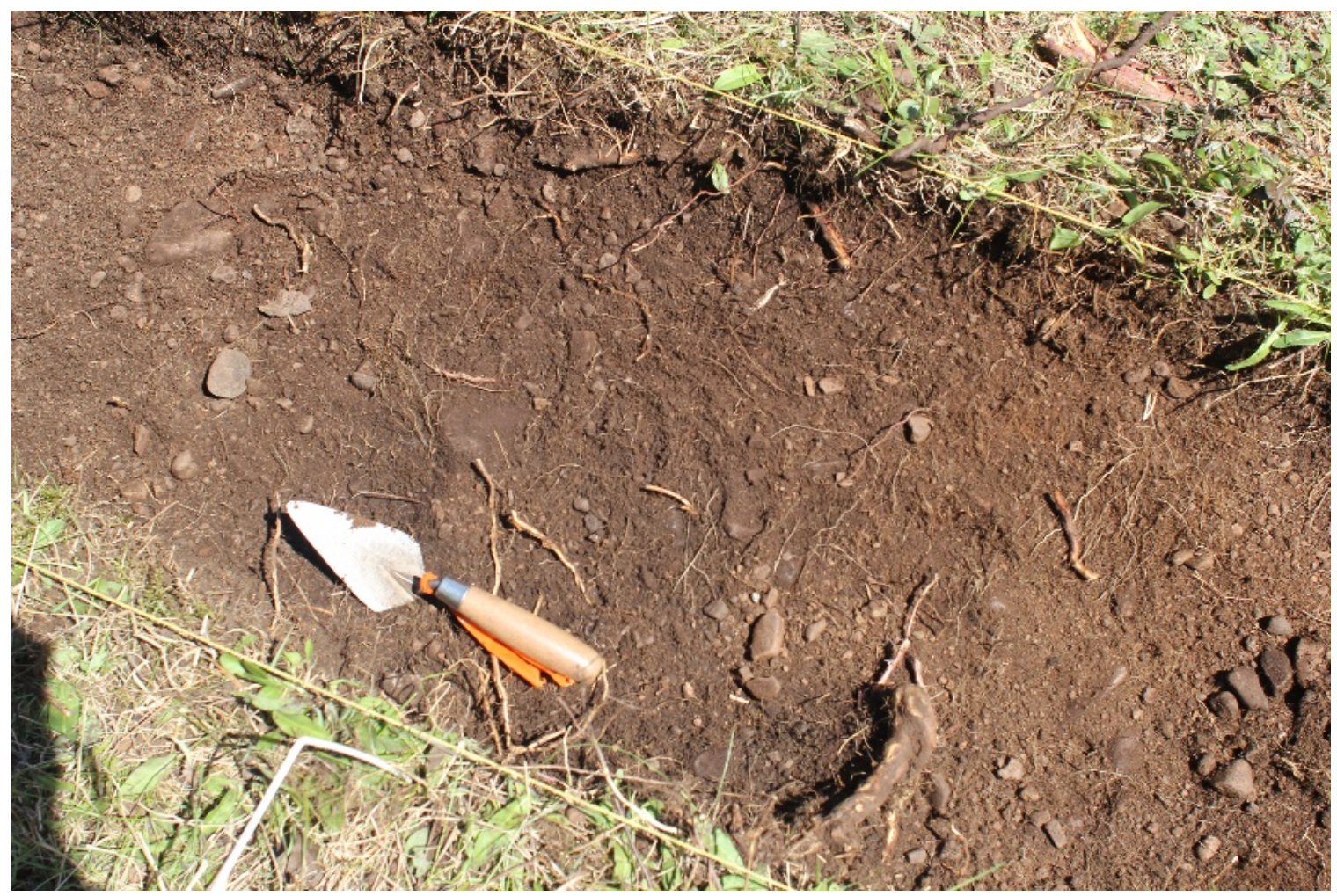

Figure 39. Detail Trench 2, Level 2 showing subtlety of stain 20 minutes after excavation. Stain extends from point of trowel to roughly $10 \mathrm{~cm}$ behind handle. Photo by author, 2015 . 


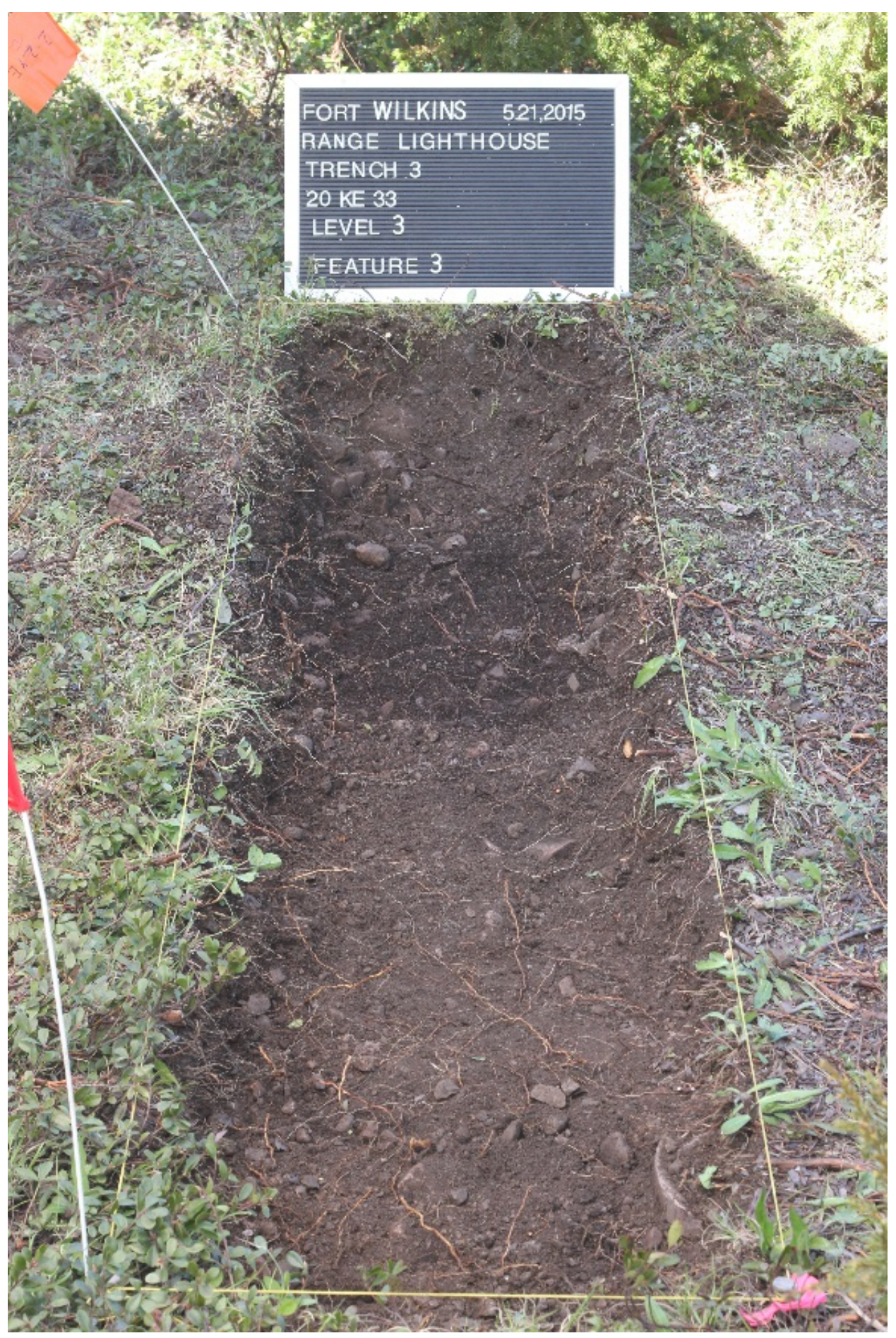

Figure 40. Trench 4, Level 3 showing stain approximately 10 minutes after excavation. View North. Photoboard Trench \# is incorrect. Photo by author, 2015. 


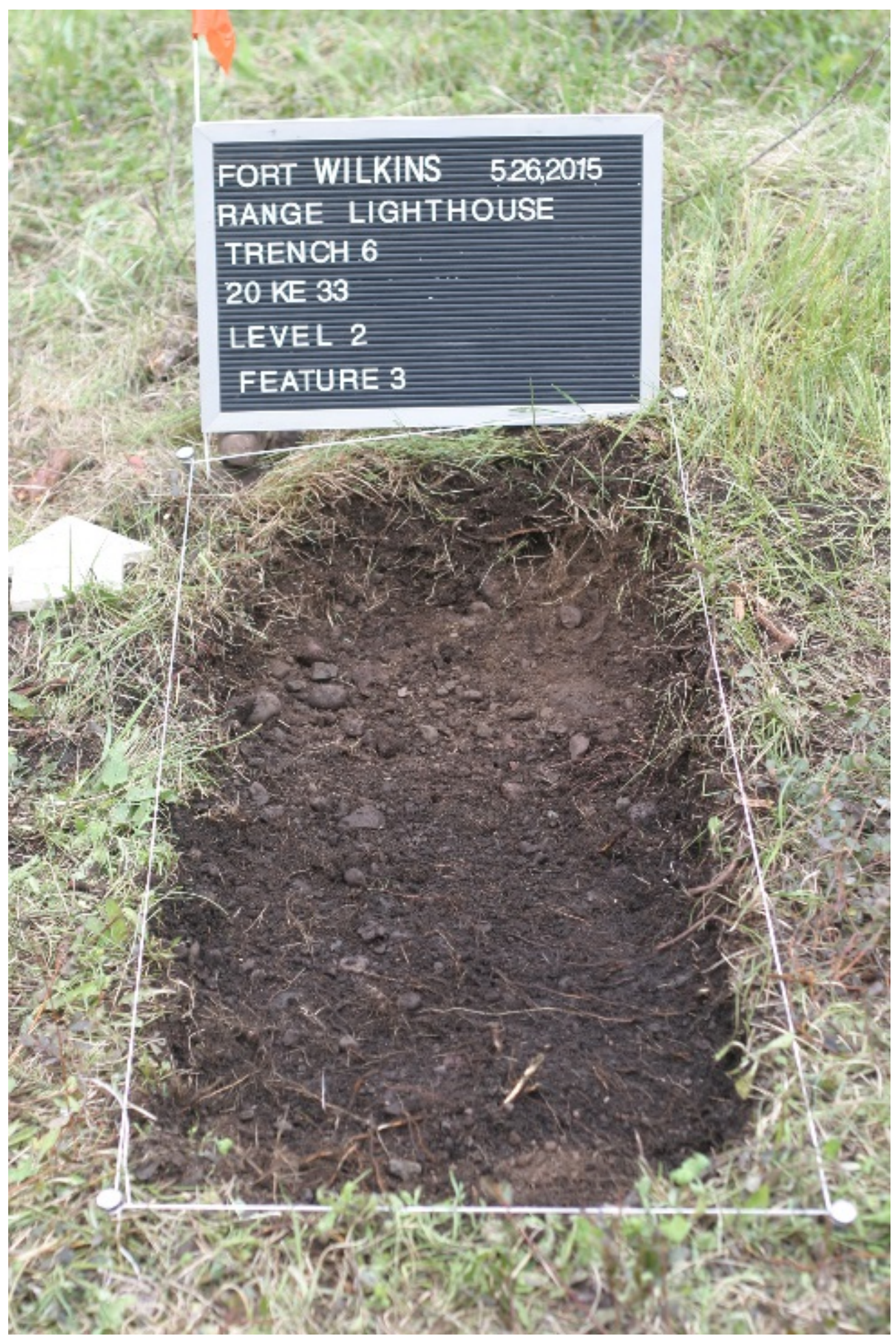

Figure 41. Trench 6, Level 2 showing stain immediately after excavation. View North. Photo by author, 2015. 


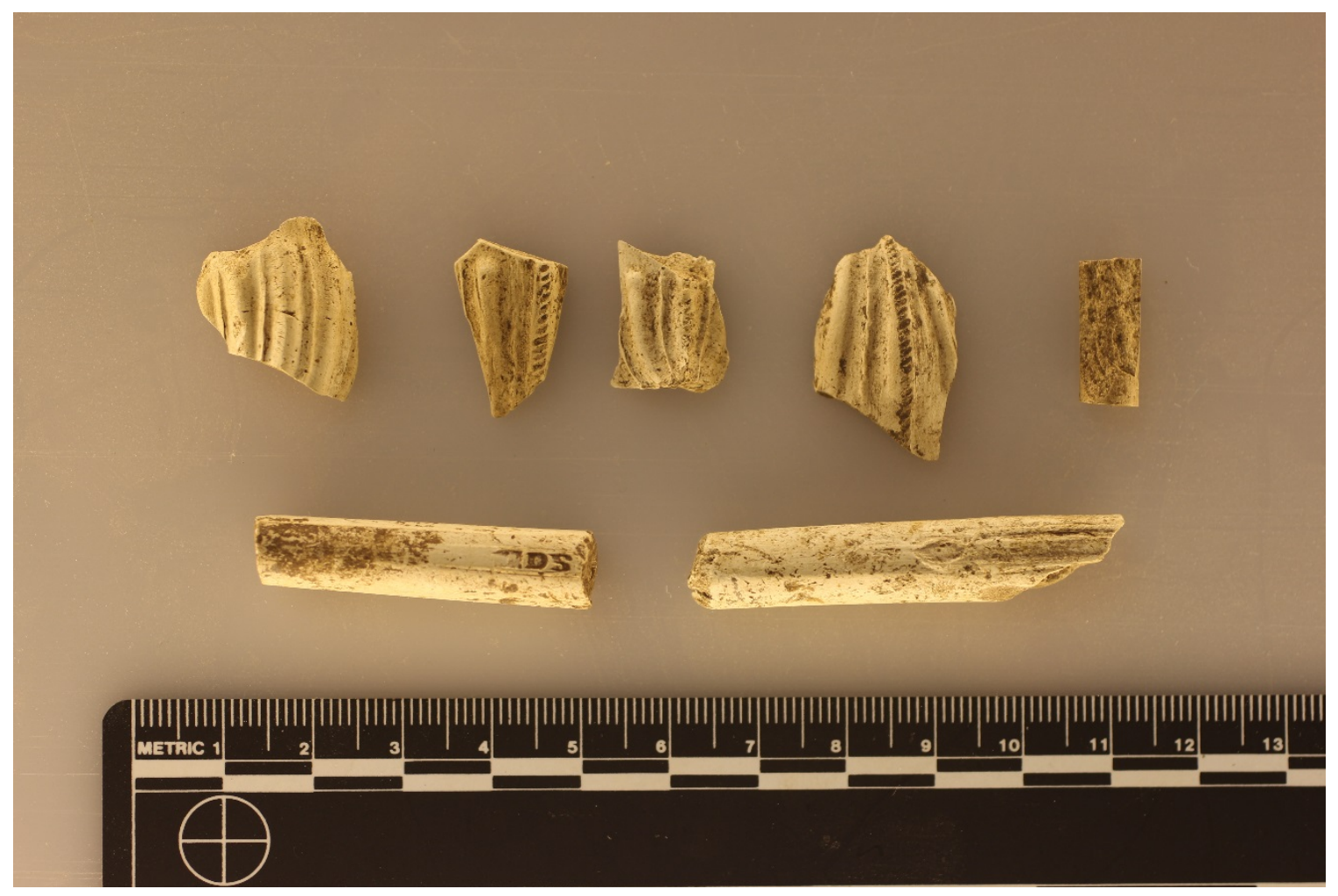

Figure 42. Sample of pipe fragments from Feature 3. Photo by author, 2016.

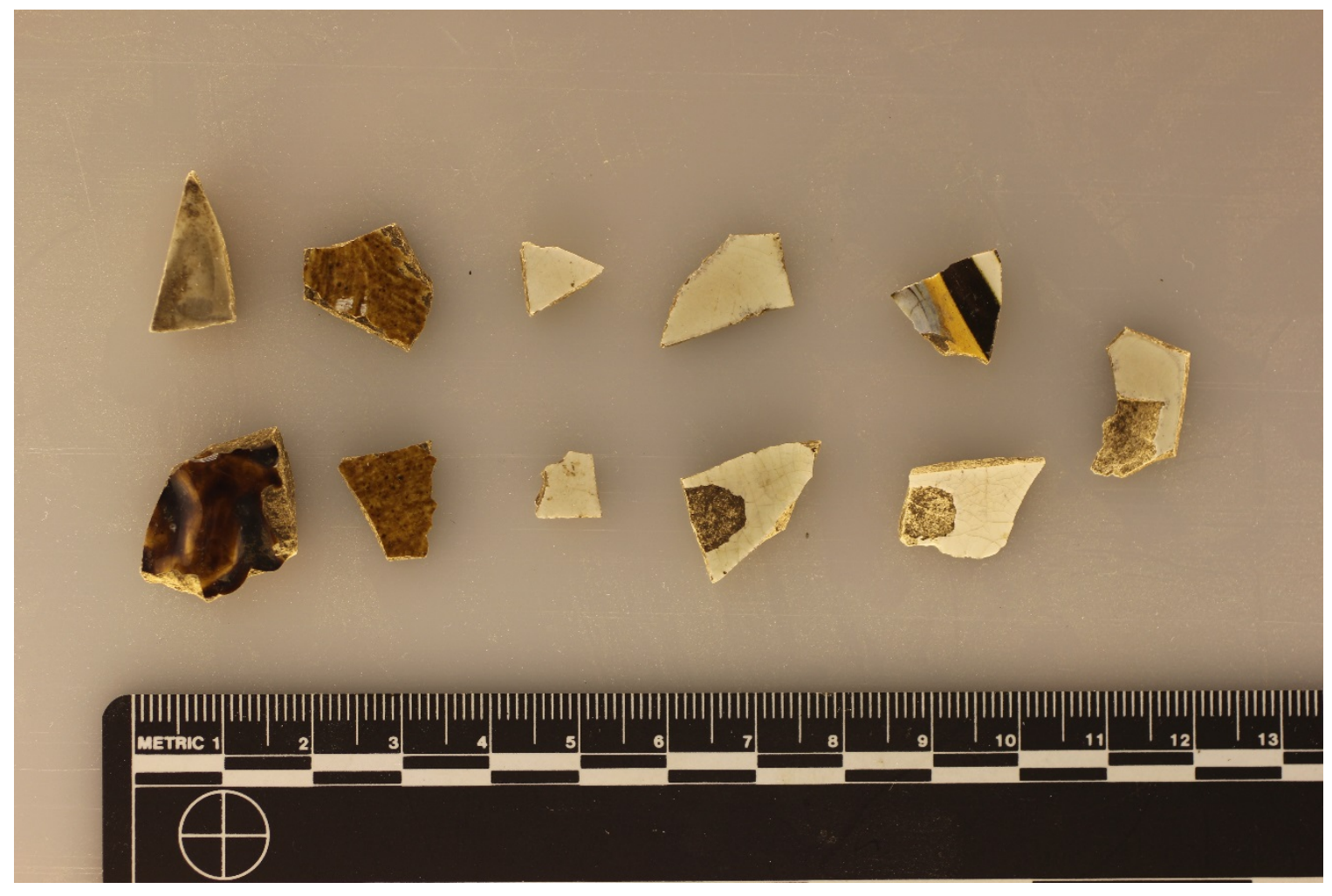

Figure 43. Sample of ceramics recovered from Feature 3. Photo by author, 2016. 


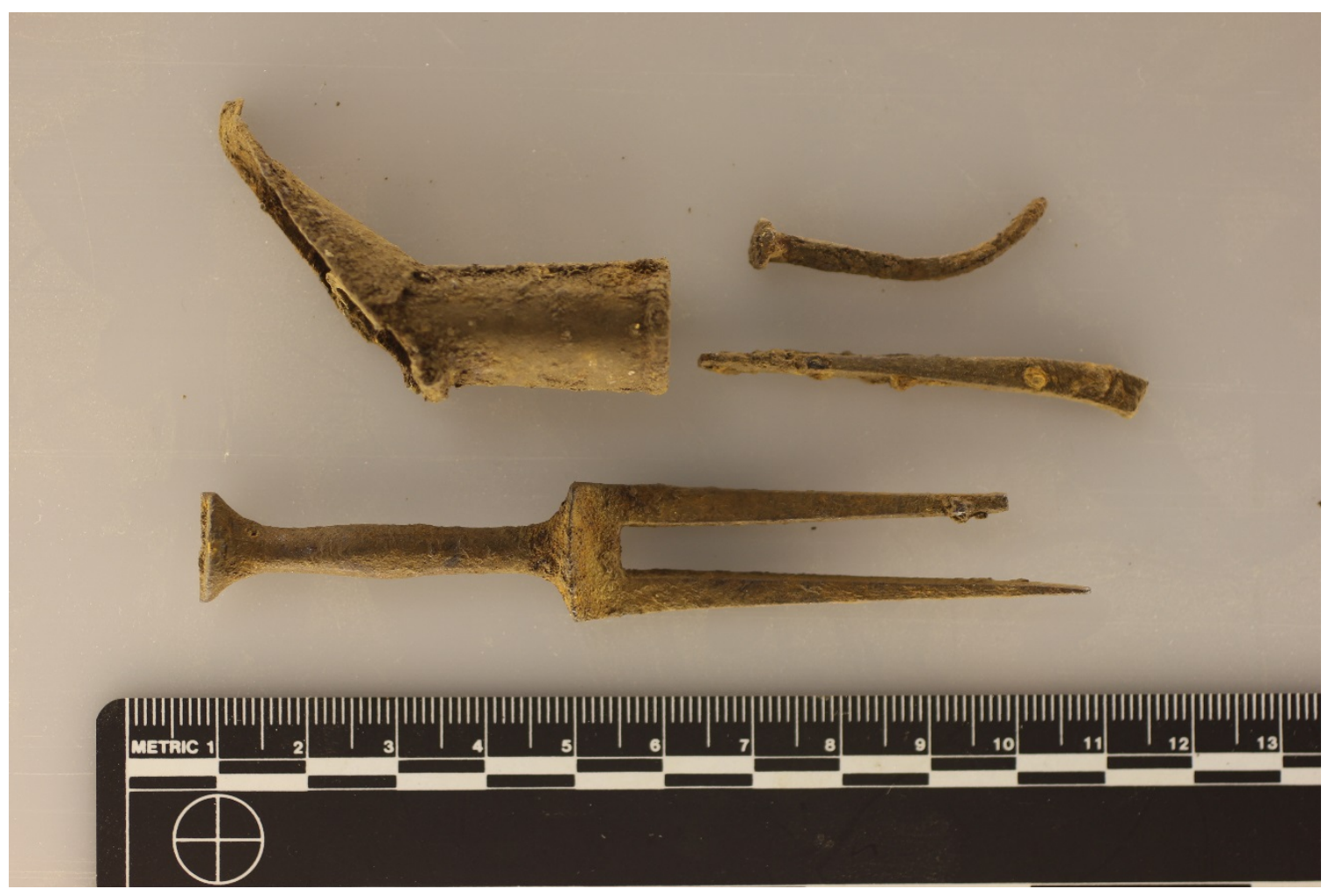

Figure 44. Sample of metal artifacts recovered from Feature 3. Photo by author, 2016. 


\section{Feature 4}

Feature 4 represents two buildings that were removed by the Park in the 1940s. Feature 4 consists of the privy and wash house/summer kitchen for the Range Lighthouse. Historic photographs and maps showing the feature guided initial inquiries. As discussed in the History Section of this report, the sources are not fully consistent with one another in regards to these buildings proximity to one another or their precise location on the site. These buildings' were treated as a single feature due to their proximity to one another and the fact that they shared a common walkway. These features were also removed at the same time by Fort Wilkins State Park. The exact method of removal is not known, whether it was a piece by piece deconstruction or bulldozing.

Team members found during initial shovel test pitting on the $10 \mathrm{~m}$ grid that there was a consistent background level of artifacts spread in the area that was once the yard on the south and west side of the Range Lighthouse. Using the historic photographs of the site a $2 \mathrm{~m}$ grid was established within the $10 \mathrm{~m}$ grid in the area of the privy and wash house despite finding no particular concentration of artifacts there. This grid of test pits was to the east and south of the Range Lighthouse. During shovel pit testing two slabs of sidewalk concrete were uncovered that were part of the walkway that led from the Range Lighthouse to the outbuildings. Further probing showed that these were the only remaining sidewalk slabs. Based on the location of the slabs relative to the Range Lighthouse it was concluded that these were likely those shown in the extreme right hand side of Figure 44 in front of the privy. Why these slabs were left in place when all of the others were removed is not clear.

Excavators laid a .5x2m trench (Trench 1) in parallel to the sidewalk slabs in hopes of cross cutting an east-west wall of the privy. $9 \mathrm{~cm}$ below the surface a foundation of laid stones was uncovered running roughly north-south. The mortar utilized in construction is very dark in color as well as being very soft and prone to crumbling. Being of low quality it is likely that this mortar was locally sourced or even made on site. The stones utilized for construction are locally sourced cobbles similar to those found in Feature 7.

Excavators laid a second trench of .5x1.5m (Trench 3) extending from the southeast corner of Trench 1 to the east. Proximity to the bank limited the length of this trench. The goal of this was to either locate another wall or expose the privy hole. Neither was accomplished. At $9 \mathrm{~cm}$ below the surface a sandy soil was encountered in the western end of the trench. This soil abutted the foundation and extended for another $10 \mathrm{~cm}$ of excavation when the unit was called without reaching a new soil. The survey team concluded that this sandy soil was most likely fill for the privy hole.

After this, investigations were shifted to locating the wash house/summer kitchen. Based on the historical photographs showing the west walls of the privy and wash house being 
roughly in line with one another excavators placed a .5x2m trench (Trench 5) 4 meters to the south of Trench 1 and in line with it with the idea once again being to crosscut a foundation. A small concrete slab which is falling down the eroding riverbank also contributed to this decision as there was a walking bridge over Fanny Hooe Creek at one time, extending from the rear of the wash house/summer kitchen. A large number of artifacts were recovered from this trench including butchered pig bone fragments. Also recovered were various pieces of hardware, bottle glass, spent small caliber (.25 Stevens Rimfire) cartridge cases, and ceramics. However, no indications of the foundation or walls were evident.

The survey team had come to distrust the maps showing this area due to errors and the inconsistencies when compared to photographs. Due to this the team decided to dig two $.5 \times 1 \mathrm{~m}$ trenches with one (Trench 7) extending to the west and another (Trench 9) extending to the east out from the side of Trench 5 . Trench 7 was negative regarding foundational remains, although numerous artifacts were recovered consistent with the adjacent Trench 5 including more butchered bone. An alignment of stones was located $15 \mathrm{~cm}$ below the surface in Trench 9 . These stones are similar to those found in the foundation of the privy, however the mortar has shed from the rocks in the form of small balls which crumble to the touch and are deeper despite the ground level actually being slightly lower in this area than at the privy. Probing into the walls with a chaining pin suggested that this alignment continues.

The foundation evident in Trench 1 is very probably the western wall of the privy. The location is consistent with historical photographs and the sandy soil found to the east in Trench 3 could well be fill for the privy hole dating from when the Department of Conservation had the building removed. Artifacts recovered from these units included building hardware including nails, screws, a bolt, and a latch hook. Also recovered were pieces of tar paper and a fragments of wood siding. No artifacts were recovered within the sandy soil, this is reasonable if it is indeed fill for the privy hole. Approximately 20$25 \mathrm{~cm}$ below the surface is bedrock. To regularly move the privy as is common elsewhere would have entailed drilling and blasting a new privy hole. It is far more likely that the hole was cleaned out on a semi-regular basis.

The alignment of stones unearthed in Trench 9 is plausibly identified as part of the foundation for the wash house/summer kitchen. The location is consistent with historical photographs and the artifact scatter is consistent with a space that was used for food processing and preparation. Relatively few artifacts were uncovered in Trench 9, those being limited to some small pieces of building material, nails and glass fragments. This is in contrast to Trenches 5 and 7 (and the surrounding test pits) which were rich with artifacts that included building materials but also butchered bone, window glass, bottle fragments, a serving fork, and numerous ceramics. Ceramics included a mix of coarse materials as well as some mid-grade stonewares. The area surrounding the wash 
house/summer kitchen is littered with the remains of trash as would be expected of an area of heavy use by a series of families over the period of 70 years.

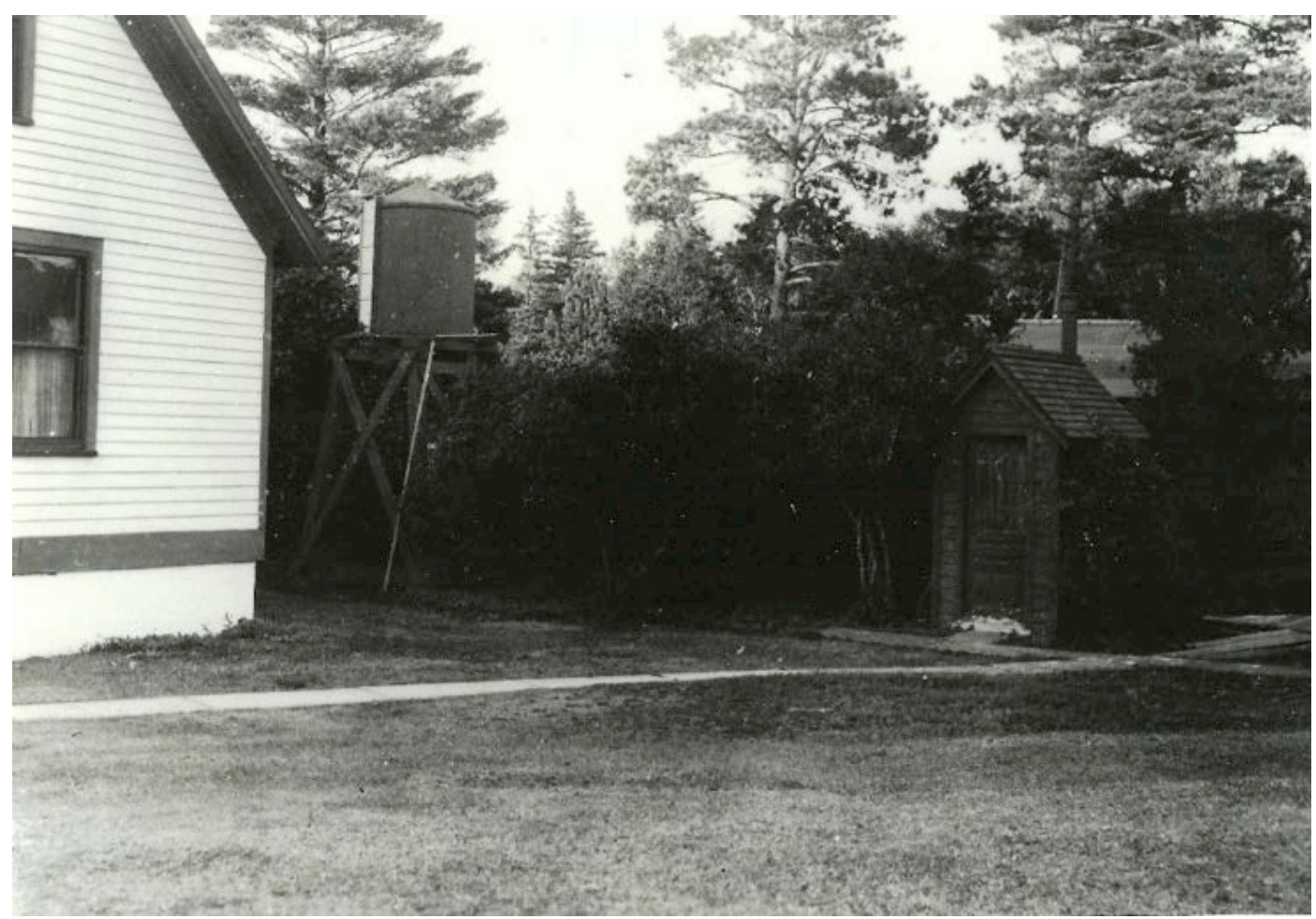

Figure 45. 1941 photograph showing sidewalk leading to privy and water tower. Image courtesy of the Michigan Historical Center, Michigan Iron Industry Museum.

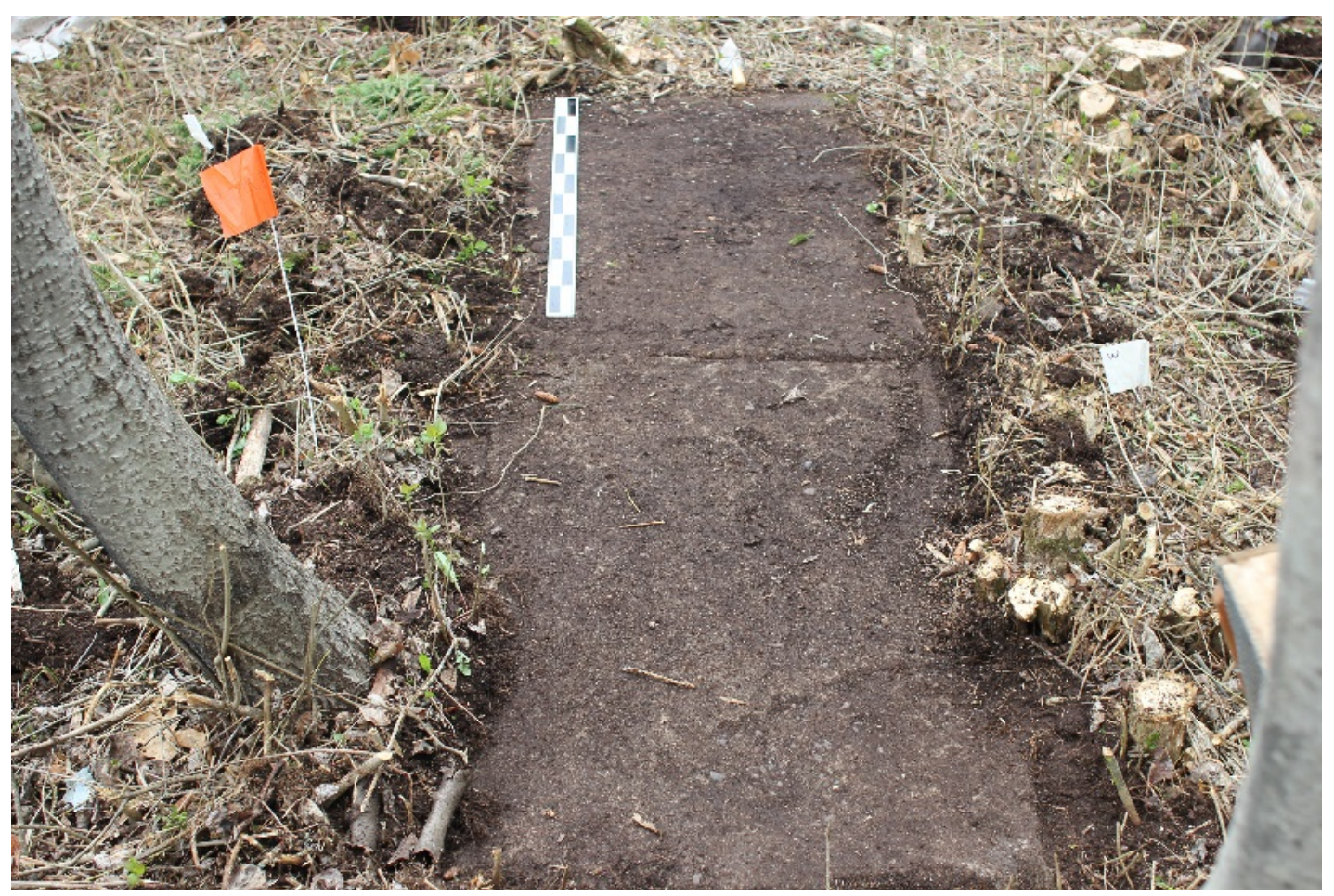

Figure 46. Sidewalk slabs uncovered during test pitting. View North. Photo by author, 2015. 


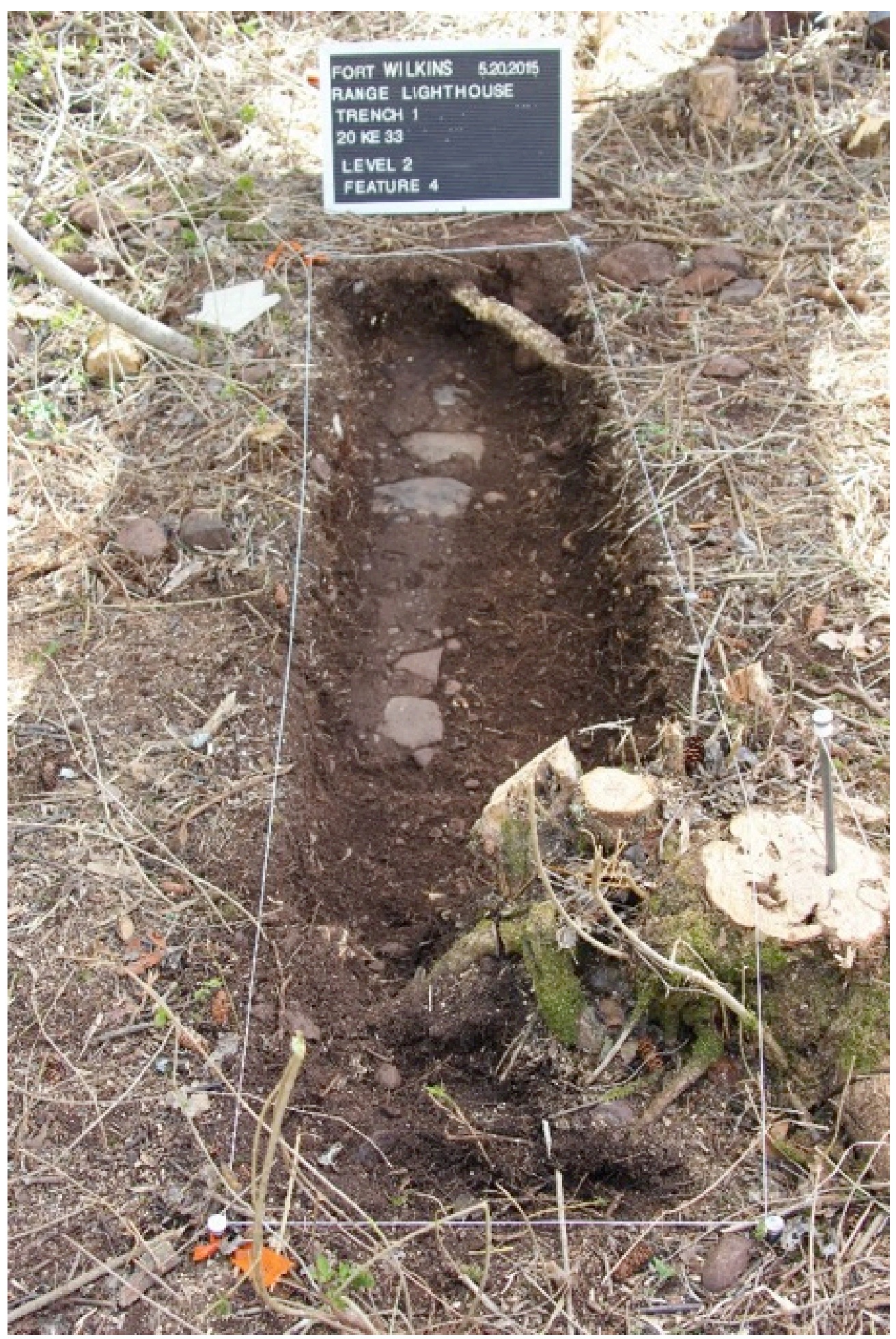

Figure 47. Trench 1, Level 2. Privy foundation evident. Photo by author, 2015. 


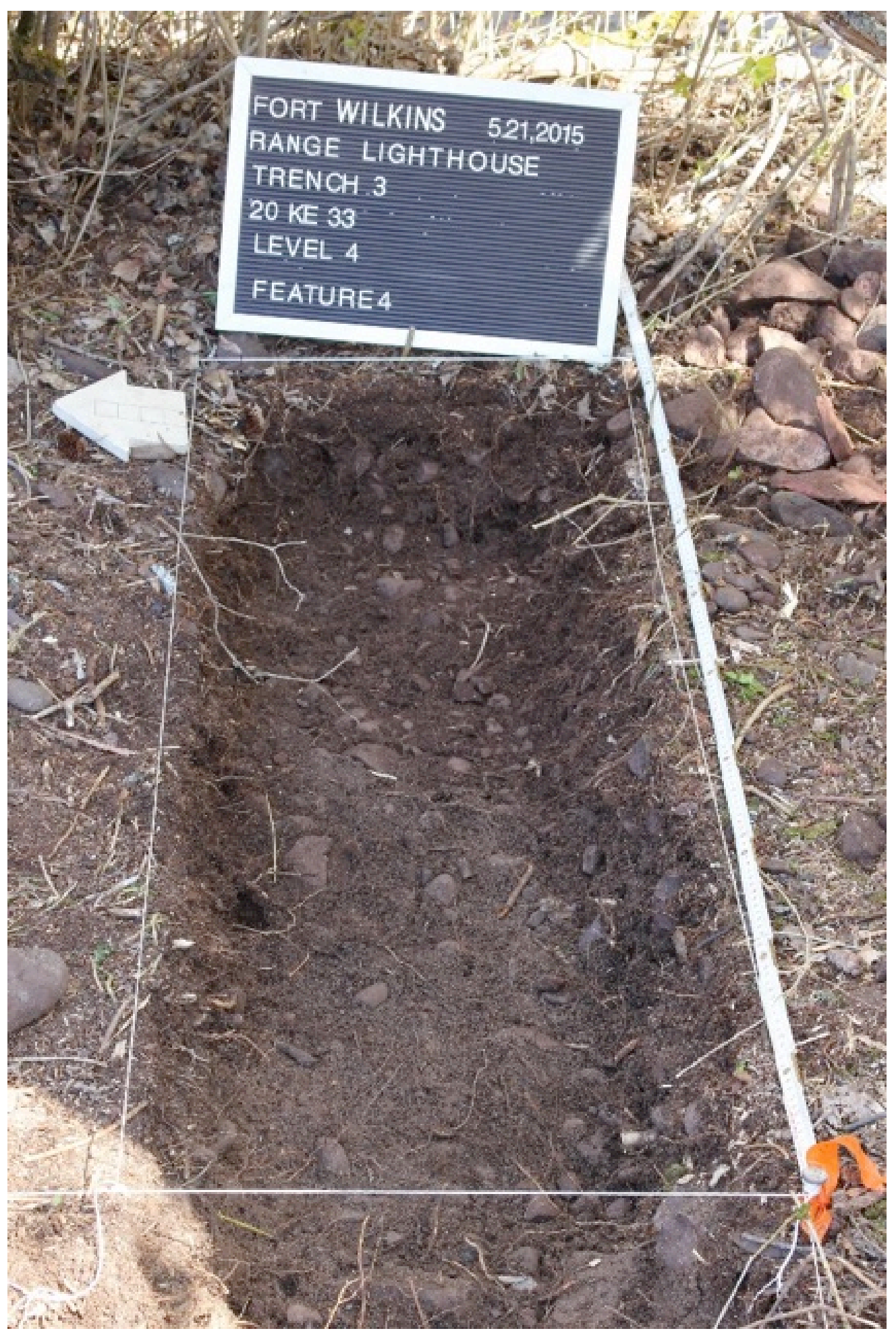

Figure 48. Trench 3, Level 4 showing sandy soil in west side of unit. View East. Photo by author, 2015. 


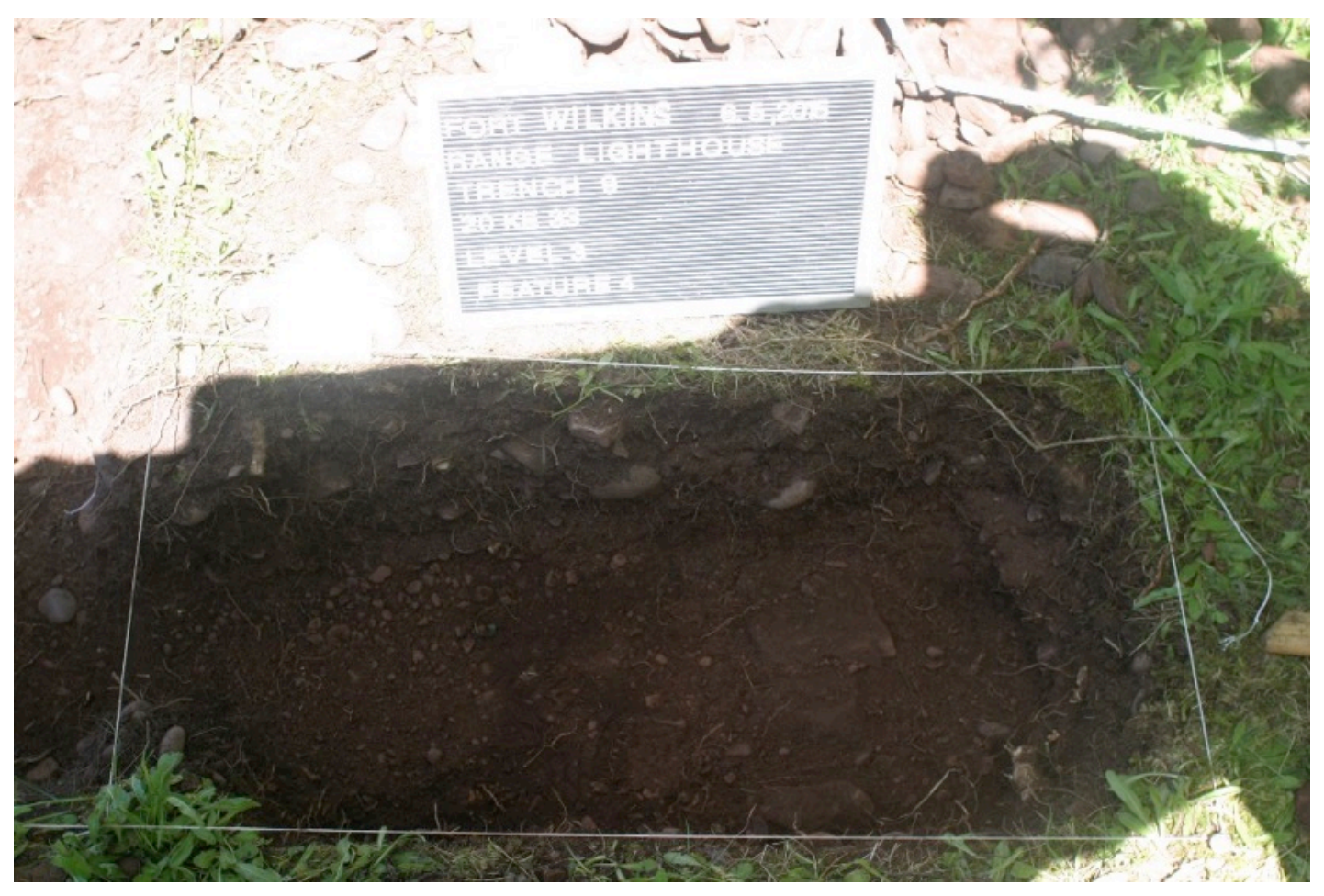

Figure 49. Trench 9, Level 4. Stone alignment on left in shaded area. View North. Photo by author, 2015.

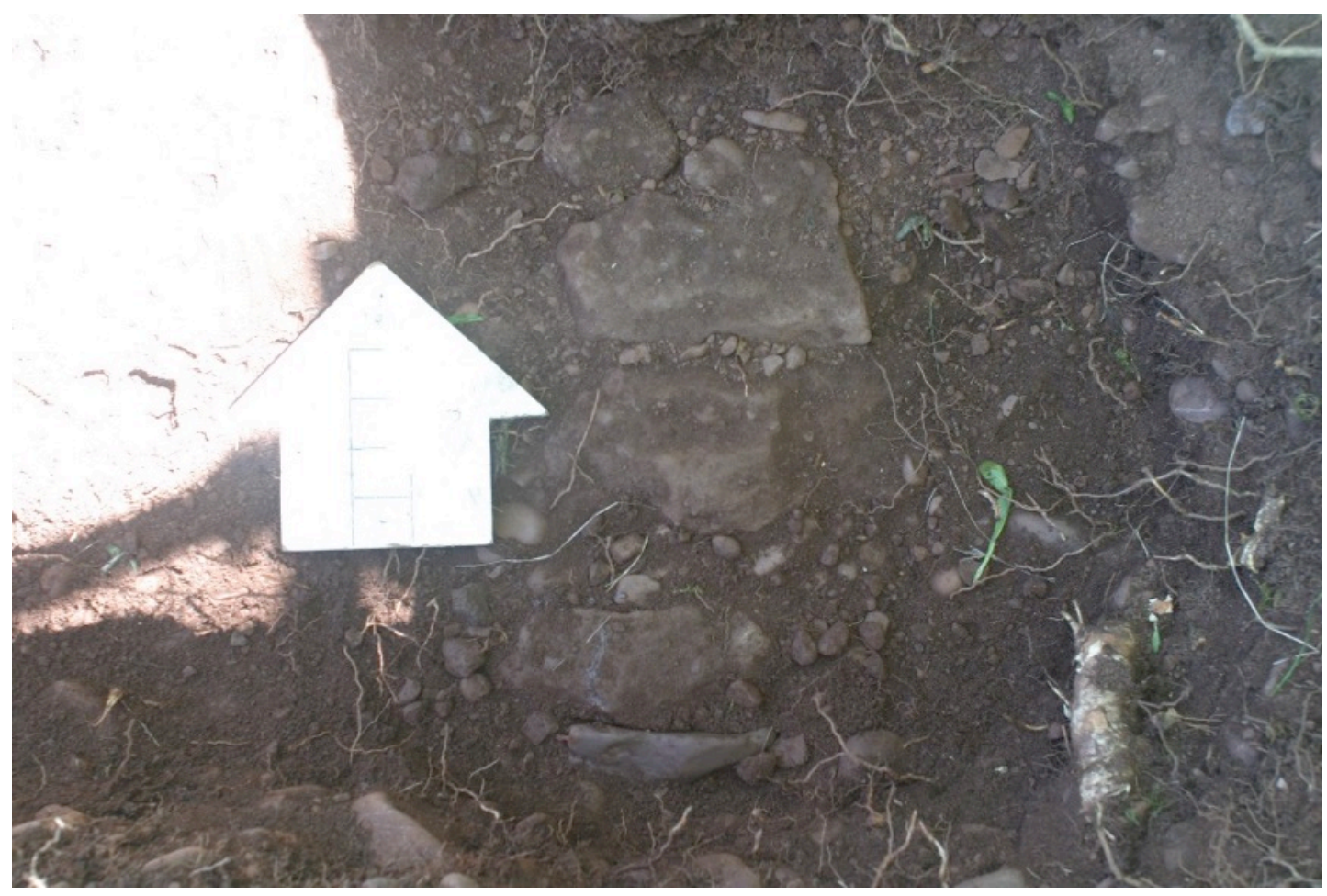

Figure 50. Detail of stone alignment in Trench 9. Note small balls of mortar. View North. Photo by author, 2015. 


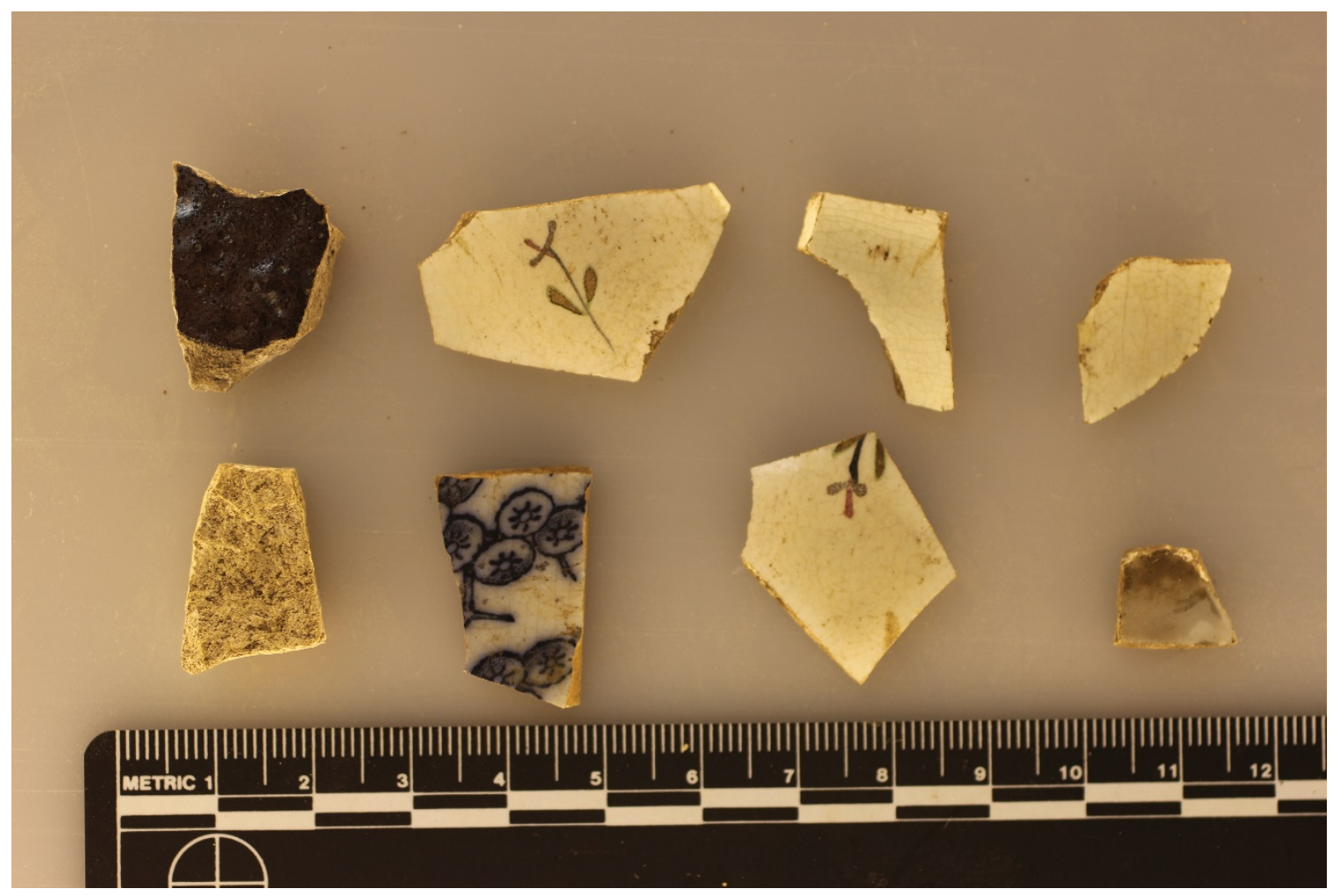

Figure 51. Sample of ceramics recovered from Feature 4. Photo by author, 2016.

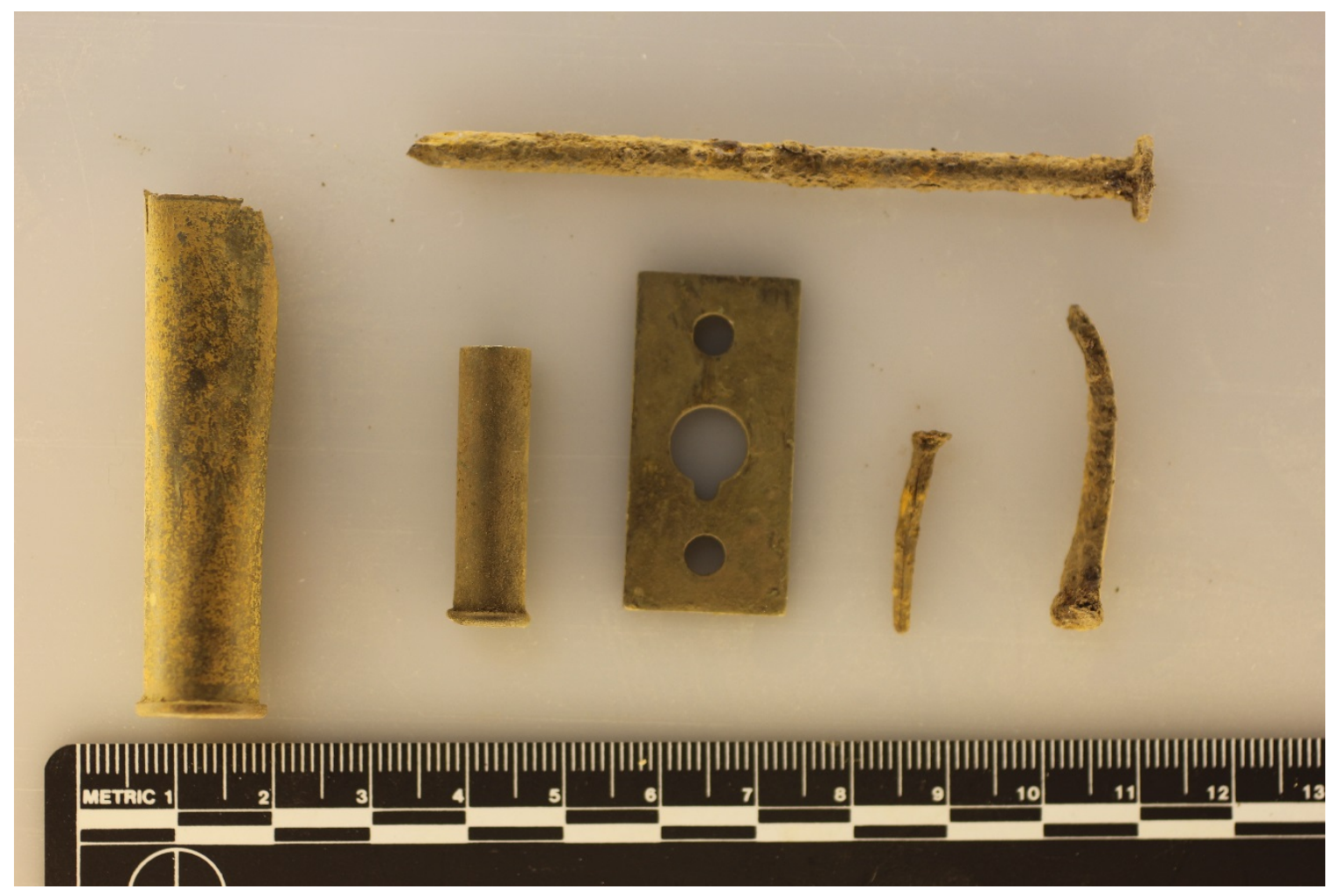

Figure 52. Sample of metal artifacts recovered from Feature 4. Photo by author, 2016. 


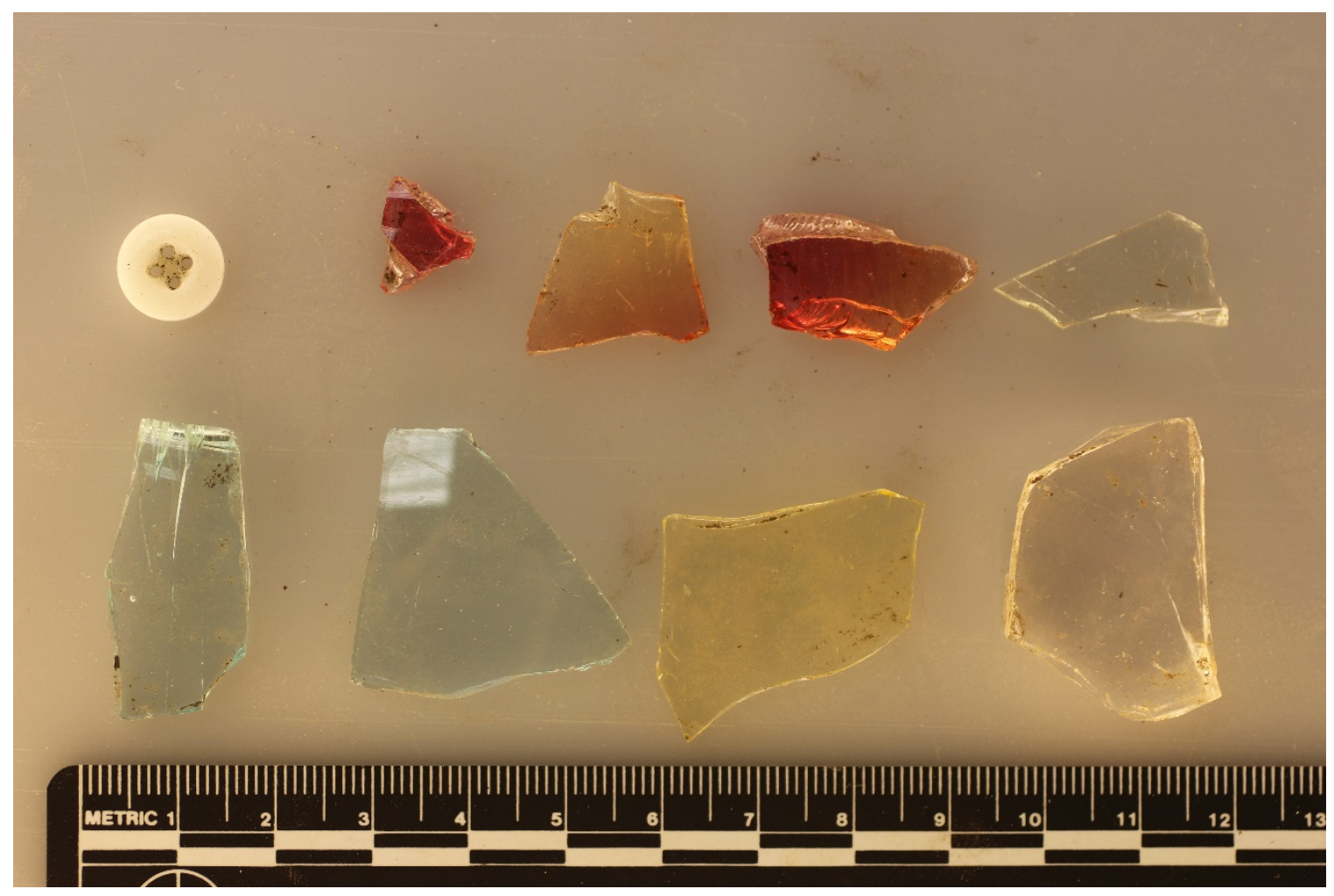

Figure 53. Sample of non-window glass recovered from Feature 4. Photo by author, 2016.

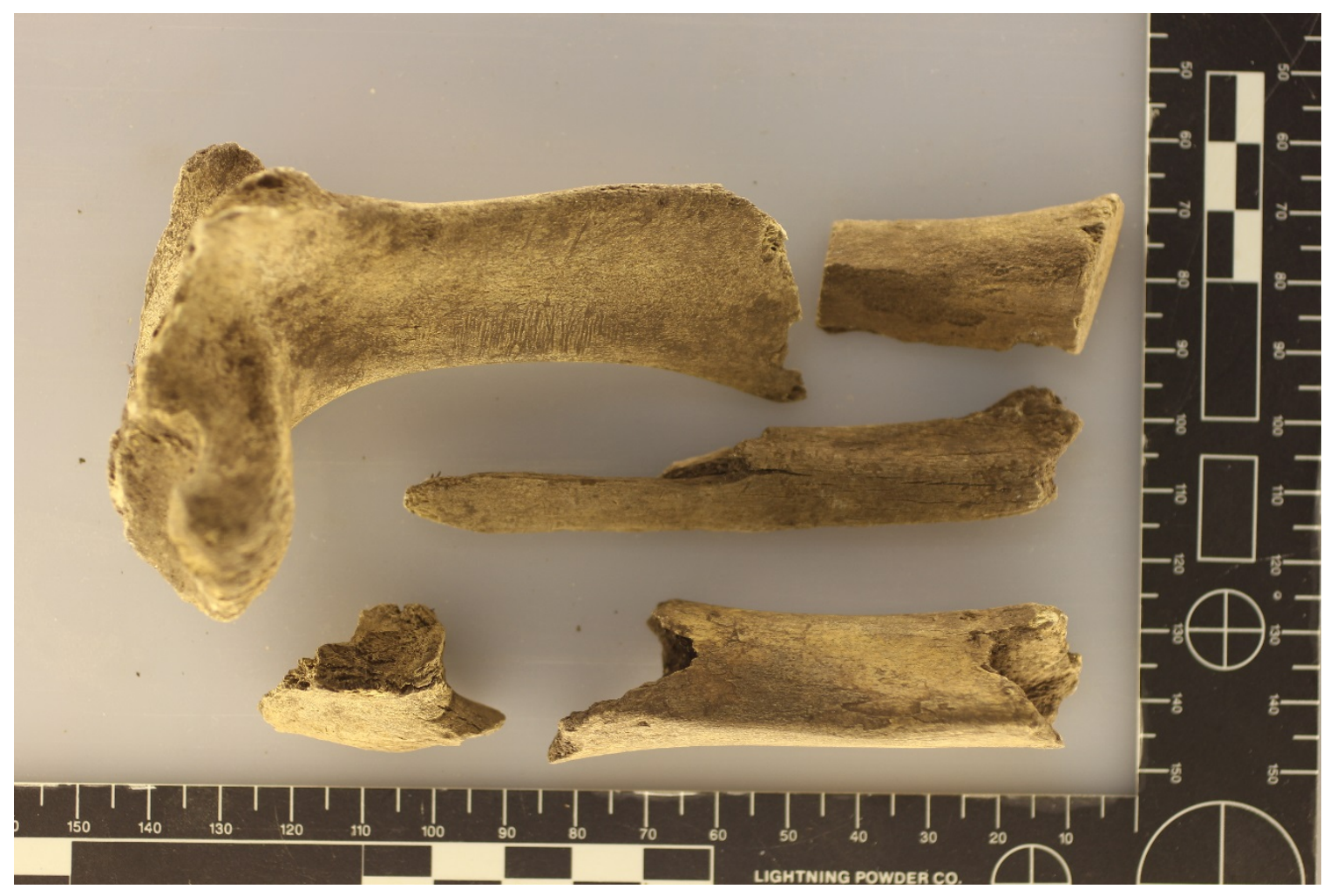

Figure 54. Sample of bone fragments recovered from Feature 4. Photo by author, 2016. 


\section{Feature 5}

Feature 5 is a survey benchmark that has been carved into the bedrock on the shoreline $5 \mathrm{~m}$ west of the base of Astor Point. The benchmark reads "Lat. 47²8'11" O.B.W. U.S.L.S. 1864". This feature was made by the United States Lake Survey which was performed by the U.S. Army Topographical Engineers (later merged with the U.S. Army Corps of Engineers) who were charged by Congress with preparing and publishing nautical charts beginning in March of 1841. The survey was completed by 1882. Benchmarks of this type served as datums from which topographic features could be mapped. O.B.W. are the initials of Orlando B. Wheeler, a University of Michigan graduate who was in charge of astronomical and geodetical triangulation parties for the United Lakes Lake Survey from 1863-1871. The 29 year old Wheeler surveyed the Copper Harbor shoreline from June 25th-28th under Henry Gillman working from west to east. This feature is 20KE25.

The benchmark is still quite legible although there is damage to the bottom left portion of the engraving and general weathering as would be expected given its location on the shoreline. This benchmark also appears in Gillman's notebook of the survey.

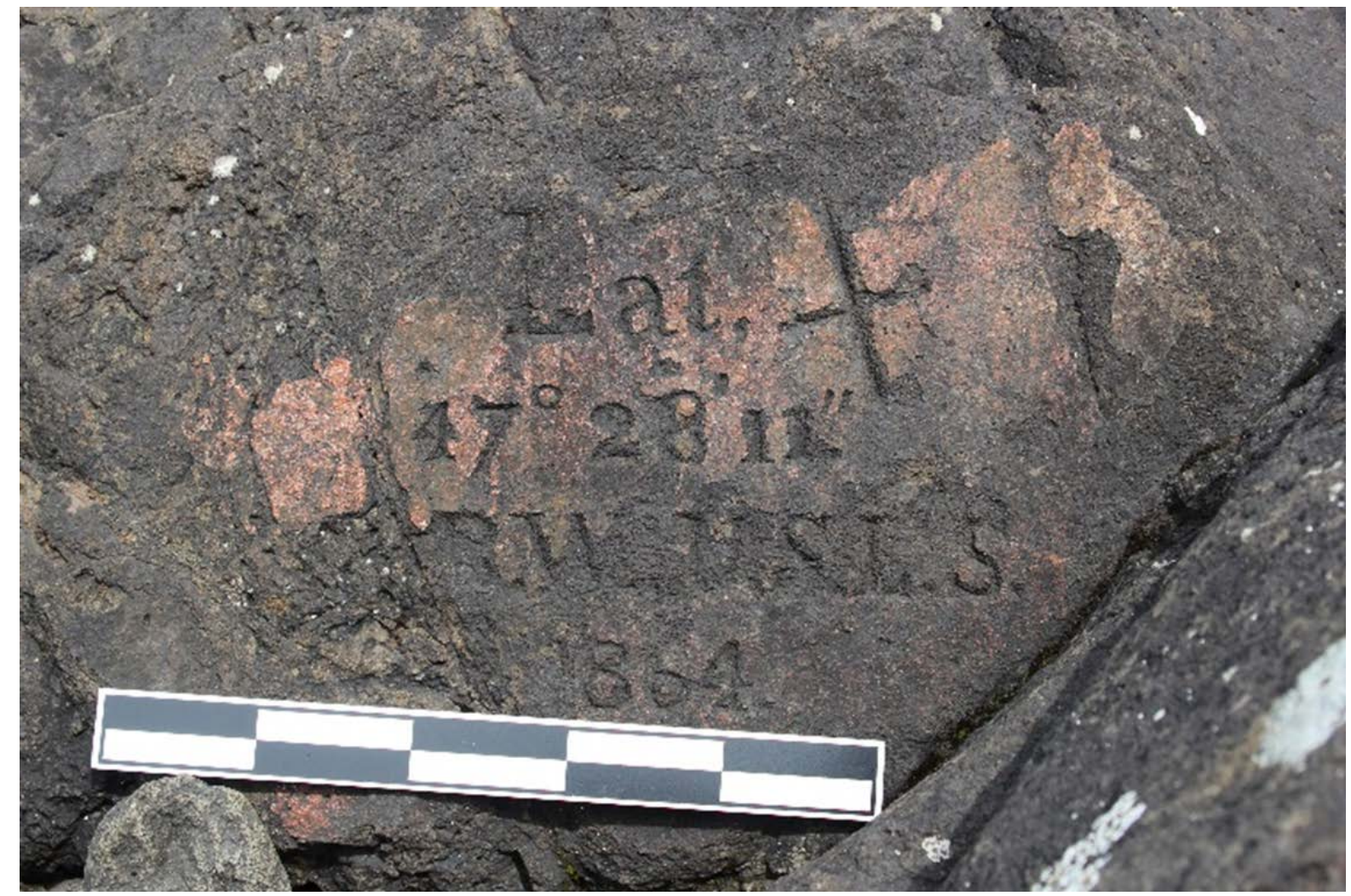

Figure 55. Detail Feature 5. Photo by author, 2015. 


\section{Feature 6}

Feature 6 is the location of an historic boathouse. There are no visible physical remains of the structure which appears to have been quite ephemeral. The structure is visible in a photo of Fanny Hooe Creek taken in 1889. It does not appear in maps of the creek. The structure was built abutting the outcrop of rock that forms the west bank of Fanny Hooe Creek. This outcrop is straight with a right angle cut into rock and appears to have been dressed flat. No artifacts were located and soil in the area around this feature is extremely thin, consisting almost solely of vegetation debris.

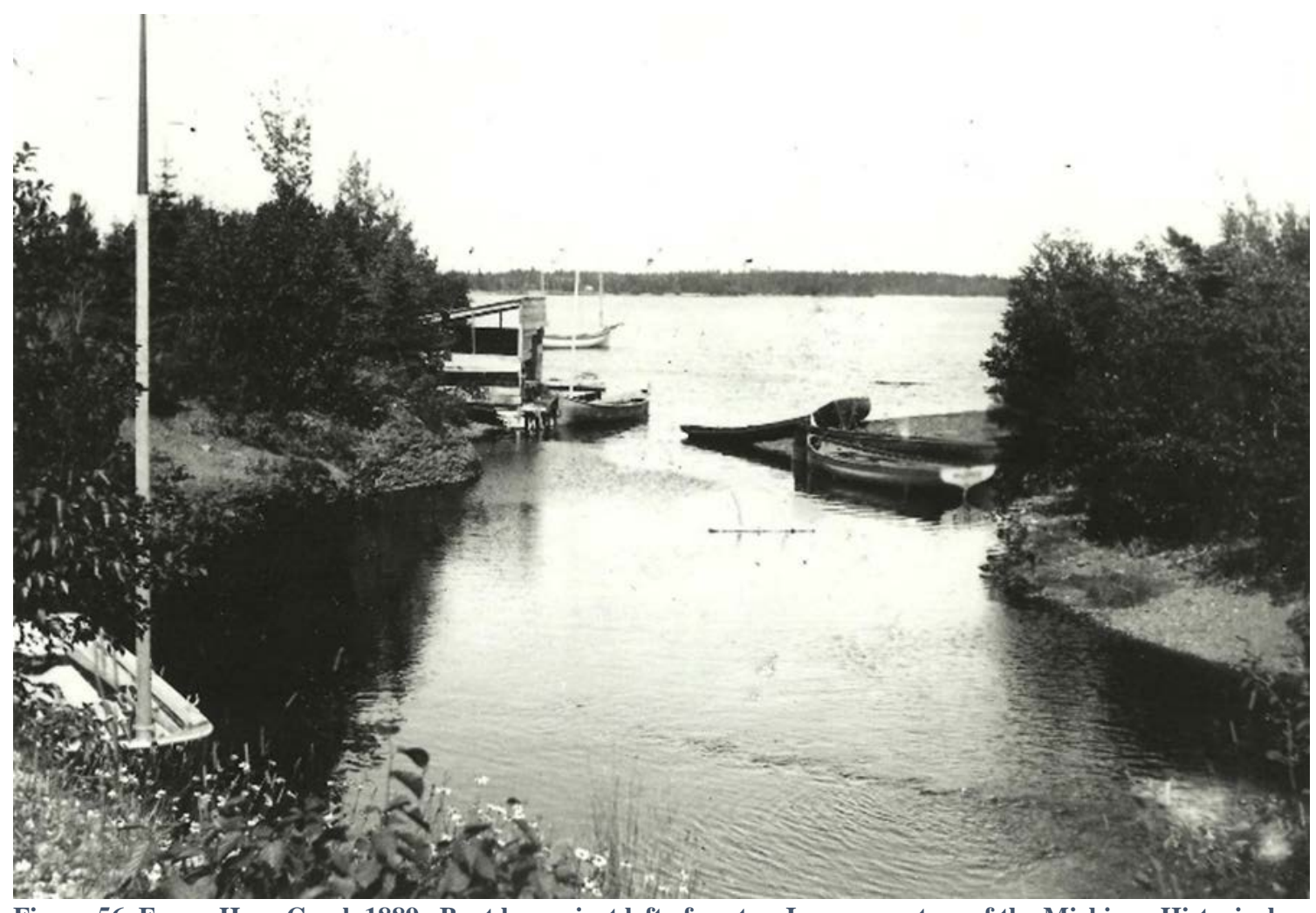

Figure 56. Fanny Hooe Creek 1889. Boat house just left of center. Image courtesy of the Michigan Historical Center, Michigan Iron Industry Museum. 


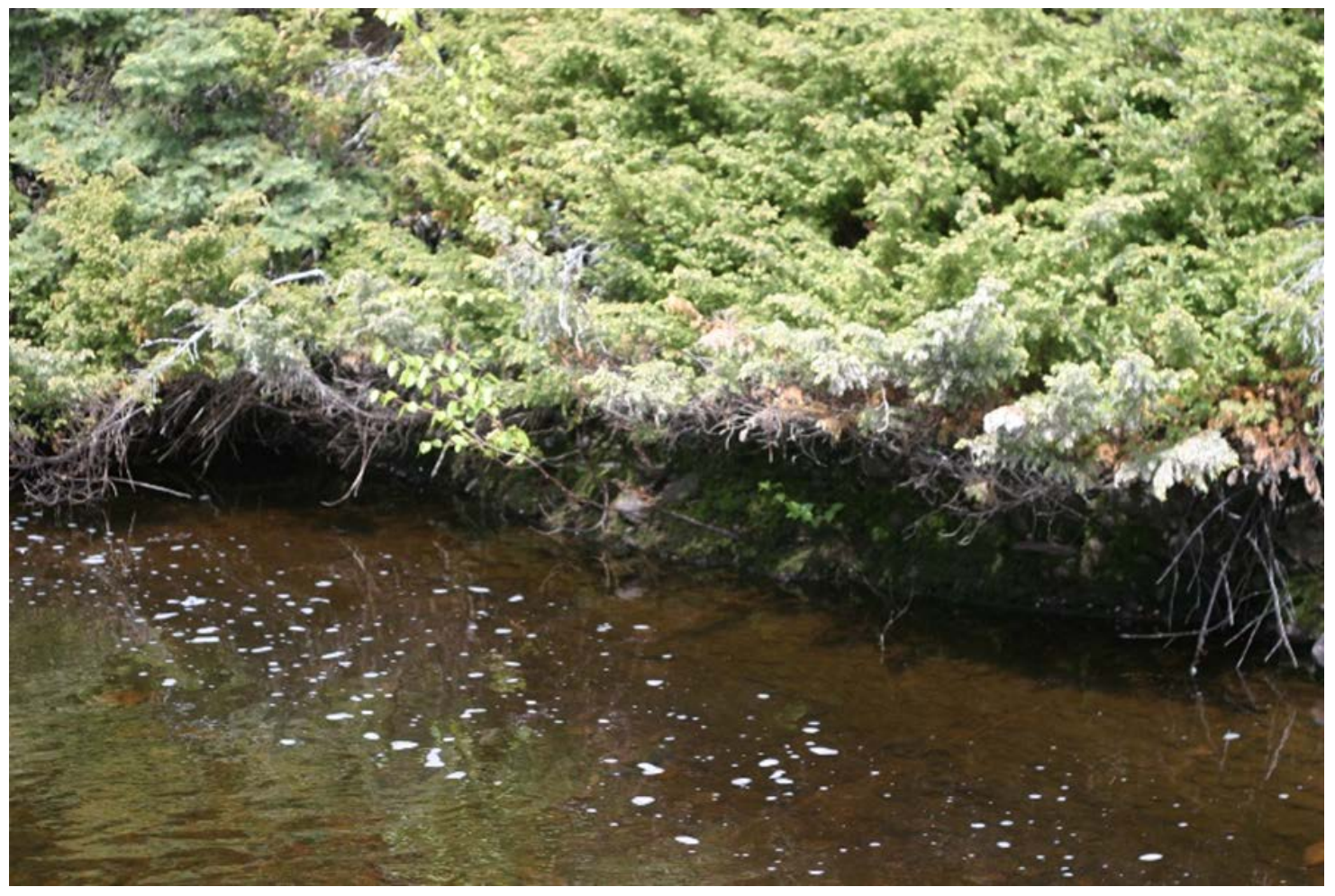

Figure 57. Feature 6. Note right angle notch to left. Photo by author, 2015. 


\section{Feature 7}

Feature 7 is located roughly halfway between the Rear and Front Range Lights on the west bank of Fanny Hooe Creek. Originally suspected of being a bridge abutment, this feature is most likely a retaining wall. It is a wall of laid stone $3.6 \mathrm{~m}$ long built into the bank. It was apparently built of whatever stone was at hand being a mix of broken pieces of conglomerate and glacial cobbles such as those found along the beach on the opposite side of Fanny Hooe Creek. There is no evidence of there having been a matching feature on the opposite bank supporting the idea that this is not a bridge abutment. On June 10th, 1896 the light keeper noted in his journal that he had "Braced up the walk where the creek has washed out”, Feature 7 may be either the bracing referred to or a later and more permanent solution. The bank on either side of this wall is severely eroded and threatening to undermine the sidewalk leading between the Range Lights. This feature is suffering from the roots of plants intruding between the stones although it continues to prevent erosion in this location.

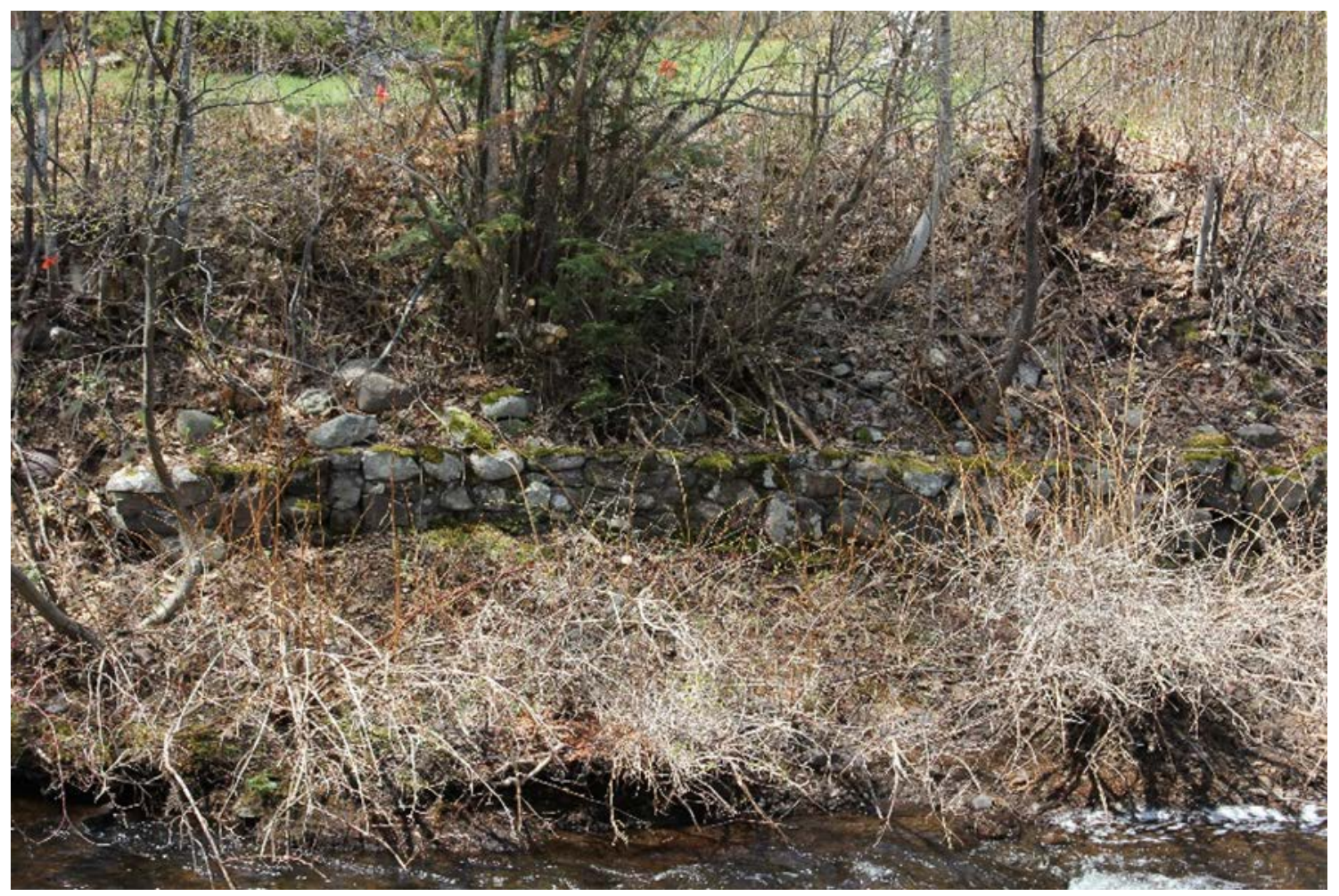

Figure 58. Feature 7. Note right angle notch to left. Photo by author, 2015. 


\section{Feature 8}

Feature 8 is an historic bridge abutment north of the Range Lighthouse. This abutment is made of concrete over stones laid in course. It appears to have been built directly over an earlier abutment on the same site. This feature appears in numerous maps both historic and recent. A wagon road once crossed Fanny Hooe Creek at this point. This feature has a flat concrete pad $(2.5 \times 2.25 \mathrm{~m})$ with a bolt and pipe cast into it on the North side. Four stairs head up to ground level to the West. To the South there is another pad $(2.3 \times 1.25 \mathrm{~m})$ sitting roughly $40 \mathrm{~cm}$ higher with two stairs on the South side leading to a third pad $(2.2 \times 1 \mathrm{~m})$ at ground level.

The bank has been severely eroded on the south side, undermining this feature and exposing wooden timbers, some of which are now in the stream bed. There are also a number of stones and concrete fragments from the feature in the water. It appears that this portion is in danger of collapse.

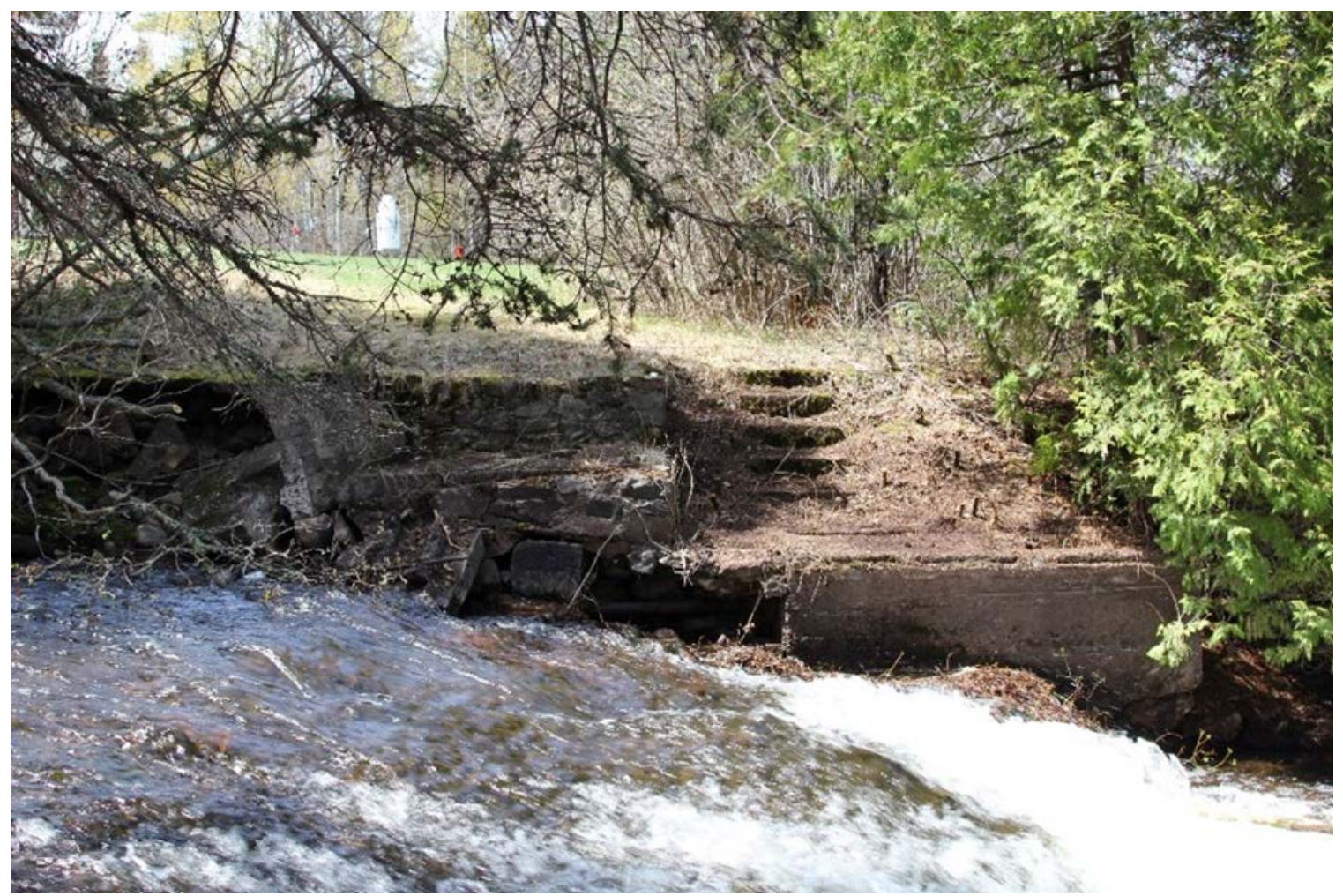

Figure 59. Feature 8 from east bank of Fanny Hooe Creek. Severe erosion on left. Photo by author, 2015. 


\section{$\underline{\text { Recommendations }}$}

\section{Feature 1 - Trash Pit}

Feature 1 sits in heavy undergrowth where it is unlikely to be noticed let alone molested. There numerous other similar trash pits throughout the park including those identified during fieldwork performed in 2013 and 2014. There is no particular need to excavate the site unless perhaps it is endangered by future construction and the park wishes to recover the artifacts.

\section{Feature 2 - Concrete Pad}

Feature 2 is exposed but being concrete it is unlikely to be damaged. The only concern would be in the remaining bolts corroded to the point of damaging the concrete. It does not contribute to the historic character of the site.

\section{Feature 3 - Astor House}

This feature is a candidate for further excavation. Apparently the site of the earliest hotel in the Copper Country as well as the home to the first newspaper for the region, it is a significant site. Fieldwork thus far has only established the location of the feature, not its boundaries. Full excavation of the site would be ideal in order to determine its boundaries and patterns of use. Attention should also be paid to determining where the kitchen shelter and privy were located.

The Astor House site also presents an excellent interpretive opportunity for the Park. The fact that a crude log structure was considered a hotel, and got repeated historical mention, helps demonstrate the frontier nature of the region in its earliest years. The excellent historic accounts of those who stayed in the Astor House would also lend visitors insights into what visiting the region would have been like in the mid-1840s. Furthermore, any interpretation done at the Astor House site could be tied in to existing interpretation at the Lighthouse overlook regarding the wreck of the John Jacob Astor.

There are multiple options for interpreting the Astor House for park guests. One would be to continue the Park's long tradition of reconstructing important buildings. With the range of activities that took place in the Astor House there are a variety of different aspects of life from the frontier era of the Copper Country which could be discussed. The richest areas for interpretation would be cooking/eating, the sleeping arrangements, and printing. Historic recreations of print shops in other institutions are popular and offer an interactive element to interpretation. The multiuse, ever-changing, rough and tumble 
nature of the Astor House would serve as an interesting counterpoint to the regimented use of space within Fort Wilkins in which the areas for different activities are clearly separated. The downside to this method of interpretation is that it would be expensive and most likely require an employee dedicated to working at the structure.

Included here is a hypothetical floorplan of the Astor House showing that the printing equipment would have taken up less than half of the structure. While historical accounts do not include mention of a staircase one be necessary for getting visitors to the upper story so it was included. Historically, access could have been via a ladder or staircase.

Another option would be to use the "ghost structure" concept as used to depict Benjamin Franklin's home and print shop at Independence National Historic Park. This would entail creating a frame indicating the size, location, and orientation of the structure. The ghost structure is usually used in instances where there is limited information about what the depicted structure would have looked like as was the case with Franklin's home (and is the case here). Another justification for the use of ghost structures is limited funds for building/maintenance. These structures are also suitable in areas where it is not desired to have an employee present for interpretation. As the Astor House is well removed from the rest of the interpreted structures at Fort Wilkins it would probably require a dedicated staff member were it reconstructed making the ghost structure even more economical. Coupled with interpretive signage describing the history of the site and its role in the story of early Copper Harbor this would be adequate to give visitors some understanding of the site. This option would be relatively low cost and could even serve as a temporary solution.

Using interpretive signage alone would be the cheapest option. In spite of its low cost interpretive signage could do an effective job of describing the history of the site while conveying some sense of what was there. The experiential component would be lost with this option. 


\section{Possible Astor House Floor Plan}

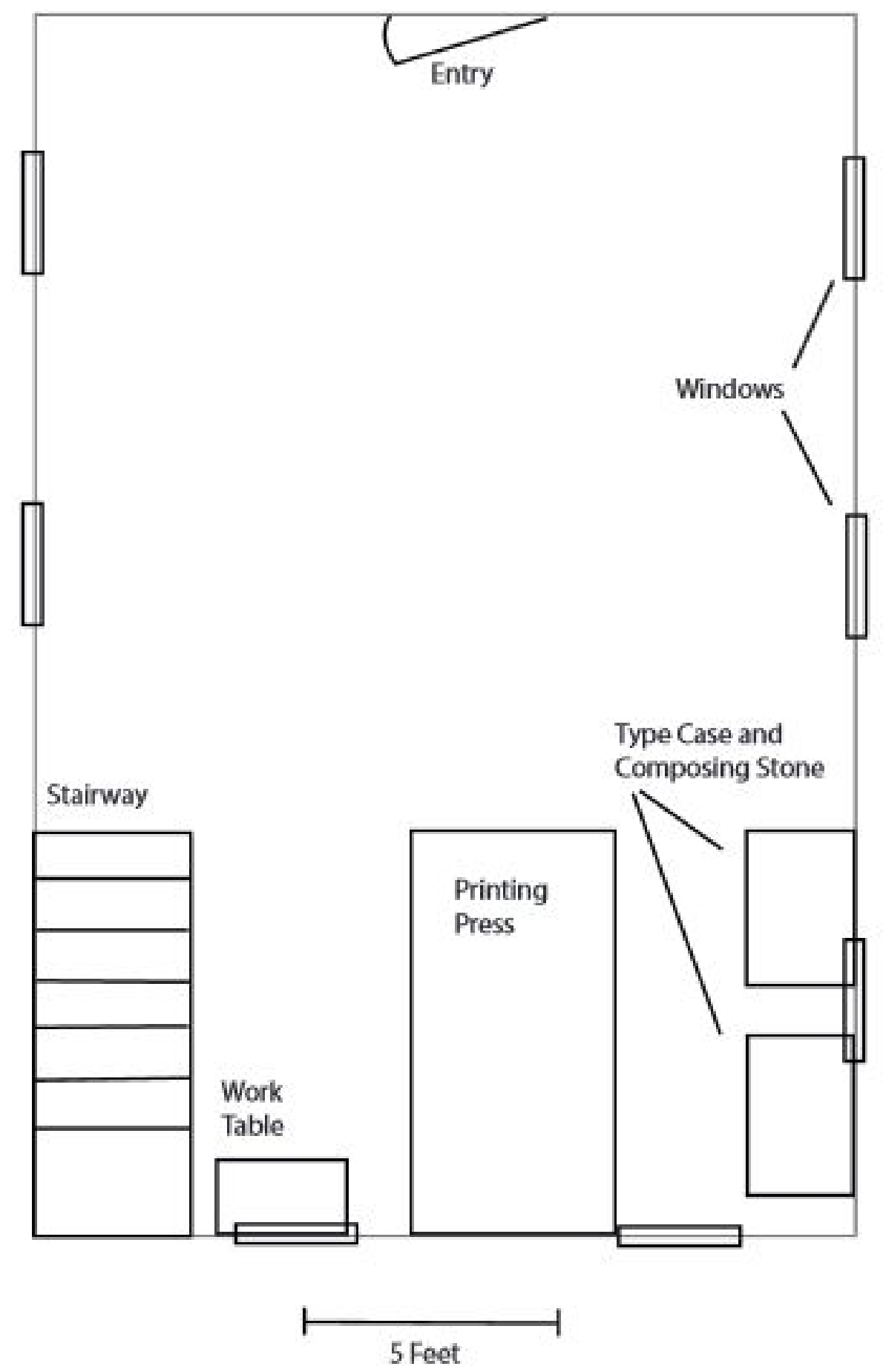

Figure 20. Hypothetical floor plan of Astor House. Equipment dimensions based on measurements of contemporary artifacts. Stairway dimensions based on those found in 1860s era outbuildings in Eagle River and Tapiola, Michigan. Image by Author, 2016. 


\section{Feature 4 - Range Lighthouse Outbuildings}

This feature would be an excellent candidate for interpretation or rebuilding should the park choose to do interpretation on the Range Lighthouse. In particular the wash house/summer kitchen would provide visitors with the opportunity to understand some of the basic chores that were a part of life for the light keepers and their families. While people are widely familiar with privies the idea of a summer kitchen and outdoor laundry may be far more alien to most visitors.

Reconstructing these buildings would be relatively easy due to their small size, simple construction, and the large number of photographs depicting them from multiple angles. Little needs to be done for interpreting a privy. The wash house/summer kitchen would be more interesting with the options of using it to showcase the historic photographs of the property or to outfit the interior as a wash house would have been during the period of use. The latter option would be best if the Range Lighthouse was also being interpreted as historic photographs could be exhibited in the larger structure leaving the wash house to its original purpose.

If reconstruction is not pursued it would be worthwhile to include the historic photographs of the structures on an interpretive sign or in another structure in order to demonstrate that during the $19^{\text {th }}$ and early $20^{\text {th }}$ century a house was rarely a stand-alone structure. Outbuildings performed important roles and are one aspect of the historic landscape that is often absent and forgotten.

While only a single wall of the foundation for each building was uncovered further excavations are most likely not required at this site given the excellent photographic evidence available of both buildings. Whether or not it would be prudent to do reconstructions on the original sites is an open question, given the continued erosion of the banks of Fanny Hooe Creek and these structures' extreme proximity to the Western bank.

\section{Feature 5 - Survey Benchmark}

Given the location of Feature 5 out on the rocky shoreline it is unlikely that anyone would tamper with it. However, it is weathering due to the freeze/thaw cycle and buildup of ice that occurs over the winter. How this damage could be curtailed is not clear. For the sake of conservation it may be prudent to not make visitors aware of the location of this feature as rubbings (as commonly done on gravestones) are damaging in the long term due to abrasion. 


\section{Feature 6 - Boathouse}

Very little remains of Feature 6 aside from the rocky notch in which it sat. Overland, the path to it is severely overgrown. While visible from the East bank of Fanny Hooe Creek it is unlikely that it would be recognized as the site of a former boathouse. Should there be a desire to interpret the feature the brush on top of the rock outcropping would need to be removed to make the feature more visible.

\section{Feature 7 - Retaining Wall}

This feature is in relatively good condition for the time being although plant and tree roots have begun to work in between the stones. This feature is an excellent example of late $19^{\text {th }}$ and early $20^{\text {th }}$ century landscape engineering continuing to perform its job as evident by the extreme erosion on either side of the feature.

While hardly spectacular this feature is interesting due to its age and the readily apparent effect that it has had in controlling the erosion of the creek bank. If visitors will be using the pathway out to the Front Range and Astor House it would be easy to have a small interpretive sign explaining what this feature is and showing the quote from the Lightkeeper's journal referring to its probable construction.

\section{Feature 8 - Bridge Abutment}

This historic bridge abutment is in poor condition. The Southern portion has been undercut by erosion and the masonry is decaying with some falling into Fanny Hooe Creek. The concrete portion is also in poor condition with pieces spalling off in several areas.

In spite of the poor condition, reconstructing a walking bridge over Fanny Hooe Creek would have numerous benefits. By having a means to cross directly from the Lighthouse Overlook Parking Lot it would encourage visitors to explore the Range Lighthouse grounds and provide a means for visitors to get out to Astor Point. Currently it is not clear to most visitors that they are even permitted on the Range Lighthouse grounds. A bridge would serve to connect the Range Lighthouse to the existing interpretation at the Lighthouse Overlook as well as the waterfront trail along Lake Superior. It would also be an ideal spot for photography if the area was brushed out.

\section{Historic Barn}

If the Range Lighthouse and its outbuildings are to be interpreted it would be of value to include the barn in this interpretation. While the historic structure is currently being used 
to house seasonal employees, it was an important aspect of the site housing animals for transportation as well as food.

One option would be to include signage explaining the transformation of the barn into a living space and its migration across the property. The excellent historic photographs available of the structure would make this option straightforward. This would let the structure remain in its current use.

The other option would be to have a barn on the original site. Whether this be the original structure renovated and moved to the original location or a new structure, the presence of the barn would complete the historic scene. Both of these options would be expensive and if the original were rebuilt and moved it would create a lack of housing for employees. 


\section{Bibliography}

American Antiquarian Society Newspaper Project. Worchester, Massachusetts. Lake Superior News and Miners’ Journal.

Archibald, Robert. Northern Border: History and Lore of Michigan's Upper Peninsula and Beyond. Marquette, MI: Northern Michigan University Press, 2014.

"Articles of Association of the Pittsburgh and Boston Copper Harbor Mining Company.” Pittsburgh: George Parkin \& Co., 1846.

Chaput, Donald. The Cliff: America’s First Great Copper Mine. Kalamazoo, MI: Sequoia Press, 1971.

"Charter and By Laws of the Pittsburgh and Boston Mining Company of Pittsburgh." Pittsburgh: George Parkin \& Co., 1848.

Clarke, Don. Pittsburgh and Boston Copper Harbor Mining Company. Bay City, MI: s.n., 1974.

Fadner, Lawrence. Fort Wilkins, 1844, and the U.S. Mineral Land Agency, 1843 Copper Harbor, Michigan, Lake Superior. New York: Vantage Press, 1966.

Forster, John Harris “Early Settlement of the Copper Regions of Lake Superior,” Michigan Pioneer and Historical Society Collections 7 (1886).

Frimodig, Mac. The Fort Wilkins Story. Lansing, MI: Fort Wilkins Natural History Association, 1970.

Gohman, Sean M. "Phase One Archaeological and Historical Survey, Fort Wilkins Historic State Park: South Shore of Lake Fanny Hooe and Lake Manganese Properties, Keweenaw County, Michigan.” Report written for the Department of Natural Resources and Michigan Library and Historical Center. Houghton, MI, 2013.

Iverson, Richard J. The Shotshell in the United States. Jefferson, ME: Circus Publications, 1988.

Ives, William. “General Land Office Survey Notes.” Washington, D.C., 1846. Department of Natural Resources Collection, Record Group 81-74: Field note transcripts of original surveys, 1815-1880. Microfilmed on reels 6528-6615 (series 1). 
James, Barry. Lighting the Way: A History of the Copper Harbor Lighthouse. Copper Harbor: Fort Wilkins Natural History Association, 1999.

Krause, David J. The Making of a Mining District: Keweenaw Native Copper 1500-1870. Great Lakes Books; Variation: Great Lakes Books. Detroit: Wayne State University Press, 1992.

LaVanway, Paul. “A History of Keweenaw County’s Roads and Highways.” The Superior Signal, 2007.

Madson, Michael J. "History and Archaeology of the Pittsburgh and Boston Copper Harbor Mining Company and Blacksmith Shop.” Master’s Thesis, Michigan Technological University, 2002.

Martin, Patrick E., and Susan R. Martin. "Final Report: The 1988 Lac La Belle Archaeological Project”. Field Report, Houghton, MI, 1988.

Martin, Susan R. Wonderful Power: the Story of Ancient Copper Working in the Lake Superior Basin. Detroit: Wayne State University Press, 1999.

Moir, Randall W. "Socioeconomic and Chronometric Patterning of Window Glass in Historic Buildings, Material Culture, and People of the Prairie Margin.” Richland Creek Technical Series, vol. V (1987): 73-81.

Moran, James. Printing Presses: History and Development from the $15^{\text {th }}$ Century to Modern Times. Berkley: University of California Press, 1973.

Shepherd, Forrest. Geological Survey of the Mineral Lands on the Southern Shore of Lake Superior: Belonging to the Pittsburgh and Boston Copper Harbor Mining Company. Pittsburgh: George Parkin \& Co., 1846.

St John, John. A True Description of the Lake Superior Country. New York: W.H. Graham, 1846.

Stone, Lyle M. "Archaeological Investigations at Fort Wilkins State Park, Keweenaw County, Michigan 1977.” Field Report, Tempe, AZ, 1978.

Tardy, Stephen. “Soil Survey of Keweenaw County Area, Michigan.” Natural Resources Conservation Service. Washington, D.C., 2006.

Thayer, George W. "From Vermont to Lake Superior in 1845," Michigan Pioneer and Historical Society Collections 30 (1905). 
Van Lingen, Gary W. "The Interpretation of Archaeological Remains at the Pittsburgh and Boston Copper Harbor Copper Mining Company's Second Campsite: Evaluating a Structural Component and Its Potential Uses and Contexts.” Master's Thesis, Michigan Technological University, 2003.

Williams, Ralph. The Honorable Peter White, a Biographical Sketch of the Lake Superior Iron Country, Cleveland: Penton Pub. Co., 1907.

Woodford, Arthur M. Charting the Inland Seas: A History of the U.S. Lake Survey. Detroit: Wayne State University Press, 1994. 


\section{Photograph Catalog}

\begin{tabular}{|c|c|c|c|c|c|}
\hline Photo Number & Date & Direction Taken & STP & Feature & Description \\
\hline IMG_0008 & $5 / 11 / 2015$ & $S$ & & & 8 Bridge Abutment West \\
\hline IMG_0009 & $5 / 11 / 2015$ & $S$ & & & 8 Bridge Abutment West \\
\hline IMG_0010 & $5 / 11 / 2015$ & $S$ & & & 8 Bridge Abutment West \\
\hline IMG_0011 & $5 / 11 / 2015$ & W & & & 8 Bridge Abutment West \\
\hline IMG_0012 & $5 / 11 / 2015$ & $\mathrm{~N}$ & & & 8 Bridge Abutment West \\
\hline IMG_0013 & $5 / 13 / 2015$ & $E$ & & & 8 Pipe Under Abutment \\
\hline IMG_0014 & $5 / 13 / 2015$ & W & & & 8 Bridge Abutment West \\
\hline IMG_0015 & $5 / 13 / 2015$ & W & & & 8 Bridge Abutment West \\
\hline IMG_0016 & $5 / 13 / 2015$ & W & & & 8 Bridge Abutment West \\
\hline IMG_0017 & $5 / 13 / 2015$ & W & & & 7 Retaining Wall \\
\hline IMG_0018 & $5 / 13 / 2015$ & W & & & 7 Retaining Wall \\
\hline IMG_0019 & $5 / 13 / 2015$ & W & & & 6 Boathouse site \\
\hline IMG_0020 & $5 / 13 / 2015$ & W & & & 6 Boathouse site \\
\hline IMG_0021 & $5 / 13 / 2015$ & W & & & 6 Boathouse site \\
\hline IMG_0022 & $5 / 13 / 2015$ & W & & & 6 Boathouse site \\
\hline IMG_0023 & $5 / 13 / 2015$ & W & & & 6 Boathouse site \\
\hline IMG_0024 & $5 / 13 / 2015$ & W & & & 6 Boathouse site \\
\hline IMG_0025 & $5 / 13 / 2015$ & $\mathrm{~N}$ & & & Astor Point \\
\hline IMG_0026 & $5 / 13 / 2015$ & $\mathrm{~N}$ & & & Astor Point \\
\hline IMG_0027 & $5 / 13 / 2015$ & $N$ & & & Astor Point \\
\hline IMG_0028 & $5 / 13 / 2015$ & $E$ & & & 2 Concrete slab \\
\hline IMG_0029 & $5 / 13 / 2015$ & E & & Single Artifact & Iron Roller \\
\hline IMG_0030 & $5 / 13 / 2015$ & $N$ & & & 5 Survey inscription \\
\hline IMG_0031 & $5 / 13 / 2015$ & $N$ & & & 5 Survey inscription \\
\hline IMG_0032 & $5 / 13 / 2015$ & Down & & & Date on sidewalk slab \\
\hline IMG_0033 & $5 / 14 / 2015$ & Down & STP $16-1 \mathrm{~W}$ & & Lead Flashing in STP \\
\hline IMG_0034 & $5 / 15 / 2015$ & Down & STP $16-1 \mathrm{~W}$ & & Lead Flashing in STP \\
\hline IMG_0035 & $5 / 16 / 2015$ & Down & STP $16-1 \mathrm{~W}$ & & Lead Flashing in STP \\
\hline IMG_0036 & $5 / 18 / 2015$ & $N$ & & Single Artifact & Concrete slab \\
\hline IMG_0037 & $5 / 18 / 2015$ & $\mathrm{~N}$ & & Single Artifact & Concrete slab \\
\hline IMG_0038 & $5 / 18 / 2015$ & $\mathrm{~N}$ & & Single Artifact & Concrete slab \\
\hline IMG_0039 & $5 / 18 / 2015$ & $N$ & & Single Artifact & Concrete slab \\
\hline IMG_0040 & $5 / 19 / 2015$ & $\mathrm{~N}$ & & Single Artifact & Concrete slab \\
\hline IMG_0054 & $5 / 19 / 2015$ & $\mathrm{~S}$ & & & 4 Opening Trench 1 \\
\hline IMG_0055 & $5 / 19 / 2015$ & $S$ & & & 4 Opening Trench 2 \\
\hline IMG_0056 & $5 / 19 / 2015$ & $S$ & & & 4 Opening Trench 3 \\
\hline IMG_0057 & $5 / 20 / 2015$ & $S$ & & & 4 Level 1 Trench 1 \\
\hline IMG_0058 & $5 / 20 / 2015$ & $S$ & & & 4 Level 1 Trench 2 \\
\hline IMG_0059 & $5 / 20 / 2015$ & $N$ & & & 3 Opening Trench 2 \\
\hline IMG_0060 & $5 / 20 / 2015$ & $\mathrm{~N}$ & & & 3 Opening Trench 2 \\
\hline IMG_0061 & $5 / 20 / 2015$ & $\mathrm{~N}$ & & & 3 Level 1 Trench 2 \\
\hline IMG_0062 & $5 / 20 / 2015$ & $N$ & & & 3 Level 1 Trench 2 \\
\hline IMG_0063 & $5 / 20 / 2015$ & $N$ & & & 3 Level 2 Trench 2 \\
\hline IMG_0064 & $5 / 20 / 2015$ & $\mathrm{~N}$ & & & 3 Level 2 Trench 2 \\
\hline IMG_0065 & $5 / 20 / 2015$ & $E$ & & & 3 Detail Level 2 Trench 2 \\
\hline IMG_0066 & $5 / 20 / 2015$ & $N$ & & & 3 Level 3 Trench 2 \\
\hline IMG_0067 & $5 / 20 / 2015$ & $N$ & & & 3 Level 3 Trench 3 \\
\hline IMG_0068 & $5 / 20 / 2015$ & $N$ & & & 3 Level 3 Trench 4 \\
\hline IMG_0069 & $5 / 20 / 2015$ & $S$ & & & 4 Level 2 Trench 1 \\
\hline IMG_0070 & $5 / 20 / 2015$ & $S$ & & & 4 Level 2 Trench 1 \\
\hline IMG_0071 & $5 / 20 / 2015$ & $S$ & & & 4 Level 2 Trench 1 \\
\hline IMG_0072 & $5 / 20 / 2015$ & $S$ & & & 4 Level 2 Trench 1 \\
\hline IMG_0073 & $5 / 20 / 2015$ & $S$ & & & 4 Level 2 Trench 1 \\
\hline
\end{tabular}




\begin{tabular}{|c|c|c|}
\hline IMG_0074 & $5 / 20 / 2015 \mathrm{~S}$ & 4 Level 2 Trench 1 \\
\hline IMG_0075 & $5 / 20 / 2015 \mathrm{~S}$ & 4 Level 2 Trench 1 \\
\hline IMG_0076 & $5 / 21 / 2015 E$ & 4 Opening Trench 3 \\
\hline IMG_0077 & $5 / 21 / 2015 E$ & 4 Opening Trench 3 \\
\hline IMG_0078 & $5 / 21 / 2015 E$ & 4 Level 1, Trench 3 \\
\hline IMG_0079 & $5 / 21 / 2015 E$ & 4 Level 1, Trench 3 \\
\hline IMG_0080 & $5 / 21 / 2015 E$ & 4 Level 1, Trench 3 \\
\hline IMG_0081 & $5 / 21 / 2015 \mathrm{E}$ & 4 Level 1, Trench 3 \\
\hline IMG_0082 & $5 / 21 / 2015 \mathrm{~N}$ & 3 Closing Trench 2 \\
\hline IMG_0083 & $5 / 21 / 2015 \mathrm{~N}$ & 3 Closing Trench 2 \\
\hline IMG_0084 & $5 / 21 / 2015 \mathrm{~N}$ & 3 Opening Trench 4 \\
\hline IMG_0085 & $5 / 21 / 2015 \mathrm{~N}$ & 3 Opening Trench 4 \\
\hline IMG_0086 & $5 / 21 / 2015 E$ & 4 Level 2, Trench 3 \\
\hline IMG_0087 & $5 / 21 / 2015 E$ & 4 Level 2, Trench 3 \\
\hline IMG_0088 & $5 / 21 / 2015 \mathrm{~N}$ & 3 Level 1, Trench 4 \\
\hline IMG_0089 & $5 / 21 / 2015 \mathrm{~N}$ & 3 Level 1, Trench 4 \\
\hline IMG_0090 & $5 / 21 / 2015 \mathrm{~N}$ & 3 Level 2, Trench 4 \\
\hline IMG_0091 & $5 / 21 / 2015 \mathrm{~N}$ & 3 Level 2, Trench 4 \\
\hline IMG_0092 & $5 / 21 / 2015 E$ & 4 Level 3, Trench 3 \\
\hline IMG_0093 & $5 / 21 / 2015 \mathrm{E}$ & 4 Level 3, Trench 3 \\
\hline IMG_0094 & $5 / 21 / 2015 \mathrm{~N}$ & 3 Level 3, Trench 4 \\
\hline IMG_0095 & $5 / 21 / 2015 \mathrm{~N}$ & 3 Level 3, Trench 4 \\
\hline IMG_0096 & $5 / 21 / 2015 \mathrm{E}$ & 4 Level 4, Trench 3 \\
\hline IMG_0097 & $5 / 21 / 2015 \mathrm{E}$ & 4 Level 4, Trench 3 \\
\hline IMG_0098 & $5 / 21 / 2015 E$ & 4 Level 4, Trench 3 \\
\hline IMG_3115 & $5 / 21 / 2015 E$ & 4 Workers \\
\hline IMG_3116 & $5 / 26 / 2015 \mathrm{~N}$ & 3 Opening, Trench 6 \\
\hline IMG_3117 & $5 / 26 / 2015 \mathrm{~N}$ & 3 Opening, Trench 6 \\
\hline IMG_3118 & $5 / 26 / 2015 \mathrm{~N}$ & 3 Level 1, Trench 6 \\
\hline IMG_3119 & $5 / 26 / 2015 \mathrm{~N}$ & 3 Level 1, Trench 6 \\
\hline IMG_3120 & $5 / 26 / 2015 \mathrm{~N}$ & 3 Level 1, Trench 6 \\
\hline IMG_3125 & $5 / 26 / 2015 \mathrm{~N}$ & 3 Level 2, Trench 6 \\
\hline IMG_3126 & $5 / 27 / 2015 \mathrm{~N}$ & 4 Opening, Trench 5 \\
\hline IMG_3127 & $5 / 27 / 2015 \mathrm{~N}$ & 4 Opening, Trench 5 \\
\hline IMG_3128 & $5 / 27 / 2015 \mathrm{~N}$ & 4 Level 1, Trench 5 \\
\hline IMG_3129 & $5 / 27 / 2015 \mathrm{~N}$ & 4 Level 1, Trench 5 \\
\hline IMG_3130 & $5 / 27 / 2015 \mathrm{~N}$ & 4 Level 2, Trench 5 \\
\hline IMG_3131 & $5 / 27 / 2015 \mathrm{~N}$ & 4 Level 2, Trench 5 \\
\hline IMG_3132 & $5 / 27 / 2015 \mathrm{~N}$ & 4 Level 3, Trench 5 \\
\hline IMG_3133 & $5 / 27 / 2015 N$ & 4 Level 3, Trench 5 \\
\hline IMG_3134 & $5 / 27 / 2015 \mathrm{~N}$ & 4 Level 4, Trench 5 \\
\hline IMG_3135 & $5 / 27 / 2015 \mathrm{~N}$ & 4 Level 4 , Trench 5 \\
\hline IMG_3149 & $6 / 2 / 2015 S$ & 3 Overview of Units $2,4,6$ \\
\hline IMG_3150 & $6 / 2 / 2015 \mathrm{~S}$ & 3 Overview of Units $2,4,6$ \\
\hline IMG_3151 & $6 / 2 / 2015 \mathrm{~S}$ & 3 Overview of Units $2,4,6$ \\
\hline IMG_3152 & $6 / 2 / 2015 \mathrm{~S}$ & 3 Overview of Units $2,4,6$ \\
\hline IMG_3153 & $6 / 2 / 2015 \mathrm{~S}$ & Front and Rear Range Lights \\
\hline IMG_3154 & $6 / 2 / 2015 \mathrm{NE}$ & Copper Harbor Lighthouse form Astor Point \\
\hline IMG_3155 & $6 / 2 / 2015 \mathrm{NE}$ & Copper Harbor Lighthouse form Astor Point \\
\hline IMG_3156 & $6 / 2 / 2015 \mathrm{E}$ & 3 Astor Point from Trench 4 \\
\hline IMG_3157 & $6 / 2 / 2015 \mathrm{~W}$ & 3 Trenches from Astor Point \\
\hline IMG_3158 & $6 / 2 / 2015 W$ & 3 Overview of Units $2,4,6$ \\
\hline IMG_3159 & $6 / 2 / 2015 \mathrm{E}$ & 4 Range Light House \\
\hline IMG_3160 & $6 / 2 / 2015 \mathrm{E}$ & 4 Range Light House \\
\hline
\end{tabular}




\begin{tabular}{|c|c|c|}
\hline IMG_3161 & $6 / 2 / 2015 \mathrm{E}$ & 4 Overview of Trenches \\
\hline IMG_3162 & $6 / 2 / 2015 \mathrm{E}$ & 4 Overview of Trenches \\
\hline IMG_3163 & $6 / 2 / 2015 \mathrm{E}$ & 4 Recreation of historic privy photo \\
\hline IMG_3164 & $6 / 2 / 2015 \mathrm{~S}$ & Range Light House \\
\hline IMG_3165 & $6 / 2 / 2015 N$ & Front Range Light \\
\hline IMG_3166 & $6 / 2 / 2015 N$ & Front Range Light \\
\hline IMG_3167 & $6 / 2 / 2015 N$ & Front Range Light \\
\hline IMG_3168 & $6 / 2 / 2015 \mathrm{~S}$ & Rear Range Light \\
\hline IMG_3169 & $6 / 2 / 2015 N$ & Modern Tower \\
\hline IMG_3170 & $6 / 2 / 2015 N$ & Rear Range Light and Barn \\
\hline IMG_3171 & $6 / 2 / 2015 N$ & Rear Range Light and Barn \\
\hline IMG_3172 & $6 / 2 / 2015 \mathrm{~S}$ & Rear Range Light \\
\hline IMG_3173 & $6 / 2 / 2015 \mathrm{~S}$ & Rear Range Light \\
\hline IMG_3174 & $6 / 2 / 2015 \mathrm{~S}$ & Rear Range Light \\
\hline IMG_3175 & $6 / 2 / 2015 \mathrm{E}$ & 4 Overview of units 1,3 \\
\hline IMG_3176 & $6 / 2 / 2015 \mathrm{E}$ & 4 Overview of units 1,4 \\
\hline IMG_3177 & $6 / 2 / 2015 \mathrm{E}$ & 4 Overview of units 1,5 \\
\hline IMG_3178 & $6 / 2 / 2015 N$ & Fanny Hooe Creek \\
\hline IMG_3179 & $6 / 2 / 2015 \mathrm{~W}$ & 4 Water line to house embedded in bank. \\
\hline IMG_3180 & $6 / 2 / 2015 \mathrm{~N}$ & Astor Point \\
\hline IMG_3181 & $6 / 2 / 2015 N$ & Astor Point \\
\hline IMG_3182 & $6 / 2 / 2015 \mathrm{~W}$ & 6 Boathouse site \\
\hline IMG_3183 & $6 / 2 / 2015 \mathrm{~W}$ & 8 Bridge Abutment West \\
\hline IMG_3184 & $6 / 2 / 2015 \mathrm{E}$ & 8 Bridge Abutment East \\
\hline IMG_3185 & $6 / 2 / 2015 E$ & 8 Bridge Abutment East \\
\hline IMG_3186 & $6 / 2 / 2015 N$ & Fanny Hooe Creek \\
\hline IMG_3187 & $6 / 2 / 2015 \mathrm{~S}$ & 8 Bridge Abutment West \\
\hline IMG_3188 & $6 / 3 / 2015 N$ & 4 Level 5 , Trench 5 \\
\hline IMG_3189 & $6 / 3 / 2015 N$ & 4 Level 5, Trench 5 \\
\hline IMG_3190 & $6 / 3 / 2015 N$ & 4 Level 5, Trench 5 \\
\hline IMG_3191 & $6 / 3 / 2015 N$ & 4 Opening, Trench 7 \\
\hline IMG_3192 & $6 / 3 / 2015 N$ & 4 Opening, Trench 7 \\
\hline IMG_3193 & $6 / 4 / 2015 N$ & 4 Level 1, Trench 7 \\
\hline IMG_3194 & $6 / 4 / 2015 N$ & 4 Level 1, Trench 7 \\
\hline IMG_3195 & $6 / 4 / 2015 N$ & 4 Level 1, Trench 7 \\
\hline IMG_3196 & $6 / 4 / 2015 N$ & 4 Level 1, Trench 7 \\
\hline IMG_3197 & $6 / 5 / 2015 \mathrm{~N}$ & 4 Level 1, Trench 7 \\
\hline IMG_3198 & $6 / 5 / 2015 \mathrm{~N}$ & 4 Level 2, Trench 7 \\
\hline IMG_3199 & $6 / 5 / 2015 \mathrm{~N}$ & 4 Level 2, Trench 7 \\
\hline IMG_3200 & $6 / 5 / 2015 \mathrm{~N}$ & 4 Opening, Trench 9 \\
\hline IMG_3201 & $6 / 5 / 2015 \mathrm{~N}$ & 4 Opening, Trench 9 \\
\hline IMG_3202 & $6 / 5 / 2015 \mathrm{~N}$ & 4 Opening, Trench 9 \\
\hline IMG_3203 & $6 / 5 / 2015 \mathrm{~N}$ & 4 Level 1, Trench 9 \\
\hline IMG_3204 & $6 / 5 / 2015 N$ & 4 Level 1 , Trench 9 \\
\hline IMG_3205 & $6 / 5 / 2015 N$ & 4 Level 1 , Trench 9 \\
\hline IMG_3206 & $6 / 5 / 2015 \mathrm{~N}$ & 4 Level 1, Trench 9 \\
\hline IMG_3207 & $6 / 5 / 2015 \mathrm{~N}$ & 4 Level 1 , Trench 9 \\
\hline IMG_3208 & $6 / 5 / 2015 \mathrm{~N}$ & 4 Overview, Trenches 5,7,9 \\
\hline IMG_3209 & $6 / 5 / 2015 \mathrm{~S}$ & 4 Overview, Trenches 5,7,9 \\
\hline IMG_3210 & $6 / 5 / 2015 E$ & 4 Trenches 5,9 \\
\hline IMG_3211 & $6 / 5 / 2015 \mathrm{~N}$ & 4 Level 2, Trench 9 \\
\hline IMG_3212 & $6 / 5 / 2015 \mathrm{~N}$ & 4 Level 2, Trench 9 \\
\hline IMG_3213 & $6 / 5 / 2015 \mathrm{~N}$ & 4 Level 2, Trench 9 \\
\hline IMG_3214 & $6 / 5 / 2015 \mathrm{~N}$ & 4 Level 3, Trench 9 \\
\hline IMG_3215 & $6 / 5 / 2015 N$ & 4 Level 3, Trench 9 \\
\hline IMG_3216 & $6 / 5 / 2015 N$ & 4 Level 3, Trench 9 Detail of Alignment \\
\hline
\end{tabular}




\section{Artifact Catalog}

\begin{tabular}{|c|c|c|c|c|c|c|c|}
\hline Year & \begin{tabular}{|l|} 
Catalog \\
Number \\
\end{tabular} & Feature & Unit/TP Number & Level & Group & Sub-Group & Details \\
\hline 2015 & 1 & 3 & Trench 2 & 1 & Kitchen & Beer & "Falstaff" Screw top \\
\hline 2015 & 1 & 3 & Trench 2 & 1 & Kitchen & Beer & "Not to be refilled" Pop off top \\
\hline 2015 & 2 & 3 & Trench 2 & 1 & Architecture & Square Nails & \\
\hline 2015 & 2 & 3 & Trench 2 & 1 & Architecture & Square Nails & \\
\hline 2015 & 2 & 3 & Trench 2 & 1 & Architecture & Square Nails & \\
\hline 2015 & 2 & 3 & Trench 2 & 1 & Architecture & Mortar & \\
\hline 2015 & 2 & 3 & Trench 2 & 1 & Architecture & Mortar & \\
\hline 2015 & 2 & 3 & Trench 2 & 1 & Kitchen & Beer & Fragment \\
\hline 2015 & 3 & 3 & Trench 2 & 1 & Architecture & Window Glass & Fragment \\
\hline 2015 & 4 & 3 & Trench 2 & 1 & Kitchen & Wine/Liquor & Neck and mouth \\
\hline 2015 & 4 & 3 & Trench 2 & 1 & Architecture & Window Glass & Fragment \\
\hline 2015 & 4 & 3 & Trench 2 & 1 & Architecture & Window Glass & Fragment \\
\hline 2015 & 4 & 3 & Trench 2 & 1 & Activity & Iron Scrap & Fragment \\
\hline 2015 & 4 & 3 & Trench 2 & 1 & Activity & Iron Scrap & Fragment \\
\hline 2015 & 4 & 3 & Trench 2 & 1 & Activity & Iron Scrap & Fragment \\
\hline 2015 & 5 & 3 & Trench 2 & 1 & Architecture & Window Glass & Fragment, found along N. Wall \\
\hline 2015 & 5 & 3 & Trench 2 & 1 & Architecture & Window Glass & Fragment, found along N. Wall \\
\hline 2015 & 5 & 3 & Trench 2 & 1 & Architecture & Window Glass & Fragment, found along N. Wall \\
\hline 2015 & 5 & 3 & Trench 2 & 1 & Architecture & Window Glass & Fragment, found along N. Wall \\
\hline 2015 & 5 & 3 & Trench 2 & 1 & Architecture & Window Glass & Fragment, found along N. Wall \\
\hline 2015 & 5 & 3 & Trench 2 & 1 & Architecture & Window Glass & Fragment, found along N. Wall \\
\hline 2015 & 5 & 3 & Trench 2 & 1 & Architecture & Window Glass & Fragment, found along N. Wall \\
\hline 2015 & 5 & 3 & Trench 2 & 1 & Architecture & Window Glass & Fragment, found along N. Wall \\
\hline 2015 & 6 & 3 & Trench 2 & 1 & Architecture & Window Glass & Fragment \\
\hline 2015 & 6 & 3 & Trench 2 & 1 & Architecture & Window Glass & Fragment \\
\hline 2015 & 6 & 3 & Trench 2 & 1 & Architecture & Window Glass & Fragment \\
\hline 2015 & 6 & 3 & Trench 2 & 1 & Architecture & Window Glass & Fragment \\
\hline 2015 & 6 & 3 & Trench 2 & 1 & Architecture & Window Glass & Fragment \\
\hline 2015 & 6 & 3 & Trench 2 & 1 & Architecture & Window Glass & Fragment \\
\hline 2015 & 6 & 3 & Trench 2 & 1 & Architecture & Window Glass & Fragment \\
\hline 2015 & 6 & 3 & Trench 2 & 1 & Architecture & Window Glass & Fragment \\
\hline 2015 & 6 & 3 & Trench 2 & 1 & Architecture & Window Glass & Fragment \\
\hline 2015 & 6 & 3 & Trench 2 & 1 & Architecture & Window Glass & Fragment \\
\hline 2015 & 6 & 3 & Trench 2 & 1 & Architecture & Window Glass & Fragment \\
\hline 2015 & 6 & 3 & Trench 2 & 1 & Architecture & Window Glass & Fragment \\
\hline 2015 & 6 & 3 & Trench 2 & 1 & Architecture & Square Nails & \\
\hline 2015 & 6 & 3 & Trench 2 & 1 & Architecture & Square Nails & \\
\hline 2015 & 6 & 3 & Trench 2 & 1 & Architecture & Square Nails & \\
\hline 2015 & 6 & 3 & Trench 2 & 1 & Architecture & Square Nails & \\
\hline 2015 & 6 & 3 & Trench 2 & 1 & Architecture & Square Nails & \\
\hline 2015 & 6 & 3 & Trench 2 & 1 & Architecture & Square Nails & \\
\hline 2015 & 6 & 3 & Trench 2 & 1 & Architecture & Square Nails & \\
\hline 2015 & 6 & 3 & Trench 2 & 1 & Architecture & Square Nails & \\
\hline 2015 & 6 & 3 & Trench 2 & 1 & Architecture & Square Nails & \\
\hline 2015 & 6 & 3 & Trench 2 & 1 & Architecture & Square Nails & \\
\hline 2015 & 6 & 3 & Trench 2 & 1 & Architecture & Square Nails & \\
\hline 2015 & 7 & 3 & Trench 2 & 2 & Kitchen & Glassware & Very thin glass \\
\hline 2015 & 7 & 3 & Trench 2 & 2 & Kitchen & Glassware & Very thin glass \\
\hline 2015 & 7 & 3 & Trench 2 & 2 & Kitchen & Glassware & Very thin glass \\
\hline 2015 & 7 & 3 & Trench 2 & 2 & Kitchen & Glassware & Very thin glass \\
\hline 2015 & 7 & 3 & Trench 2 & 2 & Architecture & Window Glass & Fragment \\
\hline 2015 & 7 & 3 & Trench 2 & 2 & Architecture & Window Glass & Fragment \\
\hline 2015 & 7 & 3 & Trench 2 & 2 & Architecture & Window Glass & Fragment \\
\hline 2015 & 7 & 3 & Trench 2 & 2 & Architecture & Window Glass & Fragment \\
\hline 2015 & 7 & 3 & Trench 2 & 2 & Architecture & Window Glass & Fragment \\
\hline 2015 & 7 & 3 & Trench 2 & 2 & Architecture & Window Glass & Fragment \\
\hline 2015 & 7 & 3 & Trench 2 & 2 & Architecture & Window Glass & Fragment \\
\hline 2015 & 7 & 3 & Trench 2 & 2 & Architecture & Window Glass & Fragment \\
\hline 2015 & 7 & 3 & Trench 2 & 2 & Architecture & Window Glass & Fragment \\
\hline
\end{tabular}




\begin{tabular}{|c|c|c|c|c|c|c|c|}
\hline 2015 & 7 & 3 & Trench 2 & 2 & Architecture & Window Glass & Fragment \\
\hline 2015 & 7 & 3 & Trench 2 & 2 & Architecture & Window Glass & \begin{tabular}{|l|} 
Fragment \\
\end{tabular} \\
\hline 2015 & 7 & 3 & Trench 2 & 2 & Architecture & Window Glass & Fragment \\
\hline 2015 & 7 & 3 & Trench 2 & 2 & Architecture & Window Glass & Fragment \\
\hline 2015 & 7 & 3 & Trench 2 & 2 & Architecture & Window Glass & Fragment \\
\hline 2015 & 7 & 3 & Trench 2 & 2 & Architecture & Window Glass & \begin{tabular}{|l|} 
Fragment \\
\end{tabular} \\
\hline 2015 & 7 & 3 & Trench 2 & 2 & Architecture & Window Glass & Fragment \\
\hline 2015 & 7 & 3 & Trench 2 & 2 & Architecture & Square Nails & \\
\hline 2015 & 7 & 3 & Trench 2 & 2 & Architecture & Square Nails & \\
\hline 2015 & 7 & 3 & Trench 2 & 2 & Architecture & Square Nails & \\
\hline 2015 & 7 & 3 & Trench 2 & 2 & Architecture & Square Nails & \\
\hline 2015 & 7 & 3 & Trench 2 & 2 & Architecture & Square Nails & \\
\hline 2015 & 7 & 3 & Trench 2 & 2 & Architecture & Square Nails & \\
\hline 2015 & 7 & 3 & Trench 2 & 2 & Architecture & Square Nails & \\
\hline 2015 & 7 & 3 & Trench 2 & 2 & Architecture & Square Nails & \\
\hline 2015 & 7 & 3 & Trench 2 & 2 & Architecture & Square Nails & \\
\hline 2015 & 7 & 3 & Trench 2 & 2 & Architecture & Square Nails & \\
\hline 2015 & 7 & 3 & Trench 2 & 2 & Architecture & Square Nails & \\
\hline 2015 & 7 & 3 & Trench 2 & 2 & Architecture & Square Nails & \\
\hline 2015 & 7 & 3 & Trench 2 & 2 & Tobacco & Bowl & Fragment \\
\hline 2015 & 7 & 3 & Trench 2 & 2 & Tobacco & Bowl & Fragment \\
\hline 2015 & 7 & 3 & Trench 2 & 2 & Tobacco & Bowl & Fragment \\
\hline 2015 & 7 & 3 & Trench 2 & 2 & \begin{tabular}{|l} 
Tobacco \\
\end{tabular} & Bowl & \begin{tabular}{|l|} 
Fragment \\
\end{tabular} \\
\hline 2015 & 7 & 3 & Trench 2 & 2 & Tobacco & Bowl & Fragment \\
\hline 2015 & 8 & 3 & Trench 2 & 2 & Tobacco & Bowl & Fragment \\
\hline 2015 & 8 & 3 & Trench 2 & 2 & Tobacco & Stem & Fragment \\
\hline 2015 & 8 & 3 & Trench 2 & 2 & Tobacco & Stem & Fragment \\
\hline 2015 & 8 & 3 & Trench 2 & 2 & \begin{tabular}{|l} 
Tobacco \\
\end{tabular} & Stem & \begin{tabular}{|l|} 
Fragment \\
\end{tabular} \\
\hline 2015 & 8 & 3 & Trench 2 & 2 & Tobacco & Stem & \begin{tabular}{|l|} 
Fragment \\
\end{tabular} \\
\hline 2015 & 8 & 3 & \begin{tabular}{|l|} 
Trench 2 \\
\end{tabular} & 2 & \begin{tabular}{|l|} 
Tobacco \\
\end{tabular} & Stem & Fragment \\
\hline 2015 & 8 & 3 & Trench 2 & 2 & Tobacco & Stem & Fragment \\
\hline 2015 & 8 & 3 & Trench 2 & 2 & Tobacco & Stem & Fragment \\
\hline 2015 & 8 & 3 & Trench 2 & 2 & Tobacco & Stem & Fragment \\
\hline 2015 & 8 & 3 & Trench 2 & 2 & Tobacco & Stem & \begin{tabular}{|l|} 
Fragment \\
\end{tabular} \\
\hline 2015 & 8 & 3 & Trench 2 & 2 & Tobacco & Stem & Fragment \\
\hline 2015 & 8 & 3 & Trench 2 & 2 & Tobacco & Stem & Fragment \\
\hline 2015 & 8 & 3 & Trench 2 & 2 & Tobacco & Stem & Fragment \\
\hline 2015 & 8 & 3 & Trench 2 & 2 & Tobacco & Window Glass & \begin{tabular}{|l|} 
Fragment \\
\end{tabular} \\
\hline 2015 & 8 & 3 & Trench 2 & 2 & Architecture & Window Glass & \begin{tabular}{|l|} 
Fragment \\
\end{tabular} \\
\hline 2015 & 8 & 3 & Trench 2 & 2 & Architecture & Window Glass & Fragment \\
\hline 2015 & 8 & 3 & Trench 2 & 2 & Architecture & Window Glass & \begin{tabular}{|l|} 
Fragment \\
\end{tabular} \\
\hline 2015 & 8 & 3 & \begin{tabular}{|l} 
Trench 2 \\
\end{tabular} & 2 & Architecture & Window Glass & Fragment \\
\hline 2015 & 8 & 3 & Trench 2 & 2 & Architecture & Window Glass & Fragment \\
\hline 2015 & 8 & 3 & Trench 2 & 2 & Architecture & Window Glass & \begin{tabular}{|l|} 
Fragment \\
\end{tabular} \\
\hline 2015 & 8 & 3 & Trench 2 & 2 & Architecture & Window Glass & \begin{tabular}{|l|} 
Fragment \\
\end{tabular} \\
\hline 2015 & 8 & 3 & Trench 2 & 2 & Architecture & Square Nails & \\
\hline 2015 & 8 & 3 & Trench 2 & 2 & Architecture & Square Nails & \\
\hline 2015 & 8 & 3 & Trench 2 & 2 & Architecture & Square Nails & \\
\hline 2015 & 8 & 3 & Trench 2 & 2 & Architecture & Square Nails & \\
\hline 2015 & 8 & 3 & Trench 2 & 2 & Architecture & Square Nails & \\
\hline 2015 & 8 & 3 & Trench 2 & 2 & Architecture & Square Nails & \\
\hline 2015 & 8 & 3 & Trench 2 & 2 & Architecture & Square Nails & \\
\hline 2015 & 8 & 3 & Trench 2 & 2 & Architecture & Square Nails & \\
\hline 2015 & 8 & 3 & Trench 2 & 2 & Architecture & Square Nails & \\
\hline 2015 & 8 & 3 & Trench 2 & 2 & Architecture & Square Nails & \\
\hline 2015 & 8 & 3 & Trench 2 & 2 & Architecture & Square Nails & \\
\hline 2015 & 8 & 3 & Trench 2 & 2 & Architecture & Square Nails & \\
\hline 2015 & 8 & 3 & Trench 2 & 2 & Architecture & Square Nails & \\
\hline 2015 & 8 & 3 & Trench 2 & 2 & Architecture & Square Nails & \\
\hline 2015 & 8 & 3 & Trench 2 & 2 & Architecture & Square Nails & \\
\hline
\end{tabular}




\begin{tabular}{|c|c|c|c|c|c|c|c|}
\hline 2015 & 8 & 3 & Trench 2 & 2 & Architecture & Square Nails & \\
\hline 2015 & 8 & 3 & Trench 2 & 2 & Architecture & Square Nails & \\
\hline 2015 & 8 & 3 & Trench 2 & 2 & Architecture & Square Nails & \\
\hline 2015 & 8 & 3 & Trench 2 & 2 & Architecture & Square Nails & \\
\hline 2015 & 8 & 3 & Trench 2 & 2 & Architecture & Square Nails & \\
\hline 2015 & 8 & 3 & Trench 2 & 2 & Architecture & Square Nails & \\
\hline 2015 & 8 & 3 & Trench 2 & 2 & Architecture & Square Nails & \\
\hline 2015 & 8 & 3 & Trench 2 & 2 & Architecture & Square Nails & \\
\hline 2015 & 8 & 3 & Trench 2 & 2 & Architecture & Square Nails & \\
\hline 2015 & 8 & 3 & Trench 2 & 2 & Architecture & Square Nails & \\
\hline 2015 & 8 & 3 & Trench 2 & 2 & Architecture & Square Nails & \\
\hline 2015 & 8 & 3 & Trench 2 & 2 & Architecture & Square Nails & \\
\hline 2015 & 8 & 3 & Trench 2 & 2 & Architecture & Square Nails & \\
\hline 2015 & 8 & 3 & Trench 2 & 2 & Architecture & Square Nails & \\
\hline 2015 & 8 & 3 & Trench 2 & 2 & Architecture & Mortar & ? \\
\hline 2015 & 8 & 3 & Trench 4 & 1 & Architecture & Mortar & $?$ \\
\hline 2015 & 9 & 3 & Trench 4 & 1 & Architecture & Window Glass & Fragment \\
\hline 2015 & 9 & 3 & Trench 4 & 1 & Architecture & Window Glass & Fragment \\
\hline 2015 & 9 & 3 & Trench 4 & 1 & Architecture & Window Glass & Fragment \\
\hline 2015 & 9 & 3 & Trench 4 & 1 & Architecture & Window Glass & Fragment \\
\hline 2015 & 9 & 3 & Trench 4 & 1 & Architecture & Window Glass & Fragment \\
\hline 2015 & 9 & 3 & Trench 4 & 1 & Architecture & Window Glass & Fragment \\
\hline 2015 & 9 & 3 & Trench 4 & 1 & Architecture & Window Glass & Fragment \\
\hline 2015 & 9 & 3 & Trench 4 & 1 & Architecture & Window Glass & Fragment \\
\hline 2015 & 10 & 3 & Trench 4 & 2 & Architecture & Window Glass & Fragment \\
\hline 2015 & 10 & 3 & Trench 4 & 2 & Architecture & Square Nails & \\
\hline 2015 & 10 & 3 & Trench 4 & 2 & Architecture & Square Nails & \\
\hline 2015 & 10 & 3 & Trench 4 & 2 & Architecture & Square Nails & \\
\hline 2015 & 10 & 3 & Trench 4 & 2 & Architecture & Square Nails & \\
\hline 2015 & 10 & 3 & Trench 4 & 2 & Architecture & Mortar & \\
\hline 2015 & 10 & 3 & Trench 4 & 2 & Tobacco & Stems & Full \\
\hline 2015 & 11 & 3 & Trench 4 & 1 & \begin{tabular}{|l|} 
Tobacco \\
\end{tabular} & Stems & Fragment \\
\hline 2015 & 11 & 3 & Trench 4 & 1 & Tobacco & Stems & Fragment \\
\hline 2015 & 11 & 3 & Trench 4 & 1 & Kitchen & Glassware & Small fragment \\
\hline 2015 & 11 & 3 & Trench 4 & 1 & Kitchen & Glassware & Small fragment \\
\hline 2015 & 11 & 3 & Trench 4 & 1 & Kitchen & Glassware & Small fragment \\
\hline 2015 & 11 & 3 & Trench 4 & 1 & Kitchen & Glassware & Small fragment \\
\hline 2015 & 11 & 3 & Trench 4 & 1 & Kitchen & Glassware & Small fragment \\
\hline 2015 & 11 & 3 & Trench 4 & 1 & Kitchen & Glassware & Small fragment \\
\hline 2015 & 11 & 3 & Trench 4 & 1 & Kitchen & Glass ware & Small fragment \\
\hline 2015 & 11 & 3 & Trench 4 & 1 & Kitchen & Glass ware & Small fragment \\
\hline 2015 & 11 & 3 & Trench 4 & 1 & Kitchen & Glass ware & Small fragment \\
\hline 2015 & 11 & 3 & Trench 4 & 1 & Kitchen & Glassware & Small fragment \\
\hline 2015 & 11 & 3 & Trench 4 & 1 & Kitchen & Utensil & Two tine fork \\
\hline 2015 & 11 & 3 & Trench 4 & 1 & Kitchen & & Fragment \\
\hline 2015 & 11 & 3 & Trench 4 & 1 & Kitchen & Ceramic & Fragment \\
\hline 2015 & 11 & 3 & Trench 4 & 1 & Kitchen & Ceramic & Fragment \\
\hline 2015 & 11 & 3 & Trench 4 & 1 & Kitchen & Ceramic & Fragment \\
\hline 2015 & 11 & 3 & Trench 4 & 1 & Kitchen & Ceramic & Fragment \\
\hline 2015 & 11 & 3 & Trench 4 & 1 & Kitchen & Ceramic & Fragment \\
\hline 2015 & 11 & 3 & Trench 4 & 1 & Kitchen & Ceramic & Fragment \\
\hline 2015 & 11 & 3 & Trench 4 & 1 & Kitchen & Ceramic & Fragment \\
\hline 2015 & 11 & 3 & Trench 4 & 1 & Kitchen & Ceramic & Fragment \\
\hline 2015 & 11 & 3 & Trench 4 & 1 & Kitchen & Ceramic & Fragment \\
\hline 2015 & 11 & 3 & Trench 4 & 1 & Kitchen & Ceramic & Fragment \\
\hline 2015 & 11 & 3 & Trench 4 & 1 & Kitchen & Ceramic & Fragment \\
\hline 2015 & 11 & 3 & Trench 4 & 1 & Kitchen & Ceramic & Fragment \\
\hline 2015 & 11 & 3 & Trench 4 & 1 & Architecture & Window Glass & Fragment \\
\hline 2015 & 11 & 3 & Trench 4 & 1 & Architecture & Window Glass & Fragment \\
\hline 2015 & 11 & 3 & Trench 4 & 1 & Architecture & Window Glass & Fragment \\
\hline
\end{tabular}




\begin{tabular}{|c|c|c|c|c|c|c|c|}
\hline 2015 & 11 & 3 & Trench 4 & 1 & Architecture & Window Glass & Fragment \\
\hline 2015 & 11 & 3 & Trench 4 & 1 & Architecture & Square Nails & \\
\hline 2015 & 11 & 3 & Trench 4 & 1 & Architecture & Square Nails & \\
\hline 2015 & 11 & 3 & Trench 4 & 1 & Architecture & Square Nails & \\
\hline 2015 & 11 & 3 & Trench 4 & 1 & Architecture & Square Nails & \\
\hline 2015 & 11 & 3 & Trench 4 & 1 & Architecture & Square Nails & \\
\hline 2015 & 11 & 3 & Trench 4 & 1 & Architecture & Square Nails & \\
\hline 2015 & 11 & 3 & Trench 4 & 1 & Architecture & Square Nails & \\
\hline 2015 & 11 & 3 & Trench 4 & 1 & Architecture & Square Nails & \\
\hline 2015 & 11 & 3 & Trench 4 & 1 & Architecture & Square Nails & \\
\hline 2015 & 11 & 3 & Trench 4 & 1 & Architecture & Square Nails & \\
\hline 2015 & 11 & 3 & Trench 4 & 1 & Architecture & Square Nails & \\
\hline 2015 & 11 & 3 & Trench 4 & 1 & Architecture & Square Nails & \\
\hline 2015 & 11 & 3 & Trench 4 & 1 & Architecture & T-Nail & \\
\hline 2015 & 11 & 3 & Trench 4 & 1 & Architecture & Mortar & \\
\hline 2015 & 11 & 3 & Trench 4 & 1 & Architecture & Mortar & \\
\hline 2015 & 11 & 3 & Trench 4 & 2 & Tobacco & Stems & Hatched \\
\hline 2015 & 11 & 3 & Trench 4 & 1 & Tobacco & Bowl & Small fragment \\
\hline 2015 & 11 & 3 & Trench 4 & 1 & \begin{tabular}{|l|} 
Tobacco \\
\end{tabular} & Bowl & Small fragment \\
\hline 2015 & 11 & 3 & Trench 4 & 1 & Clothing & Button & Half glass button \\
\hline 2015 & 11 & 3 & Trench 4 & 1 & Other & Bone & Burnt \\
\hline 2015 & 11 & 3 & Trench 4 & 1 & Other & Bone & Burnt \\
\hline 2015 & 11 & 3 & Trench 4 & 1 & \begin{tabular}{|l|} 
Other \\
\end{tabular} & Bone & Burnt \\
\hline 2015 & 12 & 3 & Trench 4 & 2 & Clothing & Tin button & No markings or impressions \\
\hline 2015 & 13 & 3 & Trench 4 & 2 & Architecture & Window Glass & Fragment \\
\hline 2015 & 13 & 3 & Trench 4 & 2 & Architecture & Window Glass & Fragment \\
\hline 2015 & 13 & 3 & Trench 4 & 2 & Architecture & Square Nails & \\
\hline 2015 & 13 & 3 & Trench 4 & 2 & Architecture & Square Nails & \\
\hline 2015 & 13 & 3 & Trench 4 & 2 & Architecture & Square Nails & \\
\hline 2015 & 13 & 3 & Trench 4 & 2 & Activity & Scrap Iron & Iron strap \\
\hline 2015 & 14 & 3 & Trench 4 & 2 & Architecture & Square Nails & \\
\hline 2015 & 14 & 3 & Trench 4 & 2 & Architecture & Square Nails & \\
\hline 2015 & 14 & 3 & Trench 4 & 2 & Architecture & Square Nails & \\
\hline 2015 & 14 & 3 & Trench 4 & 2 & Architecture & Square Nails & \\
\hline 2015 & 14 & 3 & Trench 4 & 2 & Architecture & Square Nails & \\
\hline 2015 & 14 & 3 & Trench 4 & 2 & Architecture & Square Nails & \\
\hline 2015 & 14 & 3 & Trench 4 & 2 & Architecture & Square Nails & \\
\hline 2015 & 14 & 3 & Trench 4 & 2 & Architecture & Square Nails & \\
\hline 2015 & 14 & 3 & Trench 4 & 2 & Architecture & Square Nails & \\
\hline 2015 & 14 & 3 & Trench 4 & 2 & Architecture & Square Nails & \\
\hline 2015 & 14 & 3 & Trench 4 & 2 & Architecture & Square Nails & \\
\hline 2015 & 14 & 3 & Trench 4 & 2 & Architecture & Square Nails & \\
\hline 2015 & 14 & 3 & Trench 4 & 2 & Architecture & Square Nails & \\
\hline 2015 & 14 & 3 & Trench 4 & 2 & Architecture & Square Nails & \\
\hline 2015 & 14 & 3 & Trench 4 & 2 & Architecture & Square Nails & \\
\hline 2015 & 14 & 3 & Trench 4 & 2 & Architecture & Square Nails & \\
\hline 2015 & 14 & 3 & Trench 4 & 2 & Architecture & Square Nails & \\
\hline 2015 & 14 & 3 & Trench 4 & 2 & Architecture & Square Nails & \\
\hline 2015 & 14 & 3 & Trench 4 & 2 & Architecture & Square Nails & \\
\hline 2015 & 14 & 3 & Trench 4 & 2 & Architecture & Square Nails & \\
\hline 2015 & 14 & 3 & Trench 4 & 2 & Architecture & Square Nails & \\
\hline 2015 & 15 & 3 & Trench 4 & 2 & Architecture & Window Glass & Fragment \\
\hline 2015 & 15 & 3 & Trench 4 & 2 & Architecture & Window Glass & Fragment \\
\hline 2015 & 15 & 3 & Trench 4 & 2 & Architecture & Window Glass & Fragment \\
\hline 2015 & 15 & 3 & Trench 4 & 2 & Architecture & Window Glass & Fragment \\
\hline 2015 & 15 & 3 & Trench 4 & 2 & Architecture & Window Glass & Fragment \\
\hline 2015 & 15 & 3 & Trench 4 & 2 & Architecture & Window Glass & Fragment \\
\hline 2015 & 15 & 3 & Trench 4 & 2 & Architecture & Window Glass & Fragment \\
\hline 2015 & 15 & 3 & Trench 4 & 2 & Architecture & Window Glass & Fragment \\
\hline 2015 & 15 & 3 & Trench 4 & 2 & Architecture & Window Glass & Fragment \\
\hline
\end{tabular}




\begin{tabular}{|c|c|c|c|c|c|c|c|}
\hline 2015 & 15 & 3 & Trench 4 & 2 & Architecture & Window Glass & Fragment \\
\hline 2015 & 15 & 3 & Trench 4 & 2 & Architecture & Window Glass & Fragment \\
\hline 2015 & 15 & 3 & Trench 4 & 2 & Architecture & Window Glass & \begin{tabular}{|l|} 
Fragment \\
\end{tabular} \\
\hline 2015 & 15 & 3 & Trench 4 & 2 & Architecture & Window Glass & Fragment \\
\hline 2015 & 15 & 3 & Trench 4 & 2 & Architecture & Window Glass & Fragment \\
\hline 2015 & 15 & 3 & Trench 4 & 2 & Architecture & Window Glass & Fragment \\
\hline 2015 & 15 & 3 & Trench 4 & 2 & Architecture & Window Glass & Fragment \\
\hline 2015 & 15 & 3 & Trench 4 & 2 & Architecture & Window Glass & Fragment \\
\hline 2015 & 15 & 3 & Trench 4 & 2 & Architecture & Window Glass & Fragment \\
\hline 2015 & 15 & 3 & Trench 4 & 2 & Architecture & Square Nails & \\
\hline 2015 & 15 & 3 & Trench 4 & 2 & Architecture & Square Nails & \\
\hline 2015 & 15 & 3 & Trench 4 & 2 & Architecture & Square Nails & \\
\hline 2015 & 15 & 3 & Trench 4 & 2 & Architecture & Square Nails & \\
\hline 2015 & 15 & 3 & Trench 4 & 2 & Architecture & Square Nails & \\
\hline 2015 & 15 & 3 & Trench 4 & 2 & Architecture & Square Nails & \\
\hline 2015 & 15 & 3 & Trench 4 & 2 & Architecture & Square Nails & \\
\hline 2015 & 15 & 3 & Trench 4 & 2 & Architecture & Square Nails & \\
\hline 2015 & 15 & 3 & Trench 4 & 2 & Architecture & Square Nails & \\
\hline 2015 & 15 & 3 & Trench 4 & 2 & Architecture & Square Nails & \\
\hline 2015 & 15 & 3 & Trench 4 & 2 & Architecture & Square Nails & \\
\hline 2015 & 15 & 3 & Trench 4 & 2 & Architecture & Square Nails & \\
\hline 2015 & 15 & 3 & Trench 4 & 2 & Architecture & Square Nails & \\
\hline 2015 & 15 & 3 & Trench 4 & 2 & Architecture & Square Nails & \\
\hline 2015 & 15 & 3 & Trench 4 & 2 & Architecture & Square Nails & \\
\hline 2015 & 15 & 3 & Trench 4 & 2 & Tobacco & Stems & Grooved \\
\hline 2015 & 15 & 3 & \begin{tabular}{|l|} 
Trench 4 \\
\end{tabular} & 2 & \begin{tabular}{|l|} 
Tobacco \\
\end{tabular} & Stems & Grooved \\
\hline 2015 & 15 & 3 & \begin{tabular}{|l|} 
Trench 4 \\
\end{tabular} & 2 & \begin{tabular}{|l|} 
Tobacco \\
\end{tabular} & Stems & Grooved \\
\hline 2015 & 15 & 3 & Trench 4 & 2 & Tobacco & Bowls & "TD" stamped, hatched with 13 stars \\
\hline 2015 & 15 & 3 & Trench 4 & 2 & Tobacco & Bowls & "TD" stamped, hatched with 13 stars \\
\hline 2015 & 15 & 3 & Trench 4 & 2 & Tobacco & Bowls & "TD" stamped, hatched with 13 stars \\
\hline 2015 & 15 & 3 & Trench 4 & 2 & Tobacco & Bowls & Undecorated \\
\hline 2015 & 15 & 3 & Trench 4 & 2 & Other & Bone & Unidentifyed \\
\hline 2015 & 16 & 3 & Trench 4 & 3 & Architecture & Window Glass & Fragment \\
\hline 2015 & 16 & 3 & Trench 4 & 3 & Architecture & Window Glass & Fragment \\
\hline 2015 & 16 & 3 & Trench 4 & 3 & Architecture & Window Glass & Fragment \\
\hline 2015 & 16 & 3 & Trench 4 & 3 & Architecture & Window Glass & Fragment \\
\hline 2015 & 16 & 3 & Trench 4 & 3 & Architecture & \begin{tabular}{|l} 
Square Nail \\
\end{tabular} & \\
\hline 2015 & 17 & 3 & Trench 6 & 1 & Architecture & Square Nails & \\
\hline 2015 & 17 & 3 & Trench 6 & 1 & Architecture & Square Nails & \\
\hline 2015 & 17 & 3 & Trench 6 & 1 & Architecture & Square Nails & \\
\hline 2015 & 17 & 3 & Trench 6 & 1 & Architecture & Square Nails & \\
\hline 2015 & 17 & 3 & Trench 6 & 1 & Architecture & Square Nails & \\
\hline 2015 & 17 & 3 & Trench 6 & 1 & Architecture & Square Nails & \\
\hline 2015 & 17 & 3 & Trench 6 & 1 & Architecture & Window Glass & Fragment \\
\hline 2015 & 17 & 3 & Trench 6 & 1 & Architecture & Window Glass & \begin{tabular}{|l|} 
Fragment \\
\end{tabular} \\
\hline 2015 & 17 & 3 & Trench 6 & 1 & Architecture & Window Glass & Fragment \\
\hline 2015 & 17 & 3 & Trench 6 & 1 & Architecture & Window Glass & Fragment \\
\hline 2015 & 17 & 3 & Trench 6 & 1 & Architecture & Window Glass & Fragment \\
\hline 2015 & 17 & 3 & Trench 6 & 1 & Architecture & Window Glass & Fragment \\
\hline 2015 & 17 & 3 & Trench 6 & 1 & Architecture & Window Glass & Fragment \\
\hline 2015 & 17 & 3 & Trench 6 & 1 & Architecture & \begin{tabular}{|l} 
Window Glass \\
\end{tabular} & \begin{tabular}{|l|} 
Fragment \\
\end{tabular} \\
\hline 2015 & 17 & 3 & Trench 6 & 1 & Architecture & Window Glass & Fragment \\
\hline 2015 & 17 & 3 & Trench 6 & 1 & Architecture & Window Glass & Fragment \\
\hline 2015 & 17 & 3 & Trench 6 & 1 & Architecture & Window Glass & Fragment \\
\hline 2015 & 17 & 3 & Trench 6 & 1 & Tobacco & Stems & Hatched \\
\hline 2015 & 17 & 3 & Trench 6 & 1 & Tobacco & Bowl & "TD" stamped, hatched with 13 stars \\
\hline 2015 & 17 & 3 & Trench 6 & 1 & Tobacco & Bowl & $\begin{array}{l}\text { Hatched, articulates with "TD" } \\
\text { stamped }\end{array}$ \\
\hline 2015 & 17 & 3 & Trench 6 & 1 & Tobacco & Bowl & Hatched \\
\hline 2015 & 17 & 3 & Trench 6 & 1 & Tobacco & Bowl & Undecorated \\
\hline 2015 & 18 & 3 & Trench 6 & 1 & Tobacco & Stems & Fragment, Grooved \\
\hline
\end{tabular}




\begin{tabular}{|c|c|c|c|c|c|c|c|}
\hline 2015 & 19 & 3 & Trench 6 & 1 & Tobacco & Stems & Fragment, Grooved \\
\hline 2015 & 20 & 3 & Trench 6 & 1 & \begin{tabular}{|l} 
Kitchen \\
\end{tabular} & Wine/Liquor & Green wine fragment \\
\hline 2015 & 20 & 3 & \begin{tabular}{|l|} 
Trench 6 \\
\end{tabular} & 1 & Kitchen & Ceramic & Earthenware, brown \\
\hline 2015 & 20 & 3 & Trench 6 & 1 & Architecture & Window Glass & fragment \\
\hline 2015 & 20 & 3 & Trench 6 & 1 & Architecture & Window Glass & fragment \\
\hline 2015 & 21 & 3 & Trench 6 & 1 & Architecture & Window Glass & fragment \\
\hline 2015 & 21 & 3 & Trench 6 & 1 & Architecture & Window Glass & fragment \\
\hline 2015 & 21 & 3 & Trench 6 & 1 & Architecture & Window Glass & fragment \\
\hline 2015 & 21 & 3 & Trench 6 & 1 & Architecture & Window Glass & fragment \\
\hline 2015 & 21 & 3 & Trench 6 & 1 & Architecture & Square Nail & \\
\hline 2015 & 21 & 3 & Trench 6 & 1 & Architecture & Square Nail & \\
\hline 2015 & 22 & 3 & Trench 6 & 2 & Kitchen & Ceramic & Earthenware, brown \\
\hline 2015 & 23 & 3 & Trench 6 & 2 & Kitchen & Ceramic & Earthenware, brown \\
\hline 2015 & 23 & 3 & \begin{tabular}{|l|} 
Trench 6 \\
\end{tabular} & 2 & Kitchen & Ceramic & Stoneware \\
\hline 2015 & 23 & 3 & Trench 6 & 2 & Kitchen & Ceramic & Stoneware \\
\hline 2015 & 24 & 3 & Trench 6 & 2 & Architecture & Window Glass & \begin{tabular}{|l|} 
Fragment \\
\end{tabular} \\
\hline 2015 & 24 & 3 & Trench 6 & 2 & Architecture & Window Glass & Fragment \\
\hline 2015 & 24 & 3 & \begin{tabular}{|l|} 
Trench 6 \\
\end{tabular} & 2 & Architecture & Window Glass & Fragment \\
\hline 2015 & 24 & 3 & Trench 6 & 2 & Architecture & Window Glass & \begin{tabular}{|l|} 
Fragment \\
\end{tabular} \\
\hline 2015 & 24 & 3 & Trench 6 & 2 & Architecture & Window Glass & Fragment \\
\hline 2015 & 24 & 3 & Trench 6 & 2 & Architecture & Window Glass & \begin{tabular}{|l|} 
Fragment \\
\end{tabular} \\
\hline 2015 & 24 & 3 & Trench 6 & 2 & Architecture & Window Glass & Fragment \\
\hline 2015 & 24 & 3 & Trench 6 & 2 & Architecture & Window Glass & Fragment \\
\hline 2015 & 24 & 3 & Trench 6 & 2 & Architecture & Window Glass & \begin{tabular}{|l|} 
Fragment \\
\end{tabular} \\
\hline 2015 & 24 & 3 & \begin{tabular}{|l|} 
Trench 6 \\
\end{tabular} & 2 & Architecture & Window Glass & Fragment \\
\hline 2015 & 24 & 3 & \begin{tabular}{|l|} 
Trench 6 \\
\end{tabular} & 2 & Architecture & Window Glass & \begin{tabular}{|l|} 
Fragment \\
\end{tabular} \\
\hline 2015 & 24 & 3 & Trench 6 & 2 & Architecture & Window Glass & \begin{tabular}{|l|} 
Fragment \\
\end{tabular} \\
\hline 2015 & 24 & 3 & Trench 6 & 2 & Architecture & Window Glass & \begin{tabular}{|l|} 
Fragment \\
\end{tabular} \\
\hline 2015 & 24 & 3 & Trench 6 & 2 & Architecture & Window Glass & \begin{tabular}{|l|} 
Fragment \\
\end{tabular} \\
\hline 2015 & 24 & 3 & Trench 6 & 2 & Architecture & Window Glass & \begin{tabular}{|l|} 
Fragment \\
\end{tabular} \\
\hline 2015 & 24 & 3 & Trench 6 & 2 & Architecture & Square Nails & \\
\hline 2015 & 24 & 3 & \begin{tabular}{|l} 
Trench 6 \\
\end{tabular} & 2 & Architecture & Square Nails & \\
\hline 2015 & 24 & 3 & Trench 6 & 2 & Architecture & Square Nails & \\
\hline 2015 & 24 & 3 & \begin{tabular}{|l|} 
Trench 6 \\
\end{tabular} & 2 & Architecture & Square Nails & \\
\hline 2015 & 24 & 3 & Trench 6 & 2 & Architecture & Square Nails & \\
\hline 2015 & 24 & 3 & Trench 6 & 2 & Tobacco & Stems & undecorated \\
\hline 2015 & 25 & 4 & Trench 1 & Opening & Architecture & Window Glass & Fragment \\
\hline 2015 & 25 & 4 & Trench 1 & Opening & Architecture & Window Glass & \begin{tabular}{|l|} 
Fragment \\
\end{tabular} \\
\hline 2015 & 25 & 4 & Trench 1 & Opening & Architecture & Other & Tar paper \\
\hline 2015 & 25 & 4 & Trench 1 & Opening & Architecture & Other & \begin{tabular}{|l|} 
Tar paper \\
\end{tabular} \\
\hline 2015 & 25 & 4 & Trench 1 & Opening & Architecture & Other & Tar paper \\
\hline 2015 & 26 & 4 & Trench 1 & Opening & Kitchen & Wine/Liquor & Small fragment \\
\hline 2015 & 26 & 4 & Trench 1 & Opening & Kitchen & Wine/Liquor & clear \\
\hline 2015 & 26 & 4 & Trench 1 & Opening & Kitchen & Wine/Liquor & Liquor, bluish/green \\
\hline 2015 & 26 & 4 & Trench 1 & Opening & Kitchen & Wine/Liquor & Liquor, bluish/green \\
\hline 2015 & 26 & 4 & Trench 1 & Opening & Kitchen & Wine/Liquor & Liquor, bluish/green \\
\hline 2015 & 26 & 4 & Trench 1 & Opening & Kitchen & Wine/Liquor & Liquor, bluish/green \\
\hline 2015 & 26 & 4 & Trench 1 & Opening & \begin{tabular}{|l|} 
Kitchen \\
\end{tabular} & Wine/Liquor & Liquor, bluish/green \\
\hline 2015 & 26 & 4 & \begin{tabular}{|l|} 
Trench 1 \\
\end{tabular} & Opening & Kitchen & Wine/Liquor & Liquor, bluish/green \\
\hline 2015 & 26 & 4 & Trench 1 & Opening & Kitchen & Wine/Liquor & Liquor, bluish/green \\
\hline 2015 & 26 & 4 & Trench 1 & Opening & Architecture & Window Glass & Fragment \\
\hline 2015 & 26 & 4 & Trench 1 & Opening & Architecture & Window Glass & Fragment \\
\hline 2015 & 26 & 4 & Trench 1 & Opening & Architecture & Window Glass & \begin{tabular}{|l|} 
Fragment \\
\end{tabular} \\
\hline 2015 & 26 & 4 & Trench 1 & Opening & Architecture & Square Nails & \\
\hline 2015 & 26 & 4 & Trench 1 & Opening & Architecture & Square Nails & \\
\hline 2015 & 26 & 4 & \begin{tabular}{|l|} 
Trench 1 \\
\end{tabular} & Opening & Architecture & Square Nails & \\
\hline 2015 & 26 & 4 & Trench 1 & Opening & Architecture & Square Nails & \\
\hline 2015 & 26 & 4 & Trench 1 & Opening & Architecture & Square Nails & \\
\hline 2015 & 26 & 4 & Trench 1 & Opening & Architecture & Square Nails & \\
\hline 2015 & 26 & 4 & Trench 1 & Opening & Architecture & Square Nails & \\
\hline
\end{tabular}




\begin{tabular}{|c|c|c|c|c|c|c|c|}
\hline 2015 & 26 & 4 & Trench 1 & Opening & Architecture & Square Nails & \\
\hline 2015 & 26 & 4 & Trench 1 & Opening & Architecture & Mortar & \\
\hline 2015 & 26 & 4 & Trench 1 & Opening & Arms & \begin{tabular}{|l|} 
Cartridges \\
\end{tabular} & "US" .32 Long \\
\hline 2015 & 26 & 4 & Trench 1 & Opening & Clothing & Button & plastic \\
\hline 2015 & 26 & 4 & Trench 1 & Opening & Other & Bone & Mammal \\
\hline 2015 & 27 & 4 & Trench 1 & Opening & Activity & Scrap Iron & Unknown scrap \\
\hline 2015 & 28 & 4 & Trench 1 & Surface & Kitchen & Wine/Liquor & Liquor, bluish/green \\
\hline 2015 & 28 & 4 & Trench 1 & Surface & Kitchen & Wine/Liquor & Clear, bottle neck \\
\hline 2015 & 28 & 4 & Trench 1 & Surface & Kitchen & Ceramic & Iron Stone \\
\hline 2015 & 29 & 4 & Trench 1 & Level 1 & Kitchen & Ceramic & Semi-Porcelain, gilt \\
\hline 2015 & 29 & 4 & Trench 1 & Level 1 & Kitchen & Ceramic & Semi-Porcelain, makers mark \\
\hline 2015 & 29 & 4 & Trench 1 & Level 1 & Kitchen & Ceramic & Semi-Porcelain \\
\hline 2015 & 29 & 4 & Trench 1 & Level 1 & Kitchen & Ceramic & Iron Stone \\
\hline 2015 & 29 & 4 & Trench 1 & Level 1 & Kitchen & Ceramic & $\begin{array}{l}\text { Refined wear, Green exterior, Brown } \\
\text { interior }\end{array}$ \\
\hline 2015 & 29 & 4 & Trench 1 & Level 1 & Kitchen & Ceramic & Earthen ware, brown glazed \\
\hline 2015 & 29 & 4 & Trench 1 & Level 1 & Kitchen & Ceramic & Earthen ware, brown glazed \\
\hline 2015 & 29 & 4 & Trench 1 & Level 1 & Kitchen & Beer & Fragment \\
\hline 2015 & 29 & 4 & Trench 1 & Level 1 & Kitchen & Beer & Fragment \\
\hline 2015 & 29 & 4 & Trench 1 & Level 1 & Kitchen & Beer & Fragment \\
\hline 2015 & 29 & 4 & Trench 1 & Level 1 & Kitchen & Beer & Fragment \\
\hline 2015 & 29 & 4 & Trench 1 & Level 1 & Kitchen & Beer & Fragment \\
\hline 2015 & 29 & 4 & Trench 1 & Level 1 & Kitchen & Beer & Fragment \\
\hline 2015 & 29 & 4 & Trench 1 & Level 1 & Kitchen & Wine/Liquor & Purple \\
\hline 2015 & 29 & 4 & Trench 1 & Level 1 & Kitchen & Wine/Liquor & Purple \\
\hline 2015 & 29 & 4 & Trench 1 & Level 1 & Kitchen & Wine/Liquor & Purple \\
\hline 2015 & 29 & 4 & Trench 1 & Level 1 & Kitchen & Wine/Liquor & Blue and ground glass \\
\hline 2015 & 29 & 4 & Trench 1 & Level 1 & Kitchen & Wine/Liquor & Blue and ground glass \\
\hline 2015 & 29 & 4 & Trench 1 & Level 1 & Kitchen & Wine/Liquor & Clear, bottle neck \\
\hline 2015 & 29 & 4 & Trench 1 & Level 1 & Kitchen & Wine/Liquor & Clear, bottle neck \\
\hline 2015 & 29 & 4 & Trench 1 & Level 1 & Kitchen & Wine/Liquor & Clear, bottle neck \\
\hline 2015 & 29 & 4 & Trench 1 & Level 1 & Kitchen & Wine/Liquor & Clear, bottle neck \\
\hline 2015 & 29 & 4 & Trench 1 & Level 1 & Kitchen & Wine/Liquor & Clear, bottle neck \\
\hline 2015 & 29 & 4 & Trench 1 & Level 1 & Kitchen & Wine/Liquor & Clear, bottle neck \\
\hline 2015 & 29 & 4 & Trench 1 & Level 1 & Kitchen & Wine/Liquor & Clear, bottle neck \\
\hline 2015 & 29 & 4 & Trench 1 & Level 1 & Kitchen & Wine/Liquor & Clear, bottle neck \\
\hline 2015 & 29 & 4 & Trench 1 & Level 1 & Kitchen & Wine/Liquor & Clear, bottle neck \\
\hline 2015 & 29 & 4 & Trench 1 & Level 1 & Kitchen & Wine/Liquor & Clear, bottle neck \\
\hline 2015 & 29 & 4 & Trench 1 & Level 1 & Kitchen & Wine/Liquor & Clear, bottle neck \\
\hline 2015 & 29 & 4 & Trench 1 & Level 1 & Kitchen & Wine/Liquor & Clear, bottle neck \\
\hline 2015 & 29 & 4 & Trench 1 & Level 1 & Kitchen & Wine/Liquor & Clear, bottle neck \\
\hline 2015 & 29 & 4 & Trench 1 & Level 1 & Kitchen & Wine/Liquor & Clear, bottle neck \\
\hline 2015 & 29 & 4 & Trench 1 & Level 1 & Kitchen & Wine/Liquor & Clear, bottle neck \\
\hline 2015 & 29 & 4 & Trench 1 & Level 1 & Kitchen & Wine/Liquor & Clear, bottle neck \\
\hline 2015 & 29 & 4 & Trench 1 & Level 1 & Kitchen & Wine/Liquor & Clear, bottle neck \\
\hline 2015 & 29 & 4 & Trench 1 & Level 1 & Kitchen & Wine/Liquor & Clear, bottle neck \\
\hline 2015 & 29 & 4 & Trench 1 & Level 1 & Kitchen & Wine/Liquor & Clear, bottle neck \\
\hline 2015 & 29 & 4 & Trench 1 & Level 1 & Architecture & Window Glass & Fragment \\
\hline 2015 & 29 & 4 & Trench 1 & Level 1 & Architecture & Window Glass & Fragment \\
\hline 2015 & 29 & 4 & Trench 1 & Level 1 & Architecture & Window Glass & Fragment \\
\hline 2015 & 29 & 4 & Trench 1 & Level 1 & Architecture & Window Glass & Fragment \\
\hline 2015 & 29 & 4 & Trench 1 & Level 1 & Architecture & \begin{tabular}{|l|} 
Window Glass \\
\end{tabular} & Fragment \\
\hline 2015 & 29 & 4 & Trench 1 & Level 1 & Architecture & Window Glass & Fragment \\
\hline 2015 & 29 & 4 & Trench 1 & Level 1 & Architecture & Window Glass & Fragment \\
\hline 2015 & 29 & 4 & Trench 1 & Level 1 & Architecture & Window Glass & Fragment \\
\hline 2015 & 29 & 4 & Trench 1 & Level 1 & Architecture & Window Glass & Fragment \\
\hline 2015 & 29 & 4 & Trench 1 & Level 1 & Architecture & Window Glass & Fragment \\
\hline 2015 & 29 & 4 & Trench 1 & Level 1 & Architecture & Window Glass & Fragment \\
\hline 2015 & 29 & 4 & Trench 1 & Level 1 & Architecture & Window Glass & Fragment \\
\hline 2015 & 29 & 4 & Trench 1 & Level 1 & Architecture & Window Glass & Fragment \\
\hline 2015 & 29 & 4 & Trench 1 & Level 1 & Architecture & Window Glass & Fragment \\
\hline
\end{tabular}




\begin{tabular}{|c|c|c|c|c|c|c|c|}
\hline 2015 & 29 & 4 & Trench 1 & Level 1 & Architecture & Window Glass & Fragment \\
\hline 2015 & 29 & 4 & Trench 1 & Level 1 & Architecture & Round Nails & \\
\hline 2015 & 29 & 4 & Trench 1 & Level 1 & Architecture & Round Nails & \\
\hline 2015 & 29 & 4 & Trench 1 & Level 1 & Architecture & Round Nails & \\
\hline 2015 & 29 & 4 & Trench 1 & Level 1 & Architecture & Round Nails & \\
\hline 2015 & 29 & 4 & Trench 1 & Level 1 & Architecture & Round Nails & \\
\hline 2015 & 29 & 4 & Trench 1 & Level 1 & Architecture & Round Nails & \\
\hline 2015 & 29 & 4 & Trench 1 & Level 1 & Architecture & Round Nails & \\
\hline 2015 & 29 & 4 & Trench 1 & Level 1 & Architecture & Round Nails & \\
\hline 2015 & 29 & 4 & Trench 1 & Level 1 & Architecture & Round Nails & \\
\hline 2015 & 29 & 4 & Trench 1 & Level 1 & Architecture & Square Nails & \\
\hline 2015 & 29 & 4 & Trench 1 & Level 1 & Architecture & Square Nails & \\
\hline 2015 & 29 & 4 & Trench 1 & Level 1 & Architecture & Square Nails & \\
\hline 2015 & 29 & 4 & Trench 1 & Level 1 & Architecture & Square Nails & \\
\hline 2015 & 29 & 4 & Trench 1 & Level 1 & Architecture & Square Nails & \\
\hline 2015 & 29 & 4 & Trench 1 & Level 1 & Architecture & Square Nails & \\
\hline 2015 & 29 & 4 & Trench 1 & Level 1 & Architecture & Square Nails & \\
\hline 2015 & 29 & 4 & Trench 1 & Level 1 & Architecture & Square Nails & \\
\hline 2015 & 29 & 4 & Trench 1 & Level 1 & Architecture & Square Nails & \\
\hline 2015 & 29 & 4 & Trench 1 & Level 1 & Architecture & Square Nails & \\
\hline 2015 & 29 & 4 & Trench 1 & Level 1 & Architecture & Door Hardware & Door latch \\
\hline 2015 & 29 & 4 & Trench 1 & Level 1 & Architecture & Other & Screw \\
\hline 2015 & 29 & 4 & Trench 1 & Level 1 & Architecture & Other & Screw \\
\hline 2015 & 29 & 4 & Trench 1 & Level 1 & Clothing & Buttons & Glass \\
\hline 2015 & 29 & 4 & Trench 1 & Level 1 & Other & Bone & \\
\hline 2015 & 29 & 4 & Trench 1 & Level 1 & Other & Bone & \\
\hline 2015 & 29 & 4 & Trench 1 & Level 1 & Other & Bone & \\
\hline 2015 & 29 & 4 & Trench 1 & Level 1 & Other & Bone & \\
\hline 2015 & 29 & 4 & Trench 1 & Level 1 & Other & Bone & \\
\hline 2015 & 29 & 4 & Trench 1 & Level 1 & Other & Bone & \\
\hline 2015 & 30 & 4 & Trench 1 & Level 2 & Kitchen & Ceramic & Semi-Porcelain \\
\hline 2015 & 30 & 4 & Trench 1 & Level 2 & Kitchen & Ceramic & Semi-Porcelain \\
\hline 2015 & 30 & 4 & Trench 1 & Level 2 & Kitchen & Beer & Base, Vacuum Blown \\
\hline 2015 & 30 & 4 & Trench 1 & Level 2 & Kitchen & Beer & Fragment \\
\hline 2015 & 30 & 4 & Trench 1 & Level 2 & Kitchen & Beer & Fragment \\
\hline 2015 & 30 & 4 & Trench 1 & Level 2 & Kitchen & Beer & Fragment \\
\hline 2015 & 30 & 4 & Trench 1 & Level 2 & Kitchen & Wine/Liquor & Clear \\
\hline 2015 & 30 & 4 & Trench 1 & Level 2 & Kitchen & Wine/Liquor & Clear \\
\hline 2015 & 30 & 4 & Trench 1 & Level 2 & Kitchen & Wine/Liquor & Blue \\
\hline 2015 & 30 & 4 & Trench 1 & Level 2 & Kitchen & Wine/Liquor & Blue \\
\hline 2015 & 30 & 4 & Trench 1 & Level 2 & Architecture & Window Glass & Fragment \\
\hline 2015 & 30 & 4 & Trench 1 & Level 2 & Architecture & Window Glass & Fragment \\
\hline 2015 & 30 & 4 & Trench 1 & Level 2 & Architecture & Window Glass & Fragment \\
\hline 2015 & 30 & 4 & Trench 1 & Level 2 & Architecture & Window Glass & Fragment \\
\hline 2015 & 30 & 4 & Trench 1 & Level 2 & Architecture & Window Glass & Fragment \\
\hline 2015 & 30 & 4 & Trench 1 & Level 2 & Architecture & Window Glass & Fragment \\
\hline 2015 & 30 & 4 & Trench 1 & Level 2 & Architecture & Window Glass & Fragment \\
\hline 2015 & 30 & 4 & Trench 1 & Level 2 & Architecture & Window Glass & Fragment \\
\hline 2015 & 30 & 4 & Trench 1 & Level 2 & Architecture & Window Glass & Fragment \\
\hline 2015 & 30 & 4 & Trench 1 & Level 2 & Architecture & Window Glass & Fragment \\
\hline 2015 & 30 & 4 & Trench 1 & Level 2 & Architecture & Window Glass & Fragment \\
\hline 2015 & 30 & 4 & \begin{tabular}{|l|} 
Trench 1 \\
\end{tabular} & Level 2 & Architecture & Window Glass & Fragment \\
\hline 2015 & 30 & 4 & Trench 1 & Level 2 & Architecture & Window Glass & Fragment \\
\hline 2015 & 30 & 4 & Trench 1 & Level 2 & Architecture & Window Glass & Fragment \\
\hline 2015 & 30 & 4 & Trench 1 & Level 2 & Architecture & Round Nails & \\
\hline 2015 & 30 & 4 & Trench 1 & Level 2 & Architecture & Round Nails & \\
\hline 2015 & 30 & 4 & Trench 1 & Level 2 & Architecture & Round Nails & \\
\hline 2015 & 30 & 4 & Trench 1 & Level 2 & Architecture & Round Nails & \\
\hline 2015 & 30 & 4 & Trench 1 & Level 2 & Architecture & Round Nails & \\
\hline 2015 & 30 & 4 & Trench 1 & Level 2 & Architecture & Round Nails & \\
\hline
\end{tabular}




\begin{tabular}{|c|c|c|c|c|c|c|c|}
\hline 2015 & 30 & 4 & Trench 1 & Level 2 & Architecture & Round Nails & \\
\hline 2015 & 30 & 4 & Trench 1 & Level 2 & Architecture & Round Nails & \\
\hline 2015 & 30 & 4 & Trench 1 & Level 2 & Architecture & Round Nails & \\
\hline 2015 & 30 & 4 & Trench 1 & Level 2 & Architecture & Round Nails & \\
\hline 2015 & 30 & 4 & Trench 1 & Level 2 & Architecture & Round Nails & \\
\hline 2015 & 30 & 4 & Trench 1 & Level 2 & Architecture & Round Nails & \\
\hline 2015 & 30 & 4 & Trench 1 & Level 2 & Architecture & Round Nails & \\
\hline 2015 & 30 & 4 & Trench 1 & Level 2 & Architecture & Round Nails & \\
\hline 2015 & 30 & 4 & Trench 1 & Level 2 & Architecture & Round Nails & \\
\hline 2015 & 30 & 4 & Trench 1 & Level 2 & Architecture & Brick Fragment & \\
\hline 2015 & 30 & 4 & Trench 1 & Level 2 & Architecture & Brick Fragment & \\
\hline 2015 & 30 & 4 & Trench 1 & Level 2 & Architecture & Wood Sample & Paint mixer? \\
\hline 2015 & 30 & 4 & Trench 1 & Level 2 & Architecture & Wood Sample & Paint mixer? \\
\hline 2015 & 30 & 4 & Trench 1 & Level 2 & Architecture & Hardware & Hook latch \\
\hline 2015 & 30 & 4 & Trench 1 & Level 2 & Architecture & Tar paper & fragments, poor condition \\
\hline 2015 & 30 & 4 & Trench 1 & Level 2 & Architecture & Tar paper & fragments, poor condition \\
\hline 2015 & 30 & 4 & Trench 1 & Level 2 & Architecture & Tar paper & fragments, poor condition \\
\hline 2015 & 30 & 4 & Trench 1 & Level 2 & Architecture & Tar paper & fragments, poor condition \\
\hline 2015 & 30 & 4 & Trench 1 & Level 2 & Activity & Tar paper & fragments, poor condition \\
\hline 2015 & 30 & 4 & \begin{tabular}{|l} 
Trench 1 \\
\end{tabular} & Level 2 & Activity & Tar paper & fragments, poor condition \\
\hline 2015 & 30 & 4 & Trench 1 & Level 2 & Activity & Brass scrap & $2 \mathrm{~mm}$ thick, $1 \mathrm{x} 3 \mathrm{~cm}$ \\
\hline 2015 & 30 & 4 & Trench 1 & Level 2 & Activity & Other & Bone \\
\hline 2015 & 31 & 4 & Trench 1 & Level 2 & Architecture & Brick Fragment & Machine made \\
\hline 2015 & 31 & 4 & Trench 1 & \begin{tabular}{|l|} 
Level 2 \\
\end{tabular} & Architecture & Brick Fragment & Poor condition \\
\hline 2015 & 32 & 4 & Trench 3 & Opening & Architecture & Round nails & \\
\hline 2015 & 32 & 4 & Trench 3 & Opening & Architecture & Round nails & \\
\hline 2015 & 32 & 4 & Trench 3 & Opening & Architecture & Round nails & \\
\hline 2015 & 32 & 4 & Trench 3 & Opening & Architecture & Round nails & \\
\hline 2015 & 32 & 4 & Trench 3 & Opening & Architecture & Round nails & \\
\hline 2015 & 32 & 4 & Trench 3 & Opening & Architecture & Round nails & \\
\hline 2015 & 32 & 4 & Trench 3 & Opening & Architecture & Round nails & \\
\hline 2015 & 32 & 4 & Trench 3 & Opening & Architecture & Round nails & \\
\hline 2015 & 32 & 4 & Trench 3 & Opening & Architecture & Round nails & \\
\hline 2015 & 32 & 4 & Trench 3 & Opening & Architecture & Round nails & \\
\hline 2015 & 32 & 4 & Trench 3 & Opening & Architecture & Round nails & \\
\hline 2015 & 32 & 4 & Trench 3 & Opening & Architecture & Round nails & \\
\hline 2015 & 32 & 4 & Trench 3 & Opening & Architecture & Round nails & \\
\hline 2015 & 32 & 4 & Trench 3 & Opening & Architecture & Tar paper & Fragments, poor condition \\
\hline 2015 & 32 & 4 & Trench 3 & Opening & Architecture & Tar paper & Fragments, poor condition \\
\hline 2015 & 32 & 4 & Trench 3 & Opening & Architecture & Tar paper & Fragments, poor condition \\
\hline 2015 & 32 & 4 & Trench 3 & Opening & Architecture & Tar paper & Fragments, poor condition \\
\hline 2015 & 32 & 4 & Trench 3 & Opening & Architecture & Tar paper & Fragments, poor condition \\
\hline 2015 & 32 & 4 & Trench 3 & Opening & Architecture & Tar paper & Fragments, poor condition \\
\hline 2015 & 32 & 4 & Trench 3 & Opening & Architecture & Tar paper & Fragments, poor condition \\
\hline 2015 & 32 & 4 & Trench 3 & Opening & Kitchen & Wine/Liquor & Blue/Green \\
\hline 2015 & 33 & 4 & Trench 5 & Opening & Architecture & Window Glass & Fragment \\
\hline 2015 & 33 & 4 & Trench 5 & Opening & Architecture & Window Glass & \begin{tabular}{|l|} 
Fragment \\
\end{tabular} \\
\hline 2015 & 33 & 4 & Trench 5 & Opening & Architecture & Window Glass & \begin{tabular}{|l|} 
Fragment \\
\end{tabular} \\
\hline 2015 & 33 & 4 & \begin{tabular}{|l|} 
Trench 5 \\
\end{tabular} & Opening & Architecture & Round nails & \\
\hline 2015 & 33 & 4 & Trench 5 & Opening & Architecture & Round nails & \\
\hline 2015 & 33 & 4 & Trench 5 & Opening & Architecture & Round nails & \\
\hline 2015 & 33 & 4 & Trench 5 & Opening & Architecture & Round nails & \\
\hline 2015 & 33 & 4 & Trench 5 & Opening & Architecture & Round nails & \\
\hline 2015 & 33 & 4 & Trench 5 & Opening & Architecture & Round nails & \\
\hline 2015 & 33 & 4 & Trench 5 & Opening & Architecture & Round nails & \\
\hline 2015 & 33 & 4 & Trench 5 & Opening & Architecture & Round nails & \\
\hline 2015 & 33 & 4 & Trench 5 & Opening & Architecture & Round nails & \\
\hline 2015 & 33 & 4 & Trench 5 & Opening & Architecture & Round nails & \\
\hline 2015 & 33 & 4 & Trench 5 & Opening & Architecture & Round nails & \\
\hline 2015 & 33 & 4 & Trench 5 & Opening & Architecture & Round nails & \\
\hline
\end{tabular}




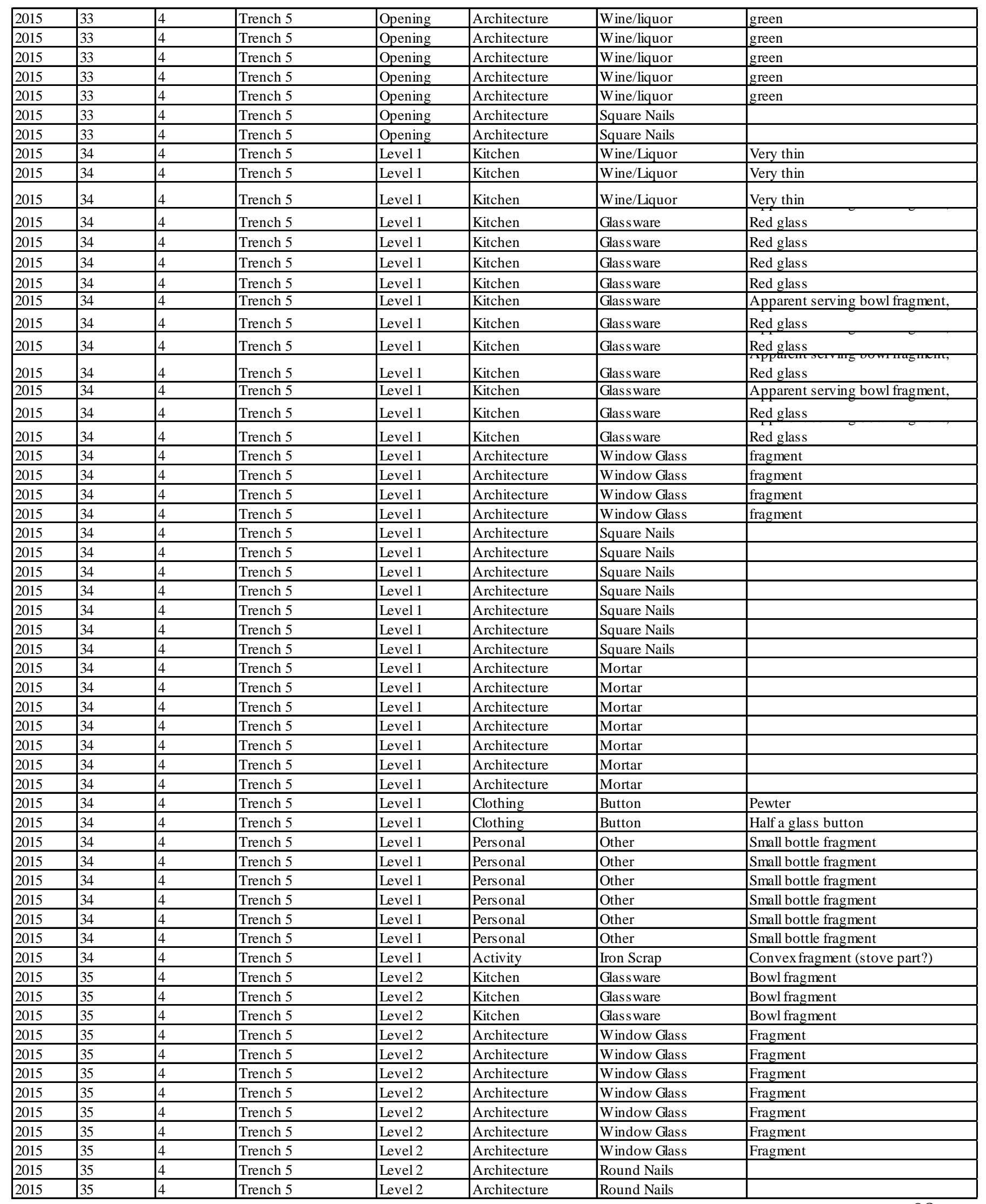




\begin{tabular}{|c|c|c|c|c|c|c|c|}
\hline 2015 & 35 & 4 & Trench 5 & \begin{tabular}{|l|} 
Level 2 \\
\end{tabular} & Architecture & Tar paper & \\
\hline 2015 & 36 & 4 & Trench 5 & Level 2 & \begin{tabular}{|l} 
Kitchen \\
\end{tabular} & Wine/Liquor & Brown \\
\hline 2015 & 36 & 4 & Trench 5 & Level 2 & Kitchen & Wine/Liquor & Brown \\
\hline 2015 & 36 & 4 & Trench 5 & Level 2 & Kitchen & Wine/Liquor & Brown \\
\hline 2015 & 36 & 4 & Trench 5 & Level 2 & Kitchen & Wine/Liquor & Brown \\
\hline 2015 & 36 & 4 & Trench 5 & Level 2 & Kitchen & Wine/Liquor & Brown \\
\hline 2015 & 36 & 4 & Trench 5 & Level 2 & Kitchen & Wine/Liquor & Brown \\
\hline 2015 & 36 & 4 & Trench 5 & Level 2 & Kitchen & Wine/Liquor & Brown \\
\hline 2015 & 37 & 4 & Trench 5 & Level 2 & Kitchen & Wine/Liquor & Clear, canning jar \\
\hline 2015 & 37 & 4 & Trench 5 & Level 2 & Kitchen & Wine/Liquor & Clear, canning jar \\
\hline 2015 & 37 & 4 & Trench 5 & Level 2 & Kitchen & Wine/Liquor & Clear, canning jar \\
\hline 2015 & 37 & 4 & Trench 5 & Level 2 & Kitchen & Wine/Liquor & Clear, canning jar \\
\hline 2015 & 37 & 4 & Trench 5 & Level 2 & Kitchen & Wine/Liquor & Clear, canning jar \\
\hline 2015 & 37 & 4 & Trench 5 & Level 2 & Kitchen & Butchered bone & pig \\
\hline 2015 & 37 & 4 & Trench 5 & Level 2 & Kitchen & Butchered bone & pig \\
\hline 2015 & 37 & 4 & Trench 5 & Level 2 & Kitchen & Butchered bone & pig \\
\hline 2015 & 37 & 4 & Trench 5 & Level 2 & Kitchen & Butchered bone & pig \\
\hline 2015 & 37 & 4 & Trench 5 & Level 2 & Kitchen & Butchered bone & pig \\
\hline 2015 & 37 & 4 & Trench 5 & Level 2 & Kitchen & Butchered bone & pig \\
\hline 2015 & 37 & 4 & Trench 5 & Level 2 & Kitchen & Butchered bone & pig \\
\hline 2015 & 37 & 4 & Trench 5 & Level 2 & Kitchen & Butchered bone & pig \\
\hline 2015 & 37 & 4 & Trench 5 & Level 2 & Kitchen & Butchered bone & pig \\
\hline 2015 & 37 & 4 & Trench 5 & Level 2 & Kitchen & Butchered bone & pig \\
\hline 2015 & 37 & 4 & Trench 5 & Level 2 & Kitchen & Butchered bone & pig \\
\hline 2015 & 37 & 4 & Trench 5 & Level 2 & Kitchen & Butchered bone & pig \\
\hline 2015 & 37 & 4 & Trench 5 & Level 2 & Kitchen & Butchered bone & pig \\
\hline 2015 & 37 & 4 & Trench 5 & Level 2 & Kitchen & Butchered bone & Unidentified, possible game animal \\
\hline 2015 & 37 & 4 & Trench 5 & Level 2 & Kitchen & Butchered bone & Unidentified, possible game animal \\
\hline 2015 & 37 & 4 & Trench 5 & Level 2 & Kitchen & Butchered bone & Unidentified, possible game animal \\
\hline 2015 & 37 & 4 & Trench 5 & Level 2 & Kitchen & Butchered bone & Unidentified, possible game animal \\
\hline 2015 & 37 & 4 & Trench 5 & Level 2 & Kitchen & Butchered bone & Unidentified, possible game animal \\
\hline 2015 & 37 & 4 & Trench 5 & Level 2 & Kitchen & Butchered bone & Unidentified, possible game animal \\
\hline 2015 & 37 & 4 & Trench 5 & Level 2 & Kitchen & Butchered bone & Unidentified, possible game animal \\
\hline 2015 & 37 & 4 & Trench 5 & Level 2 & Kitchen & Butchered bone & Unidentified, possible game animal \\
\hline 2015 & 37 & 4 & Trench 5 & Level 2 & Kitchen & Butchered bone & Unidentified, possible game animal \\
\hline 2015 & 37 & 4 & Trench 5 & Level 2 & Architecture & Window Glass & fragment \\
\hline 2015 & 37 & 4 & Trench 5 & Level 2 & Architecture & Window Glass & fragment \\
\hline 2015 & 37 & 4 & Trench 5 & Level 2 & Architecture & Window Glass & fragment \\
\hline 2015 & 37 & 4 & Trench 5 & Level 2 & Architecture & Window Glass & fragment \\
\hline 2015 & 37 & 4 & Trench 5 & Level 2 & Architecture & Window Glass & fragment \\
\hline 2015 & 37 & 4 & Trench 5 & Level 2 & Architecture & Window Glass & fragment \\
\hline 2015 & 37 & 4 & Trench 5 & Level 2 & Architecture & Window Glass & fragment \\
\hline 2015 & 37 & 4 & Trench 5 & Level 2 & Architecture & Window Glass & fragment \\
\hline 2015 & 37 & 4 & Trench 5 & Level 2 & Architecture & Window Glass & fragment \\
\hline 2015 & 37 & 4 & Trench 5 & Level 2 & Architecture & Window Glass & fragment \\
\hline 2015 & 37 & 4 & Trench 5 & Level 2 & Architecture & Window Glass & fragment \\
\hline 2015 & 37 & 4 & Trench 5 & Level 2 & Architecture & Window Glass & fragment \\
\hline 2015 & 37 & 4 & Trench 5 & Level 2 & Architecture & Window Glass & fragment \\
\hline 2015 & 37 & 4 & Trench 5 & Level 2 & Architecture & Window Glass & fragment \\
\hline 2015 & 37 & 4 & $\begin{array}{l}\text { Trench } 5 \\
\end{array}$ & \begin{tabular}{|l|} 
Level 2 \\
\end{tabular} & \begin{tabular}{|l} 
Architecture \\
\end{tabular} & Window Glass & Fragment \\
\hline 2015 & 37 & 4 & Trench 5 & Level 2 & Architecture & Round Nails & \\
\hline 2015 & 37 & 4 & Trench 5 & Level 2 & Architecture & Round Nails & \\
\hline 2015 & 37 & 4 & Trench 5 & Level 2 & Architecture & Round Nails & \\
\hline 2015 & 37 & 4 & Trench 5 & Level 2 & Architecture & Round Nails & \\
\hline 2015 & 37 & 4 & Trench 5 & Level 2 & Architecture & Round Nails & \\
\hline 2015 & 37 & 4 & Trench 5 & Level 2 & Architecture & Round Nails & \\
\hline 2015 & 37 & 4 & Trench 5 & Level 2 & Architecture & Round Nails & \\
\hline 2015 & 37 & 4 & Trench 5 & Level 2 & Architecture & Round Nails & \\
\hline 2015 & 37 & 4 & Trench 5 & \begin{tabular}{|l|} 
Level 2 \\
\end{tabular} & Architecture & Round Nails & \\
\hline 2015 & 37 & 4 & Trench 5 & Level 2 & Architecture & Round Nails & \\
\hline
\end{tabular}




\begin{tabular}{|c|c|c|c|c|c|c|c|}
\hline 2015 & 37 & 4 & Trench 5 & Level 2 & Architecture & Round Nails & \\
\hline 2015 & 37 & 4 & Trench 5 & Level 2 & Architecture & Tar paper & \\
\hline 2015 & 37 & 4 & Trench 5 & Level 2 & Architecture & Tar paper & \\
\hline 2015 & 37 & 4 & Trench 5 & Level 2 & Tobbacco & Bowl & Fragment, Undecorated \\
\hline 2015 & 38 & 4 & Trench 5 & Level 3 & Kitchen & Stove & Fragment \\
\hline 2015 & 38 & 4 & Trench 5 & Level 3 & Architecture & Window Glass & fragment \\
\hline 2015 & 38 & 4 & Trench 5 & Level 3 & Architecture & Window Glass & fragment \\
\hline 2015 & 38 & 4 & Trench 5 & Level 3 & Architecture & Window Glass & fragment \\
\hline 2015 & 38 & 4 & Trench 5 & Level 3 & Architecture & Window Glass & fragment \\
\hline 2015 & 38 & 4 & Trench 5 & Level 3 & Architecture & Window Glass & fragment \\
\hline 2015 & 38 & 4 & Trench 5 & Level 3 & Architecture & Window Glass & fragment \\
\hline 2015 & 38 & 4 & Trench 5 & Level 3 & Architecture & Window Glass & fragment \\
\hline 2015 & 38 & 4 & Trench 5 & Level 3 & Architecture & Round Nails & \\
\hline 2015 & 38 & 4 & Trench 5 & Level 3 & Architecture & Round Nails & \\
\hline 2015 & 38 & 4 & Trench 5 & Level 3 & Architecture & Round Nails & \\
\hline 2015 & 38 & 4 & Trench 5 & Level 3 & Architecture & Round Nails & \\
\hline 2015 & 38 & 4 & Trench 5 & Level 3 & Architecture & Round Nails & \\
\hline 2015 & 38 & 4 & Trench 5 & Level 3 & Architecture & Round Nails & \\
\hline 2015 & 38 & 4 & Trench 5 & Level 3 & Architecture & Round Nails & \\
\hline 2015 & 38 & 4 & Trench 5 & Level 3 & Architecture & Round Nails & \\
\hline 2015 & 38 & 4 & Trench 5 & Level 3 & Architecture & Round Nails & \\
\hline 2015 & 38 & 4 & Trench 5 & Level 3 & Architecture & Round Nails & \\
\hline 2015 & 38 & 4 & Trench 5 & Level 3 & Architecture & Round Nails & \\
\hline 2015 & 38 & 4 & Trench 5 & Level 3 & Architecture & Round Nails & \\
\hline 2015 & 38 & 4 & Trench 5 & Level 3 & Architecture & Round Nails & \\
\hline 2015 & 38 & 4 & Trench 5 & Level 3 & Architecture & Round Nails & \\
\hline 2015 & 38 & 4 & Trench 5 & Level 3 & Architecture & Round Nails & \\
\hline 2015 & 38 & 4 & Trench 5 & Level 3 & Clothing & Leather & Scrap \\
\hline 2015 & 39 & 4 & Trench 5 & Level 3 & Kitchen & Stove Part & fragment \\
\hline 2015 & 39 & 4 & Trench 5 & Level 3 & Kitchen & Utensils & Serving Fork \\
\hline 2015 & 39 & 4 & Trench 5 & Level 3 & Kitchen & Wine/Liquor & Clear \\
\hline 2015 & 39 & 4 & Trench 5 & Level 3 & Kitchen & Wine/Liquor & Blue mason jar fragment \\
\hline 2015 & 39 & 4 & Trench 5 & Level 3 & Kitchen & Wine/Liquor & Blue mason jar fragment \\
\hline 2015 & 39 & 4 & Trench 5 & Level 3 & Kitchen & Butchered Bone & Small bone fragments, unidentified \\
\hline 2015 & 39 & 4 & Trench 5 & Level 3 & Kitchen & Butchered Bone & Small bone fragments, unidentified \\
\hline 2015 & 39 & 4 & Trench 5 & Level 3 & Kitchen & Butchered Bone & Small bone fragments, unidentified \\
\hline 2015 & 39 & 4 & Trench 5 & Level 3 & Kitchen & Butchered Bone & Small bone fragments, unidentified \\
\hline 2015 & 39 & 4 & Trench 5 & Level 3 & Kitchen & Butchered Bone & Small bone fragments, unidentified \\
\hline 2015 & 39 & 4 & Trench 5 & Level 3 & Kitchen & Butchered Bone & Small bone fragments, unidentified \\
\hline 2015 & 39 & 4 & Trench 5 & Level 3 & Kitchen & Butchered Bone & Small bone fragments, unidentified \\
\hline 2015 & 39 & 4 & Trench 5 & Level 3 & Kitchen & Butchered Bone & Small bone fragments, unidentified \\
\hline 2015 & 39 & 4 & Trench 5 & Level 3 & Kitchen & Butchered Bone & Small bone fragments, unidentified \\
\hline 2015 & 39 & 4 & Trench 5 & Level 3 & Kitchen & Butchered Bone & Small bone fragments, unidentified \\
\hline 2015 & 39 & 4 & Trench 5 & Level 3 & Kitchen & Butchered Bone & Small bone fragments, unidentified \\
\hline 2015 & 39 & 4 & Trench 5 & Level 3 & Kitchen & Ceramic & Printed Stoneware \\
\hline 2015 & 39 & 4 & Trench 5 & Level 3 & Kitchen & Ceramic & Printed Stoneware \\
\hline 2015 & 39 & 4 & Trench 5 & Level 3 & Architecture & Round Nails & \\
\hline 2015 & 39 & 4 & Trench 5 & Level 3 & Architecture & Round Nails & \\
\hline 2015 & 39 & 4 & Trench 5 & Level 3 & Architecture & Round Nails & \\
\hline 2015 & 39 & 4 & Trench 5 & Level 3 & Architecture & Round Nails & \\
\hline 2015 & 39 & 4 & Trench 5 & Level 3 & Architecture & Round Nails & \\
\hline 2015 & 40 & 4 & Trench 5 & Level 4 & Kitchen & Wine/Liquor & cleat \\
\hline 2015 & 40 & 4 & Trench 5 & Level 4 & Kitchen & Wine/Liquor & clear \\
\hline 2015 & 40 & 4 & Trench 5 & Level 4 & Kitchen & Wine/Liquor & clear \\
\hline 2015 & 40 & 4 & Trench 5 & Level 4 & Kitchen & Wine/Liquor & fragment, brown \\
\hline 2015 & 40 & 4 & Trench 5 & Level 4 & Kitchen & Wine/Liquor & fragment, brown \\
\hline 2015 & 40 & 4 & Trench 5 & Level 4 & Kitchen & Wine/Liquor & fragment, brown \\
\hline 2015 & 40 & 4 & Trench 5 & Level 4 & Kitchen & Wine/Liquor & fragment, brown \\
\hline 2015 & 40 & 4 & Trench 5 & Level 4 & Kitchen & Wine/Liquor & fragment, brown \\
\hline 2015 & 40 & 4 & Trench 5 & Level 4 & Kitchen & Wine/Liquor & fragment, brown \\
\hline
\end{tabular}




\begin{tabular}{|c|c|c|c|c|c|c|c|}
\hline 2015 & 40 & 4 & Trench 5 & Level 4 & Kitchen & Wine/Liquor & fragment, brown \\
\hline 2015 & 40 & 4 & \begin{tabular}{|l|} 
Trench 5 \\
\end{tabular} & Level 4 & Kitchen & Wine/Liquor & fragment, brown \\
\hline 2015 & 40 & 4 & \begin{tabular}{|l|} 
Trench 5 \\
\end{tabular} & Level 4 & \begin{tabular}{|l|} 
Kitchen \\
\end{tabular} & Wine/Liquor & fragment, brown \\
\hline 2015 & 40 & 4 & Trench 5 & Level 4 & \begin{tabular}{|l|} 
Kitchen \\
\end{tabular} & Wine/Liquor & fragment, brown \\
\hline 2015 & 40 & 4 & Trench 5 & Level 4 & Kitchen & Wine/Liquor & fragment, brown \\
\hline 2015 & 40 & 4 & Trench 5 & Level 4 & Kitchen & Wine/Liquor & fragment, brown \\
\hline 2015 & 40 & 4 & Trench 5 & Level 4 & Kitchen & Wine/Liquor & fragment, brown \\
\hline 2015 & 40 & 4 & Trench 5 & Level 4 & Kitchen & Wine/Liquor & fragment, clear \\
\hline 2015 & 40 & 4 & Trench 5 & Level 4 & Kitchen & Wine/Liquor & fragment, clear \\
\hline 2015 & 40 & 4 & Trench 5 & Level 4 & Kitchen & Wine/Liquor & fragment, clear \\
\hline 2015 & 40 & 4 & Trench 5 & Level 4 & Kitchen & Wine/Liquor & fragment, clear \\
\hline 2015 & 40 & 4 & Trench 5 & Level 4 & Kitchen & Wine/Liquor & fragment, clear \\
\hline 2015 & 40 & 4 & Trench 5 & Level 4 & Kitchen & Wine/Liquor & fragment, clear \\
\hline 2015 & 40 & 4 & Trench 5 & Level 4 & Kitchen & Wine/Liquor & fragment, clear \\
\hline 2015 & 40 & 4 & Trench 5 & Level 4 & Kitchen & Wine/Liquor & fragment, clear \\
\hline 2015 & 40 & 4 & \begin{tabular}{|l|} 
Trench 5 \\
\end{tabular} & Level 4 & Kitchen & Wine/Liquor & fragment, clear \\
\hline 2015 & 40 & 4 & Trench 5 & Level 4 & Kitchen & Wine/Liquor & fragment, clear \\
\hline 2015 & 40 & 4 & \begin{tabular}{|l|} 
Trench 5 \\
\end{tabular} & Level 4 & Kitchen & Wine/Liquor & fragment, clear \\
\hline 2015 & 40 & 4 & \begin{tabular}{|l|} 
Trench 5 \\
\end{tabular} & Level 4 & Kitchen & Wine/Liquor & fragment, clear \\
\hline 2015 & 40 & 4 & \begin{tabular}{|l|} 
Trench 5 \\
\end{tabular} & Level 4 & Kitchen & Wine/Liquor & fragment, clear \\
\hline 2015 & 40 & 4 & \begin{tabular}{|l|} 
Trench 5 \\
\end{tabular} & Level 4 & Kitchen & Wine/Liquor & fragment, clear \\
\hline 2015 & 40 & 4 & Trench 5 & Level 4 & Kitchen & Wine/Liquor & fragment, clear \\
\hline 2015 & 40 & 4 & Trench 5 & Level 4 & Kitchen & Wine/Liquor & fragment, clear \\
\hline 2015 & 40 & 4 & Trench 5 & Level 4 & Kitchen & Wine/Liquor & fragment, clear \\
\hline 2015 & 40 & 4 & \begin{tabular}{|l|} 
Trench 5 \\
\end{tabular} & Level 4 & Kitchen & Wine/Liquor & fragment, clear \\
\hline 2015 & 40 & 4 & Trench 5 & Level 4 & Kitchen & Wine/Liquor & fragment, red \\
\hline 2015 & 40 & 4 & Trench 5 & Level 4 & Kitchen & Wine/Liquor & fragment, red \\
\hline 2015 & 40 & 4 & Trench 5 & Level 4 & Kitchen & Wine/Liquor & fragment, red \\
\hline 2015 & 40 & 4 & \begin{tabular}{|l|} 
Trench 5 \\
\end{tabular} & Level 4 & Architecture & Window Glass & \begin{tabular}{|l|} 
fragment \\
\end{tabular} \\
\hline 2015 & 40 & 4 & Trench 5 & Level 4 & Architecture & Window Glass & fragment \\
\hline 2015 & 40 & 4 & \begin{tabular}{|l|} 
Trench 5 \\
\end{tabular} & Level 4 & Architecture & Window Glass & fragment \\
\hline 2015 & 40 & 4 & \begin{tabular}{|l|} 
Trench 5 \\
\end{tabular} & Level 4 & Architecture & Window Glass & fragment \\
\hline 2015 & 40 & 4 & \begin{tabular}{|l|} 
Trench 5 \\
\end{tabular} & Level 4 & Architecture & Window Glass & fragment \\
\hline 2015 & 40 & 4 & Trench 5 & Level 4 & Architecture & Window Glass & fragment \\
\hline 2015 & 40 & 4 & \begin{tabular}{|l|} 
Trench 5 \\
\end{tabular} & Level 4 & Architecture & Window Glass & fragment \\
\hline 2015 & 40 & 4 & \begin{tabular}{|l|} 
Trench 5 \\
\end{tabular} & Level 4 & Architecture & Window Glass & fragment \\
\hline 2015 & 40 & 4 & Trench 5 & Level 4 & Architecture & Window Glass & fragment \\
\hline 2015 & 40 & 4 & Trench 5 & Level 4 & Architecture & Window Glass & fragment \\
\hline 2015 & 40 & 4 & \begin{tabular}{|l|} 
Trench 5 \\
\end{tabular} & Level 4 & Architecture & Window Glass & fragment \\
\hline 2015 & 40 & 4 & \begin{tabular}{|l|} 
Trench 5 \\
\end{tabular} & Level 4 & Architecture & Window Glass & fragment \\
\hline 2015 & 40 & 4 & Trench 5 & Level 4 & Architecture & Window Glass & fragment \\
\hline 2015 & 40 & 4 & Trench 5 & Level 4 & Architecture & Window Glass & fragment \\
\hline 2015 & 40 & 4 & \begin{tabular}{|l|} 
Trench 5 \\
\end{tabular} & Level 4 & Architecture & Window Glass & fragment \\
\hline 2015 & 40 & 4 & \begin{tabular}{|l|} 
Trench 5 \\
\end{tabular} & Level 4 & Architecture & Round Nails & \\
\hline 2015 & 40 & 4 & \begin{tabular}{|l|} 
Trench 5 \\
\end{tabular} & Level 4 & Architecture & Round Nails & \\
\hline 2015 & 40 & 4 & \begin{tabular}{|l|} 
Trench 5 \\
\end{tabular} & Level 4 & Architecture & Round Nails & \\
\hline 2015 & 40 & 4 & Trench 5 & Level 4 & Architecture & square Nails & Solitary square nail \\
\hline 2015 & 40 & 4 & Trench 5 & Level 4 & Architecture & Wood fragment & Milled, 1x2 \\
\hline 2015 & 40 & 4 & Trench 5 & Level 4 & Architecture & Wood fragment & Milled, $1 \mathrm{x} 2$ \\
\hline 2015 & 40 & 4 & Trench 5 & Level 4 & Architecture & Key & Single Pin, iron, maybe was plated \\
\hline 2015 & 40 & 4 & Trench 5 & Level 4 & Tobbacco & Stem & Fragment \\
\hline 2015 & 41 & 4 & Trench 5 & Level 4 & Kitchen & Wine/Liquor & clear \\
\hline 2015 & 41 & 4 & Trench 5 & Level 4 & Kitchen & Wine/Liquor & clear \\
\hline 2015 & 41 & 4 & Trench 5 & Level 4 & Kitchen & Wine/Liquor & clear \\
\hline 2015 & 41 & 4 & Trench 5 & Level 4 & Kitchen & Wine/Liquor & \begin{tabular}{|l|} 
clear \\
\end{tabular} \\
\hline 2015 & 41 & 4 & Trench 5 & Level 4 & Architecture & Window Glass & fragment \\
\hline 2015 & 41 & 4 & Trench 5 & Level 4 & \begin{tabular}{|l|} 
Architecture \\
\end{tabular} & Window Glass & fragment \\
\hline 2015 & 41 & 4 & \begin{tabular}{|l|} 
Trench 5 \\
\end{tabular} & Level 4 & Architecture & Window Glass & fragment \\
\hline 2015 & 41 & 4 & \begin{tabular}{|l|} 
Trench 5 \\
\end{tabular} & Level 4 & Architecture & Window Glass & fragment \\
\hline 2015 & 41 & 4 & Trench 5 & Level 4 & Architecture & Window Glass & fragment \\
\hline
\end{tabular}




\begin{tabular}{|c|c|c|c|c|c|c|c|}
\hline 2015 & 41 & 4 & Trench 5 & Level 4 & \begin{tabular}{|l|} 
Architecture \\
\end{tabular} & Window Glass & fragment \\
\hline 2015 & 41 & 4 & Trench 5 & Level 4 & Architecture & Window Glass & fragment \\
\hline 2015 & 41 & 4 & Trench 5 & Level 4 & Architecture & Window Glass & fragment \\
\hline 2015 & 41 & 4 & Trench 5 & Level 4 & Architecture & Window Glass & fragment \\
\hline 2015 & 41 & 4 & Trench 5 & Level 4 & Architecture & Window Glass & fragment \\
\hline 2015 & 41 & 4 & Trench 5 & Level 4 & \begin{tabular}{|l|} 
Architecture \\
\end{tabular} & Window Glass & fragment \\
\hline 2015 & 41 & 4 & Trench 5 & Level 4 & \begin{tabular}{|l|} 
Architecture \\
\end{tabular} & Window Glass & fragment \\
\hline 2015 & 41 & 4 & Trench 5 & Level 4 & Architecture & Window Glass & fragment \\
\hline 2015 & 41 & 4 & Trench 5 & Level 4 & Architecture & Window Glass & fragment \\
\hline 2015 & 41 & 4 & Trench 5 & Level 4 & \begin{tabular}{|l|} 
Architecture \\
\end{tabular} & Window Glass & fragment \\
\hline 2015 & 41 & 4 & Trench 5 & Level 4 & Architecture & Window Glass & fragment \\
\hline 2015 & 41 & 4 & Trench 5 & Level 4 & \begin{tabular}{|l|} 
Architecture \\
\end{tabular} & Window Glass & fragment \\
\hline 2015 & 41 & 4 & Trench 5 & Level 4 & \begin{tabular}{|l|} 
Architecture \\
\end{tabular} & Window Glass & fragment \\
\hline 2015 & 41 & 4 & Trench 5 & Level 4 & Architecture & Window Glass & fragment \\
\hline 2015 & 41 & 4 & Trench 5 & Level 4 & Architecture & Window Glass & fragment \\
\hline 2015 & 41 & 4 & Trench 5 & Level 4 & Architecture & Window Glass & fragment \\
\hline 2015 & 41 & 4 & Trench 5 & Level 4 & Architecture & Window Glass & fragment \\
\hline 2015 & 41 & 4 & Trench 5 & Level 4 & Architecture & Window Glass & fragment \\
\hline 2015 & 41 & 4 & Trench 5 & Level 4 & Architecture & Window Glass & fragment \\
\hline 2015 & 41 & 4 & Trench 5 & Level 4 & Architecture & Window Glass & fragment \\
\hline 2015 & 41 & 4 & Trench 5 & Level 4 & \begin{tabular}{|l|} 
Architecture \\
\end{tabular} & Window Glass & fragment \\
\hline 2015 & 41 & 4 & Trench 5 & Level 4 & \begin{tabular}{|l|} 
Architecture \\
\end{tabular} & Window Glass & fragment \\
\hline 2015 & 41 & 4 & Trench 5 & Level 4 & \begin{tabular}{|l|} 
Architecture \\
\end{tabular} & Window Glass & fragment \\
\hline 2015 & 41 & 4 & Trench 5 & Level 4 & Architecture & Window Glass & fragment \\
\hline 2015 & 41 & 4 & Trench 5 & Level 4 & \begin{tabular}{|l|} 
Architecture \\
\end{tabular} & Window Glass & fragment \\
\hline 2015 & 41 & 4 & Trench 5 & Level 4 & Architecture & Window Glass & fragment \\
\hline 2015 & 41 & 4 & Trench 5 & Level 4 & \begin{tabular}{|l} 
Architecture \\
\end{tabular} & Window Glass & fragment \\
\hline 2015 & 41 & 4 & Trench 5 & Level 4 & \begin{tabular}{|l|} 
Architecture \\
\end{tabular} & Window Glass & fragment \\
\hline 2015 & 41 & 4 & Trench 5 & Level 4 & Architecture & Window Glass & fragment \\
\hline 2015 & 41 & 4 & Trench 5 & Level 4 & \begin{tabular}{|l|} 
Architecture \\
\end{tabular} & Window Glass & fragment \\
\hline 2015 & 41 & 4 & Trench 5 & Level 4 & Architecture & Window Glass & fragment \\
\hline 2015 & 41 & 4 & Trench 5 & Level 4 & Architecture & Window Glass & fragment \\
\hline 2015 & 41 & 4 & Trench 5 & Level 4 & Architecture & Window Glass & fragment \\
\hline 2015 & 41 & 4 & Trench 5 & Level 4 & Architecture & Window Glass & fragment \\
\hline 2015 & 41 & 4 & Trench 5 & Level 4 & \begin{tabular}{|l|} 
Architecture \\
\end{tabular} & Window Glass & fragment \\
\hline 2015 & 41 & 4 & Trench 5 & Level 4 & Architecture & Window Glass & fragment \\
\hline 2015 & 41 & 4 & Trench 5 & Level 4 & \begin{tabular}{|l|} 
Architecture \\
\end{tabular} & Window Glass & fragment \\
\hline 2015 & 41 & 4 & Trench 5 & Level 4 & \begin{tabular}{|l|} 
Architecture \\
\end{tabular} & Window Glass & fragment \\
\hline 2015 & 41 & 4 & Trench 5 & Level 4 & \begin{tabular}{|l|} 
Architecture \\
\end{tabular} & Window Glass & fragment \\
\hline 2015 & 41 & 4 & Trench 5 & Level 4 & \begin{tabular}{|l|} 
Architecture \\
\end{tabular} & Window Glass & fragment \\
\hline 2015 & 41 & 4 & Trench 5 & Level 4 & Architecture & Window Glass & fragment \\
\hline 2015 & 41 & 4 & Trench 5 & Level 4 & Architecture & Window Glass & fragment \\
\hline 2015 & 41 & 4 & Trench 5 & Level 4 & \begin{tabular}{|l|} 
Architecture \\
\end{tabular} & Window Glass & fragment \\
\hline 2015 & 41 & 4 & Trench 5 & Level 4 & Architecture & Window Glass & fragment \\
\hline 2015 & 41 & 4 & Trench 5 & Level 4 & \begin{tabular}{|l|} 
Architecture \\
\end{tabular} & Window Glass & fragment \\
\hline 2015 & 41 & 4 & Trench 5 & Level 4 & \begin{tabular}{|l|} 
Architecture \\
\end{tabular} & Window Glass & fragment \\
\hline 2015 & 41 & 4 & Trench 5 & Level 4 & \begin{tabular}{|l|} 
Architecture \\
\end{tabular} & Window Glass & fragment \\
\hline 2015 & 41 & 4 & Trench 5 & Level 4 & \begin{tabular}{|l|} 
Architecture \\
\end{tabular} & Window Glass & fragment \\
\hline 2015 & 41 & 4 & Trench 5 & Level 4 & Architecture & Window Glass & fragment \\
\hline 2015 & 41 & 4 & Trench 5 & Level 4 & Architecture & Window Glass & fragment \\
\hline 2015 & 41 & 4 & Trench 5 & Level 4 & Architecture & Window Glass & fragment \\
\hline 2015 & 41 & 4 & Trench 5 & Level 4 & Architecture & Window Glass & fragment \\
\hline 2015 & 41 & 4 & Trench 5 & Level 4 & Architecture & Round Nails & \\
\hline 2015 & 41 & 4 & Trench 5 & Level 4 & Architecture & Round Nails & \\
\hline 2015 & 41 & 4 & Trench 5 & Level 4 & \begin{tabular}{|l|} 
Architecture \\
\end{tabular} & Round Nails & \\
\hline 2015 & 41 & 4 & Trench 5 & Level 4 & \begin{tabular}{|l|} 
Architecture \\
\end{tabular} & Round Nails & \\
\hline 2015 & 41 & 4 & Trench 5 & Level 4 & \begin{tabular}{|l} 
Architecture \\
\end{tabular} & Round Nails & \\
\hline 2015 & 41 & 4 & Trench 5 & Level 4 & \begin{tabular}{|l|} 
Architecture \\
\end{tabular} & Round Nails & \\
\hline 2015 & 41 & 4 & Trench 5 & Level 4 & Architecture & Round Nails & \\
\hline 2015 & 41 & 4 & Trench 5 & Level 4 & Architecture & Round Nails & \\
\hline
\end{tabular}




\begin{tabular}{|c|c|c|c|c|c|c|c|}
\hline 2015 & 41 & 4 & Trench 5 & Level 4 & Architecture & Round Nails & \\
\hline 2015 & 41 & 4 & Trench 5 & Level 4 & Architecture & Round Nails & \\
\hline 2015 & 41 & 4 & Trench 5 & Level 4 & Architecture & wood & Fragment, may have been milled \\
\hline 2015 & 41 & 4 & Trench 5 & Level 4 & Architecture & wood & Fragment, may have been milled \\
\hline 2015 & 41 & 4 & Trench 5 & Level 4 & Architecture & wood & Fragment, may have been milled \\
\hline 2015 & 41 & 4 & Trench 5 & Level 4 & Architecture & wood & Fragment, may have been milled \\
\hline 2015 & 41 & 4 & Trench 5 & Level 4 & Architecture & wood & Fragment, may have been milled \\
\hline 2015 & 42 & 4 & Trench 5 & Level 5 & Kitchen & beer bottle & Brown \\
\hline 2015 & 42 & 4 & Trench 5 & Level 5 & Kitchen & Wine/Liquor & \begin{tabular}{|l|l} 
clear \\
\end{tabular} \\
\hline 2015 & 42 & 4 & Trench 5 & Level 5 & Architecture & Window Glass & fragment \\
\hline 2015 & 42 & 4 & Trench 5 & Level 5 & Architecture & Window Glass & fragment \\
\hline 2015 & 42 & 4 & \begin{tabular}{|l} 
Trench 5 \\
\end{tabular} & Level 5 & Architecture & Window Glass & fragment \\
\hline 2015 & 42 & 4 & Trench 5 & Level 5 & Architecture & Window Glass & fragment \\
\hline 2015 & 42 & 4 & Trench 5 & Level 5 & Architecture & Window Glass & fragment \\
\hline 2015 & 42 & 4 & Trench 5 & Level 5 & Architecture & Window Glass & fragment \\
\hline 2015 & 42 & 4 & Trench 5 & Level 5 & Architecture & Window Glass & fragment \\
\hline 2015 & 42 & 4 & Trench 5 & Level 5 & Architecture & Window Glass & fragment \\
\hline 2015 & 42 & 4 & Trench 5 & Level 5 & Architecture & Round nails & \\
\hline 2015 & 42 & 4 & Trench 5 & Level 5 & Architecture & Round nails & \\
\hline 2015 & 42 & 4 & Trench 5 & Level 5 & Tobbacco & Round nails & \\
\hline 2015 & 42 & 4 & Trench 5 & Level 5 & Activties & Round nails & \\
\hline 2015 & 43 & 4 & Trench 7 & Surface & Kitchen & Wine/Liquor & Green, very small, perhaps modern \\
\hline 2015 & 43 & 4 & Trench 7 & Surface & Architecture & Window Glass & fragment \\
\hline 2015 & 43 & 4 & Trench 7 & Surface & Architecture & Window Glass & Fragment \\
\hline 2015 & 43 & 4 & Trench 7 & Surface & Architecture & Window Glass & Fragment \\
\hline 2015 & 43 & 4 & Trench 7 & Surface & Architecture & Window Glass & Fragment \\
\hline 2015 & 43 & 4 & Trench 7 & Surface & Architecture & Window Glass & Fragment \\
\hline 2015 & 43 & 4 & Trench 7 & Surface & Architecture & Round Nails & \\
\hline 2015 & 43 & 4 & Trench 7 & Surface & Architecture & Round Nails & \\
\hline 2015 & 43 & 4 & Trench 7 & Surface & Architecture & Round Nails & \\
\hline 2015 & 43 & 4 & Trench 7 & Level 1 & Architecture & Round Nails & \\
\hline 2015 & 44 & 4 & Trench 7 & Level 1 & Kitchen & Glassware & fragment \\
\hline 2015 & 44 & 4 & Trench 7 & Level 1 & Kitchen & Glassware & fragment \\
\hline 2015 & 44 & 4 & Trench 7 & Level 1 & Kitchen & Glass ware & fragment \\
\hline 2015 & 44 & 4 & Trench 7 & Level 1 & Architecture & Window Glass & fragment \\
\hline 2015 & 44 & 4 & Trench 7 & Level 1 & Architecture & Window Glass & fragment \\
\hline 2015 & 44 & 4 & Trench 7 & Level 1 & Architecture & Window Glass & fragment \\
\hline 2015 & 44 & 4 & Trench 7 & Level 1 & Architecture & Window Glass & fragment \\
\hline 2015 & 44 & 4 & \begin{tabular}{|l|} 
Trench 7 \\
\end{tabular} & Level 1 & Architecture & Round Nails & \\
\hline 2015 & 44 & 4 & Trench 7 & Level 1 & Architecture & Round Nails & \\
\hline 2015 & 44 & 4 & Trench 7 & Level 1 & Architecture & Round Nails & \\
\hline 2015 & 44 & 4 & Trench 7 & Level 1 & Architecture & Round Nails & \\
\hline 2015 & 44 & 4 & Trench 7 & Level 1 & Architecture & Round Nails & \\
\hline 2015 & 44 & 4 & Trench 7 & Level 1 & Architecture & Round Nails & \\
\hline 2015 & 44 & 4 & Trench 7 & Level 1 & Architecture & Round Nails & \\
\hline 2015 & 44 & 4 & Trench 7 & Level 1 & Architecture & Round Nails & \\
\hline 2015 & 44 & 4 & Trench 7 & Level 1 & Architecture & Round Nails & \\
\hline 2015 & 44 & 4 & Trench 7 & Level 1 & Architecture & staple & \\
\hline 2015 & 44 & 4 & Trench 7 & Level 1 & Architecture & staple & \\
\hline 2015 & 44 & 4 & Trench 7 & Level 1 & Architecture & staple & \\
\hline 2015 & 44 & 4 & Trench 7 & Level 1 & Architecture & Tar paper & fragment \\
\hline 2015 & 44 & 4 & Trench 7 & Level 1 & Architecture & Tar paper & fragment \\
\hline 2015 & 44 & 4 & Trench 7 & Level 1 & Architecture & Tar paper & fragment \\
\hline 2015 & 44 & 4 & Trench 7 & Level 1 & Architecture & Tar paper & fragment \\
\hline 2015 & 44 & 4 & Trench 7 & Level 1 & Architecture & Tar paper & fragment \\
\hline 2015 & 45 & 4 & Trench 7 & Level 1 & Kitchen & bone & Pig \\
\hline 2015 & 46 & 4 & Trench 7 & Level 1 & Kitchen & bone & Pig \\
\hline 2015 & 46 & 4 & Trench 7 & Level 1 & Kitchen & bone & Pig \\
\hline 2015 & 46 & 4 & Trench 7 & Level 1 & Kitchen & bone & Pig \\
\hline 2015 & 47 & 4 & Trench 7 & Level 2 & Kitchen & Ceramic & Stoneware, brown \\
\hline
\end{tabular}




\begin{tabular}{|c|c|c|c|c|c|c|c|}
\hline 2015 & 47 & 4 & Trench 7 & Level 2 & Kitchen & Ceramic & Stoneware, brown \\
\hline 2015 & 47 & 4 & Trench 7 & Level 2 & Kitchen & Ceramic & Stoneware, brown \\
\hline 2015 & 47 & 4 & \begin{tabular}{|l|} 
Trench 7 \\
\end{tabular} & Level 2 & Kitchen & Ceramic & Stoneware, brown \\
\hline 2015 & 47 & 4 & \begin{tabular}{|l|} 
Trench 7 \\
\end{tabular} & Level 2 & Kitchen & Ceramic & Stoneware, brown \\
\hline 2015 & 47 & 4 & Trench 7 & Level 2 & Architecture & window Glass & fragment \\
\hline 2015 & 47 & 4 & \begin{tabular}{|l|} 
Trench 7 \\
\end{tabular} & Level 2 & Architecture & window Glass & fragment \\
\hline 2015 & 47 & 4 & \begin{tabular}{|l|} 
Trench 7 \\
\end{tabular} & Level 2 & Architecture & window Glass & fragment \\
\hline 2015 & 47 & 4 & \begin{tabular}{|l|} 
Trench 7 \\
\end{tabular} & Level 2 & Architecture & window Glass & fragment \\
\hline 2015 & 47 & 4 & Trench 7 & Level 2 & Architecture & window Glass & fragment \\
\hline 2015 & 47 & 4 & Trench 7 & Level 2 & Architecture & window Glass & fragment \\
\hline 2015 & 47 & 4 & Trench 7 & Level 2 & Architecture & Round Nails & \\
\hline 2015 & 47 & 4 & Trench 7 & Level 2 & Architecture & Round Nails & \\
\hline 2015 & 47 & 4 & \begin{tabular}{|l|} 
Trench 7 \\
\end{tabular} & Level 2 & Architecture & Round Nails & \\
\hline 2015 & 47 & 4 & Trench 7 & Level 2 & Architecture & Round Nails & \\
\hline 2015 & 47 & 4 & \begin{tabular}{|l|} 
Trench 7 \\
\end{tabular} & Level 2 & Architecture & Round Nails & \\
\hline 2015 & 47 & 4 & \begin{tabular}{|l|} 
Trench 7 \\
\end{tabular} & Level 2 & Architecture & Round Nails & \\
\hline 2015 & 47 & 4 & Trench 7 & Level 2 & Architecture & Round Nails & \\
\hline 2015 & 47 & 4 & \begin{tabular}{|l|} 
Trench 7 \\
\end{tabular} & Level 2 & Architecture & Round Nails & \\
\hline 2015 & 47 & 4 & Trench 7 & Level 2 & Architecture & Round Nails & \\
\hline 2015 & 47 & 4 & Trench 7 & Level 2 & Architecture & Round Nails & \\
\hline 2015 & 47 & 4 & \begin{tabular}{|l|} 
Trench 7 \\
\end{tabular} & Level 2 & Architecture & Round Nails & \\
\hline 2015 & 47 & 4 & Trench 7 & Level 2 & Architecture & Round Nails & \\
\hline 2015 & 47 & 4 & \begin{tabular}{|l|} 
Trench 7 \\
\end{tabular} & Level 2 & other & bone & Small fragment \\
\hline 2015 & 47 & 4 & \begin{tabular}{|l|} 
Trench 7 \\
\end{tabular} & Level 2 & other & bone & Small fragment \\
\hline 2015 & 48 & 4 & \begin{tabular}{|l|} 
Trench 7 \\
\end{tabular} & Level 3 & Architecture & Round Nails & \\
\hline 2015 & 48 & 4 & Trench 7 & Level 3 & Architecture & Round Nails & \\
\hline 2015 & 48 & 4 & \begin{tabular}{|l|} 
Trench 7 \\
\end{tabular} & Level 3 & Architecture & Round Nails & \\
\hline 2015 & 48 & 4 & Trench 7 & Level 3 & Architecture & Round Nails & \\
\hline 2015 & 48 & 4 & \begin{tabular}{|l|} 
Trench 7 \\
\end{tabular} & Level 3 & Architecture & Round Nails & \\
\hline 2015 & 48 & 4 & Trench 7 & Level 3 & Architecture & Round Nails & \\
\hline 2015 & 48 & 4 & Trench 7 & Level 3 & Architecture & Window glass & Fragment \\
\hline 2015 & 49 & 4 & Trench 9 & Level 1 & Kitchen & bottle glass & Brown \\
\hline 2015 & 49 & 4 & Trench 9 & Level 1 & Kitchen & Wine/Liquor & clear very small fragments \\
\hline 2015 & 49 & 4 & Trench 9 & Level 1 & Kitchen & Wine/Liquor & clear very small fragments \\
\hline 2015 & 49 & 4 & Trench 9 & Level 1 & Kitchen & Wine/Liquor & clear very small fragments \\
\hline 2015 & 49 & 4 & \begin{tabular}{|l|} 
Trench 9 \\
\end{tabular} & Level 1 & Kitchen & Wine/Liquor & clear very small fragments \\
\hline 2015 & 49 & 4 & Trench 9 & Level 1 & Kitchen & Wine/Liquor & clear very small fragments \\
\hline 2015 & 49 & 4 & \begin{tabular}{|l|} 
Trench 9 \\
\end{tabular} & Level 1 & Kitchen & Wine/Liquor & clear very small fragments \\
\hline 2015 & 49 & 4 & Trench 9 & Level 1 & Kitchen & Wine/Liquor & clear very small fragments \\
\hline 2015 & 49 & 4 & Trench 9 & Level 1 & Architecture & Window Glass & fragment \\
\hline 2015 & 49 & 4 & Trench 9 & Level 1 & Architecture & Window Glass & fragment \\
\hline 2015 & 49 & 4 & \begin{tabular}{|l|} 
Trench 9 \\
\end{tabular} & Level 1 & Architecture & Window Glass & fragment \\
\hline 2015 & 49 & 4 & Trench 9 & Level 1 & Architecture & Window Glass & fragment \\
\hline 2015 & 49 & 4 & \begin{tabular}{|l|} 
Trench 9 \\
\end{tabular} & Level 1 & Architecture & Window Glass & fragment \\
\hline 2015 & 49 & 4 & Trench 9 & Level 1 & Architecture & Round Nails & \\
\hline 2015 & 49 & 4 & Trench 9 & Level 1 & Architecture & Round Nails & \\
\hline 2015 & 50 & 4 & \begin{tabular}{|l|} 
Trench 9 \\
\end{tabular} & Level 2 & Architecture & Round Nails & \\
\hline 2015 & 50 & 4 & Trench 9 & Level 2 & Architecture & Round Nails & \\
\hline 2015 & 50 & 4 & \begin{tabular}{|l|} 
Trench 9 \\
\end{tabular} & Level 2 & Architecture & Round Nails & \\
\hline 2015 & 50 & 4 & Trench 9 & Level 2 & Architecture & Round Nails & \\
\hline 2015 & 50 & 4 & Trench 9 & Level 2 & Architecture & Round Nails & \\
\hline 2015 & 50 & 4 & Trench 9 & Level 2 & Architecture & Round Nails & \\
\hline 2015 & 50 & 4 & \begin{tabular}{|l|} 
Trench 9 \\
\end{tabular} & Level 2 & Architecture & Round Nails & \\
\hline 2015 & 50 & 4 & \begin{tabular}{|l|} 
Trench 9 \\
\end{tabular} & Level 2 & Architecture & Round Nails & \\
\hline 2015 & 50 & 4 & \begin{tabular}{|l|} 
Trench 9 \\
\end{tabular} & Level 2 & Architecture & Tar paper & Fragments \\
\hline 2015 & 50 & 4 & \begin{tabular}{|l|} 
Trench 9 \\
\end{tabular} & Level 2 & Architecture & Tar paper & Fragments \\
\hline 2015 & 50 & 4 & Trench 9 & Level 2 & Architecture & Tar paper & Fragments \\
\hline 2015 & 50 & 4 & Trench 9 & Level 2 & Architecture & Tar paper & Fragments \\
\hline 2015 & 50 & 4 & \begin{tabular}{|l|} 
Trench 9 \\
\end{tabular} & Level 2 & Architecture & Tar paper & Fragments \\
\hline 2015 & 50 & 4 & Trench 9 & Level 2 & Architecture & Tar paper & Fragments \\
\hline
\end{tabular}




\begin{tabular}{|c|c|c|c|c|c|c|c|}
\hline 2015 & 50 & 4 & Trench 9 & Level 2 & Architecture & Tar paper & Fragments \\
\hline 2015 & 50 & 4 & Trench 9 & Level 2 & Architecture & Tar paper & Fragments \\
\hline 2015 & 50 & 4 & Trench 9 & Level 2 & Kitchen & Bone & Fragments, tiny \\
\hline 2015 & 50 & 4 & Trench 9 & Level 2 & Kitchen & Bone & Fragments, tiny \\
\hline 2015 & 51 & 4 & Trench 9 & Level 3 & Kitchen & Bone & Fragments, tiny \\
\hline 2015 & 51 & 4 & Trench 9 & Level 3 & Architecture & Round Nails & \\
\hline 2015 & 51 & 4 & Trench 9 & Level 3 & Architecture & Round Nails & \\
\hline 2015 & 51 & 4 & Trench 9 & Level 3 & Architecture & Round Nails & \\
\hline 2015 & 51 & 4 & Trench 9 & Level 3 & Architecture & Round Nails & \\
\hline 2015 & 51 & 4 & Trench 9 & Level 3 & Architecture & Round Nails & \\
\hline 2015 & 51 & 4 & Trench 9 & Level 3 & Architecture & Round Nails & \\
\hline 2015 & 51 & 4 & Trench 9 & Level 3 & Architecture & Round Nails & \\
\hline 2015 & 51 & 4 & Trench 9 & Level 3 & Architecture & Round Nails & \\
\hline 2015 & 51 & 4 & Trench 9 & Level 3 & Architecture & Round Nails & \\
\hline 2015 & 51 & 4 & Trench 9 & Level 3 & Architecture & Round Nails & \\
\hline 2015 & 51 & 4 & Trench 9 & Level 3 & Architecture & Round Nails & \\
\hline 2015 & 51 & 4 & Trench 9 & Level 3 & Architecture & Round Nails & \\
\hline 2015 & 51 & 4 & Trench 9 & Level 3 & Architecture & Round Nails & \\
\hline 2015 & 51 & 4 & Trench 9 & Level 3 & Architecture & Tar paper & Fragments \\
\hline 2015 & 51 & 4 & Trench 9 & Level 3 & Architecture & Tar paper & Fragments \\
\hline 2015 & 52 & & $1-1 \mathrm{E}$ & N/A & Other & Scrap Metal & \\
\hline 2015 & 52 & & $1-1 \mathrm{E}$ & N/A & Other & Scrap Metal & \\
\hline 2015 & 52 & & $1-1 \mathrm{E}$ & N/A & Other & Scrap Metal & \\
\hline 2015 & 52 & & $1-1 \mathrm{E}$ & N/A & Other & Scrap Metal & \\
\hline 2015 & 52 & & $1-1 \mathrm{E}$ & N/A & Other & Scrap Metal & \\
\hline 2015 & 52 & & $1-1 \mathrm{E}$ & N/A & Other & Scrap Metal & \\
\hline 2015 & 52 & & $1-1 \mathrm{E}$ & N/A & Other & Scrap Metal & \\
\hline 2015 & 52 & & $1-1 \mathrm{E}$ & N/A & Other & Paint can & \\
\hline 2015 & 52 & & $1-1 \mathrm{E}$ & N/A & Other & Paint brush & \\
\hline 2015 & 53 & & $1-4 \mathrm{E}$ & N/A & Architecture & Cut Nails & \\
\hline 2015 & 53 & & $1-4 \mathrm{E}$ & N/A & Architecture & Cut Nails & \\
\hline 2015 & 53 & & $1-4 \mathrm{E}$ & N/A & Architecture & Cut Nails & \\
\hline 2015 & 53 & & $1-4 \mathrm{E}$ & N/A & Architecture & Cut Nails & \\
\hline 2015 & 53 & & $1-4 \mathrm{E}$ & N/A & Architecture & Cut Nails & \\
\hline 2015 & 54 & & $2-2 W$ & N/A & Architecture & Cut Nails & \\
\hline 2015 & 55 & & $2-1 E$ & N/A & Kitchen & Ceramic & Fragment \\
\hline 2015 & 55 & & $2-1 E$ & N/A & Architecture & Glass & \\
\hline 2015 & 55 & & $2-1 \mathrm{E}$ & N/A & Architecture & Glass & \\
\hline 2015 & 56 & & $2-2 E$ & N/A & Architecture & Glass & \\
\hline 2015 & 56 & & $2-2 E$ & N/A & Architecture & Glass & \\
\hline 2015 & 56 & & $2-2 E$ & N/A & Architecture & Glass & \\
\hline 2015 & 56 & & $2-2 E$ & N/A & Architecture & Glass & \\
\hline 2015 & 56 & & $2-2 E$ & N/A & Architecture & Glass & \\
\hline 2015 & 56 & & $2-2 E$ & N/A & Architecture & Glass & \\
\hline 2015 & 57 & & $2-3 E$ & N/A & Architecture & Glass & \\
\hline 2015 & 57 & & $2-3 E$ & N/A & Architecture & Glass & \\
\hline 2015 & 57 & & $2-3 E$ & N/A & Architecture & Glass & \\
\hline 2015 & 57 & & $2-3 E$ & N/A & Architecture & Glass & \\
\hline 2015 & 57 & & $2-3 E$ & N/A & Tobacco & Stem & \\
\hline 2015 & 57 & & $2-3 E$ & N/A & Tobacco & Stem & \\
\hline 2015 & 58 & & $2-4 \mathrm{E}$ & N/A & Architecture & Glass & \\
\hline 2015 & 58 & & $2-4 \mathrm{E}$ & N/A & Architecture & Glass & \\
\hline 2015 & 58 & & $2-4 E$ & N/A & Architecture & Glass & \\
\hline 2015 & 58 & & $2-4 E$ & N/A & Architecture & Cut Nails & \\
\hline 2015 & 58 & & $2-4 \mathrm{E}$ & N/A & Architecture & Cut Nails & \\
\hline 2015 & 58 & & $2-4 \mathrm{E}$ & N/A & Architecture & Cut Nails & \\
\hline 2015 & 59 & & $3-1 E$ & N/A & Architecture & Cut Nails & \\
\hline 2015 & 59 & & $3-1 E$ & N/A & Architecture & Cut Nails & \\
\hline 2015 & 59 & & $3-1 E$ & N/A & Architecture & Cut Nails & \\
\hline 2015 & 59 & & $3-1 E$ & N/A & Architecture & Glass & \\
\hline
\end{tabular}




\begin{tabular}{|c|c|c|c|c|c|c|}
\hline 2015 & 59 & $3-1 \mathrm{E}$ & N/A & Architecture & Glass & \\
\hline 2015 & 59 & $3-1 E$ & N/A & Architecture & Glass & \\
\hline 2015 & 60 & $3-2 \mathrm{E}$ & N/A & Architecture & Glass & \\
\hline 2015 & 60 & $3-2 E$ & N/A & Architecture & Glass & \\
\hline 2015 & 60 & $3-2 \mathrm{E}$ & N/A & Architecture & Glass & \\
\hline 2015 & 60 & $3-2 E$ & N/A & Architecture & Glass & \\
\hline 2015 & 60 & $3-2 \mathrm{E}$ & N/A & Architecture & Glass & \\
\hline 2015 & 60 & $3-2 \mathrm{E}$ & N/A & Architecture & Glass & \\
\hline 2015 & 60 & $3-2 \mathrm{E}$ & N/A & Architecture & Cut Nails & \\
\hline 2015 & 60 & $3-2 \mathrm{E}$ & N/A & Architecture & Cut Nails & \\
\hline 2015 & 61 & $3-3 \mathrm{E}$ & N/A & Architecture & Cut Nails & \\
\hline 2015 & 61 & $3-3 E$ & N/A & Architecture & Cut Nails & \\
\hline 2015 & 61 & $3-3 E$ & N/A & Architecture & Cut Nails & \\
\hline 2015 & 61 & $3-3 E$ & N/A & Architecture & Glass & \\
\hline 2015 & 61 & $3-3 \mathrm{E}$ & N/A & Architecture & Glass & \\
\hline 2015 & 62 & $4-1 W$ & N/A & Architecture & Large Cut Nail & \\
\hline 2015 & 63 & $5-2 \mathrm{E}$ & N/A & Architecture & Cut Nails & \\
\hline 2015 & 63 & $5-2 \mathrm{E}$ & N/A & Architecture & Cut Nails & \\
\hline 2015 & 63 & $5-2 \mathrm{E}$ & N/A & Architecture & Cut Nails & \\
\hline 2015 & 63 & $5-2 \mathrm{E}$ & N/A & Architecture & Glass & \\
\hline 2015 & 64 & $6-0 \mathrm{E}$ & N/A & Kitchen & Ceramic & Fragment, Modern \\
\hline 2015 & 65 & $9-1 \mathrm{~W}$ & N/A & Architechture & Round Nails & \\
\hline 2015 & 65 & $9-1 \mathrm{~W}$ & N/A & Architechture & Round Nails & \\
\hline 2015 & 66 & $14-1 \mathrm{~W}$ & N/A & Kitchen & Ceramic & Fragment \\
\hline 2015 & 66 & $14-1 \mathrm{~W}$ & N/A & Architechture & Screw & \\
\hline 2015 & 67 & $15-0 \mathrm{E}$ & N/A & Architechture & Round Nails & \\
\hline 2015 & 67 & $15-0 \mathrm{E}$ & N/A & Architechture & Round Nails & \\
\hline 2015 & 67 & $15-0 \mathrm{E}$ & N/A & Architechture & Round Nails & \\
\hline 2015 & 67 & $15-0 \mathrm{E}$ & N/A & Architechture & Round Nails & \\
\hline 2015 & 67 & $15-0 \mathrm{E}$ & N/A & Architechture & Round Nails & \\
\hline 2015 & 67 & $15-0 \mathrm{E}$ & N/A & Architechture & Round Nails & \\
\hline 2015 & 67 & $15-0 \mathrm{E}$ & N/A & Architechture & Glass & \\
\hline 2015 & 67 & $15-0 \mathrm{E}$ & N/A & Architechture & Glass & \\
\hline 2015 & 68 & $15-1 \mathrm{~W}$ & N/A & Architechture & Round Nails & \\
\hline 2015 & 68 & $15-1 \mathrm{~W}$ & N/A & Architechture & Round Nails & \\
\hline 2015 & 68 & $15-1 \mathrm{~W}$ & N/A & Architechture & Glass & \\
\hline 2015 & 68 & $15-1 \mathrm{~W}$ & N/A & Architechture & Glass & \\
\hline 2015 & 69 & $16-1 \mathrm{~W}$ & N/A & Architechture & Round Nails & \\
\hline 2015 & 69 & $16-1 \mathrm{~W}$ & N/A & Architechture & Round Nails & \\
\hline 2015 & 69 & $16-1 \mathrm{~W}$ & N/A & Architechture & Round Nails & \\
\hline 2015 & 69 & $16-1 \mathrm{~W}$ & N/A & Architechture & Round Nails & \\
\hline 2015 & 69 & $16-1 \mathrm{~W}$ & N/A & Architechture & Lead Flashing & \\
\hline 2015 & 70 & $16-2 \mathrm{~W}$ & N/A & Architechture & Glass & \\
\hline 2015 & 70 & $16-2 \mathrm{~W}$ & N/A & Architechture & Glass & \\
\hline 2015 & 70 & $16-2 \mathrm{~W}$ & N/A & Architechture & Glass & \\
\hline 2015 & 70 & $16-2 \mathrm{~W}$ & N/A & Kitchen & Ceramc & \\
\hline 2015 & 70 & $16-2 \mathrm{~W}$ & N/A & Kitchen & Ceramc & \\
\hline 2015 & 70 & $16-2 \mathrm{~W}$ & N/A & Kitchen & Ceramc & \\
\hline 2015 & 71 & $16-1 \mathrm{E}$ & N/A & Architechture & Round Nails & \\
\hline 2015 & 71 & $16-1 \mathrm{E}$ & N/A & Architechture & Round Nails & \\
\hline 2015 & 71 & $16-1 \mathrm{E}$ & N/A & Architechture & Round Nails & \\
\hline 2015 & 71 & $16-1 \mathrm{E}$ & N/A & Architechture & Round Nails & \\
\hline 2015 & 71 & $16-1 \mathrm{E}$ & N/A & Architechture & Round Nails & \\
\hline 2015 & 71 & $16-1 \mathrm{E}$ & N/A & Architechture & Glass & \\
\hline 2015 & 71 & $16-1 \mathrm{E}$ & N/A & Architechture & Glass & \\
\hline 2015 & 72 & $17-0 \mathrm{E}$ & N/A & Architechture & Glass & \\
\hline 2015 & 72 & $17-0 \mathrm{E}$ & N/A & Architechture & Glass & \\
\hline 2015 & 72 & $17-0 \mathrm{E}$ & N/A & Architechture & Glass & \\
\hline 2015 & 72 & $17-0 \mathrm{E}$ & N/A & Architechture & Tar paper & \\
\hline 2015 & 72 & $17-0 \mathrm{E}$ & N/A & Architechture & Tar paper & \\
\hline
\end{tabular}




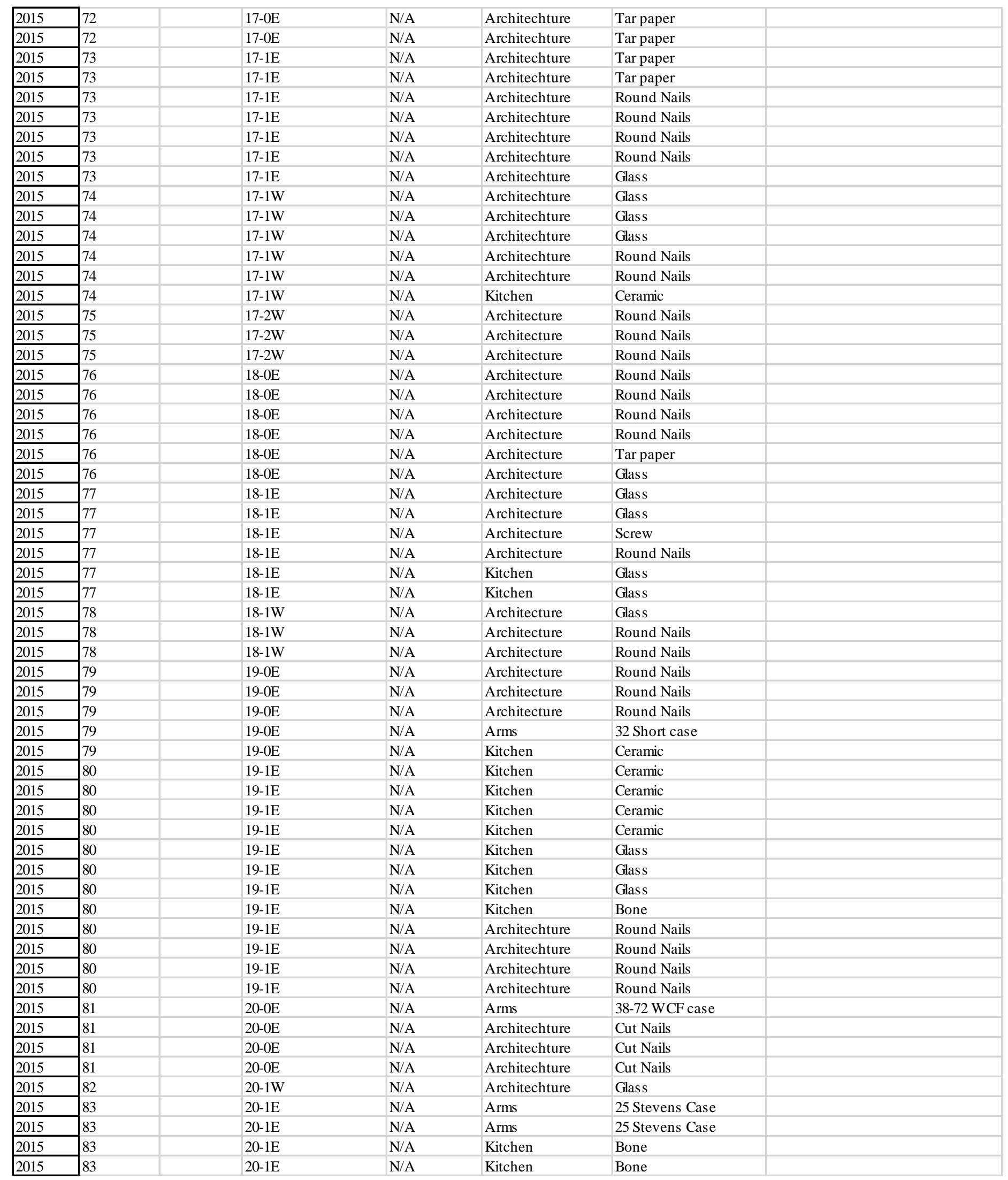

